\title{
RING ROAD DEVELOPMENT AND VACANT LANDS \\ RIYADH, SAUDI ARABIA
}

By

Khalid Alskait

B.Sc. (Hons) Architecture \& Planning, King Saud University, Riyadh 1985

M.Sc. City Planning, Georgia Institute Of Technology, Atlanta 1988

\section{A THESIS SUBMITTED IN PARTIAL FULFILMENT OF THE REQUIREMENTS FOR THE DEGREE OF DOCTOR OF PHILOSOPHY \\ in \\ FACULTY OF GRADUATE STUDIES \\ SCHOOL OF COMMUNITY AND REGIONAL PLANNING}

We accept this thesis as conforming

to the required standard

THE UNIVERSITY OF BRITISH COLUMBIA

October 1993

OKhalid Bin-Skait, 1993 
In presenting this thesis in partial fulfilment of the requirements for an advanced degree at the University of British Columbia, I agree that the Library shall make it freely available for reference and study. I further agree that permission for extensive copying of this thesis for scholarly purposes may be granted by the head of my department or by his or her representatives. It is understood that copying or publication of this thesis for financial gain shall not be allowed without my written permission.

(Signature)

Department of SLHOOL OF COMMUNTTY \&REGIONAL PLANNIG

The University of British Columbia

Vancouver, Canada

Date Nov $22^{\text {nd }}, 1993$ 


\begin{abstract}
This dissertation is concerned with the relationship between freeway development and the pattern of urban development. In particular, this research examines whether there is any relationship between ring road development and the proliferation of vacant urban lands in Riyadh, Saudi Arabia. The main hypothesis of this dissertation suggests that the development of ring roads, at a time when a substantial amount of inner lands are vacant, encourages leapfrogging growth, thus creating more vacant urban lands.
\end{abstract}

Both primary data and existing data, collected by governmental agencies, were collected and analyzed. Primary data were collected using a questionnaire survey. The survey included interviews with relevant public officials, private developers, and academics. One hundred people were approached to complete the questionnaire, and seventy-six of them responded. The primary existing data source was the Arriyadh Development Authority (ADA). The ADA provided land use data for 1986-87 and 1990-91. These data included relevant urban variables (including land use variables, population variables, dwelling unit variables) for sixteen submunicipalities in Riyadh. The analyses of land use data were supplemented by an analysis of aerial images of the city which had been taken before and after the development of the ring road, sections of which were opened in 1984 and 1986. The interviews, the land use data, and the aerial images were complementary to each other in the analysis.

The findings of this dissertation suggest that there is a correlation between the development of 
the Riyadh Ring Road and the size and distribution of current vacant urban lands. This confirms the main hypothesis. It is suggested that the timing of ring road development is critical to the increase in the amount of vacant urban lands. In order to avoid and/or to decrease such an increase in vacant lands, ring roads should be developed only after a certain percentage of the lands within the urban area have been developed. If more vacant urban lands exist at the time of the development of a ring road, then more leapfrogging growth will occur. This type of growth will result in more vacant urban lands and will stretch the city in all directions, thus reducing efficiency. 


\section{TABLE OF CONTENTS}

ABSTRACT …

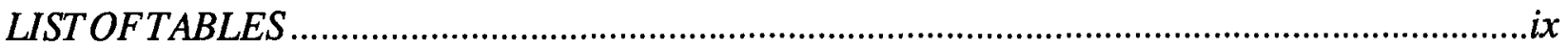

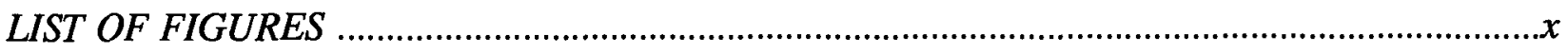

GLOSSARY …

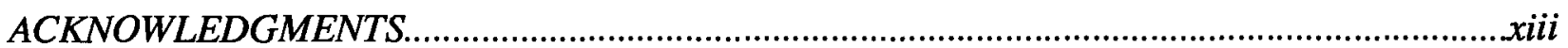

CHAPTER I: INTRODUCTION

1.OINTRODUCTION

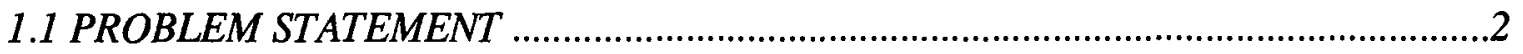

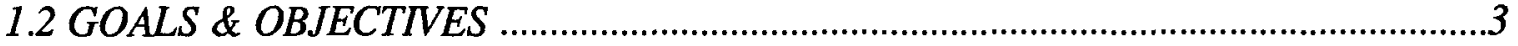

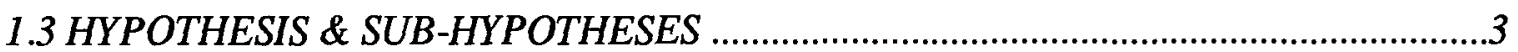

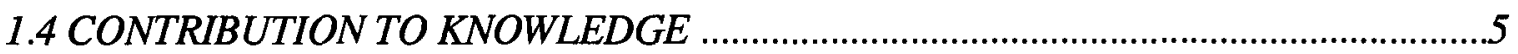

1.5 DISSERTATION STRUCTURE ..........................................................................

CHAPTER II: LITERATURE REVIEW

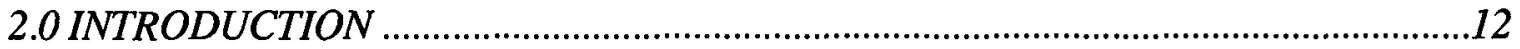

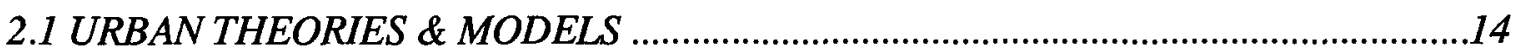

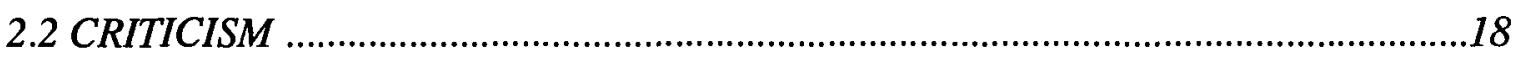

2.3 LAND USE, DEVELOPMENT AND TRANSPORTATION ……………………......20

2.4 URBAN TRANSPORT AND URBAN GROWTH …………......................................24

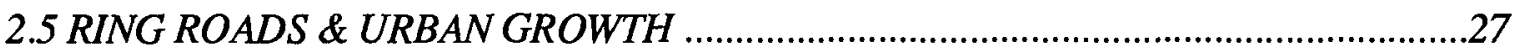

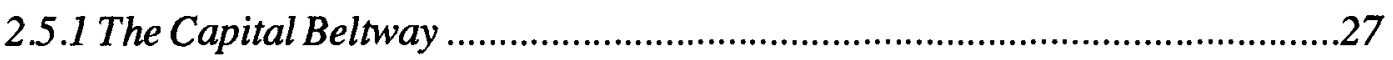

2.5.2 The London Orbital (M25) .....................................................................29

2.6 THE BLANEY-DYETT \& PAYNE-MAXIE IMPACT STUDY …….........................30

2.6.1 Effects on Regional Economic Growth ...........................................................

2.6.2 Effects on Location and Development Decisions .............................................31

2.6.3 Effects on Central Cities...................................................................................32

2.6.4 Effects on Land Use Policies and Capital Improvement Programs ...............33

2.6.5 Political and Social Effects .................................................................................34

2.6.6 Environmental Effects .....................................................................................34

2.7 GROWTH MANAGEMENT TECHNIQUES ……….................................................35 
2.7.1 Growth Managements: Critics \& Supporters ..............................................39

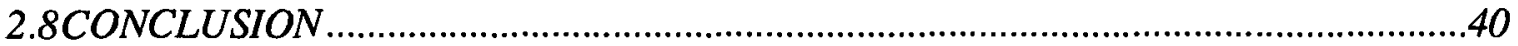

\section{CHAPTER III: RESEARCH METHODS}

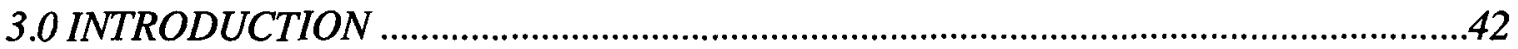

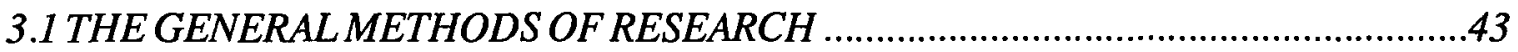

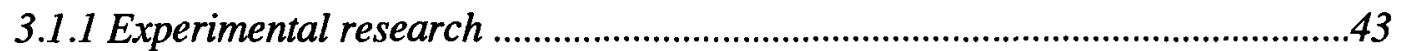

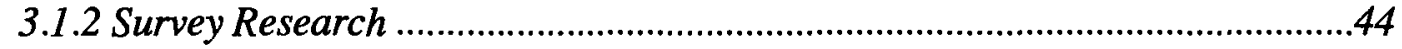

3.1.3 Field Research ..................................................................................46

3.1.4 Unobtrusive Research ..............................................................................4

3.1.5 Evaluative Research ……………………..................................................4

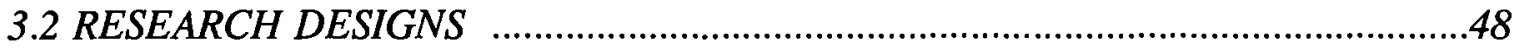

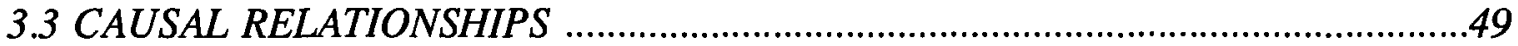

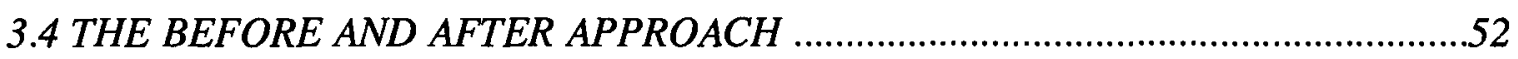

3.5 THE ANALYSIS TECHNIQUES ...............................................................53

3.5.1 Correlation Analysis ...............................................................................54

3.5.2 Regression Analysis ................................................................................54

3.5.3 Factor Analysis ........................................................................................56

3.6 THE METHODOLOGY \& DATA OF THE DISSERTATION …………....................57

3.6.1 The Dissertation Research Design ......................................................59

3.6.2 Scope Of The Study \& Unit Of Analysis ...................................................60

3.6.3 The Research Process ..................................................................................60

3.6.4 Data Description ..................................................................................61

3.6.4.1 The Primary Data Collection Technique ......................................63

3.6.4.2 Sources Of Existing Data ...........................................................64

3.7 RELEVANCY OF THE DATA ANALYSIS METHODS \& TECHNIQUES ....................66

3.8 CONCLUSION ………………………………................................................68

CHAPTER IV: THE CITY OF RIYADH

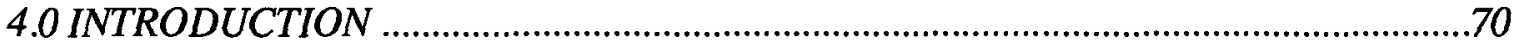

4.1 THE PLANNING SYSTEM ........................................................................

4.2 THE AVENUES OF PUBLIC PARTICIPATION …….............................................

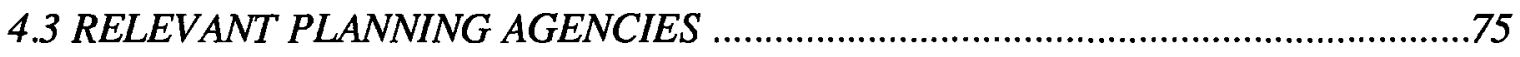

4.4 THE ISLAMIC PRINCIPLES RELATED TO PLANNING ………………………......79

4.5 RELEVANT CULTURAL DIMENSIONS ………….............................................81

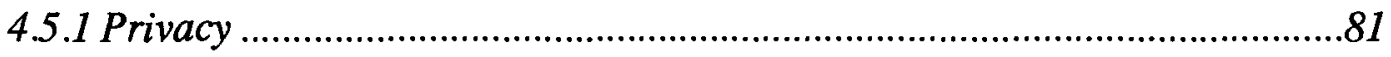

4.5.2 Automobile Dependency …………………………..................................83

4.6 THE LAND GRANTING SYSTEM …………………..........................................8 


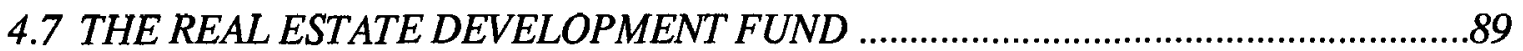

4.8 GROWTH OF RIYADH ...................................................................................92

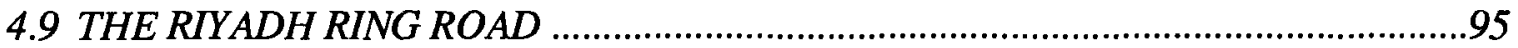

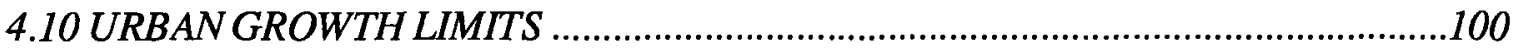

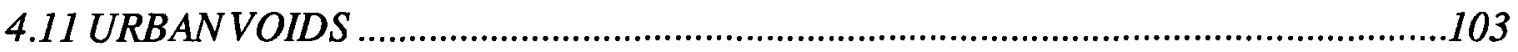

4.12 THE DRAWBACKS OF URBAN VOIDS .............................................................109

4.13 PRIVACY \& AUTO DEPENDENCY AND URBAN VOIDS ................................112

4.14 CONCLUSION ..........................................................................................114

CHAPTER V: THE QUESTIONNAIRES ANALYSIS \& RESPONSES

5.O INTRODUCTION .......................................................................................117

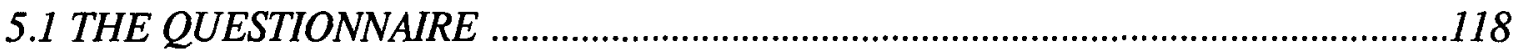

5.1.1 The Close Ended Questions ..................................................................119

5.1.2 The Open Ended Questions ....................................................................122

5.1.2.1 The Officials' Responses ..............................................................122

5.1.2.2 The Developers' Responses ..........................................................124

5.1.2.3 The Academics' Responses .........................................................125

5.2 THE RESPONSES IN LIGHT OF RESEARCH GOALS ..........................................125

5.3 THE HYPOTHESES AND QUESTIONNAIRE RESPONSES .................................131

5.3.1 The Main Hypothesis ...........................................................................131

5.3.1 Sub-Hypothesis $(A)$................................................................................133

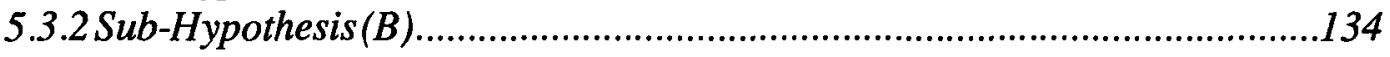

5.3.3 Sub-Hypothesis $(C)$.............................................................................135

5.4 CONCLUSION ……………………………………………………………...139

CHAPTER VI: SUBMUNICIPAL DATA ANALYSIS

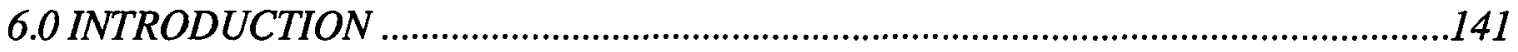

6.1 URBAN CHANGES IN RIYADH (1986 - 1991) ………....................................142

6.1.1 Population ........................................................................................142

6.1.2 Household Income \& Expenditures .........................................................143

6.1.3 Vacant Lands \& Land Uses ...............................................................143

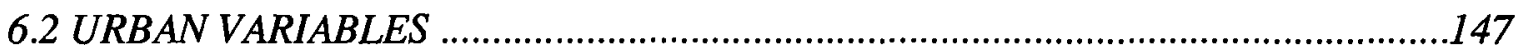

6.3 URBAN DATA ANALYSIS ...............................................................................155

6.3.1 Vacant Lands Of 1986-87 \& 1990-91: A Comparative Analysis .............156

6.3.2 Vacant Lands \& Freeway Segment Length .............................................164

6.3.3 Vacant Lands \& Distance From City Center And Approved Loans ........169

6.3.4 Vacant Lands \& Areas Reserved For Manufacturing And Service Uses.....171

6.3.5 Vacant Lands \& Dwelling Units And Population Variables ...................172 
6.3.6 The Degree Of Urbanization In Each Submunicipality ...........................175

6.3.7 Vacant Lands \& The Degree Of Urbanization ........................................179

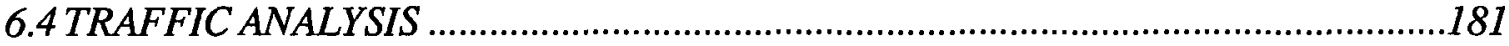

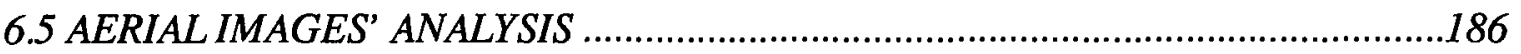

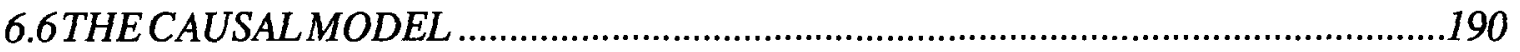

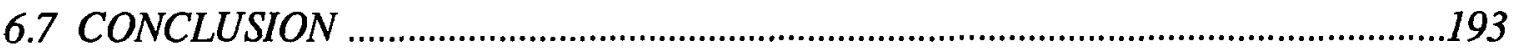

CHAPTER VII: IMPLICATIONS

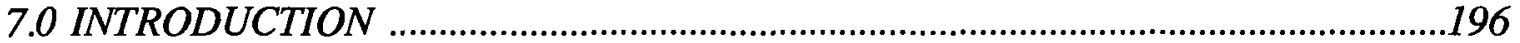

7.1 IMPLICATIONS ON FUTURE RING ROADS DEVELOPMENT ......................198

7.1.1 The Timing Model ....................................................................................198

7.2 PLANNING PHILOSOPHY IMPLICATIONS ………….....................................209

7.3 IMPLICATIONS OF THE CULTURAL DIMENSION ………..............................210

7.4 URBAN DYNAMICS \& GROWTH IMPLICATIONS ...............................................213

7.4.1 Implications From Land Use Variables .......................................................213

7.4.2 Demographic Implications..................................................................214

7.4.3 Growth Management Implications ..........................................................215

7.5 CENTRAL CITY \& COMMERCIAL ACTIVITIES IMPLICATIONS .....................217

7.6 A PROPOSED RING ROAD DEVELOPMENT PROCESS …...............................220

7.6.1 Defining The City's Boundaries .....................................................................221

7.6.2 Determining The Desired Development Ratio .........................................223

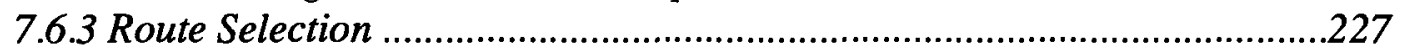

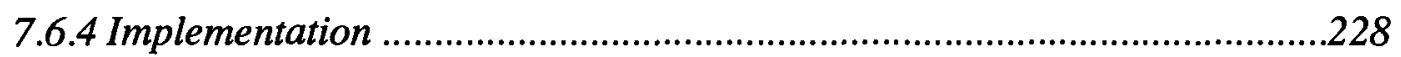

7.6.5 Responsibilities .....................................................................................228

7.6.5.1 The Mayoralty's Role ................................................................229

7.6.5.2 The ADA's Role .......................................................................230

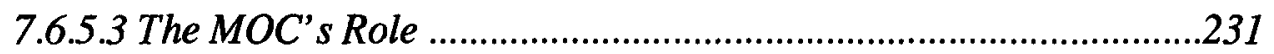

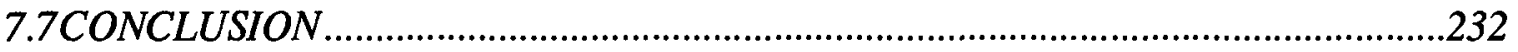

CHAPTER VIII: CONCLUSION

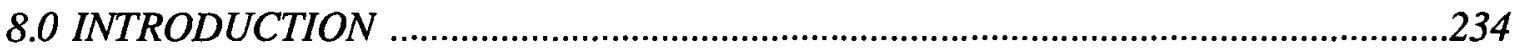

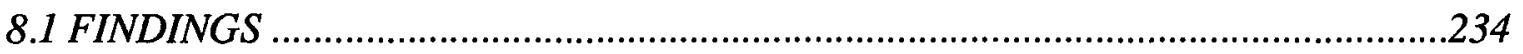

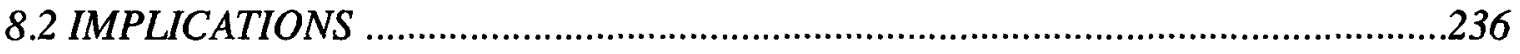

8.3 RECOMMENDATIONS FOR FURTHER RESEARCH ……..............................240

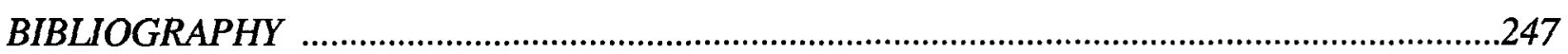

vii 


\section{APPENDICES}

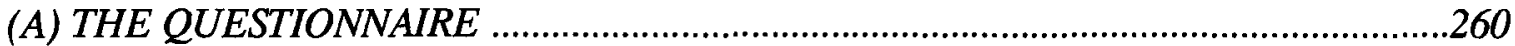

(B) THE QUESTIONNAIRES' FREQUENCIES (NORMAL PERCENTAGES) .................267

(C) THE QUESTIONNAIRES' FREQUENCIES (VALID PERCENTAGES) ......................273

(D) THE CORRELATION ANALYSIS APPENDIX …………........................................278

(E) THE REGRESSION ANALYSES APPENDIX ………….....................................283

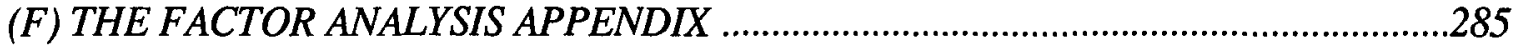

(G) THE CONCEPT OF DECENTRALIZATION ...................................................287

viii 


\section{LIST OF TABLES}

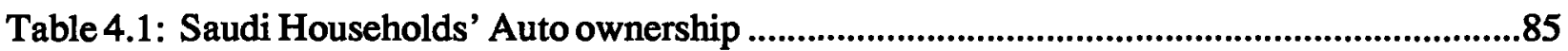

Table 5.1: The Responses (Items 2 -17 ) .....................................................................................120

Table 5.2: The Responses (Items 18 - 21) ...............................................................................121

Table 6.1: The 1986-87 Variables ..............................................................................................151

Table 6.2: The 1990-91 Variables ......................................................................................................153

Table 6.3: Change In Vacant Lands In Inner Submunicipalities (1986-91) ...............................160

Table 6.4: Potential \& Used Capacity Of Inner Submunicipalities In 1990-91 .........................162

Table 6.5: The LENGTH Variable .....................................................................................164

Table 6.6: Distance From City Center \& Approved Loans .................................................................170

Table 6.7: The URBAN Variable ...................................................................................................178

Table 6.8: Level Of Service For Basic Freeway Sections .................................................................182 


\section{LIST OF FIGURES}

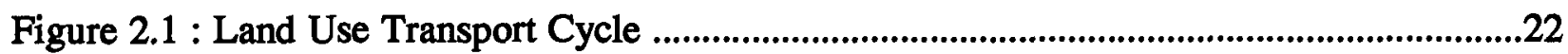

Figure 4.1 : The Neighbourhood Blocks Of The Modern And Traditional Arabic Cities ...........87

Figure 4.2 : The REDF Loans .....................................................................................................90

Figure 4.3 : Riyadh Population Growth (1910-1990) ........................................................................92

Figure 4.4 : Riyadh Physical Growth (1910-1990) ................................................................................94

Figure 4.5 : Pictures Of Segments Of The Riyadh Ring Road ....................................................97

Figure 4.6 : The Locations Of Important Institutions .......................................................................99

Figure 4.7 : The Urban Growth Limits of Riyadh (Phase I \& Phase II)...........................................101

Figure 4.8: The Classifications Of Vacant Lands ................................................................................105

Figure 4.9 : Vacant Lands \& City Boundaries ......................................................................106

Figure 4.10: Major Concentrations Of Vacant Urban Lands ...........................................................107

Figure 4.11: Government Revenues \& Expenditures ..........................................................................108

Figure 5.1 : Respondents' View On Fringes' Growth As Induced By The Ring Road .............128

Figure 6.1 : The Submunicipalities ..................................................................................................145

Figure 6.2 : The Changes In Vacant Lands (1986-90) ..................................................................146

Figure 6.3 : Vacant Lands As Function Of The LENGTH Variable .................................................166

Figure 6.4 : Freeway Impact On Urban Development .......................................................................167

Figure 6.5 : Number Of Buildings In Disrepair ....................................................................174

Figure 6.6 : The Degree Of Urbanization ..................................................................................176

Figure 6.7 : The Location Of Nakheel Community ..........................................................................180

Figure 6.8: The Locations Of Traffic Counting Devices ...............................................................183

Figure 6.9 : Traffic Distribution During An Average Day In Riyadh ..............................................185

Figure 6.10: A Satellite Image Of Riyadh (1973) ........................................................................188

Figure 6.11: A Satellite Image Of Riyadh (1992) ....................................................................189

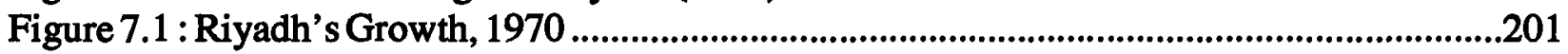

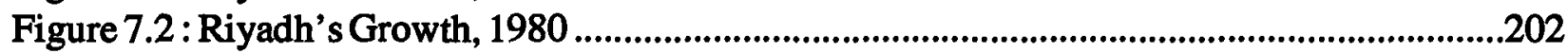

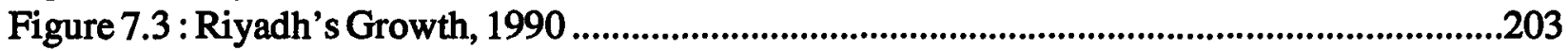

Figure 7.4 : The Timing Model .................................................................................................................208 


\section{Glossary}

Accessibility:

It shall always refer to automobile accessibility unless otherwise specified.

ADA:

Arriyadh Development Authority

ADR:

The Actual Development Ratio (The ratio of the built up area to the total city area)

DDR:

The Desired Development Ratio (the ADR at which a ring road development is recommended)

Arriyadh:

A different Spelling of Riyadh.

Developable Vacant Lands: Lands which are physically developable, e.g. lands which are not located in canyons or steep hills.

Fully Developed City: A city which has no vacant lands, or a very little amount of vacant urban land, within its boundaries.

Existing Data:

Data which are collected by governmental agencies.

Fringes:

Areas at the peripheries of the city, generally not fully serviced.

Inner Lands:

Lands located between the old sections of the city and new outer development.

Inner Submunicipalities: Those which are located within the ring road.

Outer Submunicipalities: Those which are located outside the ring road.

LGS:

Land Granting System. 
Kingdom:

MOC:

MOMRA:

Outer Areas:

REDF:

Ring road:

Secondary Data:

SR:

Submunicipality:

Vacant Lands:

Urban Voids:

UGL:

\$:
Saudi Arabia

Ministry Of Communication.

Ministry Of Municipal \& Rural Affairs

Same as fringes.

Real Estate Development Fund.

Beltway, Orbital, Circumferential.

Data which are collected by other researchers.

Saudi Riyal (1 SR $=0.33$ Canadian Dollars)

An area with known boundaries and usually represented by a governmental agency primarily tailored to maintain municipal services.

Shall always refer to "vacant urban developable lands" unless otherwise specified; these lands are privately owned undeveloped parcels within the city boundaries; the term is interchangeable with "urban voids".

Same as vacant urban developable lands.

Urban Growth Limits, a growth management technique established by the city of Riyadh.

Shall always refer to the Canadian Dollar unless otherwise specified. 


\section{ACKNOWLEDGEMENTS}

Many individuals in Canada and Saudi Arabia have contributed to this dissertation; my appreciation goes to all of them. My special thanks go to my dissertation committee. I owe a great deal of appreciation to professor Setty Pendakur, the chairman of the committee, for his devout and sincere efforts in supervising this dissertation. Professor Alan Artibise, the director of our school (1988-1993), was always helpful despite his busy schedule and his assistance is gratefully acknowledged. Professor Francis Navin's guidance and critical comments throughout the research process are very much appreciated.

In Saudi Arabia my thanks go to Dr. Nasir Alsaloom, the Deputy Minister of Communication, and to Dr. Asem Arab, the Deputy Minister of Planning for their kind cooperation. Also my thanks go to Dr. Muhammad Alhammad, the president of the Arab Urban Development Institute, for his kind assistance. In addition, I owe thanks to the ADA staff including Abdulaziz Al-Sheik, Abdulrahman Al-Sultan, Salah Al-Mousa, and Abdulrahman Al-Mosaind. Finally, I thank all my colleagues in Canada for their comments on the writing of this dissertation. In particular, I thank Reginald Faubert, a policy analyst in the Ministry of Transportation of British Columbia, for reading and commenting on this thesis. 
Chapter I

Introduction 


\subsection{Introduction}

This chapter discusses the purpose of the research, presents the goals and objectives, and states the main hypothesis. In addition, the chapter highlights the significance of this dissertation and its contribution to knowledge. It concludes by discussing the dissertation structure, the order, and the major contents of the following chapters.

\subsection{Problem Statement}

Saudi cities have witnessed immense urban growth in the last two decades. While there are causes for such a growth, e.g. the increases in oil revenues in the 1970's, its direction has primarily been influenced by the road, and particularly the freeway, network. The urban freeway network in Saudi Arabia has been highly developed in the last decade; accompanied by high increases in car ownership, this development has significantly increased automobile accessibility. However, the impact of this increase in accessibility has not been fully explored and assessed (in terms of planning studies) to provide policy guidelines for future freeway investment. The problem statement examined in this thesis is assessing ring road impact on the efficiency of urban development. The theoretical question investigated is: is there any relationship between the increased auto accessibility, with particular reference to the ring road system, and the increase of vacant urban lands (lands which are privately owned, located within the city boundaries, and have high access to services).

The purpose of this research is to examine the influence of urban freeways, primarily ring roads, on the pattern and efficiency of urban development in the capital city, Riyadh. Riyadh is a 
modern metropolis with a population of more than 2.3 millions; it covers an area of 1650 square kilometers (Alsharq Alawsat, 1993). Most infrastructures are in place including the road network. Riyadh has a very high quality freeway system which was built to high international standards.

\subsection{Goals \& Objectives}

The research has several goals:

1. Determining if the development of the ring road is related to the increase of vacant urban lands.

2. Examining the phenomenon of leapfrogging in light of the existing freeway system; and including:

a) the relationship between the development at the fringes and the existence of developable vacant land in the middle;

b) the underlying causes for leapfrogging.

3. Examining the role of the ring road system in the decentralization of urban activities, particularly the location of residential units.

\subsection{Hypothesis \& Sub-Hypotheses}

The main hypothesis of this research states that the development of ring roads at a time when a substantial amount of inner land is vacant (not developed) encourages leapfrogging growth to occur and thus creates more vacant lands. Ring roads increase accessibility to auto-users. This increase makes the development in the outer areas very possible. Outer areas enclose lots which are large and inexpensive; the advent of a ring road make them very accessible and, 
therefore, their development becomes inevitable. The growth of outer areas at the expense of inner areas leaving vacant urban lands in between is the leapfrogging phenomenon.

There are several sub-hypotheses, which relate to the main hypothesis, as follows:

A) The introduction of ring roads prior to full utilization of serviced land within the inner areas encourages new housing units to locate in the outer areas. This was also helped by the availability of inexpensive lands in the outer areas. These lands are either owned by those who originally obtained them via the Land Granting System (LGS, introduced in Chapter IV), or those who bought them from the original owners. In any case, these lands were obtained at no cost at their initial point of entry to market. While accessibility is a major contributor to leapfrogging in Riyadh, the fact that land values in the outer areas are relatively low encourages new housing units to locate in these areas.

B) Ring roads contribute to the decentralization of economic activities thereby reducing the vitality of the city center. The economic value of the city center could be expected to decrease with the improvement of accessibility to the outer areas. Improvement in accessibility and communication technology may reduce the needs for agglomeration economies and encourage economic activities to migrate to locations where space is abundant, and an affluent population is located.

C) The prevalent contemporary socioeconomic setting in Riyadh promotes "automobilization". This may be attributed to many variables, including those of an 
economic, cultural, and climatic nature. ${ }^{1}$ When these factors act simultaneously, they further dependence on the automobile, rendering it the only viable mode of travel. Leapfrogging growth and household locational decisions are not only a function of income and improved accessibility but also a function of cultural factors. While income and accessibility may determine household locational decisions, cultural factors that are peculiar to Saudi society (e.g. selecting locations based on proximity to relatives or friends) are also important.

The ring road of Riyadh is part of the freeway system which include two important radial freeways, Makkah road and King Fahad road. Makkah road runs along an east-west access. King Fahad road runs along a north-south access (when it leaves the city it is called Qassim road, but this radial road will be refer to as King Fahad road to simplify the discussion). Along with the ring road, these two radials represent the relevant components of the freeway system of Riyadh. However, this thesis will be more concerned with the ring road because of its unique impact on the urban environment as subsequent discussions in this thesis will reveal.

\subsection{Contribution To Knowledge}

Contribution to knowledge is one of the four principles of original research: objectivity, empirical verification, contribution to knowledge, and publication (True, 1983: 19-20). Objectivity refers to the quality of seeing things (objects or ideas) as they exist in the world. In other words, objectivity requires the total elimination of bias which may distort the outcome of the research.

\footnotetext{
It is assumed here that the climatic factor is part of the socioeconomic settings. Climate may affect the social behaviour in different ways. For example, harsh climates may restrict social interaction (i.e. visitation among families, business opening and closing times, etc.) during certain periods of the day thus affecting the general travel behaviour in the city.
} 
A sign of objectivity may be seen when different researchers reach the same conclusion pertaining to the researched topic. Empirical verification refers to the quality of subjecting the hypothesis or the theory to testing. Contribution to knowledge refers to the quality of contributing new ideas or new dimensions of existing ideas to the existing body of knowledge. For example, a study to explore or explain a known phenomenon in a certain culture could contribute new dimensions if it is conducted with respect to another culture. Publication refers to the quality of sharing the research outcomes with others. This will assist other researchers to update their base of knowledge.

This research will provide a new perspective in understanding the impact of ring road development on vacant land distribution in Riyadh, an environment that is strongly dominated by a distinct Islamic-Arabic culture. Such understanding will make future ring road development in Riyadh, other Saudi cities, and similar cities in the region compatible with achieving compact cities which utilize its urban lands efficiently. The research will show the importance of the timing of ring road development on the efficiency of the city, a very crucial factor for future planning policies.

\subsection{Dissertation Structure}

The dissertation consists of eight chapters. Chapter I introduces the problem statement, the research goals and objectives, the hypothesis, the significance of the study (contribution to knowledge), and the dissertation structure. 
Chapter II reviews relevant literature. It starts by discussing relevant urban theories and models. The chapter then relates the interaction between land use and transportation and discusses the relationships between urban transport and urban growth. The subject of ring roads and urban growth is introduced and discussed. The discussions cover the subjects of The Capital Beltway (a ring road which encircles the U.S. capital, Washington) and The London Orbital (a ring road which encircles the British capital, London). In addition, the chapter reviews the Blaney-Dyett \& Payne-Maxie Study which was initiated by the U.S. government, covering 54 cities, 27 of which are beltway (ring road) cities. The last section reviews major growth management techniques and discusses the arguments against and for them.

Chapter III explains the general methods of original research and highlights those which are most relevant to the purpose of this thesis. The chapter starts by introducing the three major research purposes: exploration, description, and explanation. In addition, it covers the major modes of research: experimentation, survey research, field research, unobtrusive research, and evaluative research. Causal relationships are also covered showing the nature of causal relations in urban planning, e.g., probabilistic and deterministic relationships. The discussion extends to cover the before and after approach and the analysis techniques relevant to the purpose of this dissertation.

The final section of chapter III discusses the specific methodology of this dissertation. It starts by examining the suitability of the introduced modes of research to the purpose of this dissertation. Then it discusses the research design, the scope of the study and its units of analysis. The discussion then covers the research process, the research data, its methods of collection, and 
its sources. This section concludes by examining the relevancy of the methods and analysis techniques to the collected data.

Chapter IV examines the city of Riyadh and its setting. It starts by discussing the planning approach in the city and the philosophy which shapes such a paradigm. The discussion also covers the major government agencies involved in articulating and implementing urban planning policies. In addition, the Land Granting System (LGS) and Real Estate Development Fund (REDF), which are the same all over the Kingdom, are introduced.

The discussion proceeds to cover relevant Islamic and cultural dimensions. It then discusses the stages of the growth of the city in both population and area. Next, the Urban Growth Limits (UGL), a growth management technique developed by the city planners in Riyadh, is discussed. The chapter concludes by examining the phenomenon of vacant urban lands (urban voids) and its drawbacks.

Chapter V provides an extensive analysis of the primary data in light of the research goals and objectives. The chapter starts by introducing the questionnaire and the results. Then it examines these outcomes through the goals and objectives of the research. The discussion extends to examine the hypotheses in light of the questionnaire responses.

The topic of chapter VI is the submunicipal data analysis which examines the relationships among urban variables. Traffic analysis follows, covering relevant portions of the ring road and 
the two radials. The discussion concludes by examining and analyzing selected aerial images of the city of Riyadh.

Chapter VII examines the planning implications, based on the analyses and discussions of this dissertation. The chapter starts by defining planning implications for future ring road developments. It introduces a timing model devised to assist decision makers to choose the appropriate timing for ring road development. The discussion on planning implications extends to examine planning philosophy implications and uncovers implications from the cultural side. Urban dynamics and growth implications are also discussed. The discussion proceeds to examine implications on central cities and commercial activities.

The chapter concludes with a section on a proposed planning process tailored to future ring road development. The process is meant to provide a planning guideline for future ring road development. Policy makers may find this process instrumental when the aim is to develop a ring road and at the same time avoid the potential spread of vacant lands. Chapter VIII ,the concluding chapter, summarizes the research findings. In addition, it examines and suggests recommended future research.

Finally, relevant materials and numerical analyses which are not shown in the text of this thesis are included in the appendices at the end of the dissertation. Appendix A presents the questionnaire; most of the questions in this questionnaire are structured to satisfy the purpose of this thesis, but some questions were included for other purposes (i.e. to enhance the response 
rate). Appendix B and C provide the numerical outcomes of the pre-coded questions. The difference between Appendix B and Appendix C is that the former shows the normal percentages of the questionnaire's frequencies while the latter shows its valid percentages (the discussion in Chapter V elaborates on this difference). Appendix D includes the correlation analysis matrices for both 1990-91 data and 1986-87 data. Appendix E shows regression analysis equations which are not included in the text of the thesis. Appendix F presents the numerical outcomes of the factor analysis. Finally, Appendix G discusses the arguments for decentralization, a concept that is occasionally referred to in this dissertation. 
Chapter II

\section{Literature Review}




\subsection{Introduction}

This chapter reviews relevant urban theories and models, land use and transportation interaction, urban transport and urban growth, ring roads (beltways) and urban growth, and growth management techniques. The discussion starts by highlighting the ideas of David Richardo (1819) and Von Thunen (1826). It then covers the star theory of Hurd (1903) and the contribution of Haig (1927) who related transport cost to land rent. The discussion broadens to cover the classical models of urban structure: the concentric zone model of Burgess (1925), the sector model of Hoyt (1939), and the multi-nuclei model of Harris and Ulman (1945). The works of Wingo (1961), Alonso (1964), Muth (1969), Siegel (1970), and Thomson (1977) are also introduced.

The chapter then relates the interaction between land use and transportation. The discussion investigates major factors shaping our cities, e.g. market and political forces. The relationships between urban transport and urban growth are then discussed covering the two major arguments: the first which suggests that transport improvement lead to economic development, which in turns facilitate urban growth (Dodge 1965, Hunter 1965, and Wilson 1966); the second which suggests that economic development leads to transport improvements (Brown 1973, and Rich 1978).

The chapter then discusses the impact of ring roads on urban growth. The discussion covers the Capital Beltway Study (in Washington D.C.) which examines the impact of the circular freeway. In addition, it covers the analysis of the London Orbital, which circles the city. The next portion 
reviews the Blaney-Dyett \& Payne-Maxie Study prepared for the U.S. department of transportation and the U.S. department of housing. The study covers 54 metropolitan areas, 27 of which are circled by beltways.

Finally, the discussion concludes by reviewing major growth control measures. It extends to cover the argument against growth management (Downs, 1992) and the argument for it (Godschalk, 1992). 


\subsection{Urban Theories and Models}

Western theories of urban structure have been emerging for a few centuries. ${ }^{1}$ In the 18 th and 19th centuries, authors such as David Richardo (1819) and Von Thunen (1826) wrote on such subjects. Richardo tried to explain the ultimate use of land based on its competitive advantage, primarily dealing with farm land. According to him, competitive advantage depends on the inherent qualities of land (fertility, geography, geology, etc.) and its location with respect to market and raw materials. The essence of his theory is that economic rent is the surplus yield between lands which differ in productivity. If a land produces more, in the agricultural sense, than another land, then the economic rent of the former is the difference between the values of the produce of the two lands.

Thunen observed that transport cost is an important dimension of the quality of land; transport cost determines the economic rent if fertility is constant. Thunen assumed a uniform flat plain traversable in all directions, with zones encircling one another and, ultimately, the market town (Hoover \& Giarratani, 1984: 143). He suggested a role for determining each land use, in each circle, based on the amount of production. Activities with large amounts of output per acre are to locate closest to the market and so on (Ibid: 144).

Following previous works, Hurd (1903) suggested that a city grows from its center along its major arterials, a notion known as the star theory (Wilson \& Schulz, 1978: 42). This notion reflected the urban form of cities when street cars and passenger trains were the primary modes

\footnotetext{
The discussion in this paragraph is highly informed by course notes and discussions during Prof. Gerald Brown's course "Urban Methods \& Models" (Civil Engineering Department, winter of 1990).
} 
of travel. Nearness to the city center was seen by Hurd to determine land value, building upon Thunen's theory. Haig (1927) also followed the same line as he related transport cost to land rent. He suggested that site rent and transport cost are complementary values representing the total cost of friction (Korcelli, 1982: 97). Hawely (1950) suggested that land values are a function of competition among various land users. His theory "assumes a given pattern of rent values as a framework for the development of social patterns over urban space" (Ibid: 97).

The classical models of urban spatial structure are the concentric zone model (developed by Burgess, 1925), the sector model (developed by Hoyt, 1939), and the multi-nuclei model (developed by Harris and Ulman, 1945) (Ayeni, 1979: 12-14). The concentric zone model suggests an urban structure with more activities at the center and less activities at the fringes. The model suggests that the city consists of different zones encircling the center. The central business district (CBD) is the center in this model. This district may have some manufacturing activities at its fringes. The second zone comprises some low-quality residential areas often occupied by new migrants. The third zone consists of independent working men homes (second generation migrants). The fourth zone contains middle class residences (i.e. managers, clerks). The final zone is the commuters' zone which encompass small cities, towns and suburbs working as dormitories for well-off city dwellers (Ibid: 12).

The sector model introduced the concept of transportation lines as corridors of sectoral growth; therefore, the concept of encircling zones, as in the previous model, does not have a clear acceptance here. The prevalent urban pattern--according to this model--is that different land uses 
radiate from the city center in sector-like patterns. The multi-nuclei model is based on the concept of having many centers around which growth may take place. It is a critique of the two previous models, both of which assume one center, i.e. CBD, around which different zones circle or sectorally radiate. The multi-nuclei model's centers could be residential, industrial, commercial, etc (Tbid: 14).

The explanations of urban structure introduced by early writers such as Thunen were furthered recently by several urban thinkers, including Wingo (1961), Alonso (1964), Muth (1969), and Siegel (1970). Wingo's model suggests that the journey to work is the critical factor in residential locations. The basic assumptions of the models of constant income and housing consumption made the application of the model rather difficult. Around the same time, Alonso developed a model in which he suggested that the housing decision is a trade-off between the amount of land consumed for housing and the distance from the CBD, assuming that the cost of goods other than housing is constant (Wilson \& Schulz, 1978: 54). Since Alonso's model did not restrict income and housing consumption, assuming both vary among different households, the model was more on the practical side than that of Wingo. ${ }^{2}$

While using the same variables of distance and cost, Muth's contribution lies in suggesting that income increases allow households to consume more land; this is the case because commuting costs increase at a low rate while land prices decrease at a high rate in successive outer areas

\footnotetext{
2 Indeed the assumptions of both models (Alonso's and Wingo's) can be seen as unrealistic. For example, Alonso assumes one employment center and an urban area that is traversable in all directions (for further discussions of both models please see Concepts and Techniques in Urban Analysis by Ayeni, 1979). However, both models contributed to better the understanding of the urban structure of the North American city.
} 
(Ibid: 55). Siegel also utilized distance and costs but added other variables such as accessibility, environmental quality, public services, and aesthetic characteristics; in other words, a consumer will try to maximize the utility of not only land and transport cost but also these other variables (Ibid: 55).

Thomson (1977) classifies cities, with respect to their transport systems, into the following categories: ${ }^{3}$

1. the fully-motorized city has no radial transport system and no city center in the full sense of the term. Here the freeways constitute the primary transport network. Examples of this archetype include Los Angeles, Detroit, Denver, and Salt Lake city.

2. the weak-center city has a radial road network that is meant to serve a relatively small city center, the workers in which are mainly auto users. The majority of jobs are in the suburbs, taking advantage of high capacity ring roads. Examples of this archetype include Melbourne, Copenhagen, San Francisco, Chicago, and Boston.

3. the strong-center city consists of a strong radial transport, rail and road system, without high capacity ring roads except close to the center itself. Examples of these cities include Paris, Tokyo, New York, and Athens.

4. the low-cost strategy consists of a dense city with a major center served by numerous bus corridors in which activities other than residential concentrate. Examples of this archetype include Bogota, Lagos, Calcutta, Istanbul, and Karachi.

\footnotetext{
3 Thomson describes the components of the urban transport as parking difficulties, environmental impact, difficulties for pedestrians, off-peak inadequacy of public transport, peak-hour crowding on public transport, accidents, and traffic movement (Thomson, 1977).
} 
5. the traffic-limitation strategy has a very strong city center that is well served by public transport (bus, rail ... etc.). The city center represents the top of the hierarchy of centers which include sector centers, suburban centers, and neighbourhood centers. In this archetype a radial rail system exists and a ring railway may exist to connect sector centers. Examples of this archetype include London, Singapore, Hong Kong, and Vienna.

\subsection{Criticism}

The aforementioned theories and models have been criticized for several reasons, including restrictive assumptions, applicability, and incorporation of insufficient variables (i.e., those of cultural dimensions). Early criticism can be traced to the writings of Firey (1945), and Alihan (1938) and can be extended to the writings of Wilson \& Schulz (1978), Ayeni (1979), and Bale $(1985)^{4}$

The above discussed theories and models are weak when viewed across cultural lines because their development reflects mostly the attributes of Western cities. They are culturally specific to the value system which dominated the research environments. For example, Wingo's work which suggests that the journey to work is the critical factor in household locational decisions is not relevant to Riyadh and other Saudi cities, because the factors which affect household locational

\footnotetext{
4 There are other models which endeavour to explain and contribute to the understanding of urban dynamics. Population models are good examples. They are introduced to facilitate the understanding of the urban structure. According to Korcelli (1982), Clark's (1951) population density model has often been widely validated (Korcelli, 1982: 100). The model simply describes the inter-urban density pattern as a negative exponential function of the distance from the center of a city (Ibid: 99). Another model, also population-related, was introduced by Hansen (Lee, 1973 op cit. in Khisty, 1990). Hansen's model--also known as an accessibility model--considers employment to be the major factor in population location.
} 
decisions in Saudi Arabia are different from those in North America. For example, the Land Granting System (a program that will be discussed in Chapter IV) is an important factor in Saudi household locational decisions, but this program does not exist in North America. In addition, auto ownership is high and operating costs are quite low (i.e gasoline cost is 11 Canadian cents per liter) when compared to North America. Therefore, the application of the Western theories and models without any modification might not best explain the urban structures in cities of different cultures such as Riyadh. However, the understanding of these theories and models is relevant to the understanding of city structures in general, even in culturally different cities.

Human behaviour is influenced (particularly in certain cultures such as the Islamic-Arabic culture) more by the dominant value system than other factors (i.e., economic constraints). Therefore, the cultural dimension must be considered when new models are developed. It is the view of the author that there are four stipulations needed to make a model applicable to a set of cities. These conditions are:

(a) The cities must be very similar in terms of their culture, value system, economic and political institutions.

(b) The cities must possess a similar economic base.

(c) The cities must share certain basic characteristics in terms of their urban transport structure. For example, they must fall in the same category in Thomson's classification of cities.

(d) The cities must have similar topographical/climatic settings.

A model capable of predicting an urban form of a city should be better equipped in terms of 
predicting and explaining another urban form for another city so long as such cities share the above four conditions. Since satisfying such postulates is difficult as these conditions may change among cities even within one country, planners should not expect any ideal, universally accepted urban model. Rather they should be satisfied with limited models as long as they are valid for the very type(s) of city(ies) they are supposed to explain.

\subsection{Land Use, Development and Transportation}

The land use system refers to the way in which land uses are determined and regulated. The system is to reconcile individual or market objectives with collective or governmental objectives. For example, a land occupied by a palm grove may better serve the public interest if it is kept as a palm grove to provide its community with a source of fresh air. The same land can be put into commercial use by developing it as a shopping area. While the private owner wants the maximum utility of land, the public utility may be maximized if no development occurs. The land use system is presumed to reconcile the public and private interests. Sometimes land use planning is to conciliate different interest groups over the use of certain public land (Mather, 1986: 212).

The philosophy which shapes land use patterns in our cities is by no means objective. Decisions which are made to determine the shape of our urban areas are not purely based on scientific logic. Political and market forces are quite important in shaping land use decisions. Some writers see land use planning as an ultimate function of political power: 
Ultimately, land use planning depends on how political power is distributed and exercised. It cannot be simply a technical [scientific] value free exercise (Ibid: 241).

Market forces (particularly in market economies) are important in shaping land use patterns simply because land value is a good proxy of potential land use. Indeed, market forces often lead political forces and may eventually determine the land use. However, political forces and market forces may conflict to make the need for a conciliatory land use system even greater.

The urban structure of most cities can be viewed as a function of their transport system. By interacting with different land uses, the transport system contributes to the development of the rent and density patterns which represent important components of the urban structure. For example, urban density in a certain area of a city might increase when a new transport improvement (e.g. a light rail) serve that area. This improvement may result in more development and thus intensification of the uses in that particular area. It safe to assume that land development might not occur without transport development. Indeed, land development and transport development are components of the urban cycle or, more precisely, the land use-transport cycle: 
Figure 2.1: Land Use-Transport Cycle

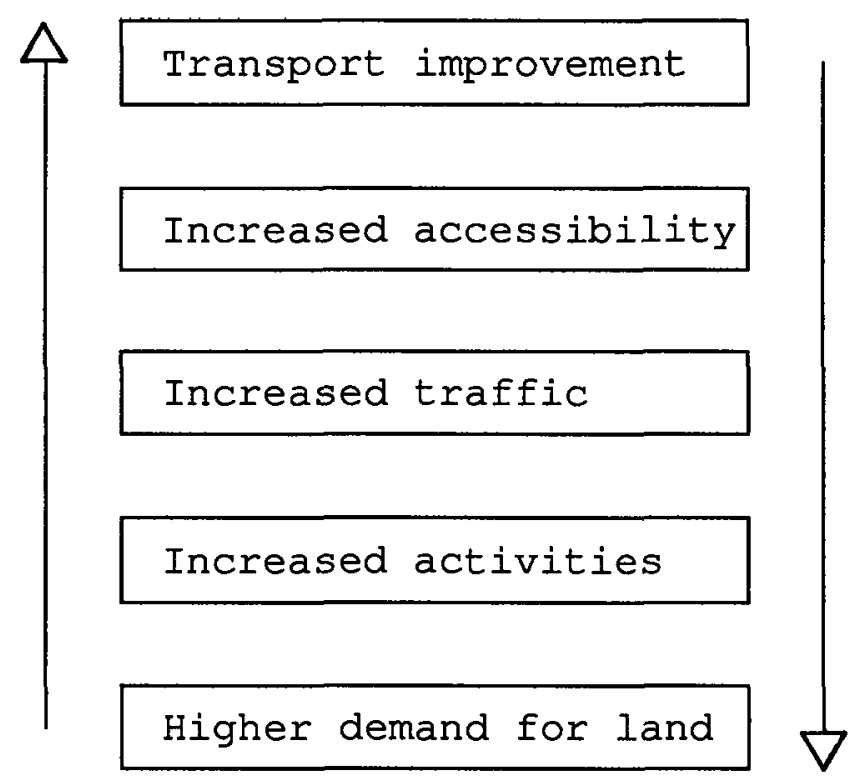

Source: ITE, 1988.

There are many forces which influence the dynamics of land development. They include government policies, change in family incomes and preferences, and development of transport technologies and systems (ITE, 1988:3). While government policies can be influenced by planners, the remaining forces are not as susceptible. For example, there is little, if anything, a planner can do to change family income. Government policies in this sense are expressed in comprehensive planning, zoning, and subdivision regulations. Planners, through government policies, play a major role in shaping land development and, indirectly, the land use / transport interaction. 
There is a causal relationship between transport and land development. ${ }^{5}$ The relationship is quite strong primarily when transport development results in an improvement in accessibility. Studies suggest that lands which experience improved accessibility, due to the transport improvement, increase their values (Putman, 1976: 7). In particular, commercial activities intensify around improved arterials and highway interchanges, a phenomenon that results from improved accessibility which increase land values. However, transport improvements which do not change the pre-improvement level of accessibility may result in an adverse outcome. For example, housing prices may go down if the housing units are located adjacent to a new freeway but with no immediate access to it. These units may suffer more noise and pollution than before, while their unenhanced accessibility provides little to gain from such a freeway.

The accessibility issue is central to the transportation system impact on land values and land development. $^{6}$ Indeed, it can easily be seen that the highest positive impact (in terms of attracting urban development) of transport improvement often occurs next to the accessibility points, such as highway interchanges and transit stations. For example, major traffic generators tend to locate near high accessibility points (Ibid: 11). Without doubt, accessibility can

\footnotetext{
5 The conditions of true causal relationships are discussed in detail in chapter III. The concept of causality is very relevant to this research. Causal relationships will be referred to frequently throughout this dissertation.

6 While transportation impact on land developments is of interest to planners, it is but one component of the whole impact package. This package is broadly twofold: microimpact and macroimpact. The former refers to the immediate impact in space and time, while the latter refers to the general impact on the whole area including the long term. Microimpact can be dealt with by regulating the immediate area of the facility (i.e. access control). Changes in land values (i.e. due to a certain transport improvement) is within the microimpact. Controlling access, for instance, to the improved facility may reduce the impact of transport on land values. Such controlling is a policy component at the disposal of the politicians and planners. Macroimpact, however, relates the improved facility to the whole transport system. Its management requires matching traffic characteristics resulting from the facility with the overall transport system.
} 
legitimately be considered a major determinant of land development, values, and rent.

\subsection{Urban Transport \& Urban Growth}

In the past, urban areas were dense because the urban radius was limited to distances that were walkable (Owen, 1968: 7). As technological improvements in transportation increased, people were able to live further away from their work, yet commute with relative ease. It is possible to say that overcoming the distance barrier is a major ingredient for dispersed growth.

Transport's role in the urban growth process can be seen as two stages. The first stage represents that period when mechanized vehicles (e.g., trains) replaced organic transport (e.g. foot or horse transport). This stage witnessed the spark of urban growth, however, cities and urban communities remained relatively dense and small in size. The second stage represents the period when motorized transport (e.g., automobiles) became affordable to a larger share of the population. It is during this period that the automobile began to impact growth trends. The advent of the automobile accompanied by the introduction of thoroughfares and freeways played a major role in urban growth and development, especially in wealthy nations. During this stage, several explanations of the interaction between transport and land development appeared. The land use-transport cycle may be considered a good explanation of such interaction. This cycle is an urban cycle in which transport improvement may result in higher demand for land and vice

versa. In general, the relationship between transport improvement and land improvement (an outcome of higher demand on land) is a chicken and egg relationship. 
Many scholars have researched the relationships between transport improvement and economic developments, of which land development is an important component. Dodge (1965), Hunter (1965), and Wilson (1966), suggest that transport investment could cause economic development. Indeed, Wilson, in his study of some developing countries, found that road investment is a prerequisite for development:

In the former group [Bolivia, Guatemala and India] the road was at least a partial initiator, inducing a development that would not otherwise be expected to occur (Wilson, 1966: 188).

Such an observation can be accepted because in most developing countries the private sector is marginal in initiating capital development projects. Therefore, when the government takes the initiative (i.e. building a road), the private sector responds to take advantage of any cost free investment. Even in developed countries, the above pattern may find support, as an historical vantage point may suggest:

Historically, the development of transportation facilities has tapped new areas and intensified land use, with consequent increases in land values along major routes. Thus, the Gulf Freeway in Houston, the Shaker Heights rapid transit in Cleveland, the subway in Toronto, the seaport of New Bedford, and the river ports of Cincinnati and St. Louis have all stimulated development and affected land values within their zones of influence (Smith, 1961: 43, based on Host, Homer, One Hundred Years of Land Values in Chicago, University of Chicago Press, Chicago, Illinois, 1933).

It is safe to deduce that transport development is a major ingredient of growth in general and land development in particular.

However, one should not ignore the other argument that suggests economic development causes transportation improvements. The writings of Brown (1973), and Rich (1978), may be used as examples supportive of this argument. Brown tried to relate regional growth in employment to 
regional accessibility, but did not find any significant relationship between the two. However, he recognized the impact of road investment in shaping a region's image as suitable for industrial development (Bruton, 1985: 31). In a recent study, Rich examined Scotland's employment change in manufacturing between 1961 to 1971 . He found no evidence that improved accessibility influenced employment change between regions but he found a clear effect on employment change within regions (Ibid: 31 ).

While the bulk of this dissertation is not meant to discuss the relationship between economic growth and transport improvement, the above discussion can be used as an indicator to examine the relationship between transport improvement and land development. This is the case because the former relationship exists at a macro scale that includes the latter relationship which in turn operates at a micro scale.

Land development can be seen as a function of land value, since land with no value is rarely competed for. For example, a piece of land in the middle of a desert with no market value will probably stay undeveloped for a long period of time. Accessibility enhances land values and therefore transport improvement is seen as a major key in land development. Many studies have shown the clear role of transport improvement on land values; they include the Shore Parkway study (New York), the Henry Hudson Parkway (New York), Grand Central Parkway (New York), the Gulf Freeway (Houston), the Eastshore Freeway (Oakland and San Francisco), and the Santa Ana Freeway (Los Angeles) (Garrison \& Marts, 1958). In the Shore Parkway case, the assessed valuation of the area of influence increased by $70 \%$ between 1939 and 1953 (Ibid: 9). As a 
consequence of improved accessibility, land values increased and development followed:

The construction of Shore Parkway has been accompanied by expanded residential use of adjacent areas. Both large apartment units and garden-type apartments have been built in large numbers along the parkway, and intensively developed subdivisions of small private homes have been erected ... (Ibid: 9).

Though developments may not follow quickly, in most cases improved accessibility increases land values leading to land development. Increased land values are not the only cause of development, but they represent early, reliable signs that precede development.

\subsection{Ring Roads \& Urban Growth}

Ring roads began to appear in major cities in the 1960's and 1970's. They are also called circular routes, circumferential roads, orbital roads, and beltways. While they may not be the primary cause of urban development, they contribute in shaping the urban structure of their cities. With the completion of some of these roads, studies began to analyze the impact of such huge urban projects on the urban scene.

\subsubsection{The Capital Beltway}

The Capital Beltway Study investigated and assessed the impact of the capital beltway on the urban life of Northern Virginia (Connally, 1968: 1). ${ }^{7}$ The study was meant to assess changes in population trends, land use, real estate activities and traffic volumes, that can be attributed to the construction of the Capital Beltway in the Washington D.C. metropolitan area. The researchers involved in the Capital Beltway study found that significant changes were brought

\footnotetext{
7 The study was prepared by the Bureau of Population and Economic Research, University of Virginia, Charlottesville, Virginia, in cooperation with the Virginia Department of Highways and the U.S. Department of Transportation, Bureau of Public Roads, 1968. The principal researcher was Julia A. Connally.
} 
about by the Beltway:

Many aspects of the social and economic life of Northern Virginia owe their present-day character, at least partially, to the Capital Beltway (Ibid: 115).

The followings summarize the main, relevant points of the study:

Industrial firms increased their market as their services expanded to cover the whole metropolitan region. The Beltway influenced the economic decentralization process in the metropolitan area, playing a major role in locational decisions (Ibid: 116). The Beltway led to a concentration of residential units near its interchanges. Such a concentration does not mean that residential development was caused by the road, since they would have sprawled along the radials anyway. However, interchange areas are highly accessible and therefore tend to form natural growth points. In other words, the Beltway may not have caused the growth, but it did direct it. Commercial activities also surged at interchange areas.

- Land values adjacent to the Capital Beltway have increased. Such an increase can be attributed to the presence of the beltway. Studies have shown that the average price of an unimproved acre, zoned industrial, was $\$ 46,700$, while the average value in interchange areas amounted to $\$ 66,000$ per acre (Ibid: 117 ). The difference among land values as a function of their accessibility to the Beltway can be seen as a proxy for the impact of the road on land values in the city in general. 
However, such an impact is a distributional one, as opposed to a purely original one. ${ }^{8}$ A distributional impact on land values means a change in the distribution of highly valued land after the completion of the Beltway:

[T]he Beltway may not have had significant effects on the general level of residential real estate values, it has had influence on the spatial distribution of increases in land values (Ibid: 118).

This suggests that certain locations, e.g. interchange sites, have greatly benefited from the beltway (in terms of increases in land values), while other locations may have lost. In addition, and in terms of economic decentralization, the study concluded that the Beltway provided direction but cannot be considered the original stimulus (Ibid: 118).

\subsubsection{The London Orbital (M25)}

Another example of Beltways is the M25 (the London Orbital) which circles London in the United Kingdom. Hall suggests that the Orbital influenced urban life:

The M25 has dramatically changed the lifestyle of the Southeast. It has transformed the way people shop and where they work (Peter Hall in DeBres, 1989: 15).

Changes in lifestyle and urban behaviour may lead to changes in the urban scene. The M25 has opened new opportunities for local residents of the towns near to it. As such opportunities were exploited by residents, the level of use on the road increased and nearby areas became more attractive for commercial development. Offices, industries and shopping center developers are searching for areas off the M25, and six shopping centers locations in the green belt area will

\footnotetext{
8 An original impact--in this context--would sharply increase the average land values all the over the city. A distributional impact would only raise the average land values in some areas and at the same time would reduce such values in other areas; so the overall average land values in a city would not change significantly.
} 
be approved (DeBres: 16). According to DeBres, the Orbital road may lead to growth of suburban malls and a declining inner city. Such an outcome will reduce the tax base of the city and make shopping choices for non-car owners rather limited. The Americanization of the British economic landscape, as she puts it, will result in inner city decline and highway congestion (Tbid: 8 ).

\subsection{The Blaney-Dyett \& Payne-Maxie Study}

A comprehensive study titled, The Land Use and Urban Development Impacts of Beltways, was prepared for the U.S. Department of Transportation and the U.S. Department of Housing and Urban Development (Blaney-Dyett, Urban and Regional Planner \& Payne-Maxie Consultants, 1980). It consists of four reports (the technical report, the final report, the guide book and the executive summary). The section which follows highlights the major points of this study following its own lines and headings. Unless otherwise specified, this section reflects the point of view of the study authors (Blaney-Dyett \& Payne-Maxie).

The U.S. federal government initiated the study for several reasons, including to determine whether beltways undermine central city revitalization efforts as well as the achievements of a compact, energy conserving and healthy land use pattern (Ibid: 1). The study covered 54 metropolitan areas, 27 of which are beltway cities while the other half is non-beltway cities. The comparative analysis of such metropolitan areas suggested (Ibid: 7-8):

complete loop beltways do not impact urban areas very differently when compared to partially looped ways (partial circumferential highways); 
spacing of interchanges and existence of frontage roads are critical to developing adjacent lands because of the increased accessibility both provide for the surrounding areas;

lack of coordination between land use planning and transportation planing may result in increased traffic on intersecting local streets and radial highways;

the coordination between interchange location and corridor land use is very important to avoid adverse socioeconomic, fiscal and environmental impacts;

- a beltway can represent an important component of the freeway system providing alternative routes to non-downtown trips.

The authors of this study have organized the principal findings of their research by subject, including regional economic growth, location and development decisions, effects on central cities, land use policy and capital improvement programming, political and social effects, and environmental effects. The following is a summary of these findings organized using their original headings and order:

2.6.1 Effects on Regional Economic Growth: There was no evidence to suggest that beltways enhance a city's competitive advantages, although there was slight but positive effects on population growth. This finding suggests that it is very difficult to justify beltway construction on the basis that it will improve the region's economic growth.

2.6.2 Effects on Location and Development Decisions: Beltways seem to impact the distributive dimension of residential, commercial and industrial activities, notwithstanding that the impact as 
a growth stimulus is limited. Beltways provide more accessible intra-regional locations. This could pose a problem for the attractiveness of city locations. People and firms may find outlying sites more attractive to utilize. In addition, it was found that beltway sites attract office development and garden apartments. Generally, beltways seem to stimulate development in growth areas but do little in areas with poor development images. Vacant lands in beltway cities near areas of poor images did not command premium prices. A beltway can improve development opportunities in its corridors as well as emphasize dominant urban patterns. It would also help in facilitating compact development. Beltway interchanges are preferred by regional shopping centers. However, it is important to note that, where possible, these centers will develop regardless of the existence of a beltway. Therefore, their overall feasibility is not dependent on the beltway. In addition, industrial and office park developers appear to be willing to bid premiums on accessible as well as visible beltway sites. Finally, multifamily housing seems to respond to beltway development, while the case is not true for single family housing. The above discussion, according to the authors (Blayney-Dyett \& Payne-Maxie), requires the development of effective and coherent land use policies to control beltway-induced developments and to make them conform with local land use plans and objectives.

2.6.3 Effects on Central Cities: Beltways have, generally, adverse effects on central cities. The severity of the effects is sharper where beltways are located outside city boundaries. The study investigators suggest that permissive land use policies accompanied by a beltway development may indeed harm the central city and downtown. The research shows that central cities with suburban beltways have attained lower gains in retail sales when compared to cities with city- 
beltways or no beltways. In addition, beltways are shown to have a one time effect of the distribution of new office space, usually weakening central city office space market. During the 1972-77 period, beltways showed a small but statistically significant negative relationship with central city employment in wholesale, service, and industrial sectors. While a shift in employment location from central city to suburb may negatively affect the fiscal resource of a city, a well-articulated revitalization program can more than compensate for the negative, usually short term, impact of a beltway. The policy mandate espoused by the authors is to establish and support local urban revitalization programs. Local initiatives can play a major role in offsetting or reducing the impacts of beltways and other forces which may undermine the vitality of the central city.

2.6.4 Effects on Land Use Policies and Capital Improvement Programs: Since beltways may change the distribution of activities in urban areas, policy and programming may be affected as the distribution of physical resources among jurisdictions change. In addition, locations and quantities of public services may change too. The study suggests that most economic and land use effects of beltways are but transfers of activities from one area to another. While planners recognized the potential influence of beltways on land use, there was little political support for policies tailored to manage corridor and interchange areas. Moreover, the authors did not find in any of the studied areas an analysis of the relationship between corridor land uses and downtown development policies. Also there was lack of coordination between sewer and water service extension policies and beltway planning. According to the authors, there is an urgent need to implement effective and coherent land use controls in the proximity of the beltways. 
These controls are meant to achieve compact and nodal development, complement central city revitalization processes, protect the environment and provide efficient public services.

2.6.5 Political and Social Effects: While beltways, like highways, increase accessibility for auto users, they reduce mobility for public transport users. Public transport will not compete, in terms of attracting users, with improved auto-transport, resulting usually in a costly, inefficient public transport system. With the potential suburbanization to be brought up by beltways, central city residents as well as captive transport users will find themselves alienated from suburban employment centers. The disadvantaged groups will rarely be helped by beltway developments; for example, industrial development prefers beltway sites, thereby causing less job opportunities in downtown areas. According to the author, the policy mandate, following the above effects, requires examining all transport options to assure that there are no other alternatives which provide the same accessibility, yet without the adverse effects on central city residents.

2.6.6 Environmental Effects: While suburbanization may be facilitated by beltways, the rate at which it occurs is not sensitive to beltway development, according to the study authors. High rates of suburbanization result in more automobile usage, which in turn, has adverse effects on the environment, but since these rates are not sensitive to beltway development, then this development is not an environmental hazard. If nodal development intensifies around interchange areas, then public transport may even benefit from beltways. The study authors suggest that further research of the environmental consequences of beltways is needed. 
The above summary discussion of the Payne-Maxie \& Blayney-Dyett study leads to one clear conclusion: beltways are not detrimental to the achievement of an efficient urban spatial system as long as well articulated, carefully examined, and highly enforceable land use and urban growth policies are put into effect.

The following section reviews urban growth techniques which are meant to manage and control urban growth. Their understanding is instrumental to the development of urban policies that can contribute to managing the potential impacts of future ring road development.

\subsection{Growth Management Techniques}

There are several growth management techniques which are developed to deal with urban growth. However, most of these techniques represent a response to a certain problem emerging in certain cities or towns thereby reflecting the values and cultures of these cities and towns. Therefore, the adoption of such techniques should take into account the environment in which they are to operate.

Burrows classified these techniques into first and second sets. The first set includes public acquisition of open spaces, zoning, interim development controls and division of land. The second set includes urban service areas, cap rates, annual permit limitations and adequate public facility programming (Burrows, 1978). Public acquisition of open space refers to enabling the government to own lands vulnerable for conversion and other growth features. The government has a better opportunity to manage lands which are publicly owned (Ibid: 18). In order for any 
government to own privately owned lands, it must purchase them and here lies the major weakness of this technique. Land acquisition cost is prohibitive especially in free market systems.

Zoning refers to the mapping and classification of land uses into zones (Davis, 1976: 64). Each zone may be subject to certain regulations. Zoning may take the forms: (1) Exclusive zoning in which high density zones are rezoned for exclusive low density zones; for example, rezoning residential areas into agricultural areas or zoning exclusively for single family residence rather than multi-family residence (Burrows, 1978: 33). (2) Non-residential zoning which restricts residential development in order to avoid urban encroachment and protect outlying areas by putting them in agricultural use (Ibid: 33); (3) Alternative configurations primarily refers to protecting conventional housing unit zones from the development of other housing types, e.g., mobile homes and apartments; (4) Special permit is a form of zoning in which uses that will be permitted are listed not as a matter of right, but rather, at the discretion of the local authority based on given criteria; for example, Ramapo (N.Y.) instituted a point scale system linking building permits to infrastructure capacity (Ibid: 42). Because most of these zoning techniques came into being as a result of existing problems, an inherited degree of rigidity makes the universal applicability of most, if not all, limited.

Interim development controls are means to slow or block development so that revision of new plans or existing ones can be performed unaffected by potential developments. These techniques can be effected by undertaking a planning pause, a moratorium on building permits, and 
moratorium on water and sewer provisions (Ibid: 47). ${ }^{9}$ Generally speaking, this technique has a limited short-term impact, yet it may influence the long-term urban dynamic. Like all temporary solutions, the little positive impact they accomplish during the designated time period is often offset by the long-term reaction to such planning tools.

Division of land is the most common device after zoning in the growth management field; the technique controls growth by regulating land development, location and quality. It uses subdivision regulations, annexation policies, official maps and exactions to achieve control (Ibid: 85). Subdivision regulations establish conditions and stipulations which have to be adhered to before plans can be approved. Annexation policies are geared to prevent annexing development areas that are either discordant or ill-suited for the existing service capacity. Official mapping is little different from land division controls; it specifies areas contemplated for public works (e.g., roads) so that any proposed development, which is inconsistent with the existing developed portions, is prohibited. Exaction is a method requiring developers to provide money, land or improvements prior to plan approval (Ibid: 58). Such a method is intended to make the cost of service provisions to new development shared by developers.

Urban service areas, the first item of the second set techniques, refer to establishing a cordon or boundary line beyond which development is not permissible (Ibid: 73). The boundary line is supposed to be identified based on several indicators such as, but not limited to, projected

\footnotetext{
9 A planning pause in all Saudi cities was employed between 1986 and 1988. This meant that during such period there were no subdivision plan approvals. The purpose of the planning pause is to give cities and towns enough time so that they can develop their urban plans. During that period Riyadh developed its Urban Growth Limit (UGL), a growth management technique which will be discussed in detail in chapter IV.
} 
demographic growths and capital improvement plan goals. The problem with this technique is artificial inflation of land prices. Drawing such a line may restrict land supply to a critical level.

The second item of the second set is cap rates. In cap rates, absolute ceilings on population growth are applied. The major fault of this technique is in its lack of practicality. It is not only difficult to provide accurate population projections to start with, but is also difficult to determine the time at which the cap applies (Ibid: 79). Annual permit limitation is the third item of the second set of growth management techniques. The technique basically determines an annual building permit figure which is not to be exceeded. The technique creates competition among all projects which compete for permits. However, the technique is not sensitive to development timing, which is a necessary factor for effective growth management (Ibid: 90).

Adequate public facilities programming is the last of these techniques. It is a method of guiding development and directing it as opposed to retarding it (Ibid: 93). The approach is meant to direct growth to areas that are designated for service provision in the future. It is geared to provide for adequate municipal expansion. The technique manifests into two programs: the limited phasing mechanism and the expanding phasing mechanism (Ibid). The former uses one or two service variables (e.g., sewer/water) as critical variables. The developer must prove that the project is consistent with the required specifications of these variables. The latter is similar except in that the developer must satisfy a series of critical variables and prove adequacy in all cases. A deficiency with such a technique may result when temporary service inadequacy occurs which may result in development denial. In addition, municipalities do not always control 
services upon which development is predicated; therefore, it is not logical for a municipality to deny a development based on services which may be provided by another authority (Ibid: 94 ). ${ }^{10}$

\subsubsection{Growth Management: Critics \& Supporters}

Growth management techniques as government interventional tools have critics and supporters. Some see government regulations having an adverse effect on the availability and production of low cost homes (Downs, 1992). In addition, other studies on local communities' caps technique suggest that the negative aspects of growth control were only avoided because relatively few communities adopted them and because the adopted programs prove porous (Landis, 1992). Other researchers defend growth management and question blaming low-cost homes affordablity on it (Godschalk, 1992). Some went further and suggested that certain growth management techniques to protect certain uses (e.g., farm lands) proved to be effective (Nelson, 1992).

Growth controls have often resulted in higher land cost. In Britain, for example, restrictions on land development resulted in high developable land prices and consequently high property prices (Pearce, 1992). This process caused other chain consequences. Pearce suggests that higher property prices increased business costs and thus influenced British competitiveness on the international scene. In addition, high land prices force activities to use land more intensively which eventually leads to reducing the standards of new properties and produces "town cramming" (Ibid). Increased inland prices due to growth control intervention also happened in the U.S.; e.g., the case of Santa Rosa (Dowall, 1984).

\footnotetext{
10 Some of the above techniques such urban service areas have informed Riyadh urban growth policies and thus contributed to the articulation of the UGL; Chapter IV examines in details the UGL.
} 


\subsection{Conclusion}

The discussion in this chapter has reviewed relevant urban theories and models. It is important to understand that many of these models reflect the dominant value system and attributes of the cities in which they are developed, and therefore, applying such models, without any modification, to culturally different cities, like Riyadh, may not be fruitful.

The analysis also shows that market forces along with political powers are very relevant to the ultimate shape of our urban areas. Urban models and theories should not totally ignore these powers if fruitful contributions are expected. In addition, the discussion of ring road impacts on urban growth suggests that these massive urban investments have a noticeable role in the ultimate shape of cities. While they do not represent a major stimulus for growth, ring roads (or beltways as they are called in North America) greatly influence the direction of growth. Previous studies suggest that ring roads may not be detrimental to the achievement of healthy cities so long as well articulated land development policies are devised.

The discussions of growth management techniques showed their strengths and their weaknesses. Since their development was in response to growth problems in certain cities, their application in culturally different cities should take into account the attributes of such different cities. 


\section{Chapter III \\ The Research Methods}




\subsection{Introduction}

This chapter covers general research methods, which can be used in other fields, and then narrows down to the specific methods of this dissertation, explaining why such methods are appropriate to satisfy the purpose of this dissertation. It starts by discussing the three major research types: exploration, description, and explanation. It then proceeds to introduce the major modes used in scientific research. They include experimentation, survey research, field research, unobtrusive research, and evaluation research. In addition, the discussion covers the general research designs, and data types.

The next topic of discussion relates more to the nature of this dissertation. It includes causal relationships, the before and after approach and the relevant statistical techniques, which include correlation analysis, regression analysis, and factor analysis.

The final section of this chapter examines the specific methodology of this dissertation and introduces its data. It discusses the logic behind the selection of certain research modes, identifies the appropriate research design, determines the scope of the dissertation, highlights the research process, and describes the data collected and their methods of collection. The section concludes with a discussion of the relevancy of the introduced analysis techniques to the type of collected data. 


\subsection{The General Methods of Research}

The purpose of research can be explorative, descriptive, or explanatory. Research can be classified with respect to the methods by which it is conducted. In this sense, research can be identified in different modes. These modes are experimental research (experiments), survey research, field research, unobtrusive research, and evaluation research (Babbie, 1989: 208).

\subsubsection{Experimental Research}

Experimental research is well suited for explanatory studies (Ibid: 212), since it supports hypothesis testing. In its simplest form, experimental research undertakes an action within a controlled environment and observes the consequences. Experimentation in research includes three major pairs of components: dependent and independent variables, experimental and control groups, and pretesting and posttesting (Ibid: 213). Dependent and independent variables are associated with assumed effect and cause, respectively. Causal relationships between the dependent and independent variables are essential for constructing meaningful models or equations. The pretesting and posttesting can be exemplified by measuring the value of the dependent variable before and after changing the values of the independent variables (treatment). Experimental and control groups allow for more accuracy in measurement. However, experimental and control groups ought to be similar, identical if possible, to better measure the changes in the dependent variable. Finding a good control group when studying urban activity is not always possible. For example, assessing the impact of improved accessibility on land development in a certain area may not be readily done if a control group is a prerequisite for 
such an assessment. It is difficult to find another urban entity (another area) similar in all attributes except for the improved accessibility. In addition, conducting true experimental research requires control over the experimental process, which is possible in a small environment (e.g. laboratory). As the size of the environment increases (e.g. urban areas), a true experiment becomes more difficult and, thereby, non- and quasi-experimental research become alternatives.

\subsubsection{Survey Research}

Survey research is a well known technique used to collect data about a population which is too large to be observed directly (Ibid: 237). Through the use of an appropriate sampling technique, survey research can be a valuable source of data. Survey research can be used to fulfil all purposes of research (e.g., exploration, description and explanation). Survey research is primarily undertaken using three sub-techniques: self-administered questionnaire, personal interview, or telephone interview.

Self-administered questionnaires are primarily conducted through the mail. That is, mailing the questionnaires and expecting the respondents to mail them back upon completion. Other methods of conducting self-administered questionnaires include: hand delivery with mail back response, mail delivery with hand back response, and hand delivery and response. The latter is expected to produce the highest response rates.

The personal interview differs from the self-administered questionnaire in that the respondents are directly questioned. The respondent orally responds and the interviewer records information. 
Personal interviewing ought to produce higher and better responses than that of the self-administered questionnaire. However, it is expected to be costly (especially in rich countries) as it includes hiring more staff (e.g., the interviewers) to carry out the interviewing process. The attributes of the interviewers (e.g. quality and appearance) are crucial to conducting personal interviews.

Telephone interviews are becoming quite accurate today as opposed to a few decades ago, especially in wealthy nations as a majority of their households have phones. ${ }^{1}$ There is little doubt that the telephone survey would be less costly in terms of time and money than personal interviews. Given the same amount of resources, and assuming telephones are widely used, many more telephone interviews can be completed in comparison to personal interviews. However, telephone surveys may not produce the same response rate, since it is easier to turn down a person on the phone as opposed to a person at the door. Finally, the selection of which subtechnique to use in survey research should satisfy, as much as possible, the purpose of the concerned research. ${ }^{2}$

$1 \quad$ For example, $97 \%$ of all American households have phones, according to the census bureau (1979: 582) (Babbie, 1986: 229). This situation makes telephone interview less biased in the U.S.

2 The selection of a survey research technique (self-administered questionnaire, personal interview and telephone interview) depends largely upon the researcher's resources and the nature of the research. A self-administered questionnaire may cost less and deal positively with sensitive issues. Personal interviews may cost more but produce a much higher response rate. Telephone interviews have a response rate between these two. However, a combination of some of these techniques might be appropriate under certain circumstances. Self administrated questionnaire and personal interview may together be used to increase the response rate. The case is common when the research requires interviewing very busy subjects. If the interviewer, during meeting the interviewee, finds that the time is too short to complete the interview or that the subject is not in the best mood, then it is advised that he (the interviewer) leave the questionnaire with the subject to be picked some time later. As long as the interviewer hands in the questionnaire and comes personally to pick it again, the response rate should not deteriorate. In some occasions, the interviewee may prefer to spend the first meeting with the interviewer for general 


\subsubsection{Field Research}

Field research differs from the previous research techniques in that the researcher studies a selected phenomenon in its natural setting (Guy et al, 1987: 254). Because of its nature, field research may be more appropriate to collect qualitative as opposed to quantitative data. It is suited to studying attitudes and behaviours as they evolve in their natural occurrence (e.g., studying the reaction on the street when riots are caused by increased prices of necessities in a poor country). In field research, the researcher is primarily involved in the participant observation form of studying. ${ }^{3}$

discussion and may suggest keeping the questionnaire for a few days so that he can carefully respond to it. In any case, the interviewer must be patient and must be willing to pay more than one visit to collect the questionnaires. In this research, the above discussed combination and the possible cases which may come along with it prove very valuable in enhancing the response rate. While the chosen mode is the personal interview, at several occasions the subjects preferred to keep the questionnaires for a few days before completing them. The researcher, given the time constraints, did his best to allow subjects enough time.

3 There are four roles the researcher may assume in the participant observation form: complete participant, participant-as-observer, observer-as-participant, and the complete observer (Ibid: 259-263). The complete participant role, like that of a secret informer, disguises the researcher as a member of the group he is trying to study so that information can be collected in its natural occurrence. Two problems appear when the researcher assumes this role; the issue of ethics and the possibility that he may affect the group's behaviour as he participates in their day-to-day decisions.

The participant-as-observer role differs from the previous role in that both the group and the researcher are aware of the identity of each other. Though the ethical issue is solved here, the very fact that the group is aware of his role may influence behaviour and shift attention to the researcher instead of conducting normal activities. The observer-as-participant goes to the field and collects information but does not make in any way a pretense of being a participant. The interaction with group members as data is collected counts for the participant part of this role. Because of the limited interaction with the subjects, the researcher and the subjects may misunderstand each other, thus jeopardizing the quality of the collected data.

The complete observer role requires the researcher not to participate at all or to become in any way a part of the observed group or phenomenon. He may collect information by merely observing. This role is acceptable where the observed social process can be understood completely from outside. Field research will not be of use to the purpose of this thesis. The phenomenon of urban voids does not happen at a naturally observable setting. For example, it is not possible to choose the highest location in a city and then sit and watch the spread of urban voids. We can only watch this phenomenon if we allow a long time to pass and simultaneously record data, e.g by taking aerial images. 


\subsubsection{Unobtrusive Research}

Unobstrutive research refers to that type of research where the process has no influence on the studied phenomenon. It is a way of studying social behaviour without influencing it (Babbie, 1989: 322). An example of unobtrusive research is the study of a phenomenon that happened in the past; the research process will not affect the course of action because it has already taken place. Unobtrusive research may include three different methods: content analysis, analysis of existing statistics and historical/comparative analysis (Ibid: 292). ${ }^{4}$

\subsubsection{Evaluative Research}

Evaluative research as its label says, refers to a research purpose of evaluation. It is concerned more with the purpose as opposed to the method of the research. This leads to accepting that other methods of research (experimental research, survey research ..., etc.) may be conducted for evaluative purposes. Evaluation is appropriate for assessing the impact of human or

\footnotetext{
4 Content analysis pertains to the analysis of communications. For example, the analysis of newspaper articles regarding a selected topic (to uncover what was said, by whom, for what reason, and how) is a standard form of content analysis. Content analysis may take a manifest or a latent form. For example, the content analysis of urban policy in a certain country in regard to equity may be manifest if the researcher deals with the number of times the word "equity" was mentioned in the official newspaper. It may take the latent form if the researcher reads selected articles to see if they imply equitable policies.
}

Analysis of existing statistics involves using them (primarily government statistics) for research purposes. Since most of these statistics are done on the aggregate level, one ought to be cautious when it comes to drawing conclusions at the individual level. However, existing statistics are a valuable source of information for urban planners, particularly if accompanied by some supplemental primary data for updating purposes. This form of unobstrutive research will be of use in this thesis. Indeed, all the numerical figures to be collected from relevant government agencies can fall within the domain of "existing statistics".

Historical/comparative analysis is a method that explores the patterns in the histories of cultures (Ibid: 323). The comparison of the development of certain social forms over time and across cultures is a good example of this type of research. Finally, one may observe that the above different methods of unobtrusive analysis can be used together, supplementing each other when needed, depending on the purpose and goals of the research. 
non-human intervention in the social environment; however, the former is of more concern to the purpose of this dissertation. Evaluative research will contribute to the overall research process in this thesis. The discussion in the coming chapters assesses, and evaluates the relationships between the ring road--including its radials--development and the phenomenon of urban voids.

\subsection{Research Designs}

Research design can be experimental (which was dicussed earlier), quasi-experimental, or non-experimental:

The experimental design occurs when the subjects . . . and condition . . . to be studied are manipulated (e.g. randominization) by the investigator [while] . . . non-experimental designs utilize observational methods . . . with far less direct manipulation of condition or subjects (Spector, 1981: 7-9).

Quasi-experimental design occurs when the investigator has some control over the environment.

Such a control would be less than that of true experimental design but more than that of the non-experimental. 5 Because performing true experimental design is difficult in practical life,

5 There are different designs for conducting these research designs; these designs were primarily introduced by Campbell \& Stanelly (1963). Preexperimental design (nonexperimental) includes the one shot case study, the one-group pretest-posttest design, and the static-group comparison; true experimental design includes the pretest-posttest control group design, the posttest-only control group design, the solomon four-group design; and quasi-experimental design includes the separate-sample pretest-posttest design and the nonequivalent control group design (Singleton, 1988).

There are threats to the validity of these designs, known as external and internal validities. Patton \& Sawicki explain:

Internal validity refers to the ability to determine whether unequivocal conclusions can be drawn about the experiment itself, and external validity refers to the ability to generalize from the experiment to other settings. In general, internal-validity problems [for some designs] ... include the inability to determine whether observed changes occurred because of the program or because of nonexperimental events. Such events include learning by or maturing of participants, improved scoring on a posttest as a result of taking a pretest, changes in measurements or procedures, sampling, sampling errors, false conclusions drawn from statistical tests, use of treatment and comparison groups that are not equivalent, dropping out of participants, and uneven growth or maturation of experimental and comparison groups. Any of these conditions may call into question conclusions about the particular experiment or evaluation, including its application to other settings (Patton \& Sawicki, 1986: 312-313). 
particularly where urban planning studies are concerned, quasi and non experimental designs may be used as alternatives. For example, it is not feasible to randomly select a neighbourhood (true experimental design) and pass through it a highway simply to see the impact of such a road on land development in that neighbourhood. Rather a researcher may choose a neighbourhood which is to be in the path of a proposed thoroughfare and study the impact of such investment on the before-and-after land status. By ruling out all possible effects other than that of the highway in measuring the impact and employing a control group, this case can be considered a quasi-experimental design. If no control group is employed, then the case become a nonexperimental design case. Non-experimental design could prove very valuable if the researcher is well aware of its limitations.

\subsection{Causal Relationships}

Causal relationships within the phenomenon under study are important, particularly in explanatory research, the research type used predominantly in urban planning. Understanding the cause-effect components of any phenomenon may help in controlling the effect by manipulating the cause. Cause-effect relationships can be either deterministic or probabilistic. A deterministic relationship assumes that the effect will materialize no matter what we do. ${ }^{6}$

However, true experimental designs have an overall better performance, in comparison with other different designs, against such threats.

6 An example of a deterministic relationship is the influence of time on age. No matter what a living person does, every elapsing year will add one more year to his age. This situation suggests that one's age is a deterministic function of the elapsing years. In natural sciences, deterministic functions are commonly used in cause-effect explanation. When a chemist adds compound A (cause) to material B (in a controlled experiment), then material $C$ (effect) will form. No matter how many times the experiment is repeated, the outcome will always be the same (material $\mathrm{C}$ ). 
Probabilistic cause-effect relations occur when the effect is a probabilistic function of the cause. That is the effect will probably occur if that cause is employed. In planning, probabilistic relationships among urban variables are much more dominant than deterministic ones. Indeed, it is not very common to identify urban variables which hold deterministic relationships.

Probabilistic relationships lead to what might be called probabilistic prediction, which is largely used in planning. Probabilistic prediction occurs when we use non-deterministic models (formula) to predict the future of some urban phenomenon. For example, predicting the impact of a new housing development on adjacent property values will be considered a probabilistic prediction. It is probabilistic because the prediction may or may not materialize and the predicted values are always considered approximations (e.g., averages).

Accepting the notion that the relationship among urban variables can be governed by probabilistic causation, it is possible to identify four possible causal relationships (adopted from Davis, 1985: 10):

Case (1) $\mathrm{X} \rightarrow \mathrm{Y} \quad$ (X may influence $\mathrm{Y}$ but not vice versa)

Case (2) $\mathrm{X} \leftarrow \mathrm{Y} \quad$ (Y may influence $\mathrm{X}$ but not vice versa)

Case (3) $X \rightarrow \leftarrow Y \quad(X$ and $Y$ may influence each other)

Case (4) $\mathrm{X} \leftrightarrow \mathrm{Y} \quad$ (X and $\mathrm{Y}$ are statistically correlated, but the direction of causation is not known for the present time)

$\mathrm{X}, \mathrm{Y}=$ represent some selected urban variables. 
Although the above four cases represent the possible causation pattern between two variables, they are not evenly observed among urban variables. Case (3) $(X \rightarrow \leftarrow Y)$ may be observed more frequently. For example, accessibility improvements (say construction of a road) may result in more housing development; and by the same token initiating housing development may result in an improved accessibility level. However, the causal pattern in Case (3) $(\mathrm{X} \rightarrow \leftarrow \mathrm{Y})$ when explored among urban variables, does not necessarily mean that the variables influence (cause) each other equally. Indeed, one may find either of the paths $(X \rightarrow Y$ or $X \leftarrow Y)$ to be stronger than the other. If one of the paths is very weak, then one may determine the dominant causal path. For example, if $\mathrm{X}$ influences $\mathrm{Y}$ much more than vice versa, then the path $\mathrm{X} \rightarrow \mathrm{Y}$ is considered the dominant causal path. However, for any causal path to be accepted as an explanatory path, researchers set three conditions revolving around whether causality exists:

The first condition states that there must be concomitant variation or covariation between $\mathrm{X}$ and $\mathrm{Y}$, while the second condition requires a temporal asymmetry or time ordering between the two ... The third condition is more problematic, requiring the elimination of other possible causal factors that may be producing the observed relationship between $X$ and $Y$ (Asher, 1983: 12).

Satisfaction of the above conditions, when constructing causal models is instrumental for producing meaningful results. ${ }^{7}$

Jackson explained in some detail the conditions required for establishing a causal relationship; he stated:

"To establish a causal relationship, three conditions must be met:

a. the variables are associated;

b. they are in a plausible causal sequence; and,

c. they are not spuriously connected.

To meet the associated criterion, one has to demonstrate that the two variables vary together. To argue that one is producing changes in another, it must be demonstrated that as one changes, so does the other. ... To demonstrate a plausible causal sequence is largely a matter either of theory or of common sense. Most commonly, however, a little thought given to the causal order will provide an answer. For example, it would be foolish to argue that the "size of your present community" influences the size of the "community in which you were born." The sequencing is 
The relevance of "causal relationships" to this research comes from the observed debate in the literature regarding the relationship between transport development and urban development. As shown in the second chapter, studies showed that urban development followed transport improvement (i.e. Garrison and Marts, 1958); this implies the possibility of the existence of a causal relationship. Although urban development may preceed transport improvement, it is the view of the author that in the case of Riyadh, and maybe other cities of the developing world, the dominant causal path goes from transport improvement to urban development.

\subsection{The Before and After Approach}

In order to better assess the impact of transport improvement on land use and land values, planners tend to use the before and after study. This approach assesses the status quo before and after transport development. There are many major impact categories which can be assessed by the before and after study. These include energy consumption, visual intrusion, air and noise pollution, relocation, and land development impacts.

Since the before and after approach is the one most used for assessing impacts of transport, it is worth exploring its weaknesses and strengths. The major drawback of this approach is that

wrong: the present cannot influence the past. The size of community one has chosen to live in may, of course, be influenced by the size of community in which one grew up. ... To demonstrate that a relationship is not spurious is always a challenge; one which can never be fully met. A critic may always point to some potential source of spuriousness for the relation between variables. The best the first-time researcher can hope to do is to deal with the more obvious potential sources of spuriousness (Jackson, 1988: 218, 219)." 
it is not a truly experimental design. There is little control the researcher can have over the environment in which change is to occur. While lab experiments can be carried out several times, transportation improvement (a sort of an experiment) cannot be repeated. It is done at one point in time leaving to the planner the task of deciding whether all consequence are truly due to the improvement or not. A before and after study should consider internal and external validity requirements. ${ }^{8}$ Despite the threats to the validity of the before and after approach, it still represents a major research tool in urban $\backslash$ transport analysis. As long as the researcher is aware of weaknesses and strengths of the technique under use, such threats should be minimal. The method of research in this thesis utilizes the before and after approach as the impact of transport improvement on leapfrogging is examined before and after the opening of the ring road.

\subsection{The Analysis Techniques}

As suggested earlier, the methodological theme of this research is not experimental. Experimental research does not tend to play a major role in urban research. This research will be within the domain of non-experimental studies. Techniques which are relevant to this research include

\footnotetext{
8 To be useful, any study should be internally and externally valid. An experiment or a study is internally valid if it measures exactly what it intended to measure, and it is externally valid if on a repeated basis it yields the same conclusions (Jackson, 1988:8). Any experimental research must be, at minimum, internally valid, otherwise it is of no value. If experimental research is externally valid then it is reliable and conclusions may be generalized:

External validity refers to the generalizability of the study - the ability to generalize the findings of a single study to the larger population. (Guy et al, 1987: 216).

Indeed, the satisfaction of the external validity requirement in transport-land studies is of considerable value in furthering planners' understanding of the urban environment. However, satisfaction of the validity components (external and internal) can be better attained if truly experimental designs are used. As suggested earlier, true experimental designs are impossible to use in assessing transport improvement impacts on land and urban activities. Therefore, a compromise on the issue of validity (external) is evident whenever such impact studies are carried out.
} 
correlation analysis, regression analysis, and factor analysis.

\subsubsection{Correlation analysis}

Correlation analysis is a useful technique to measure the relative strength among variables (Pfaffenberger, 1981: 409). The technique was used in urban analysis by many planners. Newman and Kenworthy used the technique to facilitate the understanding of automobile dependency (Newman and Kenworthy, 1989a \& 1991). The value of a correlation is denoted by the letter $r$. The values of $r$ range between -1 to +1 including the 0 value. When $r=-1$ then the relationship between the variables is perfectly negative. On the other hand, when $r=+1$ then the relationship is perfectly positive. An $r=0$ suggests that there is no relationship between the variables. Many statistical techniques are based on correlation analysis. A correlation matrix can be of great help to the researcher who contemplates conducting more sophisticated techniques.

\subsubsection{Regression Analysis}

Regression analysis is a powerful technique which is becoming increasingly popular among urban analysts. Several planners have used the technique in urban analysis, e.g., Bibby \& Shephered (1990), Nowlan \& Stewart (1991). It can be used to explain relationships among variables, predict the value of one variable given the value of others, and test hypotheses. Regression analysis can be bivariate or multivariate; the former used for two variable equations (dependent/independent), while the latter employs more than two variables. The general form of the regression equation is:

$$
y=a+b_{1} x_{1}+b_{2} x_{2}
$$


where

$$
\begin{aligned}
& y=a \text { dependent variable; } \\
& a=\text { intercept; } \\
& b_{1} b_{2}=\text { partial coefficients; } \\
& \mathbf{x}_{1} x_{2}=\text { independent variables. }
\end{aligned}
$$

The above equation is a multivariate regression equation; it can be changed into bivariate equation by excluding the term " $b_{2} x_{2}$ ". The regression model makes certain assumptions so that better inferences can be made. The assumptions revolve around the specification error, measurement error, and the error terms. ${ }^{9}$

The variables used in regression analysis can be any measurable variables. For example, the number of auto trips (dependent variable) made can be related to (predicted by) the residents' income, car ownership, family size (independent variables), etc. We might use regression to explain the patterns of the relationships between the above dependent and independent variables, 2.No measurement error.

Lewis-Beck gave the following assumptions for the regression technique:

"The Regression Assumptions

1.No specification error.

a. The relationship between $X_{i}$ and $Y_{i}$ is linear.

b. No relevant independent variables have been excluded.

c. No irrelevant independent variables have been included.

a. The variables $X_{i}$ and $Y_{i}$ are accurately measured.

3.The following assumptions concern the error term, $\mathrm{e}_{\mathrm{i}}$ :

a. Zero mean: $\mathrm{E}\left(\mathrm{e}_{\mathrm{i}}\right)=\mathrm{O}$.

For each observation, the expected value of the error term is zero. (We use the symbol $E\left(e_{i}\right)$ for expected value which, for a random variable, is simply equal to its mean.)

b. Homoskedasticity: $\mathrm{E}\left(\mathrm{e}_{\mathrm{i} 2}\right)=6^{2}$.

i. The variance of the error term is constant for all values of $X_{i}$.

c. No autocorrelation: $E\left(e_{i} e_{j}\right)=0 \quad(i=j)$.

i. The error terms are uncorrelated.

d. The independent variable is uncorrelated with the error term: $E\left(e_{i} X_{i}\right)=0$

e. Normality: The error term $e_{i}$ is normally distributed... (Lewis-Beck, 1980: 26)." 
or we might use regression to predict the value of the dependent variables based on our knowledge of the independent variables. Moreover, we may hypothesize about the relationships among variables and use regression analysis to test. For example, we may hypothesize that income influences generated trips. Regression can then be used to test such a hypothesis.

The regression equation (e.g. equation (3.1)), when obtained by any statistical computer program, comes with some indicators. They include the $R^{2}$, t-test, and f-ratio. The $R^{2}$ has a value between 0 and 1 , with a value of 1 indicating that all the variance in the dependent variable is explained by the independent variable(s). A value of 0 indicates that the independent variable(s) have no relation with the dependent variable. The t-test is used to see if the partial coefficients (b's in equation (3.1)) are significant from zero; in general when $t>2$ the coefficients are assumed significant from zero. The f-ratio is an overall test to see whether the independent variables are acceptable predictors of the dependent variable; in general f-ratio is preferred to be larger than 4. However, one should always remember that regression is only an analysis technique which does not override logic. Even if $R^{2}$, $t$-test, and f-ratio have very desired values the regression equation could be rejected should it conflict with logic.

\subsubsection{Factor Analysis}

Factor analysis is usually used when several variables are to be combined in few factors. Sparks \& Montemayor (1975), and Ogunjumo (1988) used factor analysis in urban and regional issues. These few factors can be used to identify relationships between these variables (Norusis, 1988: 199). The factors should correlate highly with the variables and must be independent of one 
another. A computer is a pre-requisite for the efficient use of factor analysis. A final equation of factor analysis may be expressed as:

$$
y=a x 1+b \times 2+c \times 3
$$

Where

$$
\mathrm{y}=\mathrm{a} \text { dependent variable; }
$$

a,b,c = coefficients;

x's = independent variables (factors).

Such an equation is similar to that of the regression equation; however, it differs in that the factors $(x 1, \times 2, x 3)$ are labels for several variables. ${ }^{10}$

\subsection{The Methodology \& Data Of This Dissertation}

Since this research is within the context of the urban milieu, an environment which cannot be controlled, experimental research (experimentation in which true experimental design is undertaken) cannot be used here. Experimental research requires an environment which can be subjected to perfect control such as the case within a lab environment. Without perfect control over the environment under observation, generalization will always be limited and can never be absolute. Therefore, generalization of this research will be limited to only those environments which match that of Riyadh, namely those which satisfy the four stipulations introduced in the previous chapter.

\footnotetext{
10 It is important to be aware of the drawbacks of factor analysis. Factor analysis will generate factors with no respect to logical meaning. Indeed, factor analysis will always generate factors given any group of variables. Therefore, the researcher's logical judgment is essential for producing a meaningful output.
} 
Survey research must be used to satisfy the purpose of this dissertation. It is the most appropriate way to collect primary data scientifically. Primary data are essential to achieve the goals and satisfy the means of this dissertation. Among the required means of this research is conducting interviews with relevant subjects. Such a requirement can best be satisfied by survey research.

Field research can be used in urban planning studies, but does not suit the requirements of this dissertation. It is used to examine attitudes and behaviours as they evolve in their natural setting-a purpose which does not belong to the earlier introduced goals and objectives. Urban voids are a phenomenon which cannot be observed in its natural setting in the manner defined by field research (please see the definition of field research).

The analysis of existing data, as a method of unobtrusive research, is relevant to the requirements of this dissertation. ${ }^{11}$ Most of the quantitative data of this research is of the form of existing data collected by governmental agencies. Evaluative research could contribute to this dissertation because it is suited to assessing the impact of human intervention in the social environment, assuming that ring road development is one form of this intervention.

In summary, not all these modes of research can be used in this dissertation. Some of such modes (e.g. experimental research) require resources and controlled settings which can not be satisfied

11 There are three types of data: primary, secondary, and existing data. Primary data refers to the data acquired directly by the researcher (e.g. through surveying), while secondary data refers to data acquired by someone else for purposes other than that of the concerned research but of use to it. Existing data is primarily collected by governmental agencies for statistical records. Although some may consider existing data as part of secondary data, it is intended in this research to consider it as a different classification of data; therefore existing data will refer to data collected by government agencies, while secondary data will refer to data collected by other researchers. 
given the limitation of this dissertation. Others (e.g., field research) are not suited to the purpose of this research. Therefore, the dissertation methodology will be limited to survey research and some components of unobtrusive (e.g. analysis of existing data) and evaluative research.

\subsubsection{The Dissertation Research Design}

The previous discussions in this chapter make clear that true experimental design (which requires a control group) cannot be used here. Quasi-experimental design requirements such as using a control group, makes its use difficult in this research. Non-experimental design requirements can be met giving the limitations of this dissertation. Although the first two designs are more equipped to guard against the threats of external validity (the ability to generalize safely), nonexperimental design can prove very valuable if the researcher is well aware of its limitations as well as its potentials. Many studies were contributive and original, yet did not employ a control group. Jane Jacobs famous study, The Death and Life of Great American Cities (1961), which was based on the experience of New York city contributed to the urban planning field although it focused only on one case, New York (Yin, 1989).

Researching the relationship between ring roads (and other relevant freeways such as the radials in the case of Riyadh) and the phenomenon of vacant urban lands in Riyadh represents a unique study which has not been conducted before. This study should reveal the essence of such a relationship, a finding crucial for the future development of ring roads in similar Saudi cities or in other cities which share with Riyadh the four conditions introduced in chapter II. 


\subsubsection{Scope Of The Study \& Unit Of Analysis}

The scope of this study is limited to the city of Riyadh. All collected data pertain to the city, although much could be generalized to other parts of the Kingdom. The subjects interviewed represent the first unit of analysis. The second unit of analysis is the submunicipality, an area with designated boundaries within Riyadh. Riyadh has 21 submunicipalities (according to the Arriyadh Development Authority classification of 1986 (ADA, 1986)). For the purpose of this research 16 submunicipalities are included. The included ones cover the existing urbanized area of Riyadh.

\subsubsection{The Research Process}

The logical sequence of this research can be summarized by the following steps:

- First it highlights the relationship between the ring road (and its radials) and the phenomenon of vacant urban lands.

- Second it proposes a main hypothesis relating the development of ring roads to the phenomenon of vacant urban lands, which is a major characteristic of leapfrogging growth.

Third, it investigates the research question and the hypothesis by analyzing the data which include the two major units of analysis: the 76 subjects who completed the questionnaires and the 16 submunicipalities for which there exist the urban variables.

Fourth, it synthesizes the findings and determines the range of generalization.

The above process is a simple guideline meant to clarify the chosen process of this dissertation. 
It does not delve into the details because they are well explained throughout the dissertation.

\subsubsection{Data Description}

The data collected for this research are both qualitative and quantitative. ${ }^{12}$ Qualitative data are obtained from the questionnaire survey, the primary data collection method. Quantitative data are primarily obtained from both the questionnaire survey and government data. These data were collected during two consecutive visits to Riyadh, Saudi Arabia. The first was undertaken in 1991 (July-October), and the second visit was made in 1992 (June-October). The population surveyed were of three groups: public officials whose decisions have direct or indirect impact on urban development, major land developers, and academics with expertise in the urban planning field.

The selection of these groups was based on their importance in shaping urban growth decision making. The public officials group is intended to represent the public sector view on the

12 Data can be classified into two types: qualitative and quantitative. Both are used in urban analysis. Qualitative data are those which are difficult to measure in their natural form; for example, changes in community identity due to the passing of a new thoroughfare. Quantitative data, on the other hand, are measurable in their natural form. Using the above example, the changes in land values constitute quantitative data. One is encouraged to supplement qualitative data with some quantitative data and vice versa so that both qualitative and quantitative factors can be accounted for. One should avoid extremism (when appropriate) by not ignoring either qualitative or quantitative factors:

One such extreme attitude would ignore qualitative factors, on the ground that factors that cannot be measured are unimportant. An equally extreme attitude would argue that quantitative models have no value if qualitative factors are important (Bierman \& Bonini \& Hausman, 1981: 7).

However, researchers may be inclined to give more weight to either qualitative or quantitative data. This depends largely on the researcher's interest, available form of data, and the selected method of research. For example, if the researcher chooses to do field research, then he will be moving towards a qualitative approach. If the researcher chooses experimentation, then he will be utilizing a more quantitative approach. 
dynamics of the urban growth scene. Key public agencies (e.g. relevant ministries) with responsibilities and roles in urban planning represent the scope of the first group. ${ }^{13}$ The officials interviewed in these agencies were the deputies and the department chairmen. The researcher visited all of them in order to interview the deputies and obtain information about the department heads for later interviews. In some cases the deputies kindly offered to distribute the questionnaires to their department heads.

The private developers are intended to represent the private sector view. The researcher went to the eleven major developers in the city and managed to interview eight of them. Identifying those developers took some time. The researcher went first informally and talked to many developers, asking who they believed the major developers to be. After several visits to many developers, a list of eleven names became apparent. However, the schedules of these people made interviewing difficult. Moreover, even when they were available for interviews, needs of their business would intercede, resulting in some interviews being cancelled.

The academics interviewed were from the College of Architecture and Planning at King Saud University. While academic views on many subjects can be found in scientific journals, it was thought that their experience living in the city might provide additional insights.

13 The public agencies visited by the researcher for interviewing purposes were the Ministry of Rural and Urban Affairs, the Ministry of Communication (Transportation), the Ministry of Planning, the Municipality of Riyadh, the Arriyadh Development Authority, the Saudi Real Estate Development Fund, the Arab Urban Development Institute, and the Riyadh Traffic Department. 


\subsubsection{The Primary Data Collection Technique}

The questionnaire is the primary data-collection technique. One hundred subjects were asked to complete the questionnaire. Seventy-six completed questionnaires were collected during a fourmonth period. Since the population of the surveyed groups is relatively small, the researcher conducted a full survey. The researcher, after defining the sample frame, surveyed all subjects, and the result was a $76 \%$ response rate. Each group represents a complete sample frame, equalling the number of subjects in the original population. The sample frame for the public officials group, the private developers group, and the academic group are 56 (49 responded), 11 (8 responded), and 33 (19 responded) respectively. ${ }^{14}$ After the collection of all completed questionnaires, the data were coded and then computerized to facilitate analysis.

In addition, residents living within range of the ring road (about $2 \mathrm{Km}$ ) were asked to complete the questionnaire. However, the handling of this group (residents) took the form of anecdotal sampling. ${ }^{15}$ The researcher selected several locations on the ring road, contacted persons living

14 The researcher (interviewer) personally took responsibility for handing out the questionnaires. In some cases, the interviewees completed the questionnaire with the researcher present. In other cases, the interviewees preferred to keep the questionnaire for completion as time allowed.

15 Anecdotal sampling refers to a form of sampling that has inputs from both convenient and judgment sampling. A convenient sample is obtained by selecting convenient subjects while a judgement sample is obtained by having experts select relevant subjects from a populations (based on Pffenberger \& Patterson, 1981: 227-228). The selection of residents followed these steps:

- First the researcher identified certain locations adjacent to the ring road (namely communities located around the north, south, east, and west legs of the ring road).

Second the researcher looked for people, living in these areas, who were willing to distribute the questionnaires to their neighbours.

Third, after identifying those people, the questionnaires were distributed.

The researcher's contact with the aforementioned people to distribute the questionnaires represent the convenient part of this method, while selecting the locations account for the judgmental part of this method. Interestingly, the general responses of the residences were similar to the responses of the fully surveyed groups (public officials, developers, and academics). 
within these sections, and asked them to distribute the questionnaires to their neighbours. Forty questionnaires were distributed and twenty-seven were returned. While this method used to distribute the residents' questionnaires was not entirely scientific, it nonetheless provided an idea of how people perceived the ring road impact.

\subsubsection{Sources Of Existing Data}

The major source of existing data was the Arriyadh Development Authority's (ADA) two surveys (1986-87 and 1990-91), with data available on the sub-municipal level. The first survey was a comprehensive one covering the demographic, land use, economic, and transportation aspects of the city. This survey, called the DELTA survey, was conducted in 1986-1987 (March through April) (ADA, 1987:2). While land uses were fully surveyed (100\% survey), the remaining data were obtained through probability sampling. ${ }^{16}$ The DELTA survey classified the city into 21 submunicipalities, which were then divided into smaller units. In addition, the survey classified the city into seven geographical areas, which constitute the basis for the socioeconomic data of the survey.

In 1990-91, the ADA updated its 1986-87 data base. This was done since certain indicators from various city agencies suggested an accelerated growth rate in the city. As a result, the ADA

16 Sampling, in a general form, refers to the science of selecting a portion of a population so that the characteristics of such a portion can be generalized to the whole population. Sampling designs may fall into three types: probability sampling, judgment sampling, and convenience sampling. (Pfaffenbergert \& Patterson, 1981: 207). Probability sampling requires that all units of the population have a known probability for being selected. Probability sampling includes simple random sampling, stratified sampling, cluster sampling, and systematic sampling. Judgment sampling is in use when specialists or experts familiar with the population's characteristics and distribution are asked to select the units of the sample. Convenience sampling occurs where only convenient sampling units are selected (e.g., when the first 50 people crossing the street are to be selected to make a sample). 
decided to launch another survey to complement and update the first one. The new survey tried to parallel the old one to allow for meaningful comparison. Consequently, 16 sub-municipalities have data at two points of time. In 1986-87, the survey was conducted considering the submunicipal boundaries, while in 1990-91, the survey used zonal boundaries to record data. However, the cooperation of the ADA personnel was of great help as they converted zonal data to sub-municipal data so that the researcher could take advantage of the two points of time for the same unit of analysis. ${ }^{17}$

The second source of existing data was the Ministry Of Communication (MOC). The MOC provided the researcher with several reports pertaining to the ring road and the two radials. Most of these reports were prepared by consultants working for the MOC. The third source of existing data was the Real Estate Development Fund (REDF). The researcher managed to obtain records of all approved loans between 1986-87 and 1990-91 (issued loans are a good proxy for building permits). Since REDF provides interest-free loans for any citizen who wants to build a house, almost every citizen who contemplates building applies for such a loan.

In addition, satellite images of the city of Riyadh were obtained from different sources, but originally these images were taken by LandSat, a U.S. space satellite. These images show the tremendous changes which have happened to the city over the last two decades. The first image was taken in 1973 at a time when the ring road was just an idea. The second image was taken

17 The 1986 survey has coincided with the opening of the ring road of Riyadh. Along with the primary data collected through the questionnaire, the two surveys' data constitute the bulk of this research data. 
in 1992 when most of the ring road and the radials had been completed.

Although the required land use data were available at the submunicipal level, this was not the case with socioeconomic data. Most of that data were only available for larger sectors of the city. Secondary data, data prepared by other researchers, is used--in this dissertation--to account for socioeconomic data which were not provided by relevant governmental agencies.

\subsection{Relevancy Of The Data Analysis Methods \& Techniques}

The data collected to satisfy the purpose of this dissertation are primarily quantitative. Quantitative data are instrumental to verifying causal relationships. The discussions on causal relationships and the before and after approach is important to assess the nature of the relationship between ring road development and leapfrogging growth. The analysis techniques are the tools to examine such relationship. For example, correlation and regression analysis can be used to examine the relationships between selected urban variables (e.g., to see if causal association exist). Factor analysis can be used to reduce several selected urban variables into one or more meaningful variables.

Since the purpose of this dissertation is to assess the role of the ring road and its radials in encouraging leapfrogging growth and thus creating and perpetuating the phenomenon of vacant urban lands, the above discussed methods and tools are relevant because they are the means to assess such a role. It is relevant to this research to assess the changes in vacant lands before and after the development of these roads, and examine whether there exists a causal relationship 
between the size and distribution of these lands on one hand and the development of the aforementioned roads. Such an examination can be facilitated by the use of the discussed analysis techniques. 


\subsection{Conclusion}

The discussion in this chapter has shown that experimentation and field research, as defined in this chapter, are not appropriate given the purposes and limitations of this dissertation. Survey research and analysis of existing data represent the major modes of research in this dissertation. A combination of both techniques the personal interview and the self- administered questionnaire has also been shown as the appropriate survey research tool to collect primary data for this thesis, primarily because of its high return rate.

The discussion on causal relationships has clarified how to place transport improvement and urban development in a causal frame work. In addition, the examination of the before and after approach has highlighted how to assess the impacts of transport investment on urban growth.

The discussion on the specific methodology of this dissertation and the methods of its data collection has concluded that non-experimental design is the appropriate form of research design to satisfy the requirements of this research. It has also shown that the analysis of the collected data can be satisfied with the use of certain analytical techniques such as correlation analysis, regression analysis, and factor analysis. The discussion showed that the use of such techniques would be instrumental to assess the causal relationship between transport investment (in this case ring road development) and leapfrogging growth, a necessary factor for the increase of vacant urban land. 


\section{Chapter IV}

\section{The City Of Riyadh}




\subsection{Introduction}

This chapter discusses the planning system, the Land Grant System (LGS), the Real Estate Development Fund (REDF), the stages of growth of the city, the ring road, the Urban Growth Limits (UGL), and urban voids in Riyadh. It starts by addressing the planning philosophy that shapes the planning system in the city. The discussion also covers the avenues of public participation in the city. It then highlights the roles of those public agencies whose responsibilities are related to planning.

The next topic discusses relevant Islamic principles, which are related to planning, such as ownership rights and the concept of the Qadhi (local judge). In addition, relevant cultural dimensions such as privacy and automobile dependency (although new to Riyadh culture, auto dependency is increasingly becoming an essential part of the city culture) are examined. The section to follow introduces the Land Granting System (LGS), which represents a major source of land ownership, and the Real Estate Development Fund (REDF), which represents the major financial source of land development.

The chapter concludes by discussing the city growth, its ring road, its Urban Growth Limit (UGL) policy, and its urban void problem. The discussion starts by shedding light on the city's history, its growth in both population and land area. It then illuminates the concept of the ring road, its purpose, and its relevant attributes. The discussion extends to cover the UGL and its purpose. Thereafter, it examines the phenomenon of urban voids and its drawbacks and concludes by showing how urban voids relate to elements discussed earlier such as automobile dependency. 


\subsection{The Planning System}

The discussion of planning throughout this chapter is primarily concerned with the city of Riyadh. This discussion covers the philosophy shaping the system, the agencies involved in formulating and implementing plans, the land grant system, and the major financier of land development, the Real Estate Development Fund (REDF).

Similar to many other planning systems in today's world, the planning philosophy of the city is rationalistic in nature. Many have contributed to the rational planning philosophy including Arrow (1950's), Banfield (1950's), Simon (1950's), Tinbergen (1950-60's), and Dror (1960's). The rational approach assumes perfect information and agreement on goals and values. Alexander defines rationality as "a way of choosing the best mean to attain a given goal" (Alexander, 1986: 12).

The rational planning process revolves around three themes: first, the identification of goals and objectives; second, the work on appropriate means to attain these goals and objectives; and third, the definition of the implementation and evaluation process of the selected actions. The planning process under this approach has been explored by several researchers. Among them is Banfield who describes such a process as:

1. The decision maker considers all the alternatives (courses of actions) open to him; 2. He identifies and evaluates all of the consequences which would follow from the adoption of each alternative; 3 . He selects that alternative, the probable consequences of which would be preferable in terms of his most valued ends (Banfield, 1955: 314).

Banfield's description is deemed to be reflective of the rational process. However, a decision 
maker may not be able to make a perfectly rational decision because comprehending all alternative courses of actions and all their consequences is beyond human capabilities.

This approach has been criticised by many, including Banfield (1955), Lindbloom (1959), and Friedman and Hudson (1974). However, despite its unrealistic assumptions and process, rational planning became the dominant planning paradigm, in both developed and developing nations. Modified rationalism, which equals perfect rationality less its unrealistic components, has a wide affiliation within the planning field. Its process is best described by Alexander:

Diagnosing the problem and articulating objectives and goals; analyzing the environment and identifying relevant resources and constraints; projecting the likely outcome of their alternatives; and evaluating them in the light of goalrelated criteria (Alexander, 1986: 20).

The above process seems logical and possible and here lies its attractiveness. Rational planning ideally seen or modifiedly adopted has a strong connotation to centralization. In essence, the approach suggests and legitimizes that only a few central actors, e.g. planners, are suited to use these processes in tackling urban issues; and hence, the involvement in participatory planning process is not prioritized. Rational planning, including its centralist component, is practised by planners in many cities of the developing world and Riyadh is no exception. The city is very dependent on the central government in terms of financial resources. Almost $99 \%$ of urban budgets (municipal budgets) in the country comes from the central government, while $1 \%$ is generated by local municipal revenues (Al-Ankary cited in Al-Mogren, 1992: 138). According to Al-Mogren, the municipal ordinance of 1977 , which was issued by the central government, has given municipalities, including the mayoralty of Riyadh, the power to act as independent systems, 
but such ordinance was not fully utilized and therefore centralism continues. ${ }^{1}$ Centralization, as a planning tool, at the early stages of a city's development is not necessarily unhealthy, but as a city develops and grows the minuses of centralization transcend its pluses.

\subsection{The Avenues Of Public Participation}

There are avenues for public participation in the city but quite different from what exists in the West. These avenues include the "Open Majlis" and "the local media". The "Open Majlis" is an ancient participation avenue rooted in the traditional Arabian culture and accepted by Islam. The idea is that the decision maker must have an open meeting with his fellow citizens where any person may attend and present his problems or express his opinion toward such a problem. This tradition is observed by the King, the Crown Prince, the governors, the ministers, the deputies, and other responsible officials. Ministers, deputies and responsible officials must specify at least one hour per day to fulfil the open majlis requirement (Ibid: 207).

In the Open Majlis anybody is allowed to petition; the petition can relate to any issue of concern. A person can simply go to the Open Majlis without prior appointment and wait his turn to present his concern or issue. ${ }^{2}$ The Open Majlis is observed on a daily basis by regional and local

\footnotetext{
1 The municipal ordinance of 1977 consists of 5 chapters which in turn are divided into sections; they include 49 articles (Al-Mogren, 1992: 108). Article 8-27 in section 2 of chapter 2 deals with the municipal council. The council is to be composed of a minimum of four and a maximum of fourteen members, half of which is to be selected by the Minister of the Municipal and Rural Affairs, the other half may be elected but must be approved by the Minister. The ordinance clarified the desired qualifications of the members, their terms of office, and their responsibilities. In addition, the ordinance considers the municipality a legal entity which is financially and administratively independent (Ibid: 109).

2 There are complaint procedures for those who are not satisfied with outcome of their petitions. In an interview with Faisal Al-Saud, H.R.H the governor of Riyadh (whose Open Majlis received up to 1000 people daily) has said:
} 
officials. For example, the Open Majlis of local governors, in Saudi Arabia, is accessible for the public on a daily basis.

The local media represent another avenue of public participation where residents can express their needs or comments toward their urban areas. For example, it is common for the radio station to host a public official with an open phone line to all residents to communicate with the official. In addition, local newspapers specify certain pages for public inputs so that concerned residents can express their views on issue of importance to them.

With the tremendous urbanization of the city and the high population growth (Riyadh population increased by about 700000 people during 1986-91 (ADA, 1992: 6)), other avenues of public participation should be explored to increase public inputs and alleviate the workload incurred by some officials. The municipal council, as discussed by the municipal ordinance of 1977 , represents a viable avenue for public involvement. The ordinance suggested that one-half of the council members are to be elected and approved by the minister of the Municipal and Rural Affairs (Ibid: 109). The municipal council is similar to the city council in western cities. The municipal council is an opportunity which could be utilized by municipalities, including the

... King Fahad said that when the person is not satisfied with the solution, he can go to the Minister of Interior or the Crown Prince or the King himself. Also the people can go to the director of [The Board of Grievances (Diwan Al-Mazalem)] or to the investigation department, where citizens can sue officials or complain about them. Government officials always meet with representatives of those departments who come to investigate and ask about particular things (Faisal Al-Saud 1988, cited in Al-Mogren, 1992: 208).

The above process of complaints has been observed since the inception of the Kingdom of Saudi Arabia. The Open Majlis including its complaint process represent a cornerstone in the political system of the country and it is very unlikely that it will fade in the future. Therefore, it represents a very important avenue of public participation. 
mayoralty of Riyadh.

\subsection{Relevant Planning Agencies}

While there are several agencies involved in shaping the urban life in the city, the discussion will be limited to those which are directly involved in the formulation and/or execution of the urban plans. These agencies are the Ministry of Municipal and Rural Affairs (MOMRA), the Mayoralty of Riyadh, the Arriyadh Development Authority (ADA), and the Ministry of Communications (MOC).

In 1975, MOMRA was established as a replacement to the Deputy of Municipalities. Its main aim was and still is to plan and manage the country's urban and rural affairs. Municipalities are subordinate to the ministry, while mayoralties, including that of Riyadh, have a higher degree of autonomy. ${ }^{3}$ For example, mayors, heads of mayoralties, report directly to the minister.

A study done by McKensey International for MOMRA suggested that the ministry operates along an increasingly centralized line (Ibid: 103). The study redefined the duties of MOMRA as an agency responsible to the orderly and effective development of urban and rural areas throughout the kingdom. In addition, the study identified several tasks that ought to be carried by MOMRA. They include the physical development of Saudi cities and towns, the management of needed

\footnotetext{
3 A mayoralty is a class A municipality. There are four classes of municipalities: class A, class B, class C, and class D. Population is the major criterion of the above classification. Urban centers which are large in population such as Riyadh are classified as class A municipalities, or mayoralties. The population figures (Mckensey, 1978) for each class are as follow: class A (300,000 or more), class B (100,000 or more), class C (30,000 or more), and class $\mathrm{D}$ (5,000 or more) (Ibid: 113). Mayoralties are supposed to be more independent and autonomous in running their own affairs. Their mayors report to the MOMRA Minister directly.
} 
urban services and publicly-owned properties, and the coordination of rural areas outside the jurisdiction of mayoralties and municipalities.

Riyadh had its first public agency tailored to municipal purposes in 1937 (AUDI, 1986: 85). The municipality of Riyadh at that time was limited in its duties to primarily cleaning major streets. When government ministries were transferred to Riyadh in 1955, the tasks of the municipality increased. This is the case because the transfer made the city a major attraction point where people migrate to the city to capitalize on its widening job market. The functions of the municipality, which in 1975 became a mayoralty, pertain to the organization and the beautification of the area under its jurisdiction, preservation of health, and insuring public safety (Ibid: 86). The tasks of the mayoralty include the following:

Managing the city in accordance with the plans approved by relevant authorities. Issuing licenses for purposes such as setting up installations and buildings.

Observing the cleanliness of the city and taking care of the public health (e.g. filling up ponds and swamps, flood prevention, , installing slaughter houses, etc...). Inspecting consumer goods, especially those of edible nature, and other consumer services (e.g. weight measures).

Determining general market places (public market types), street vendors, and licensing places for crafts and vocational trades.

Insuring public safety measures such as fire preventive ones and organising internal transportation including fare fixing (with coordination of relevant authorities). 
Expropriating designated real estates for public uses.

- Collecting fees and fines from relevant parties (e.g. building permit fees and code violation fines).

* Supervising elections of vocational trades and crafts.

Finally, the mayoralty also engages in several different activities ranging from the protection of archaeological sites to the establishment of cemeteries (Ibid: 87-88).

In order to reduce the work load on the mayoralty administrative staff, a decentralization measure was taken. The city was divided into several submunicipalities. These branch municipalities include Deerah, Shumaisi, Batha, Itaiga, Olaiya and Sulaimaniya, Maather, Raodah, Shamal (North), Janoob (South), Ha'ir, Irgah, and Deriyah. ${ }^{1}$ In the ADA surveys some of these branches were combined to represent only one submunicipality (e.g. Deerah and Shumaisi were combined to become Deerah) while other submunicipalities were divided into more than one submunicipality (e.g. Raodah became Raodah and Shamal). Figure 6.1 in Chapter VI shows the submunicipalities according to ADA classifications. The ADA took this step to facilitate data collection. These branches provide services such as issuing licenses, supervision of public cleaning operations, issuing certificates regarding water and electrical connections, and surveying works (Ibid: 94). In this thesis the included sumbmunicipalities are Deerah, Olaiya, Malaz, Batha, Maather, Assfarat, Oraija, Shamal, Raodah, Naseem, Assinaieya, Janoob, Manfohah, Itaigah,

\footnotetext{
1 Some of the names of these submunicipalities changed in the 1990-91 ADA survey. The names in the parentheses following a submunicipality name are the names which were used in 1986-87 ADA survey. These changes are not significant and are only noticed in some ADA materials which are written in English due to translation differences. For example, "Shamal" is an Arabic word meaning "North". In the 1986-87 survey, the data were collected for Shamal submunicipality under the name "North", but in 1990-91 the data were collected for this submunicipality under the name "Shamal".
} 
Irgah, and Deriyah.

The mayoralty of Riyadh is the largest of five mayoralties in the kingdom, both in area and population. As suggested earlier, the mayoralty practices are primarily related to maintaining and supervising activities. Although it is involved in subdivision planning, and designing certain projects, the mayoralty is an executive public agency engaging in implementing activities as opposed to planning. Certainly, the city needed a planning agency to plan the future of the city. The ADA was created in response to such a need. According to the Arab Urban Development Institute (AUDI), the ADA is meant to:

... act as the City Brain, the planner for its future development, and to be the supervisory body for the execution of its policies, to draw its plans and follow up the execution of its major projects (AUDI, 1986: 79).

The major duties of the ADA include formulating policies and strategy for city development, approving and executing the city plan, approving utilities and service programs with consideration of financial matters, formulating appropriate means to involve the private sector in the city plan, and approving areas which are to be expropriated for public corridors, e.g., roads (Ibid, op cit: 79). The ADA's major arm is the Center for Major Projects (CMP) which provides most of the technical expertise to perform the ADA duties. Since the inception of the ADA, the city has benefitted from its contributions which range from providing consultations and advice, to survey undertaking and management of important construction activities.

The Ministry of Communication (MOC) is the agency responsible for implementing public transportation projects. Its responsibility is to implement roads, particularly major roads, which 
are proposed in the master plan and approved by other concerned agencies (e.g., MOMRA). The MOC also prepares studies for certain transportation projects to assess their viability. The MOC was the agency which supervised the implementation of the ring road and other freeways in the city. Indeed, the MOC supervises all transportation projects except those of aviative nature.

\subsection{The Islamic Principles Related to Planning}

In order to better understand the dynamics of urban planning in any Muslim country, it is important to shed some light on the Islamic dimensions or aspects which govern these dynamics. The application of Islamic aspects in planning is limited in most contemporary muslim countries, but they are still quite influential in shaping the built environment. These dimensions were active since the inception of Islam until the 19th century when the Ottomans introduced more regulations. These dimensions include ownership rights, and the Qadhi (a local judge) as the arbitrator in any conflicts among residents or between residents and their local governments. Again, while these principles do not govern planning in most contemporary muslim nations today, they are always referred to by scholars and others (e.g. plaintiffs) when discussing the problems of the built environment. In other words, they can always be used as basis for new planning paradigms.

Property rights and land ownership rights are highly valued in Islam to the point that it is possible to argue against state expropriation practices. ${ }^{5}$ Akbar, for example, cited incidents from

\footnotetext{
${ }^{5}$ Sources of land ownership in Islam include: purchasing, reviving, granting, and inheriting. Purchasing is widely observed these days; people may legally acquire titles to lands by purchasing them. Reviving means putting into useful use a land that is not owned by any party.It was related that the prophet (peace and prayers be upon him) said that "he who revives dead lands acquire titles to what he has revived" (Llewellyn, 1980: 11). This principle suggests
} 
the Islamic history where the Khalif (Caliph, the head of the state) himself was not able to use the state power to expropriate land to enlarge the Prophet Mosque in Madinah in the seventh century (Akbar, 1991: 227). This incident is always used by contemporary thinkers reminding governments that even the Khalif was not allowed to enlarge an important place of worship by expropriating land without the full consent of the owner, such a consent may require compensating the owner the market value of the land.

The other dimension is the Qadhi or the judge. In essence a resident can do what ever he chooses to his property so long as he does not cause any harm to his neighbours or the community at large. If any neighbour objects to any use by any resident the issue is taken to the Qadhi who will settle the conflict. This process along with local norms resulted in an accepted land use system in most muslim cities in the past. Although there was no official land use system in these days, a person knows well in advance that if he uses his residential property for steel or copper processing, for example, he is more likely to be refrained from such a new use. As each city or town has its own Qadhi, the planning system in the past was very decentralized and more responsive to local needs.

It is the view of the author that future planning initiatives (e.g. growth control measures) must consider these dimensions if they are to produce fruitful outcomes. In many cases, lack of

that any one can own an unowned land if he puts efforts in reviving it. Granting means that a party grants another party the title for a land owned by the former party. Most of the lands in Riyadh were acquired through granting. The government has granted thousands of lots to Saudi citizens all over the country. It is the estimate of the author that more than $90 \%$ of the lands within Riyadh boundaries of 1986 (as defined by the Urban Growth Limit program, the topic of the next section) were originally acquired by granting. 
knowledge of these aspects and other related ones on the part of both local planner and foreign experts resulted in solutions that did not achieve what they were meant to achieve. For any planning solution to fully materialize it must be practical and simultaneously must be accepted by the people who will live with it. For example, growth control tools which are copied from different cultures may not work effectively if they are not modified to suit the target culture (for instance, it will be difficult for the state to legally legitimize a growth management action directed at preventing a person from building his own house on his own land). Solutions which consider the cultures in which they are to operate will have a higher chance of success than those copied from a different environment and immediately applied.

\subsection{Relevant Cultural Dimensions}

The Saudi culture originates from two elements: the Islamic Teachings and the arabic Traditions. The people of Riyadh are highly attached to both elements, and numerous dimensions have evolved from these elements. Privacy is one dimension which is relevant to the purpose of this dissertation. In addition, Riyadh's residents are very dependent on the automobile and this dependency is another dimension of relevance to this research. The increase in income (as a result of the oil boom of the 1970's) has influenced the urban behaviour of the residents and thus the culture of the city making the private auto an essential component of daily life.

\subsubsection{Privacy}

Privacy is one of the major factors which influences not only the daily behaviour of the citizens but also the city urban form. A visitor to Riyadh will notice how conservative the residents of 
the city are. Dwelling units are primarily villas, a single family unit surrounded by a solid fence which rises to at least 2.20 meters. Such a high fence is supposed to provide the unit users with full privacy so that street users can not see into these units. The glass of the windows of many of these units are of a non-transparent nature. This is meant to block each unit user from looking into the neighbouring units. Most of the people are content with this arrangement, because they do not want to see into their neighbours' units nor would they like their neighbours to see in their own units.

The people of Riyadh love open spaces, but not for congregation purposes such as the case in the West. Rather they prefer to be surrounded by open spaces to enjoy more fresh air and to minimize vision limitations. Vacant land is one form of open space. Many people would be happy if at least one of their neighbouring lands is vacant. To a villa user having a vacant neighbouring land could mean that he and his family can enjoy more freedom at one side of his unit without violating others' privacy. This freedom could be in the form of making use of more windows on that side, e.g. not worrying about closing the curtains when the windows are open, and being exposed to more fresh air. Lands which are located on more than one street are (i.e corners' location) usually more expensive than those which are located on one street. The reason for such discrepancy in price relates to the fact that lands located on several streets will have fewer immediate neighbours and therefore will allow for more freedom and privacy in terms of orienting the unit opening (e.g., main doors and windows). ${ }^{6}$

\footnotetext{
6 A unit which is located on two streets, as opposed to one, allows the owner to make two main separate entrances to the home. Some times one entrance is used for guests while the other is used for family. This helps provide more privacy for the owner as his family members use of one entrance would not interfere with the guests use of the other entrance. At social occasions, the main entrance is often kept open, a sign to welcome all guests.
} 
The citizens of the city value land ownership very highly. To many, owning a piece of land is the first priority in their adult life. Owning a lot is the most safe investment; it means independence and security. It provides hope--the most important link between the present and the future--that one day the owner will build his own house. Once a person has built his own house he would no longer worry about increasing rents. This would provide his family with a safe, stable shelter. In Saudi Arabia, one's right to build his own house on his own land is well entrenched in the cultural system.

It is not uncommon to see unit owners owning adjacent vacant lands. Some people strive to own such lands not only to free certain sides of their properties from the erection of a neighbour's house but also to provide their children with potential housing units that are very close to their parents. Saudi parents prefer to see their adult children living next to them. Visitations among Saudi families are collective in nature and serve an important role and function. It is common to see a whole family (parents, children, and teenagers) visiting another family on a weekly or a monthly basis. Therefore, it is a plus for one to live next to his relatives. Visitations among families are inherent in the culture of the city and provide entertainment for such families. Since the average family size is high (in Riyadh the average family size was 6.3 in 1986-87 and 6.8 in 1990-91 (ADA, 1992: 30)), it takes only two or three families to get together to provide enough individuals for real social entertainments.

\subsubsection{Automobile Dependency}

Automobile ownership is quite high in Riyadh. There are 1.48 cars for each Saudi household (the 
figure is about 0.94 for expatriate households) (ADA, 1988: J-1). By 1991 there were 441,000 automobiles, 307985 households and 2.1 millions people in Riyadh. There are 0.8 automobiles for each male Saudi who is 16 years or older. In $1986-87,96.5 \%$ of all inner city trips (trips originating and ending in the central area) were private auto trips (ADA, 1988: 42).

There are several reasons for such a high automobile dependency. The most obvious is the high car ownership rate. ${ }^{7}$ As suggested earlier, there is about 1.50 automobile per Saudi household-this figure is high especially if one keeps in mind that most of such households are supported by one person. In some developed countries such as the USA car ownership rate is 1.9 per household (Levinson 1978 cited in Koushki, 1988: 134). In societies where the average household are supported by both working parents, the Saudi figure (1.5) may not seem that high, but if considered as a figure per working parent, then it is quite high.

\footnotetext{
7 The relationship between car ownership and automobile dependency are complex. More car ownership may result in more automobile dependency, but once people become dependent on the private auto, demand on cars increase. In other words, automobile dependency, at later stage, may be blamed for the perpetuation of the increase in car ownership.
} 
Table 4.1: Saudi Households' Auto Ownership

\begin{tabular}{||c|c||}
\hline Number of Automobiles & Percentage of Households \\
\hline 0 & $7 \%$ \\
\hline 1 & $53 \%$ \\
\hline 2 & $22 \%$ \\
\hline+3 & $18 \%$ \\
\hline
\end{tabular}

Source: ADA, $1988 .^{8}$

Table 4.1 shows that $93 \%$ of the households in the city own cars. The remaining $7 \%$ may represent those who have just migrated to the city from distant villages and are still in the process of searching for employment.

A second reason for such high dependency on the automobile is the low cost of owning and operating a car. Automobiles in Saudi Arabia are cheaper than many places in the world. No taxes are levied on new or used cars and there are no insurance requirements. Gasoline costs are among the lowest in the world. Gasoline cost for auto-drivers in Saudi Arabia is about 1/5 the cost in Canada. One liter of gasoline in Riyadh costs 33 halalah (SR=100 halalah= $\$ 1 / 3$ Canadian); this equates to 11 or 12 Canadian cents, while in Canada the same liter costs about

8 The table is estimated from an ADA report; the table shows approximately the rates of car ownership in the city as of 1988. The ADA report is titled Demographic, Transportation, Land Use and Economic Studies For The City Of Arriyadh, 1988, pp. 42. 
50 to 55 cents. It is cheaper to use the automobile (given the large family size) than it is to use the public transport.

A third reason for such dependency is the physical layout of the city and the climate. The present city of Riyadh is horizontally spread and distances are large among most trip-generating and tripattracting locations. Most of the neighbourhoods are low in density. In Riyadh, the average dwelling units gross and net density are 2 and 31 units per hectare respectively (ADA, 1990-91). Such a physical layout is not supportive of public transportation (as we shall see in the next chapter the majority of the respondents agreed with such a notion). Unlike in the old ArabMuslim city, the streets of Riyadh are wide and flanked by detached housing units which provide little shade for pedestrians. The lack of shaded passways, accompanied by the simmering heat of Arabia, make walking--an essential component of the public transport system--a very inconvenient task.

The traditional Arabic-Islamic city was inward oriented. It was characterized by attached housing units which in turn contain courtyards; these yards satisfied the privacy requirements. Residents can open as many windows, towards these courts, as they want without worrying about violating others' privacy. The modern arabic cities lack the provision of such yards. The majority of the housing units in Riyadh are surrounded by setbacks. In the past the typical housing unit contained an open space (courtyard), while now the housing unit is surrounded by the open space (setbacks). The lack of privacy due to the abandonment of the concept of the courtyards made neighbouring vacant land an alternative which might satisfy the privacy requirements. 
Figure 4.1: The Neighbourhood Blocks Of The Modern And Traditional Arabic City

(A)

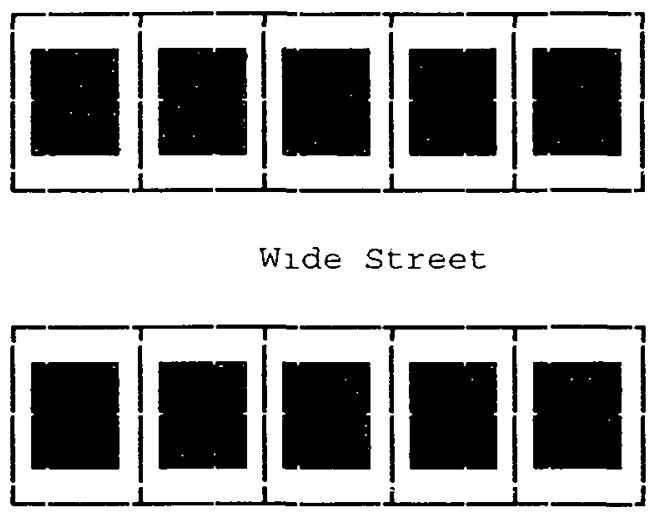

(B)

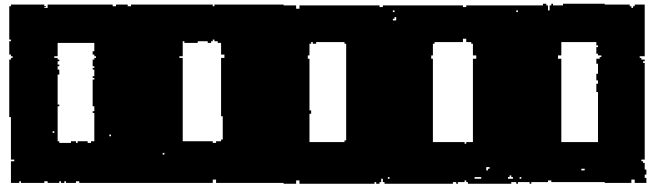

Narrow Street

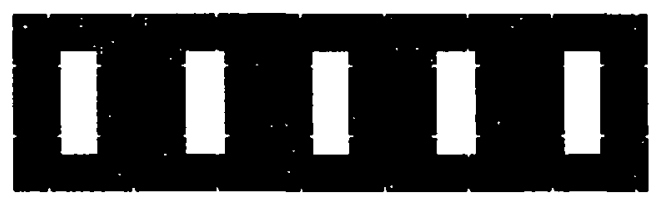

Source: The Author

Sketch (A) (Figure 4.1) resembles the modern block, while sketch (B) resembles the traditional block. The darker shapes represent the buildings, while the whiter areas represent the courtyards. As the sketches show, the traditional block contains courtyards (interior voids) and its streets are narrower to provide shady passways. 
The fourth and last reason is the availability of a very efficient road network. The road network, especially the freeway network, in Riyadh is highly developed. This network allows a level of mobility which was never observed in the past. This high level of mobility allowed many households to live in outer areas and commute easily to the workplace. Some households are relocating in the peripheries to take advantage of larger lot sizes at cheaper prices; transport cost is so low that it can not constitute a major friction factor (to the contrary of the general theme of most of the urban theories and Models which were discussed in Chapter II).

\subsection{The Land Granting System (LGS)}

There is a Saudi tradition where the government, represented by its mayoralty and municipalities, grants citizens plots on which they are to construct their homes. This tradition is expected to continue in the future ;therefore, future plans must consider it.

With the increase of population, the LGS's priorities are for those who need plots the most, the low income groups, or what could be called the financially challenged people. ${ }^{9}$ However, a person must satisfy certain conditions to be eligible for such a grant. These conditions include the following: the applicant must not have been granted land(s) before; he must not own property (a house, a land, etc..); he must be a resident in the city to which he applied; he must

\footnotetext{
9 The granted lots do not necessarily have services. However, those lots which are granted to the financially challenged people are primarily serviced. Lots which are granted to other groups might not have services at the time of the grant, but usually are serviced when enough people reside in the area housing such lots. The number of people or occupied housing units are used as criteria for service provision, but there are no exact figures beyond which the mayoralty is obliged to provide services. Indeed, the Open Majlis is many times used by residences to ask for services. When a group of people reside in a distant development which is not serviced (or not included in the service plan), they usually send some of them to attend the Open Majlis and ask for service provision.
} 
not have been previously received a Real Estate Development Fund (REDF) loan; and he must be over 18. Non-financially challenged people (moderate and high income people) can also apply for free lands through their employer (if it is a public agency), to the governor's office, or through any other official channel. While the land grant system represents a benevolent gesture from the government to its people, an accompanying feature of the system ought to be addressed. Most of the time, these lands are transferred to a very wide range of people resulting, in some cases, in uncoordinated development. It is not the common to see an area developed by one party then sold to the public. What happen most of the time is that either the area is subdivided and granted to people by the government, or subdivided and sold by a private owner. New individual owners in a subdivision will develop their lots to the best of their capabilities resulting in developments that in some cases lack a sense of community. In some cases, prime locations which can be developed to maximize societal utilization of land are owned by too many individuals making unified development and/or ownership quite difficult.

\subsection{The Real Estate Development Fund (REDF)}

The REDF was established in 1974 to help citizens finance the construction of their homes as well as provide investors with loans to construct residential, office and commercial complexes (Farsi, 1989: 73). The interest-free loan is meant to cover about $70 \%$ of a private construction and about $50 \%$ of investment construction. Any adult citizen who owns a lot is eligible once in his lifetime for such interest free loans. According to some estimates, more than $85 \%$ of the housing units built in Riyadh between 1975 and 1985 were financed by the REDF (Al-Jowair, 1990, in Al-Mogren, 1992: 261). Figure 4.2 shows the total loans provided by the REDF for 
citizens all over the Kingdom. These loans represent a huge government investment in the urban field. Growth of Riyadh has been influenced greatly by these loans.

Figure 4.2: The REDF Loans (1975-1987)

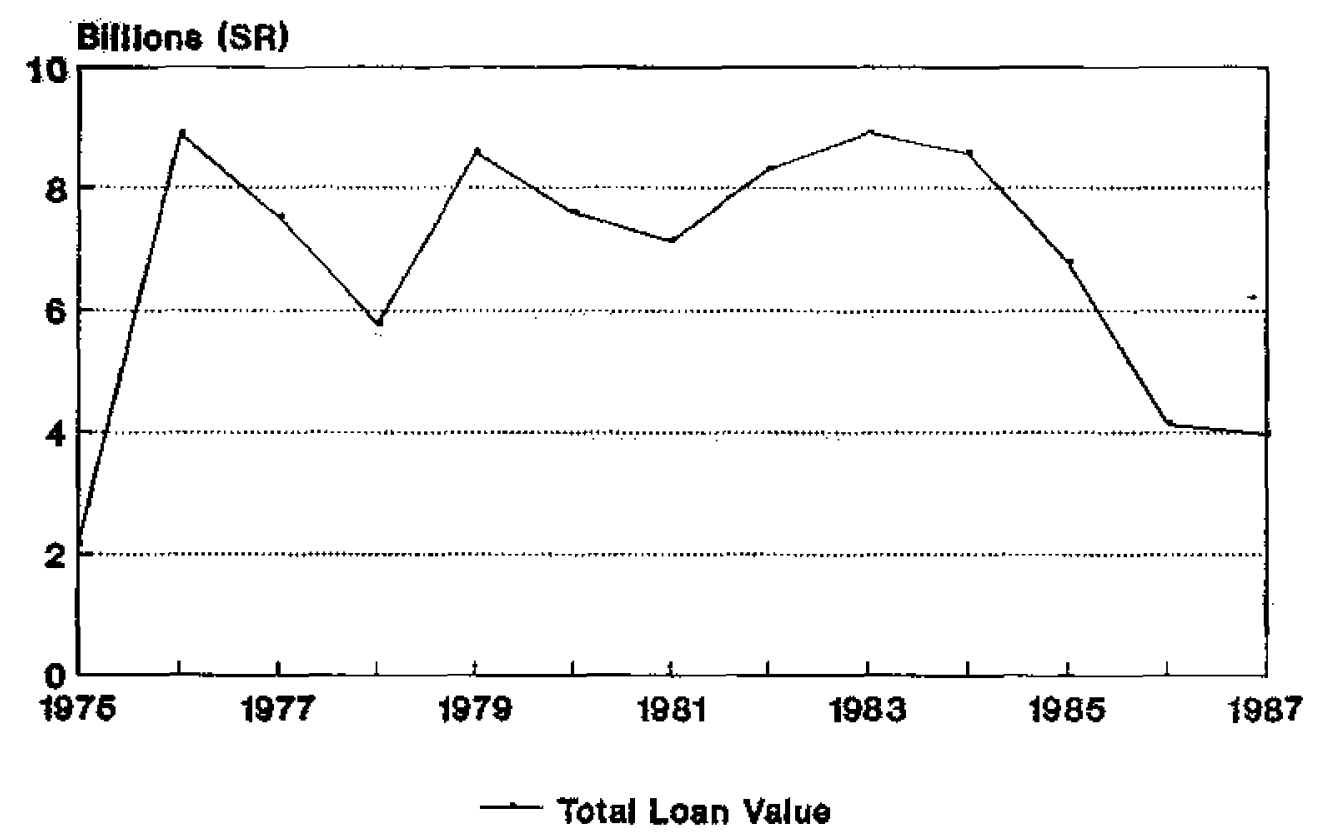

Source: Extracted from Farsi 1989, pp. 73

The REDF guidebook requires the following conditions as stipulations for private loan eligibility (Telmisani, 1989: 203). They include that the applicant must be a male adult (divorced, widowed, and unmarried female who are over 40 years old are also eligible); the applicant can not be a home-owner unless the home is unsuited for living; the applicant must build his home on the same area for which he applied; the loan is allowed only once in a lifetime; the applicant must 
start construction upon the receipt of the first instalment; the land deed and building will remain under the foreclosure of the REDF until the applicant successfully pays back all his loan (payments are interest free over a period of 25 years); those who pay their instalments on time will have a $20 \%$ discount while those who repay the whole loan in one instalment will have a $30 \%$ discount; and finally the REDF has the right to sell the property should the applicant fail to pay back his loan on the due dates.

There is little doubt that the REDF has influenced the growth of Riyadh and other cities. However, it is safe to say that its influence is more on the amount and not the direction of this growth. The urban growth of the city followed radial patterns until the initiation of the ring road where growth became multidirectional. Plot owners can apply for the loan regardless of whether their areas are fully serviced or not. Even lots in areas which were not included in the first phase of urban growth limits are eligible for the loans. ${ }^{10}$ Therefore, the road network played a major role in shaping future development areas. As long as an area is accessible, residents can assume that services will come some time in the future.

The LGS and the REDF represent measures of social equity which may not be common in other countries. Both represent powerful tools under the disposal of public planners to shape the future form of Saudi cities.

10 The Urban Growth Limits UGL, including both phases I and II, will be discussed later in this chapter. 


\subsection{Growth of Riyadh}

Riyadh witnessed its initial growth after it had became the center of power of the Arabian Peninsula. Becoming the capital of the new-found kingdom of Saudi Arabia at the beginning of this century, Riyadh grew instantly.

Figure 4.3: Riyadh Population Growth (1910-1990)

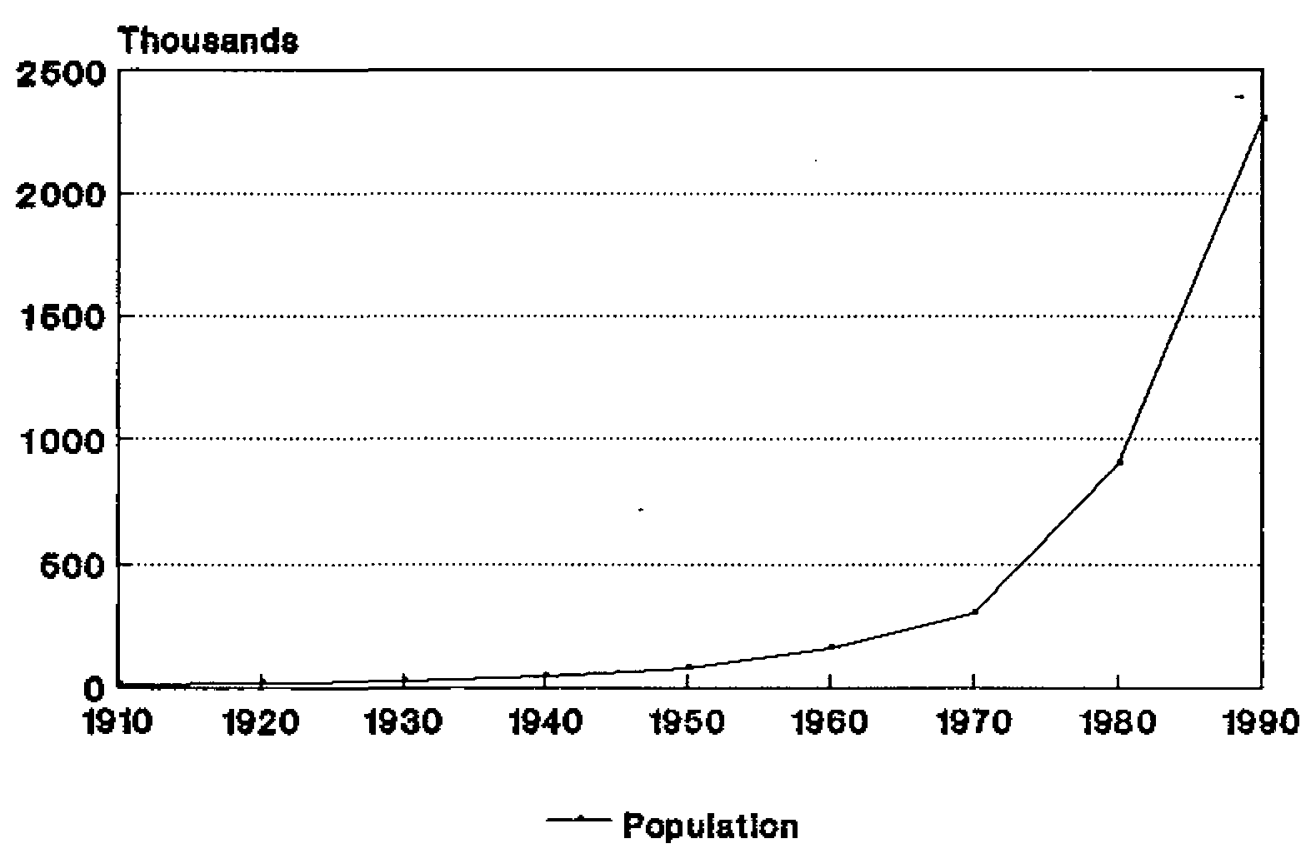

Source: different sources used in this dissertation were combined to extract this graph.

In 1862 , the population of the city was 7500 , while in 1962 it was 167000 (Daghistani, 1985 :

78). By 1992, the population had grown exponentially to an estimated 2300000 people (Figure 4.3), covering an area of approximately 1012 square kilometres. Among the first plans for the 
city of Riyadh was that of William Pulgrave in 1863. During his visit to the city, Pulgrave drew a plan and recorded other relevant features (Ibid: 46). In 1916, another European named Harry St. John Philby provided a more detailed plan of the city, including information on the city structure (ADA: 25) ${ }^{11}$ Both plans showed a walled city occupying an area less than one square kilometre.

In broad terms, the city's growth went through several stages (Ibid:23-25). The first stage is that period which preceded 1930. During this stage, the city underwent periods of rise and decline in response to the dominant political settings. The second stage was between 1930 and 1955. The city area at the beginning of this period was still within the one square kilometre limit. The early 1930's witnessed the beginning of the urban growth. The automobile, for the first time, entered the city as it grew beyond its walls. The third stage was during the period of 1955 1968. It was during this stage that major government buildings were constructed and concrete structures began to replace traditional mud buildings. The fourth stage was from 1968 to 1976. During this period the need for a city master plan was recognized. Consequently, a consulting firm was assigned the job of producing the city's first official plan. At the end of this period, the city area has increased to 45 square kilometres. The fifth stage of the growth of Riyadh covers the period from 1976 until the present. Due to the increased revenues from oil, the government was able to initiate major development projects of a physical and institutional nature, which in return induced urban growth.

11 John Philby changed his name to Abdullah after embracing Islam in the late 1920's. He is later known as Abdullah Philby. 
Figure 4.4: Riyadh Physical Growth (1910-1990)

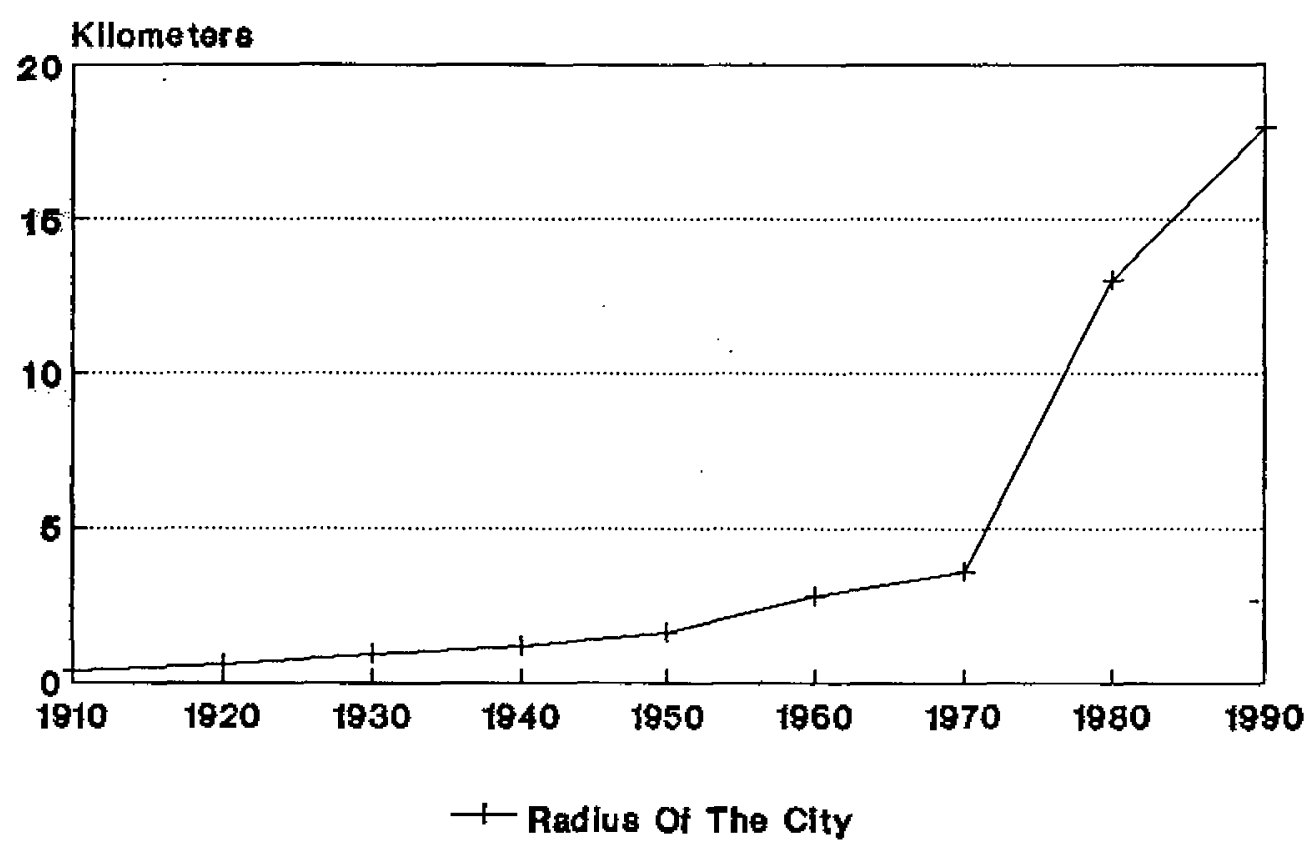

Source: different sources used in this dissertation were combined to extract this figure.

It is during this last stage, and in particular the last two decades, that the tremendous growth of Riyadh has occurred. It was during these two decades that the freeway system, including the ring road, was built. The improvement in accessibility accompanied with the increased income help account for the major changes in the city structure. As figure 4.4 shows, the growth of the city using its radius as an indicator has taken the form of an exponential function. The sharp increases in oil prices, which occurred in the early 1970's, have played a major role in the growth of not only Riyadh but also in all of the Kingdom of Saudi Arabia. 
Today, the city of Riyadh possesses certain characteristics that are worth noting. The city is a modern metropolitan area covering about 1650 square kilometers (Alsharq Alawsat 1993, Issue 5426: 13). The population is expected to be slightly more than 2.3 millions. Government employment represents the key sector of the city's economy. Physically, the city is wide-spread with many urban voids. It can be classified as a fully motorized city with a highly developed road network.

\subsection{The Riyadh Ring Road}

The first idea of a ring road for the city of Riyadh can be traced to 1968. In that year, a master plan was prepared for the city. The plan dealt with future growth and how to organize it. The master plan suggested a freeway type circumferential along with express ways, arterials and other thoroughfares (Dar Al-handasa, 1975: 1-1). In 1973, the Agency of Municipalities tendered the design and path of the road. Dar Al-handasa was the consultant chosen to undertake the project (Dar Al-handasa, 1978: 1).

The process of modification and refinement on the road design and route continued until the end of the decade. In the 1979-1980 period, the design was finalized and contracts were prepared. By 1980, contracts to implement certain sections of the ring road were signed. The road consists of seven sections; the first was opened in 1984 while the last, the southwestern leg, is still under construction. The ring road is $75.6 \mathrm{~km}$ in length with four lanes in each direction. In addition, there are service roads on either side. The road has a 100 meter right of way and intersects with 40 bridges and tunnels. 
The road implementation was a response to the increasing traffic to and within Riyadh. For those who live in the city, rush hours are a reality. Like elsewhere in the world, freeways are seen as the saviour of such peak-hours problems. Local planners saw in the implementation of ring road project several advantages (Dar Al-handasa, 1978):

The road will service new facilities, communities and institutions such as King Saud University, Imam University, Assfarat community (the Diplomatic Quarter), the Sport City, the Council of Ministers Building, King Khalid Airport, and the new train station;

- The road will facilitate the through movement of heavy traffic crossing the city;

- It will facilitate local traffic within the city; and

- It should allow the urban growth of the city of Riyadh to comply with the city master plan.

The consultant (Dar Al-handasa) suggested that the ring road operate at level of service " $\mathrm{C}$ " to accommodate about 9000 vehicles per hour in both directions (Dar Al-handasa, 1975: 1-3). In other words, the design capacity of the road will be 1500 vehicle/lane/hour. In addition, the design speed suggested by the consultant was 120 kilometers per hour (Ibid: 2-15).

The development of the ring road of Riyadh is not the only freeway development in the city. Makkah road and King Fahad road are the major radial freeways in the city. The former runs east-west, dividing the city into northern and southern sections. The latter runs north-south, dividing the city into eastern and western sections. Makkah road was opened in 1984, while King Fahad road was opened in 1992. 
Figure 4.5 (A\&B): Pictures Of The Riyadh Ring Road

(A): A Northern Segment Of The Ring Road

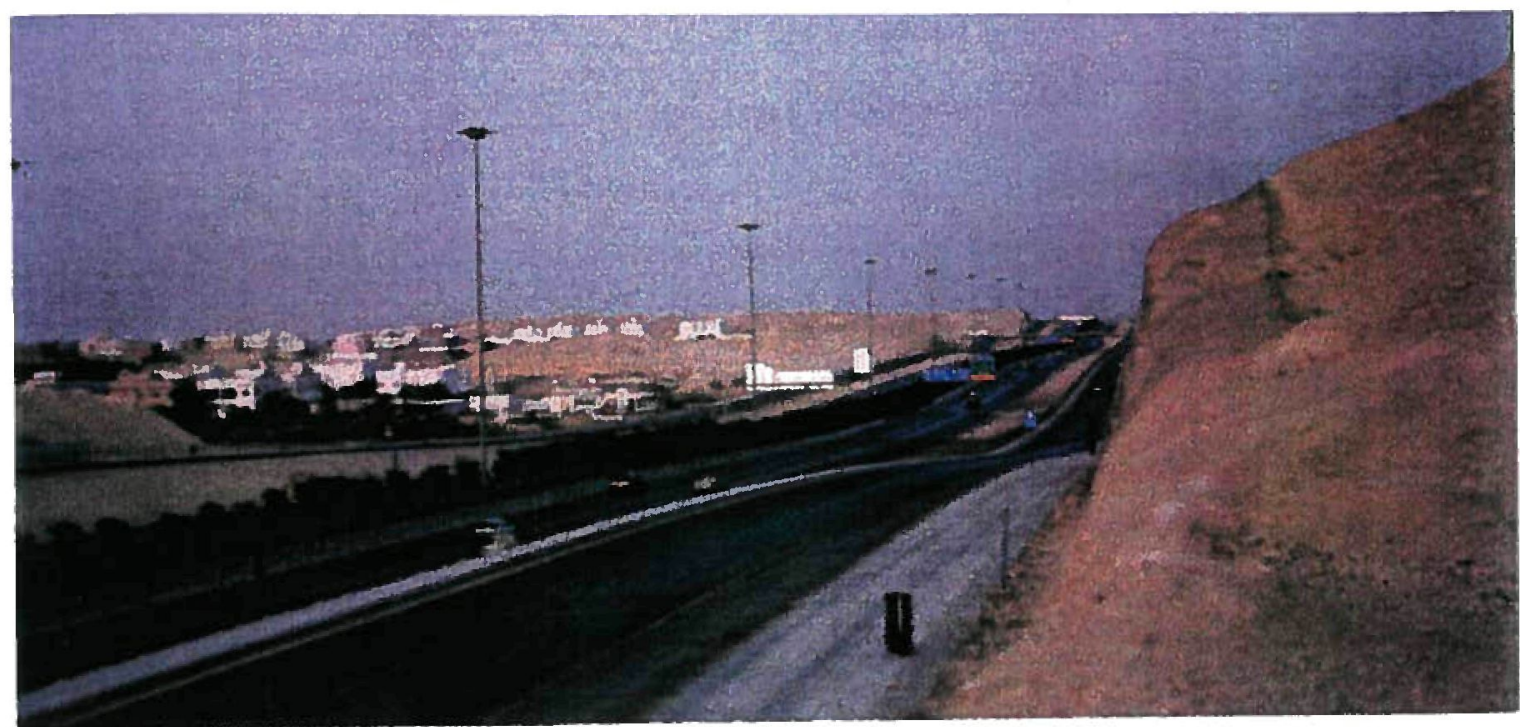

(B): An Eastern Segment Of The Ring Road

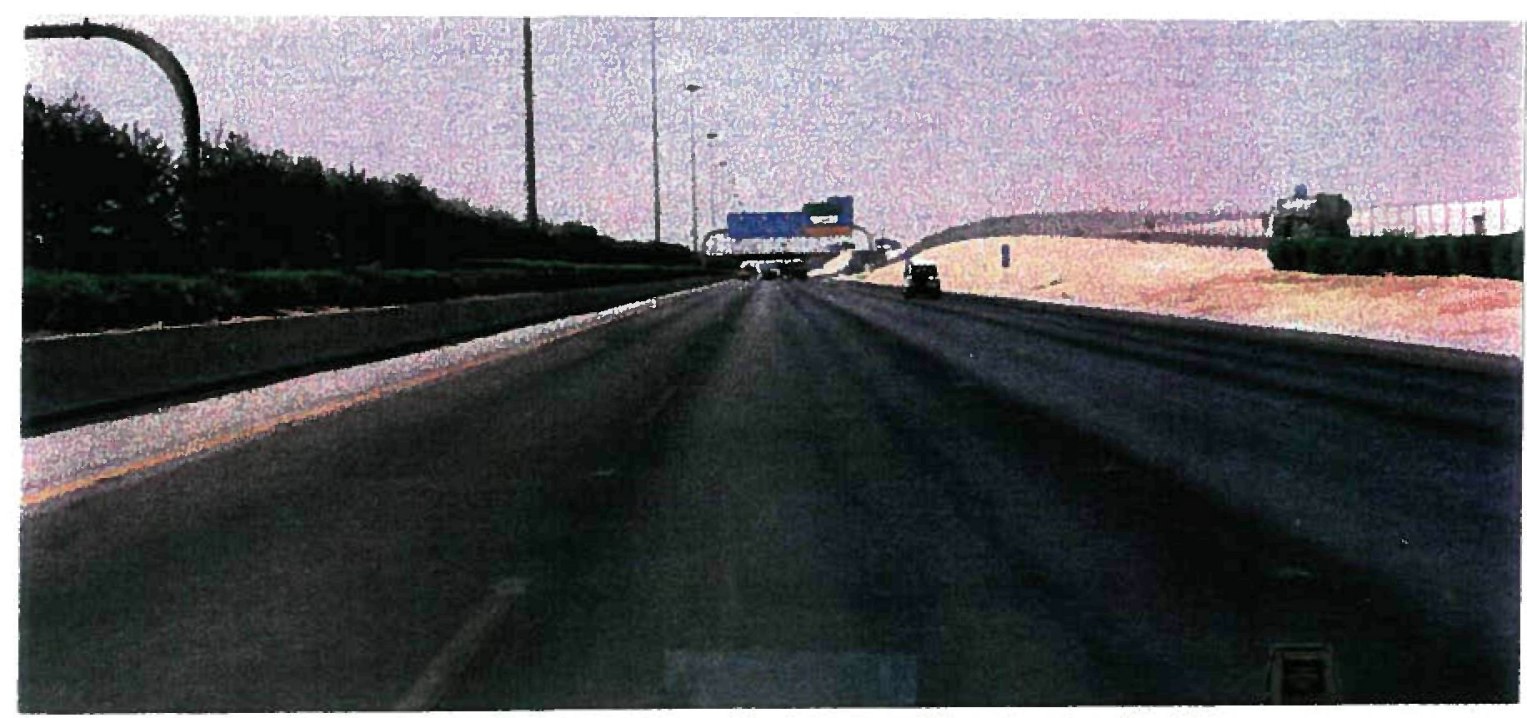


Figure 4.5 shows pictures of the Riyadh ring road. These two photographs (A\&B) represent segments of the ring road. Photograph A shows the a northern segment of the road. The housing units at the left side of the picture are located outside the ring road. Note that there exist visible amounts of urban voids among these units. Photograph B shows an eastern segment of the ring road. The standards at which the ring road is constructed made accessibility very high all over the city. This accessibility allowed residents to locate almost everywhere.

The planning of the freeway system in Riyadh accompanied the oil boom of the 1970's which precipitated tremendous urban growth. This growth manifested itself in unprecedented residential development. The Real Estate Development Fund (REDF) provided interest-free loans for citizens to construct their own houses. The eligibility for these loans was quite open, so that virtually any citizen could obtain one. With the development of the road system, including the freeway, auto-owning citizens explored the outer areas of the city. The land values in these areas are cheaper in price to the point that the majority of the citizens could afford to own plots and therefore became loan-eligible.

Low gasoline cost in an auto-oriented society, such as that of Riyadh, accompanied by an efficient transport network played a major role in the growth of the city. A growth that is characterised as horizontal with many voids. While the ring road, and the freeway system in general, cannot be considered the only stimuli of growth, they certainly played a major role in shaping the urban form of the city and its present structure. 
Figure 4.6: The Locations Of Major Institutions

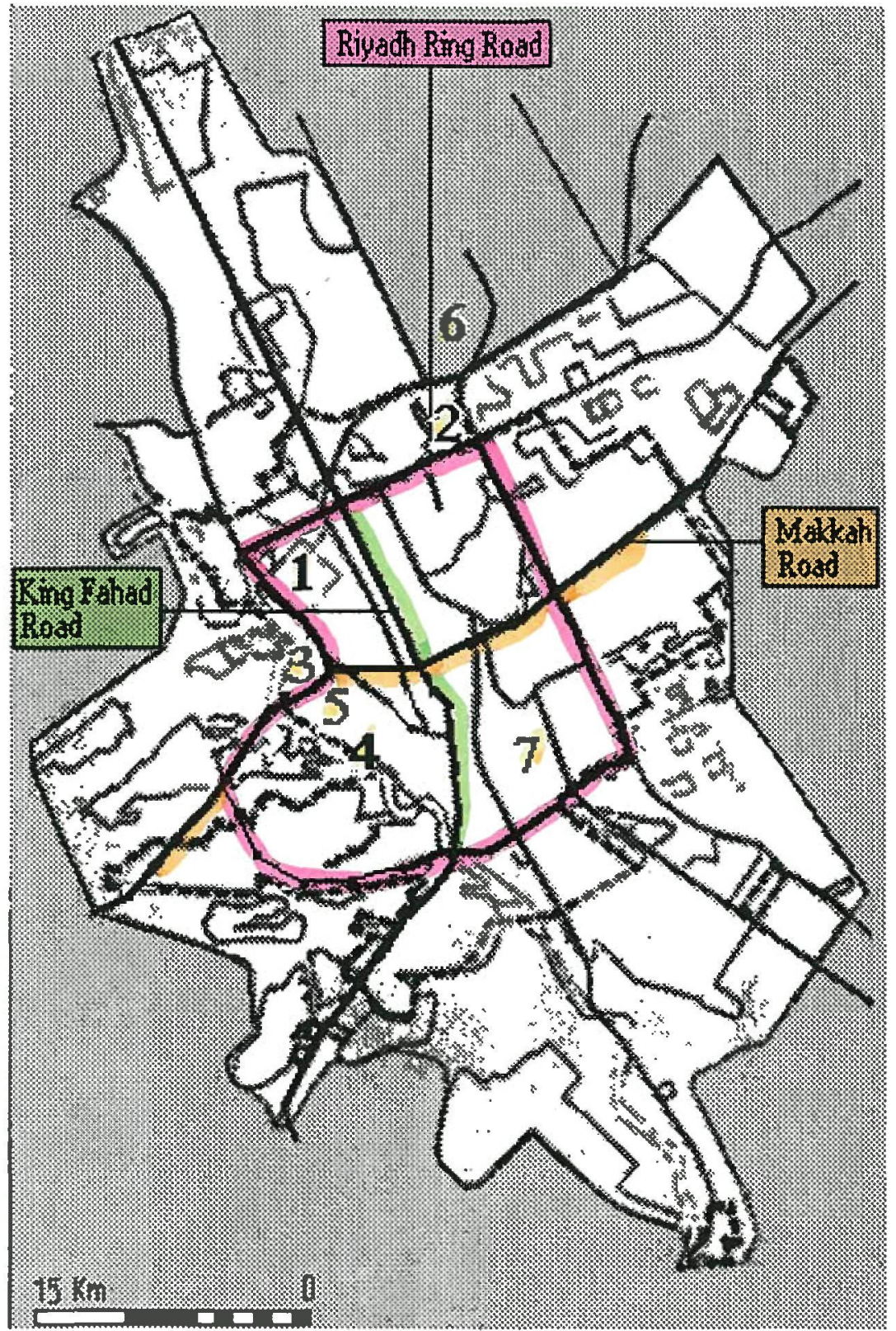

The above figure shows the locations of important institutions which are to benefit from the development of the ring road: (1) King Saud University; (2) Imam University; (3) Assfarat community; (4) the Sport City; (5) The Council of Ministers Building; (6) King Khalid International Airport; (7) The new train station.

Source: The Author. 


\subsection{Urban Growth Limits}

The city of Riyadh developed its Urban Growth Limits (UGL) by the end of the 1980 's. ${ }^{12}$ It is a service boundary. It is defined as the limits that must not be transcended by urban development (ADA, 112). The urban growth limits have two phases (UGL I \& UGL II): the first extends to the year 1995 while the second extends to the year 2005. The first phase covers more than the existing residential agglomerations. The second phase covers an area twice as large as the first phase, including the area of the first phase. The urban limits mean that unserviced lands located within the first phase will get their services by 1995 . Those who choose to develop outside the first phase and in the second phase may have to wait up to the year 2005 to get their services.

The UGL proposes several policies to plan lands within and outside its boundaries; the following lines cover the themes of such policies. Lands within the boundaries of the first phase are allowed to be subdivided according to suitable uses. Subdivision of lands which are located outside the first phase boundaries will be subject to the following factors:

- The city's urban growth rate and the need for new residential subdivisions.

The rate of growth in utilities' network.

The availability of financial resources designated for public utilities expansions.

The assessed need for non-residential development outside UGL I.

In other words, outer lands could be subdivided if the analysis of the above factors suggest so.

12 The development of the UGL has common elements with the growth management techniques discussed in Chapter II. Fore example, Riyadh has imposed a moratorium on subdivision planning for two years, 1986 to 1988. This is similar to the interim development technique. In addition, Riyadh's UGL has similarities with the urban service areas technique as both of them define boundaries beyond which development is not encouraged. 
Figure 4.7: The Urban Growth Limits Of Riyadh (Phase I \& II)

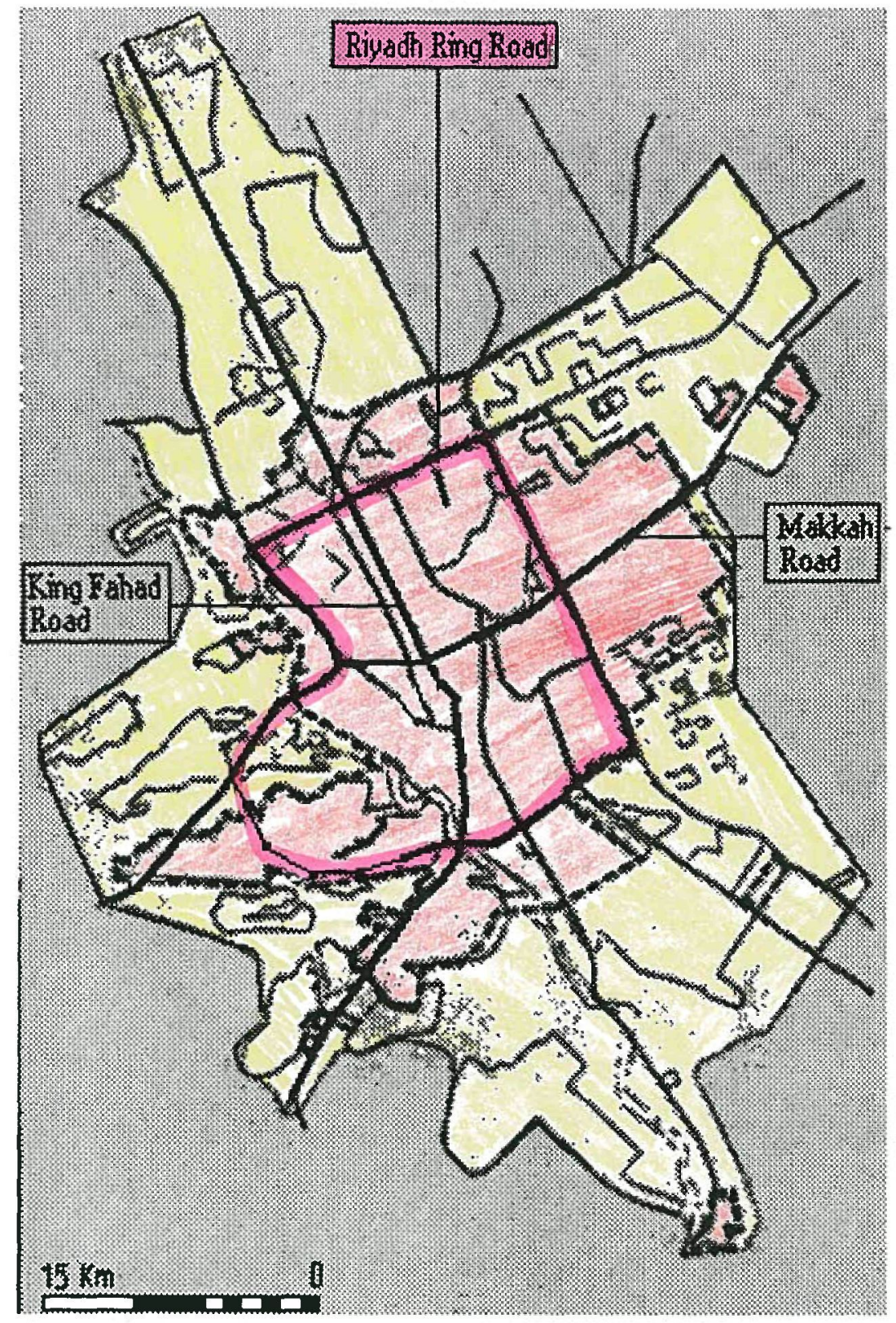

$\square$ Urban Growth Limits: Phase I

$\square \quad$ Urban Growth Limits: Phase II

Source: Developed by the author based on ADA data. 
The Urban Growth Limit (UGL) of Riyadh is similar to that of the urban service areas (discussed in chapter II). The UGL represents a line or cordon which may not be transcended by development. The UGL is meant to be a means for both controlling and guiding growth (ADA: 112); however, it can not prevent a person from building his house on his land even if the land is outside the service boundaries. This is the case because such prevention infringes on ones property right, a dimension well entrenched in the Islamic legal system. However, the UGL provides a legal basis upon which the mayoralty or other municipalities justify their inactions in terms of service provisions for outer areas. The UGL, like other techniques, was primarily a reaction to an emerging problem, namely, the increasing cost of providing infrastructure and services to all developments. In 1986, a moratorium on new subdivision approvals was imposed for two years (to allow for the development of the UGL), and in 1989 the UGL was adopted. As introduced earlier, after 1986 the major legs of the ring road were open for traffic. This temporal coincidence may explain the huge areas designated for future growth within the cordon of the UGL. Although the UGL was meant to encourage infill development, the fact that its second phase is so large induced land speculators and developers to venture out, acquiring lands for future development purposes. In two years (by 1995), the second phase of the UGL will be open for development. Interestingly, land prices since 1986 did not decrease, even after the adoption of the UGL which provided a large and new land supply. Between 1987 and 1993, land prices had increased by $20 \%$ to $25 \%$ in the city (Alsharq Alawsat 1992, Issue 5070: 11). In certain sections of the city, i.e the Nakheel community which is located just to the south of northern section of the ring road west of King Fahad road, land prices went up five times (Almajallah 1993, Issue 679: 58). 


\subsection{Urban Voids}

Urban voids are the vacant urban land which are located within the city boundaries. Figure 4.8 shows the classifications of vacant lands. They are either urban or non-urban vacant land; vacant urban land is either developable or non-developable and this thesis is concerned with the former (developable vacant urban land). All subsequent discussions and analyses shall refer to it unless otherwise specified. Figure 4.9 further illustrates the difference between urban and non-urban vacant lands taking into consideration whether a city has no boundaries (Case A) or it has boundaries (Case B).

Vacant urban lands accounted for $51 \%$ of the city lands in $1986-87 .{ }^{13}$ Figure 4.10 shows the major concentrations of vacant urban lands in Riyadh. In 1988 a report prepared by the ADA discussed the issue of vacant lands and proposed the introduction of a policy to encourage their development. The report suggested that such a policy would achieve several goals. First, the development of the voids would save money as the city would not be engaged in continually providing services to distant developments. Second, the development would raise the level at which services are used and would increase subscribers to public service companies, thus providing some public income. Third, the policy would reduce the pressure on agricultural lands for conversion into residential uses. Fourth, travel times and distances would be reduced should development take an inward direction. Fifth, communities enclosing these voids may improve their socioeconomic status when investors utilise such lands. Finally, the report suggested that eradicating these lands will improve the city image through beautification.

13 This 52\% represents the percentage of vacant lands in 1986 in the city using UGL I as the city boundaries. Data to compute the same percentage for 1991, using UGL I's boundaries, were not available. 
Though the report did not define an exact policy, it did propose some means to achieve the above goals. These means include the following:

Encourage investors and developers to use these voids (such encouragements can be done through all communication means such as media avenues, lectures etc...). Establish an information center specializing in vacant land profiles to provide data for prospective developers and citizens (established by a public agency yet enriched by information from the private sector, i.e real estate agents).

Provide financial incentives for those who choose to develop within the first urban phase [give priority to these developers in the REDF loan program, prevent the REDF from giving any loans to outer developments, and impose a zacat (an Islamic tax) on lots that were vacant for more than a year].

Establish a program for public service provisions.

Coordinate public and private investment in terms of site location in order to maximize the efficient use of land (Ibid: 22-23).

The role of the road network was not considered in the above formulation of means. It is imperative to consider the role of the road network, especially the freeway network with the ring road as its major component, in future policies if efficient urban growth, growth with little vacant lands, is desired. 
Figure 4.8: The Classifications Of Vacant Lands

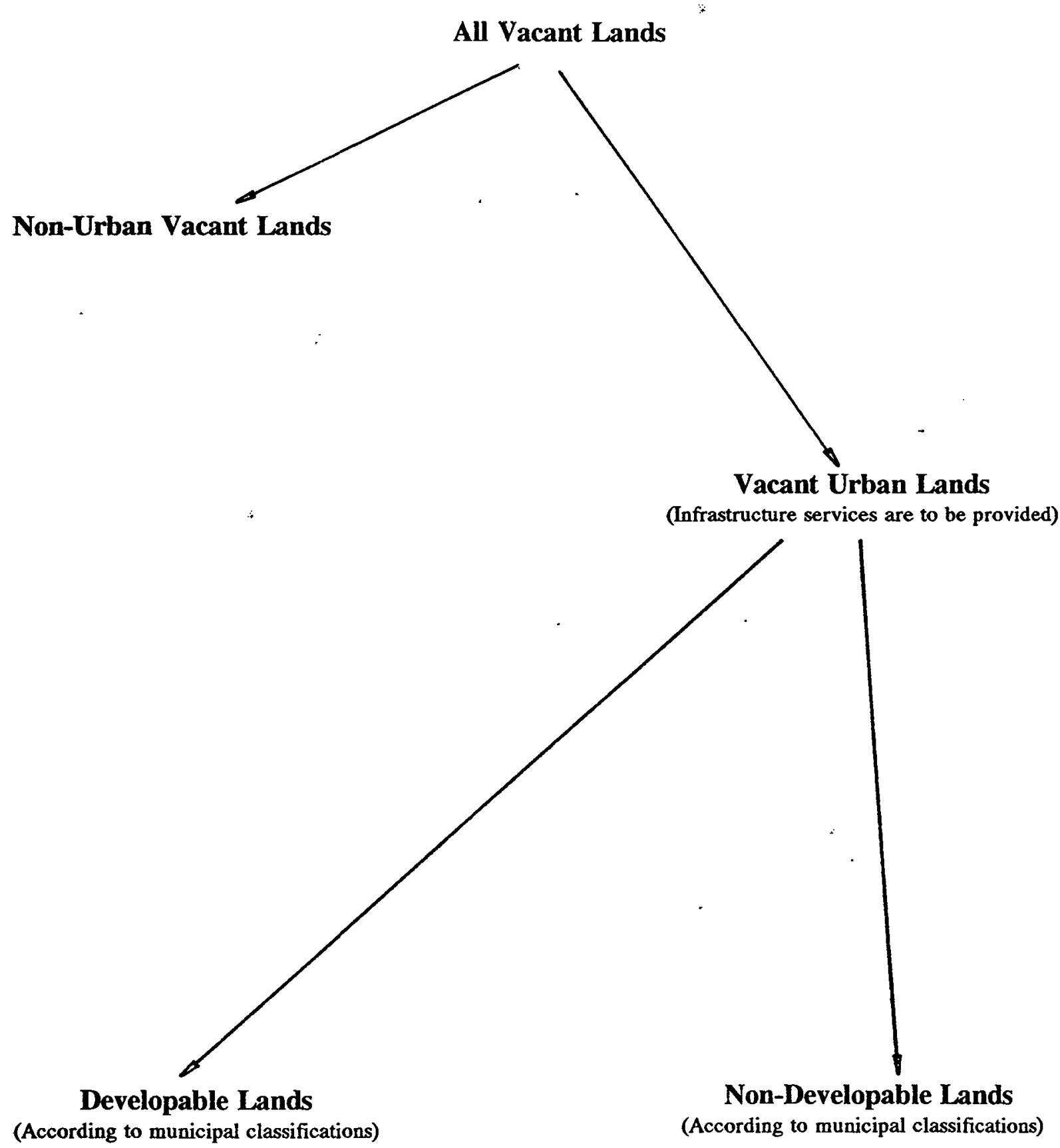

Source: Author.

j) 
Figure 4.9: Vacant Lands \& City Boundaries

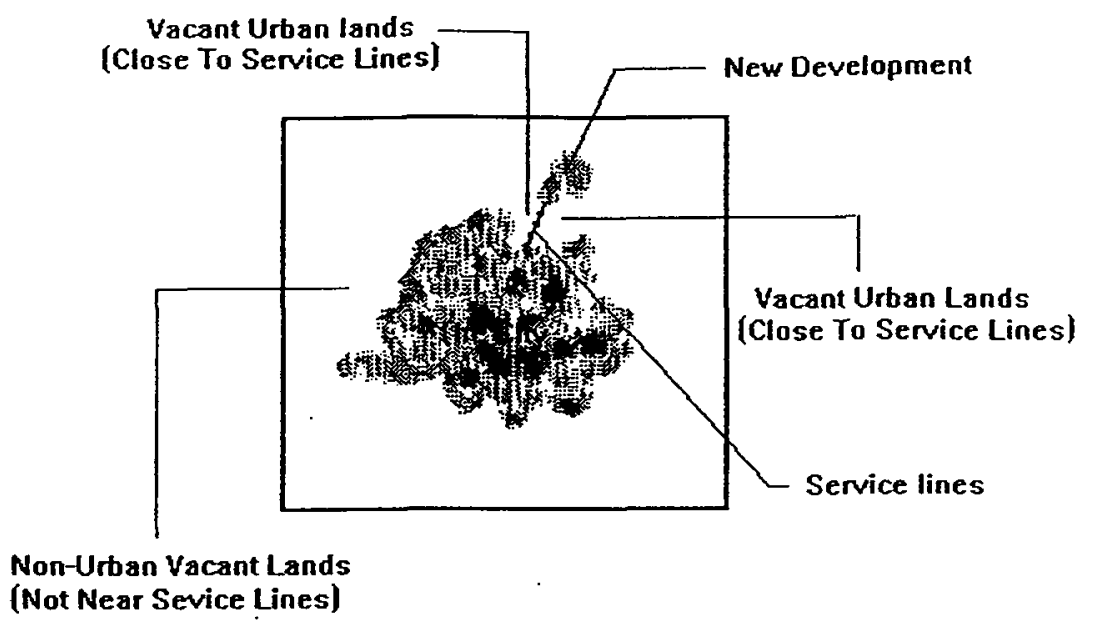

Case A: A City With No Boundaries

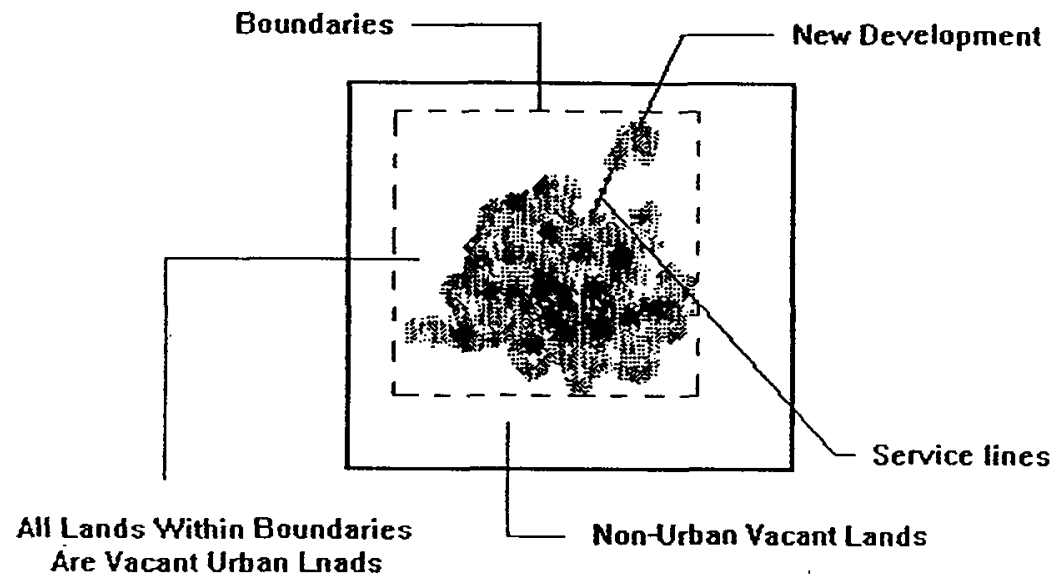

Case B: A City With Boundaries

Source: Author. 
Figure 4.10: Major Concentrations Of Vacant Urban Lands (1989)

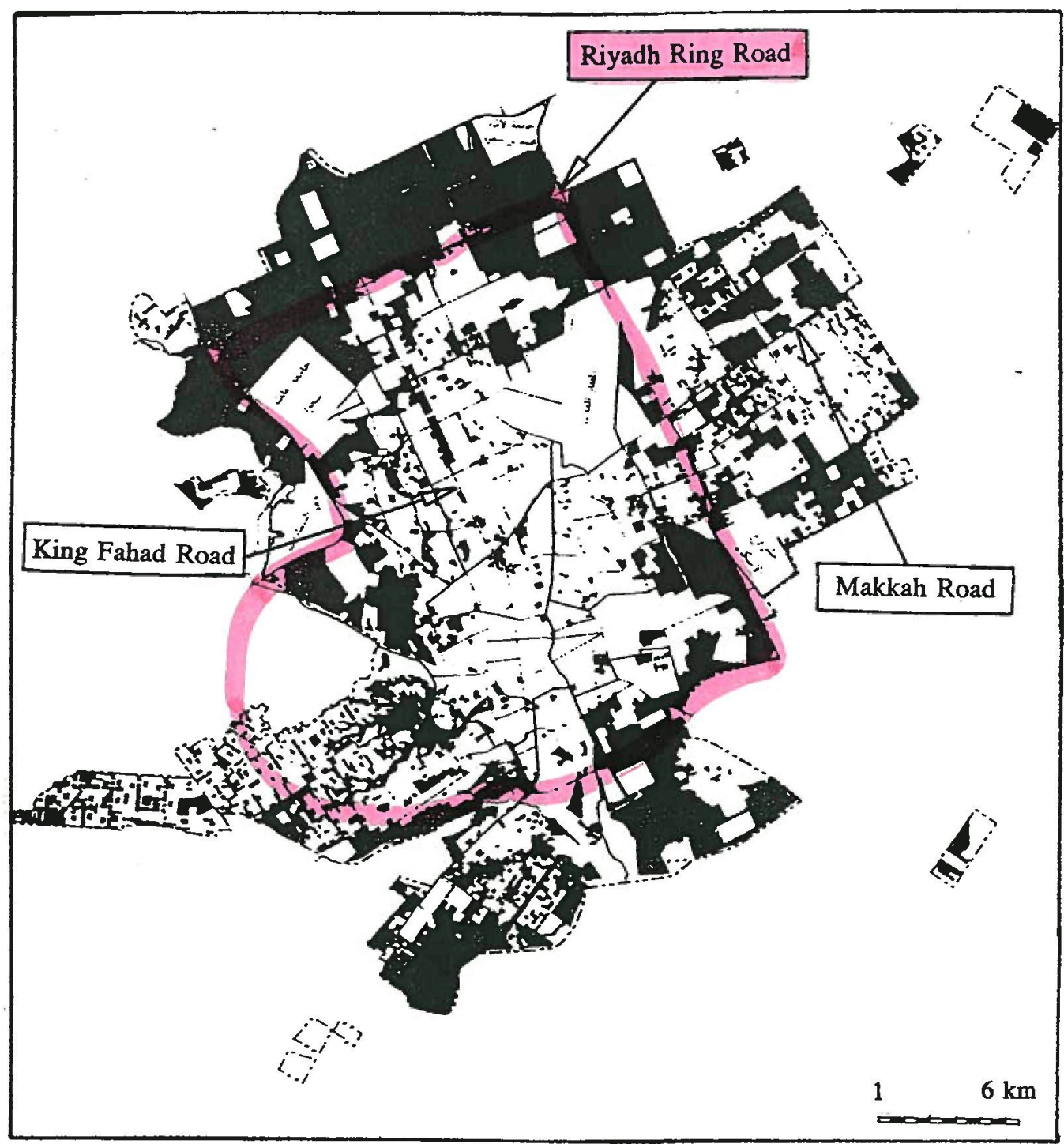

Vacant Urban Lands

Source: ADA, 1992 
Figure 4.11: Government Revenues \& Expenditures

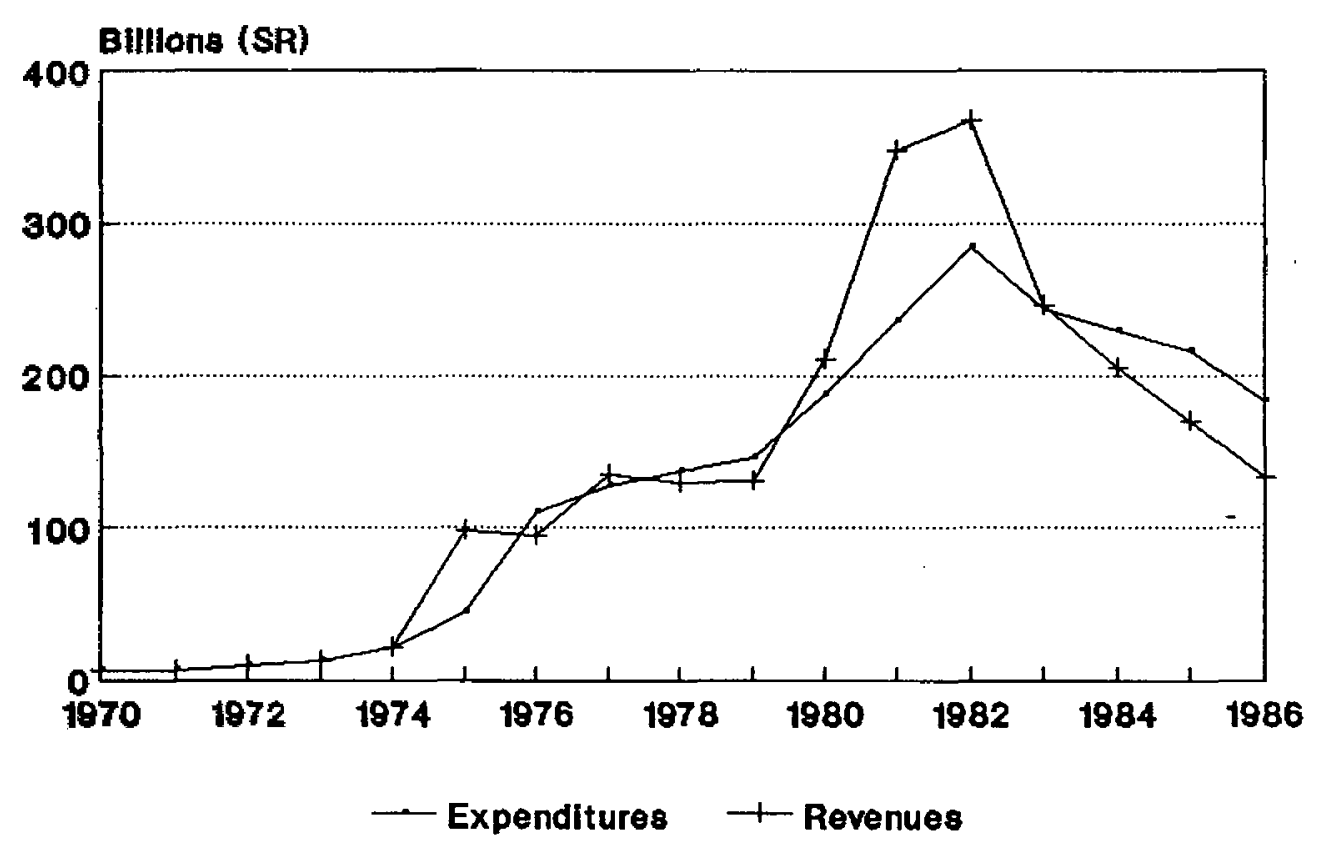

Source: Extracted From The Fifth Development Plan 1990-95, pp. 21

As the revenues decline and the expenditures rise the urban voids phenomenon continues to represent an additional strain on the economy of the country as whole, not only because Riyadh is the capital and the largest city in the country, but also because the phenomenon has started to emerge in other cities such as Madinah (Abdulaal, 1990). Unlike the period of the beginning of the 1980 's, the mid 1980 's along with the beginning of 1990 's showed an increasing national deficit. If this deficit increases as figure 4.11 shows, there will be less money available for mayoralties, municipalities, and submunicipalities to spend on maintenance and urban development works. This increase in deficit necessitates the urgent need to device urban policies which are comprehensive. These policies must deal with urban land in such away that reflect the 
impact of freeway development. If other ring roads are to be developed in the Kingdom without considering the above argument, it is probable that urban voids will accompany their development resulting in an even more economic strain on national government.

\subsection{The Drawbacks of Urban Voids}

The phenomenon of urban voids is not entirely a negative event. As discussed earlier, people use urban voids to achieve several goals. Therefore, it is appropriate to discuss the advantages of urban voids before mentioning their drawbacks. In addition to compensating for privacy and allowing fresher air to circulate, urban voids also provide the residents with other utilities. They are often used by youngsters as close playgrounds, primarily, soccer fields.

In addition, keeping these urban voids (particulary those within the ring road) vacant means sparing the city from further traffic congestion. Using the city boundaries as of 1986-87, about one-half of the city lands are vacant. Makkah road and King Fahad road have already approached their capacity at peak times. When these lands get developed, congestion may rise to high levels.

The drawbacks of urban voids are several. Considering that most of these voids (70\%) are zoned for residential uses, two categories of drawbacks will be introduced here: tangible and intangible drawbacks. From the tangible side, the existence of such voids represent an inefficient land utilization pattern. Vacant lands within the city are served by most utilities, so keeping them vacant means they are not utilizing these utilities. Provision of such utilities are an investment on the part of the city. If a sizable amount of the served lands are not using the services, the city 
loses financially because it will not generate any money (in the forms of fees, monthly bills, etc.) from such an investment. A second drawback of vacant lands is that they stretch distances among different city areas. Increased distances result in increased trip lengths which constitute costs to the travellers. Although monetary costs of longer trips are yet to be a problem in Riyadh, because of the present low gasoline prices and the well-developed road networks, the future may be quite different. Even modest increases in gasoline prices might make daily trips costly. A third drawback is the artificial inflation of land prices. As these lands are engulfed by urban development their prices rise to a level which is unaffordable to many prospective buyers. This is the case because the location of these inner vacant lands (between the old sections of the city and new outer developments) become very strategic as all service lines pass to reach outer developments. Land speculations also accompany the above process. When more people show interest in outer lands, speculators capitalize on it. It is in the land speculators' interest to first sell the most distant parcel in a subdivision; when such parcels develop the prices of closer ones increase. As the price of inner vacant lands increase and as buyers venture into the surrounding outer areas, nearby agriculture lands become vulnerable. In the arid climate of Riyadh the loss of any agricultural land is detrimental to the viability of the city. Green spaces are the lungs of the city and their loss is irretrievable.

The intangible drawbacks include polluting the air, and weakening the appreciation of resources. Longer daily trips (each vacant parcel increases trip length by its width and sometimes its length) result in more air pollution. In 1986 in certain sections of the city, the concentrations of carbon monoxide exceeded, by considerable margin, the permissible standards (koushki, 1988: 711). 
With the increase in population (about 700000 people during 1986-91) which is normally accompanied by both increases in car ownership and ultimately increases in vehicle trips, pollution could be very damaging. In addition, these voids represent another source of pollution, dust. Dust is a major problem in the city and vacant lands exaggerate it, because even modest air draft could easily blow the content of these land surfaces. The surfaces of most urban lands in the city are covered by a thin layer of sand and dust components which are easily blowable. Weakening the appreciation of resources is a another intangible drawback. As residents travel longer distances, they might develop a feeling or a habit that longer trips are normal. The quandary of developing such a habit lies in the future years. When more people are willing to drive longer distances, living in distant locations would incur no problems. When inner vacant lands get developed, commuting (on the part of those who live in outer areas) would be very difficult in such a stretched, continuous city. It is important to know that these vacant lands will get developed, they will not stay vacant for ever. Owners of such lands consider them investment to be utilized sometime in the future. Expropriating these lands for public uses would be very difficult, because of their prohibitive cost. While developing these lands at the present time may make movement in the city difficult, their future development will make movement next to unbearable. If these lands get developed now, leapfrogging will calm down. If they do not get developed now, leapfrogging will continue and thus more vacant lands will emerge and their inventible development will result in a very stretched city. In such a stretched city, travelling costs (e.g., time cost, out-of-pocket expenses, etc.) will increase and the quality of life will decrease. 


\subsection{Privacy \& Automobile Dependency And Urban Voids}

The discussion, particularly that of section 4.5 (Relevant Cultural Dimensions), shows that the striving for privacy (caused by, for example, abandoning the courtyard concept and adopting the setback regulations) perpetuates the existence of urban voids. However, the existence of such voids at their present scale would have not materialized without the highly developed transport network. The high level of mobility the network has provided accompanied by the high dependency on the automobile made leapfrogging possible. The convenient use of the auto made urban voids less of a problem at the present time. If people have to walk or bicycle or even use public transport on a daily basis, then each piece of vacant land would be seen as a cause of stretching distances. Commuting long distances, while exposed to the hot climate of Arabia, is not a very desirable exercise.

However, the existence of urban voids has not been seen as a totally negative phenomenon. The people of the city utilize such voids to compensate for lost privacy and to enjoy more fresh air. The well developed transport network has made travelling a very easy task. To some people, driving is a form of social entertainment. It is common among young people in Riyadh to go for a drive solely for the sake of enjoyment. In addition to other elements, the above factors (privacy, auto-dependency, and the highly developed transport network) made leapfrogging very likely and has thus perpetuated the phenomenon of urban voids.

It is important to note here that the discussed cultural factors are not the cause of the spread of urban voids. Rather the interaction of such factors with the city dwellers' present and changing 
needs, combined with certain cultural requirements not being met (i.e privacy), created an environment conducive to the spread of vacant urban lands. 


\subsection{Conclusion}

The discussion in this chapter shows that the rational planning approach is the dominant paradigm in the city. It also shows the need to work with relevant Islamic principles and cultural dimensions in order to maximize the utilities of urban policies. For example, providing a Qadhi for each submunicipality helps decentralization. In addition, the re-introduction of the concept of courtyard may satisfy some cultural requirements and reduce the use of vacant urban lands for privacy purposes.

The LGS and REDF are very important tools that can be used to shape growth policies in the city. The discussion shows the need to refine the LGS so that cohesive and unified development can easily take place. In addition, the analysis shows that the city is growing at very high rates both in population and area.

The UGL second phase starting in 1995 is quite large and the influence of the ring road on its boundaries is visible. The UGL was initiated after the development of the ring road, which represents a crucial accessibility tool to outer areas. The situation might have been quite different if the UGL came before the construction of the ring road. The UGL would probably have contained a smaller land area. With the existing boundaries of the UGL and the high accessibility provided by the ring road, dealing with urban voids will be more difficult.

Vacant urban lands may not reduce the livability of the city if they are kept voids, or developed as open spaces. However, the fact that most of these voids are privately owned means that their 
development is inevitable. If the future is a mere extrapolation of the present, then their development in later years will result in a stretched, continuous city that is difficult to manage and maintain. 


\section{Chapter V}

\section{The Questionnaires Analysis \& Responses}




\subsection{Introduction}

This chapter starts by introducing the respondents and the questionnaire. The respondents belong to three different groups: public officials, private developers, and academics. The questionnaire included close ended (pre-coded) and the open ended questions (items 2 through 21 and items 22 through 24 respectively). The responses to the close ended questions are tabulated, while the comments gathered from the open ended items are summarized in points and then discussed. The responses for items 2 through 17 are at two levels: personal and public (both levels will be defined later). The analysis of the responses refer to the personal answers unless specified otherwise. Primarily, public responses are used to verify personal ones; for example, if a personal answer is exactly opposite to a public answer pertaining to the same question, then both answers will be discussed and analyzed.

The next topic is the analysis of the responses in light of the research goals. It discusses the questionnaire items with respect to the research goals. This includes, for example, examining the percentages of respondents who agree or disagree with the themes of the questionnaire items and relating such examinations to the literature. Finally, the main hypothesis which states that the development of ring roads at a time when a substantial amount of inner lands is vacant encourages leapfrogging growth to occur and thus creates more vacant lands is examined in light of the questionnaire items with reference to the literature. The sub-hypotheses $A, B$,and $C$ are also examined taking into account the questionnaires' responses and the established literature. 


\subsection{The Questionnaire}

The questionnaire included 24 items and was administered to different respondents. The respondents consists of three groups: public officials, private developers, and academics. The respondents' occupations included deputy minister, department head, planner, transport planner, traffic officer, developer, professor, associate professor, and assistant professor. The first five of these occupations were in the public officials' group. The public officials are members of the following agencies: the Mayoralty of Riyadh (MOR), the Real Estate Development Fund (REDF), the Ministry of Municipal and Rural Affairs (MOMRA), the Ministry of Communications (MOC), the Riyadh Traffic Department, Arriyadh Development Authority (ADA), and the Arab Urban Development Institute (AUDI). The developers are the most well known ones in the city. The academics are members of King Saud University, College of Architecture and Planning. The questionnaire was also administered to some residents, but only in an anecdotal manner. ${ }^{1}$

The questionnaire has 24 questions, all but the last three $(22,23,24)$ are close ended. Questions 2 through 17 have two levels of five categories answers:

$$
\begin{array}{ll}
\text { Strongly Agree, Agree, No Opinion, Disagree, Strongly Disagree } & \text { (Personal) } \\
\text { Strongly Agree, Agree, No Opinion, Disagree, Strongly Disagree } & \text { (Public) }
\end{array}
$$

The first level is personal; that is the respondent's perspective as a public official, a developer, an academic. The second level is public; that is the respondents' view of what the general

\footnotetext{
1 Twenty seven residents, out of forty, completed the questionnaire. The author had picked residential locations close to the ring road for this purpose. Although the selection of the interviewees was not randomly performed, the residents responses were not very different from that of the full survey.
} 
public answer would be.

\subsubsection{The Close Ended Questions}

Table 5.1 summarizes the questionnaire; it covers questions "2" through "17" (see appendix A). The first columns of the table contain the item number (question number) and the main statement (the theme of the question). The second columns contain the categories of responses: SA (Strongly Agree), AG (Agree), NO (No Opinion), DA (Disagree), and SD (Strongly Disagree). ${ }^{2}$ The values in this column are percentages. For example, the number "57" in the first row under SA means $57 \%$ of the respondents strongly agree with item (2). The third column represents the type of the responses. The first row of percentages before each item represents the respondent's personal view (reflecting his occupation) of the statement, while the second row of these values represents the respondent's perception of what the public response would be. The percentages in the table are rounded to two digits; in addition, they include missing data, in other words they might not sum to $100 \%$. Valid percentages which do not include missing data sum to $100 \%$ but may present a distorted picture of the responses. For example, assume 10 subjects are asked to complete a questionnaire pertaining to agreeing or disagreeing with a certain issue. If only two responded and agreed, a valid percentage would suggest that $100 \%$ of the respondents agree, while a normal percentage would suggest only $20 \%$ of the respondent agreed and $80 \%$ is missing, or did not respond--certainly the latter is more accurate (Appendices A and B show normal and valid percentages respectively).

\footnotetext{
2 In the coming analysis responses which "Strongly Agree" or "Agree" with any item of the questionnaire will be interpreted as responses which agreed with that particular item unless otherwise specified. Responses which "Strongly Disagree" or "Disagree" with any questionnaire's item will be interpreted as responses which disagreed with that particular item unless otherwise specified.
} 
Table 5.1: The Responses (Items 2 - 17)

Item No. The Main Statement

$\%$ Of Total Responses

SA AG NO DA SD
Type
(2) There exists a relationship between the ring roads and sporadic development

(3) Development at the fringes is possible even with no freeway improvement

(4) Ring road helped increased the growth rate at the fringes

(5) The ring roads led to urban decentralization

(6) The ring road led to housing decentralization

(7) The ring road led to the decentralization of shopping centres

(8) The ring road affected locational decisions in the fringes

(9) Cheaper land values are a major factor in households locations in the fringes

(10) The efficiency of the transport system is the major factor that determined locational decisions in the fringes

(11) The ring road helped in decentralizing all economic activities

(12) Increasing the cost of automobile usage will result in transfer to other modes

(13) If weather is pleasant year round people will use modes other than the automobile

(14) The existing urban physical lay out of the city encourages the use of modes other than the private auto.

(15) The ring road helped in saving the overall travellers' time

\begin{tabular}{|c|c|c|c|c|c|}
\hline 57 & 32 & - & 7 & 4 & Personal \\
\hline 39 & 40 & 15 & 6 & - & Public \\
\hline 18 & 36 & 7 & 33 & 7 & Personal \\
\hline 14 & 35 & 24 & 23 & 3 & Public \\
\hline 65 & 30 & - & 4 & 1 & Personal \\
\hline 48 & 42 & 5 & 5 & - & Public \\
\hline 44 & 32 & 3 & 18 & 3 & Personal \\
\hline 31 & 43 & 14 & 12 & - & Public \\
\hline 40 & 34 & 1 & 20 & 4 & Personal \\
\hline 27 & 47 & 10 & 16 & 4 & Public \\
\hline 31 & 36 & 4 & 24 & 5 & Personal \\
\hline 26 & 36 & 16 & 23 & - & Public \\
\hline 29 & 45 & 10 & 14 & 3 & Personal \\
\hline 18 & 50 & 20 & 11 & - & Public \\
\hline 45 & 36 & 4 & 12 & 3 & Personal \\
\hline 47 & 31 & 6 & 11 & 5 & Public \\
\hline 37 & 34 & 1 & 23 & 6 & Personal \\
\hline 27 & 44 & 14 & 10 & 5 & Public \\
\hline 23 & 36 & 7 & 28 & 7 & Personal \\
\hline 15 & 38 & 24 & 22 & - & Public \\
\hline 11 & 36 & 8 & 33 & 13 & Personal \\
\hline 2 & 41 & 13 & 31 & 11 & Public \\
\hline 4 & 13 & 3 & 56 & 25 & Personal \\
\hline 2 & 11 & 14 & 52 & 21 & Public \\
\hline 15 & 17 & 4 & 36 & 28 & Personal \\
\hline 7 & 21 & 11 & 40 & 21 & Public \\
\hline 67 & 28 & 1 & 4 & - & Personal \\
\hline 54 & 34 & 8 & 3 & - & Public \\
\hline
\end{tabular}


(16) The ring road helped in reducing the overall accident rate

$\begin{array}{rrrrrl}24 & 33 & 9 & 29 & 5 & \begin{array}{l}\text { Personal } \\ \text { Public }\end{array} \\ 16 & 25 & 23 & 33 & 3 & \\ 13 & 27 & 15 & 35 & 11 & \text { Personal } \\ 10 & 23 & 19 & 39 & 10 & \text { Public }\end{array}$

(17) The ring road helped in reducing the overall fuel consumption level

Public

(SA: Strongly Agree), (AG:Agree), (NO: No Opinion), (DA: Disagree), (SD: Strongly Disagree)

Questions 18 through 21 have ranking categories, table 5.2 summarizes the responses. The first row of the table represent the statement of the item, while the first column represent the rank of the corresponding response.

Table 5.2: The Responses (Items 18 - 21)

\begin{tabular}{|l|l|l|l|l||}
\hline & $\begin{array}{l}\text { (18) The major } \\
\text { advantage of the } \\
\text { ring road }\end{array}$ & $\begin{array}{l}\text { (19) The most } \\
\text { preferred } \\
\text { development at the } \\
\text { ring road exchanges }\end{array}$ & $\begin{array}{l}\text { (20) The causes of } \\
\text { automobile } \\
\text { dependency in } \\
\text { Riyadh }\end{array}$ & $\begin{array}{l}\text { (21) Factors that } \\
\text { guide residential } \\
\text { locational decisions }\end{array}$ \\
\hline Ranked First & $\begin{array}{l}\text { Rerouting heavy } \\
\text { transport }\end{array}$ & Commercial & Social & Income \\
\hline Ranked Second & $\begin{array}{l}\text { Make a variety of } \\
\text { land prices } \\
\text { accessible to a wide } \\
\text { range of buyers }\end{array}$ & Institutional & Economic & Relatives \& \\
\hline
\end{tabular}




\begin{tabular}{||l|l|l|l|l||}
\hline Ranked Third & $\begin{array}{l}\text { Promote economic } \\
\text { growth }\end{array}$ & Industrial & Climatic & Image \\
\hline Ranked Fourth & & Residential & & Accessibility \\
\hline
\end{tabular}

\subsubsection{The Open Ended Questions}

Questions 22 through 24 are open-ended questions. Since the comments and responses to these questions differed widely from one respondent to another, it was not possible to categorize them in few categories. The following are the major points:

- The ring road helped people consume more land for housing purposes.

- The ring road is the life blood of new subdivision in outer areas.

. The ring road is a contributive to the phenomenon of urban voids.

- $\quad$ Ring road planning should be incorporated with service extension policies.

- The high level of mobility in the city attract some people to live in Riyadh.

The ring road is a successful endeavour.

The ring road influences the shape of the city (e.g., make it circular).

The discussion to follow examines these points and comments on them. While these points are the summary of the three groups responses, each group's responses will be discussed individually to allow for more accurate reflections of individual views.

\subsubsection{The Officials' Responses}

Comments from some planners suggest that the radial roads and the ring road contributed to the 
urban void phenomenon. They feel that this situation leads to a very low density city with a high management cost. Some officials see urban growth as the motivator for the improvement of the freeway system, an argument in line with that of Brown (1973), and Rich (1978). ${ }^{3}$ Some believe that the lack of public transportation at the high accessible points (ring road interchanges with the radial roads) increased the auto use of the roads. Another point raised by some respondents was that the improvement of the road network must be paralleled by other utility provisions. Utility provisions policies should be incorporated with ring road planning (Blaney-Dyett \& Payne-Maxie, 1980). In the case of Riyadh, once accessible areas are inhabited by citizens, the pressure--to provide services--on the government increases. In addition, some suggest that inner areas should develop before outer areas and not vice versa, an argument which shows the need for an infill development policy.

An interesting comment by a planner suggests that the efficient road network is a hidden cause for migration. He believed that since it is much easier to move around in Riyadh, inhabitants of villages and other urban centers in the Riyadh region migrated to the city to take advantage of such mobility. ${ }^{4}$

Some respondents believe that residential development cannot occur in inaccessible or difficult

\footnotetext{
3 Please see Chapter II (Urban Growth \& Urban Transport) for more discussion on such argument which its main theme is that economic development causes transport improvement.

4 Interestingly, during 1986-91, the population of the city increased by 700000 , about half of this growth was due to migration. The migrants are Saudi citizens who came from other towns and cities, and expatriates who came from different countries. However, improved mobility can not be the major factor behind migration. Most of the migrants to Riyadh are employment seekers, because the city is the capital and the largest urban center in the country.
} 
to access areas, a statement which emphasizes the importance of accessibility when residential locations selection is concerned. Others went further by suggesting the introduction of another ring road to make all areas accessible. One official strongly believed that the ring road is a good endeavour referring to the fact that the road is extensively used by residents and through traffic. ${ }^{5}$

\subsubsection{The Developers' Responses}

The improvement of the road network, particularly the freeway system, was seen by some respondents as a motivator for people to move outward away from the city, leaving the city with little demand on its locations. The Blaney-Dyett \& Payne-Maxie Study (1980) supports this argument. The study suggested that central cities are adversely affected by beltway development when the beltways are located outside city boundaries. Although Riyadh did not have designated boundaries at the time of the development of the ring road, the route of the road was well beyond the city limits.

Some developers believe that people can now buy larger lots at lower prices and commute reasonably via the ring road and its radials; this agrees with Muth's (1969) suggestion that people may consume more land in outer areas, because transport costs increase at a lower rate than the decrease rate of land prices in these areas. ${ }^{6}$ In addition, the area covered by the UGL

5 The daily traffic volume on a selected southern segment of the ring road exceeds 100,000 vehicle a day.

6 In addition, Muth suggested that income increases is an important factor that make people consume more land in the peripheries (Muth, 1969 cited in Wilson \& Schulz, 1978: 55). In Riyadh the case may be similar. Riyadh citizens have witnessed tremendous income increases, in the last two decades, primarily due to increases in oil prices. 
was seen to be large and thereby contributing to the urban voids phenomenon. Moreover, one developer believed that the sporadic development and leapfrogging growth resulted in the loosening of the family unit. According to him, in the past, families and their relatives lived closer to each other, while now this social fabric has started to disappear as improved accessibility made independent family units capable of moving to different areas seeking larger and cheaper lots. Other developers see the ring road as the life blood of the new subdivision areas and credit the ring road for bonding scattered portions of the city.

\subsubsection{The Academics' Responses}

While academic views on this subject are known and available in scientific journals, some insights were gathered from their open-ended comments. One believed that the road occupies a large area that has to be maintained indefinitely. Another believed that ring roads in such an environment would result in a circular-shaped city; and this type of city is not appropriate for such an environment. He suggested that longitudinal cities along a radial road which could extend to other urban centers and towns are better. The argument to determine which shape of a city (e.g., circular, longitudinal, etc.) can better suit desert climate is beyond the scope of this dissertation.

\subsection{The Responses In Light Of The Research Goals}

The responses in this section belong to all the three groups (i.e., officials, developers, academics)

The improvement in transport network in Riyadh along with the very low gasoline prices can also be seen as additional sources to income. For example, auto travel is not costly, and the roads are in good shape which means that automobiles chances to wear quickly are very low. 
without distinguishing them; they will be referred to as the general responses. The following examines the responses in light of the three research goals (as introduced in Chapter I):

\section{Determining if the development of the ring road is related to the increase of vacant urban}

lands. The general responses (both at the public and personal levels) ${ }^{7}$ suggest that there exists a relationship between vacant urban lands and the freeway system. Almost $89 \%$ of the respondents agree that the ring road is related to urban voids, vacant urban lands. ${ }^{8}$ Vacant urban lands are by-products of urban growth because these vacant lands would not be urban land if not transcended by urban growth. Studies showed that highway development resulted in an immediate land development in adjacent areas (Garrison \& Marts, 1958); this implies that there are other areas which are left undeveloped and in turn constituted vacant urban lands.

Some respondents suggested that the radial roads are also a factor in leapfrogging, thereby contributing to urban voids. Historically, Riyadh's growth, and thus urban voids, followed major radial roads. However, when the ring road came into existence, radial growth slowed down only to be replaced by circular growth. In other words, urban voids followed a radial pattern of voids

\footnotetext{
7 Throughout this research the personal responses will be used unless contradicted by the public responses. The personal response, as explained earlier, refers to the respondent's view as a public official, a developer, or an academic; the public response refers to the respondent's thought of what the general public answer would be. The use of two categories responses is instrumental to attain objective responses. It gives the respondent the freedom to reflect his professional view on an issue and at the same time allows him to expresses his views as a member of the general public. In addition, these two responses will strengthen the outcomes of the interview as public responses provide a sort of base line for check-ups. For example, if the personal responses to a certain question are against the established knowledge, one may seek to explain them by examining the public responses for the same item. If the public responses provide the same outcome, then the researcher should drop the item because it was certainly misunderstood. Fortunately, such a situation did not occur with this questionnaire.

8 The percentage correspond to item 2 in table 5.1. Item 2 in the table shows that $57 \%$ strongly agree and $32 \%$ agree with its statement. Therefore, it is possible to say that $89 \%(57 \%+32 \%)$ agree with the statement of item 2.
} 
which are limited in number and size, but with the advent of the ring road, these voids proliferated to represent all vacant urban lands within and around the ring road.

\section{Examining the leapfrogging phenomenon and its causes in light of the existing freeway} system (the ring road and its radials). While it is conceivable to see development at outer areas even without road improvement, the rate at which such development occurs would be much higher if preceded by road improvements. Of the respondents, $54 \%$ see development at the fringes possible even without freeway improvement. However, when they were asked whether the ring road increased the growth rate at the fringes, an overwhelming majority (95\%) agreed (Figure 5.1). The aerial images, which will be examined in the next chapter shows a clear growth at the fringes after the ring road development.

Land speculators may have contributed to the inefficiency of the land development process. ${ }^{9}$ Trading lands for speculative purposes constitutes a factor in the leapfrogging phenomenon (Abdulaal, 1990:737). However, improved accessibility made such speculative behaviour possible in the first place.

\footnotetext{
9 When outer areas become accessible by the road network, land developers and speculators subdivide them and put them up for sale. Then they tend to promote selling the most distant parcels first in any new subdivisions. They usually do this then wait for some time before starting to sell closer parcels. This process dramatically increases the values of the closer parcels. When enough people reside in the distant parcels, pressure mounts on local municipalities to provide all services. Such services must pass through closer parcels to reach the distant ones and resulting in an increased land prices in the closer parcels. In sum, roads are initiated first, and surrounding unserviced land becomes highly accessible; this result in a subdivision process as described above increasing the value of closer parcels. Interestingly, not all highly valued lots are sold; the owners for a variety of reasons, keep them vacant for future investment. The scale of this process is sensitive to the scale of accessibility improvement. Subdivisions accessible by new arterials are smaller in size and quantity to those accessible by a new freeway.
} 
Figure 5.1: Respondents' View On Fringes' Growth As Induced By The Ring Road

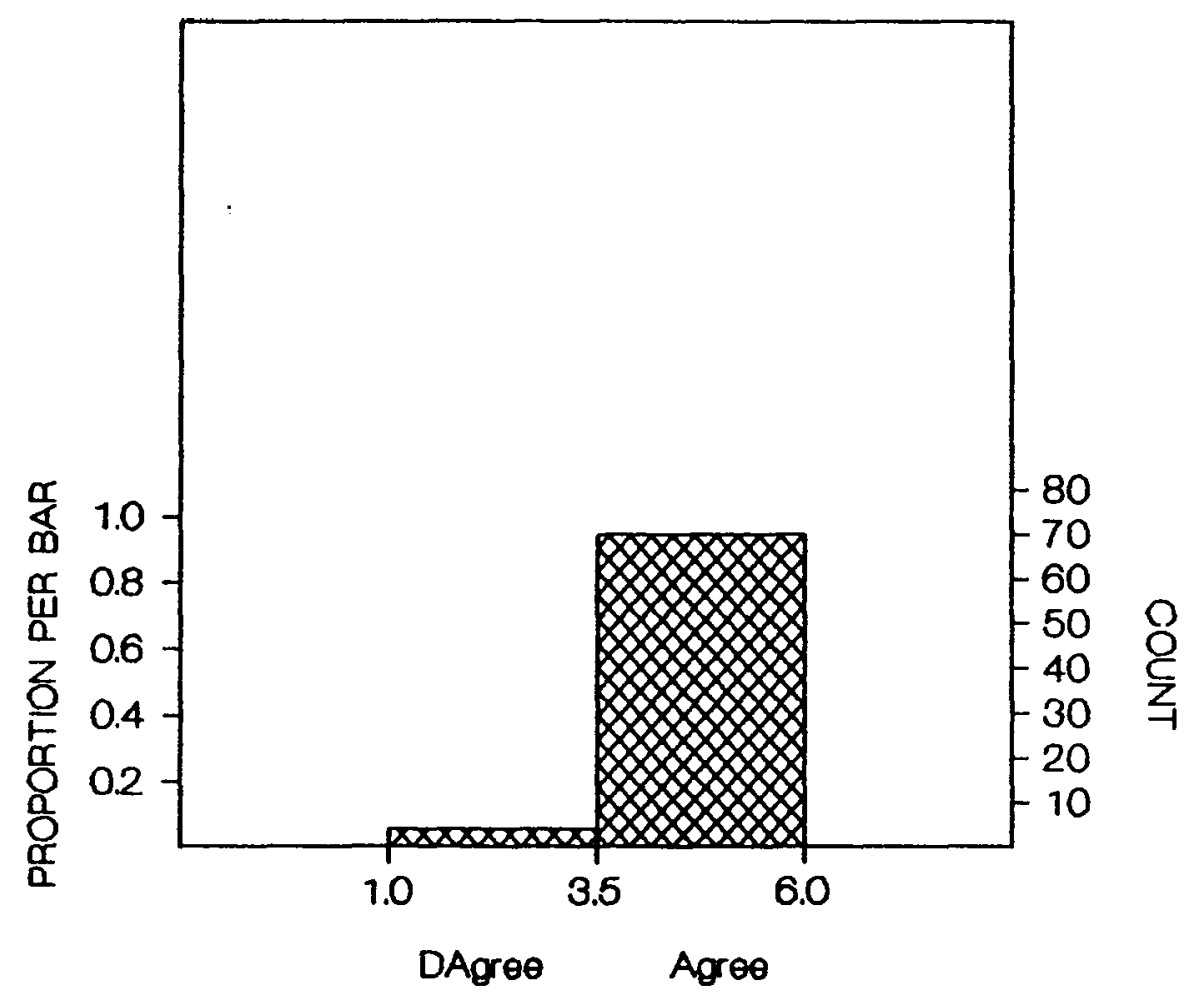

The growth of outer areas at the expense of inner areas leaving large tract of lands vacant is the leapfrogging phenomenon. Leapfrogging may result from different causes, but does not become a phenomenon without road network improvement. Roads improvements stimulate land development in their areas of influence (Smith, 1961). The fact that development take place in these areas means that urban growth is directed to certain corridors leaving other areas with less opportunities. This process is one element which contributes to the existence of vacant urban lands.

The respondents suggest that personal income and location of relatives and friends are important factors in household locational decisions (item 20, table 5.2). This is different from what Wingo 
suggested in his model that journey to work is the critical factor in household locational decision (Wingo, 1961). Outer areas have cheaper land values which are affordable to the majority of residents who, in turn, apply for government loans (i.e REDF loans). Another reason for leapfrogging might be cultural. Some residents of Riyadh enjoy living in areas which are not fully built. ${ }^{10}$

Based on observations of residential development in the city, it is possible to suggest a moving pattern of housing development. Vacant areas get developed gradually and as they reach their capacity, those who can afford it will move to other areas to escape increased density and the oldness of their houses, or to enjoy the freshness of the less developed areas. This process is another element of the urban dynamics of the city.

Leapfrogging occurs as a result of different factors but it must follow certain avenues to materialize; in the case of Riyadh, freeway improvement represents one avenue. This avenue may well change into a causal factor (the next chapter discusses in detail this causal concept). It is possible to suggest that road improvement, in addition to other factors, causes urban growth (Wilson, 1966), while freeway improvement especially that of the ring road shape such a growth (Connally, 1968). In other words, there exists a causal relationship between road improvement and urban growth with the dominant causal path going from the former to the latter. As one respondent put it "inaccessible areas cannot grow" suggesting that road improvements are

10 In the past, ancient Arabians, although tribally based, tended to keep distances among their tents to allow for privacy. Nowadays, areas which are built up might be less attractive for some parcel buyers than areas that are partially built up, all else being equal. 
prerequisite to urban development.

\section{Examining the role of the ring road system in the decentralization of urban activities,} particularly the location of residential units. The ring road impact of urban decentralization was widely stated in the responses. All the reviewed studies (Blaney-Dyett \& Payne-Maxie Study 1980, The Capital Beltway Study 1968, and the London Orbital 1989) noticed beltway impact on urban decentralization. While urban decentralization may have began before the construction of the ring road, e.g. along the east-west radial (Makkah road), the ring road intensified it. It changed the pace and the pattern of such decentralization. Instead of slow decentralization along the radials, the ring road decentralized urban activities in all direction. Of the respondents, $76 \%$ believe that the ring road led to urban decentralization and $74 \%$ agreed it did the same with housing decentralization.

The ring road impact of decentralization ought not to be limited to the time of its operation. Freeways impact urban areas in three different time stages. The first is the stage where the idea of the road comes to light. In the case of Riyadh, the ring road idea came to light in 1973 when the deputy of municipalities invited consultants to design the road. The second stage represents the time at which actual construction begins (1980 for the city of Riyadh). The third stage starts when the freeway or portions of it are open to public traffic. Portions of the ring road were opened in 1984 and 1986. Each time stage has its impact on growth, land development, and urban decentralization. Normally, the last two stages are more influential than the first. 
It is difficult to isolate and then determine each stage's impact on the urban scene. The impacts of such stages may overlap not only with each other but also with other exogenous factors. For example, in 1973 and 1979 there were sharp increases in international oil prices which impacted urban public policy and investment. While the magnitude of impacts may be susceptible to a wide range of factors, it is the author's view that the direction of impacts is more factor-specific. For example, the urban growth (in magnitude) of Riyadh can be attributed to many factors (including road investment, increased income due to increase in oil prices, etc); but the direction of such a growth can be tailored to few factors (e.g., freeway system network, land availability, etc).

The Capital Beltway Study (Connally, 1968) showed that the beltway directed urban growth in Washington D.C. by creating new natural growth points (interchange areas) which would have not existed in these particular locations without the beltway development.

\subsection{The Hypotheses and Questionnaire Responses}

The discussion in this section examines the major hypothesis and the three sub-hypotheses in light of the responses. The discussion will highlight the specific questionnaire items which correspond to these hypothesis.

\subsubsection{The Main Hypothesis}

The main hypothesis states that the development of ring roads at a time when a substantial amount of inner land is vacant encourages leapfrogging growth to occur and thus creates more 
vacant lands. The literature review of this dissertation has shown that highway improvement result in growth in adjacent areas. So it is established that ring roads (a form of highway improvements) will induce growth in adjacent areas. If a ring road is developed at a time where inner areas contain considerable amount of vacant lands, then induced development in adjacent areas will increase the amount of vacant lands because it occurs at the expense of non-adjacent areas. This becomes very apparent when induced development occurs in adjacent areas which are located outside the route of the ring road. ${ }^{11}$ The respondents agree with theme of this hypothesis; items $2,4,5,6$,and 7 (table 5.1) shows that a majority of them subscribe to such a theme. ${ }^{12}$

Items 4 and 6 (table 5.1) suggest that the respondents believe that housing development at the peripheries is related to the improvement of the ring road. The accessibility provided by the ring road make such development very likely. Indeed, beltways have been suggested to contribute in encouraging peripheral development (Browning, 1990). As suggested earlier, once development occur at the peripheries while large amount of vacant land exists in the city, leapfrogging growth starts and urban voids spread.

11 If one assumes that a ring road is a circle, then adjacent areas could be inside or outside this circle. When development occur in the outer side of the circle while the adjacent inner side is undeveloped, a leapfrogging pattern of growth takes place.

12 Leapfrogging manifests in different forms. Growth at the fringes leaving inner areas vacant is one form. Decentralization of urban activities such as housing and commercial activities may be another form. While such a decentralization may not be the cause of leapfrogging, its occupance when inner areas are vacant would certainly contribute to leapfrogging growth and the creation of the urban voids phenomenon. 


\subsubsection{Sub-Hypothesis (A)}

The first subhypothesis states that the introduction of the ring road prior to full utilization of serviced-land encourages new housing units to locate in the outer areas. After building a ring road, areas within such a road become inner areas. When development transcends these areas to outer areas, dispersion and leapfrogging take place. Beltways attract residential units to interchange areas (Connally, 1968). This situation suggests that non-interchange areas and even non-adjacent areas may not grow at the same pace of these highly accessible areas and some of them may not even get developed. As a result new housing units may locate in peripheral areas which represent an indication that ring roads encourage residents to locate in outer areas (Browning, 1990).

When a freeway is constructed, it opens a radial potential for growth. When a ring road is built, it opens circular and eventually even potential for growth. This even potential for growth is the vehicle of dispersion. People would prefer to live in outer areas to take advantage of lower land prices and larger land subdivisions. If outer areas are accessible in all directions, then development will move in any direction. The efficiency of the transport road network accompanied by cheaper land values at the fringes act together as a stimulus for leapfrogging. The major problem with this type of growth is cost where outer areas get developed, they require services. Provision of services to a horizontally expanding city is costly. The provision becomes inefficient when such a horizontal growth contains large tracts of vacant urban lands.

The respondents' views on the above hypothesis are supportive. Items "2" through "10" are 
related to this sub-hypothesis. For example, items "5, 6 and 7" suggest that over $65 \%$ of the respondents agree that urban (including housing) decentralization is furthered by the ring road. Items 8 and 9 suggest that over $70 \%$ of the respondents see cheaper outer lands and the efficiency of the freeway system as contributors to outer area developments.

\subsubsection{Sub-Hypothesis (B)}

It states that the ring road contributes to the decentralization of economic activities thereby reducing the value of the city center. The increased accessibility achieved by the freeway system led not only to residential migration to the suburbs and outer areas but also to the decline of the city center. ${ }^{13}$ City centers in fully "automobilized" cities (such as Riyadh) may not play a dominant role (Thomson, 1977). Beltways have been shown to have a general adverse effect on central cities (Blaney-Dyett \& Payne-Maxie 1980). Riyadh is both a fully "automobilized" city and a city which has a beltway.

Most of the new shopping centers are located away from the city centers. Factors such as enhanced accessibility, spacial requirements and an affluent population all contributed to the decline of the city center. The suburbs provide spacious land for development and are usually inhabited by affluent population, particularly the northern suburbs. The freeway system made

\footnotetext{
${ }^{13}$ There is a major public investment in the Riyadh city center, an attempt meant to revive the heart of the city. This investment was at two stages, the first started in 1983 and ended in 1985. The second started in 1988 and ended in 1992 and cost about SR 470,000,000 $(\$ 150,000,000)$ (ADA, 1992). This investment put the area in its old picture-architecturally--but with the use of new technology. Traditional Arabian architecture supported by up to date technology made the area quite beautiful. However, the city center has not yet gained importance as the economic heart of the city. Some time may be needed before the impact of this investment can better be assessed in terms of revitalizing the city center.
} 
such suburbs accessible to city dwellers as well as outer area dwellers. The respondents' views on the role of the ring road in economic decentralization can be deduced from items 7 and 11 as $59 \%$ of the respondents agreed that the road has a role in such a decentralization.

\subsubsection{Sub-Hypothesis (C)}

It states that the prevalent contemporary socio-economic setting in the Riyadh promotes "automobilization". Three factors contribute to the socio-economic setting: the cultural factor, the economic factor and the climatic factor. The cultural factor contributes to automobilization in several aspects. The Arabian family has a relatively high number of members (in 1986 and 1990 the average family size was 6.3 and 6.8 respectively). Family size plays a major role in mode choice. It is easier to use an automobile to convey 5 or 6 people than it is to wait at the bus stop to achieve the same goal. Automobile usage is also furthered by the fact that Arabian social activities are collective ones. For example, it is not uncommon to see a whole family, including its teenagers and adults, visiting another family (especially a relative family) on a weekly basis. In addition, most Saudi family heads do not like the idea of letting their youngsters and female family members use public transport. In Arabia, public transport is seen as being not a prestigious mode of travel and could diminish the social image of those who use it. This suggests that there is a need to develop a public transport system which considers all values and culture of resident users. In Riyadh, most of public transit users are the unskilled foreign labour. Skilled labour and other highly skilled expatriates are auto-users.

The economic factor is also critical in promoting auto dependency. There is an established 
relationship between mode choice and travel cost. Individuals normally choose the mode with lowest total cost (Frankena, 1977). In Riyadh, and with present levels of family income, virtually all families can afford at least one automobile (93\% of Saudi households in Riyadh own automobiles (ADA, 1988)). Accompanied by the fact that gasoline cost in Riyadh is very low (11 to 12 Canadian cents per liter), most people use the automobile for daily activities (indeed, it is cheaper to transport five people by an automobile than by a public transport bus). When asked whether auto-users would transfer to other modes if automobile usage costs were to be increased, the respondents were almost equally divided ( $47 \%$ agree, $46 \%$ disagree, and $8 \%$ have no opinion (item 12, table 5.1)). This suggests that increasing auto-costs alone might not suffice. Rather, a whole range of measures including, but not exclusive to, dealing positively with the dominant warm climate and the physical layout of the city.

The climatic factor is relevant to auto dependency in Riyadh. With a temperature that might reach $50^{\circ}$ in the summer, it is not a good choice to walk to the nearest bus stop. This situation is also complicated by the dusty winds which frequently expose pedestrians to the harsh desert climate. ${ }^{14}$ Given the existing physical layout of the modern arabic city such as Riyadh, climate becomes a factor that works against reducing the dependency on the private automobile. Older Arabian towns have narrow streets and high walls thus creating shaded passways all day. Modern Riyadh has wide streets and its setback regulations shift the units few meters away from

\footnotetext{
14 Controlling for all other variables, change in climate alone might not reduce auto-dependency. The majority of the respondents believe that people will still use the automobile even if the weather is pleasant year a round (item 13, table 5.1). This shows how dependent the residents are on the private automobile. It emphasises what have be suggested earlier that auto dependency is not caused only by one factor (e.g the climatic factor), rather it is a product of the interaction of several factors (i.e cultural, economic, and climatic). Therefore, successful management of autodependency must be based on a comprehensive policy which take into accounts all the aforementioned factors.
} 
the street where fences are erected. Although these fences are high (some reach to 3 meters) they are not as high as the unit itself. The wider streets with such fences expose passways to the sun all day. Therefore, walking in Riyadh is not as convenient as it was in the old city. An additional characteristic, which promotes automobilization, in Riyadh is low density. A low density city like Riyadh is, by default, not supportive of public transport. ${ }^{15}$ Studies have shown that increased population and dwelling units density contribute to the reduction of auto dependency \& auto ownership and the increase of transit use (Pusharev and Zupan 1977, Levinson and Strate 1981, and Newman and Kenworthy 1989a).

When all these factors (cultural, economic, climatic) act together, it is inconceivable to see a majority of people using public transport. The respondents ranked cultural (social) factors as the most important in terms of explaining automobile dependency. Economic factors came second, and climatic factors came last (item 20 , table 5.2). The physical layout of the city is the medium in which these factors interact. Over $60 \%$ of the respondents agreed that the physical layout of the city discourages public transport use (item 14, table 5.1). The mode split in metropolitan Riyadh is less than $3.5 \%$ transit and it is not expected to increase substantially. A study conducted by Al Muhandis and Scott Wilson Kirpatrick \& Partners in 1987 estimated that by the year 2010 the modal split will be $3.6 \%$ (Al Muhandis; 1987: H-1). The report further suggested that there is no requirement for high capacity transit services up to the year 2010.

\footnotetext{
15 Riyadh has a density of about 14 person per hectare (ADA,1986-87: 53,138). Newman and Kenworthy suggested a population density of 30 to 40 person per hectare as a figure below which a city tend to become autodependent (Newman and Kenworthy, 1989a). This shows how challenging is the task of reducing automobile dependency in Riyadh.
} 
Finally, it is worthy to shed light on the advantages of the ring road from the perspective of the respondents. The respondents ranked "rerouting heavy transport", "making variety of land prices accessible to a wide range of buyers", and "promoting economic growth" as the first, second, and third advantageous of the ring road respectively (item 18, table 5.2). In addition, an overwhelming majority of the respondents (95\%) believe that the ring road had saved the overall travellers' time (item 15, table 5.1). Moreover, 57\% of the respondents believe that the ring road have helped in reducing the overall accident rate (item 16, table 5.1). 


\subsection{Conclusion}

The major conclusion of this chapter is that leapfrogging growth and the spread of urban voids are associated with the development of the ring road and its radials. The analysis has shown that there are other factors which contributed to the leapfrogging phenomenon, but without the development of the ring road, leapfrogging and vacant urban lands would have not reached their present extent. In addition, the ring road was found to be contributive to the decentralization of urban activities such as residential units.

The analysis has also confirmed the main hypothesis which suggests that ring road development at a time when substantial amount of inner land is vacant encourages leapfrogging and thus create more vacant lands. This indicates the need to develop a policy which controls the timing of future ring road development to minimize its impact on land utilization patterns.

The examination and the analysis of the sub-hypothesis have also confirmed their themes. Subhypotheses (A) which suggests that the introduction of the ring road prior to full utilization of serviced-land encourages new housing units to locate in the outer areas, sub-hypothesis (B) which suggests that the ring road contributes to the decentralization of economic activities thereby reducing the economic value of the city center, and sub-hypothesis (C) which relates that the prevalent contemporary socio-economic setting in the Riyadh promotes "automobilization" are all confirmed by the analysis in this chapter. 


\section{Chapter VI}

\section{Submunicipal Data Analysis}




\subsection{Introduction}

This chapter starts by introducing the changes which occurred in Riyadh during 1986-91. During this five year period, the ADA conducted two surveys on which this discussion is based. It covers changes in demographics and land uses, including the changes in the amount of vacant lands. The analysis is at the submunicipal level covering the 16 included submunicipalities.

The next section introduces the urban variables and highlights those which have clear relationships with vacant urban lands. Correlation analysis, regression analysis, and factor analysis are used to discover the meaningful relations among critical variables. The analysis extends to develop a regression model to predict and explain the distribution and the amount of vacant lands. In addition, relationships among other variables are examined to provide an holistic view of the situation under study.

Traffic analysis comes next; traffic volumes on certain segments of the ring road and its radials are examined and related to the urban voids phenomenon. In order to better comprehend the impacts of these roads, two satellite images of the city of Riyadh are presented. The two images are twenty years apart (1973 \& 1992); the first predates the freeway system, while the second comes after the completion of most segments of the system. Finally, a causal model which relates the ring road and its radials with the size of vacant urban lands is discussed. 


\subsection{Urban Changes In Riyadh (1986-91)}

The following discussion includes the changes in population, income and household expenditures, and vacant lands and other land use variables. These changes were recorded in Riyadh between the two ADA surveys (1986-87 and 1990-91). ${ }^{1}$

\subsubsection{Population}

The population growth in Riyadh averaged $8.8 \%$ per year, resulting in a population of 2.1 millions in 1990-91 (an increase of about 700,000 people since 1986-87). This high growth rate is a function of three factors. First, the natural increase is high as shown by the increase of children under age 4 by $11 \%$. Second, is the increase in internal migration from different parts of the Kingdom. Third, is the increase in expatriate labour to meet the demand in certain economic sectors. About $4.1 \%$ of the population growth is accounted by migration. The natural growth of Saudis in Riyadh is about 4.7\%, a figure--although high--is typical of the Arabian Gulf countries (ADA, 1987: 137). Most Saudis (98\%) live in nuclear and extended family environments (67\% and $30 \%$ respectively). As the city population grew $50 \%$ (from 1.3 millions in $1986-87$ to 2.1 millions in $1990-91$ ), dwelling unit vacancy rate decreased by 19 percentage points from $31 \%(1986-87)$ to $12 \%(1990-91)$.

\footnotetext{
1 In 1986-87, the ADA undertook a study titled Demographic, Transportation, Land Use, And Economic Studies For The City Of Riyadh; this study was comprehensive. It included surveying land use variables (e.g area of residential uses) and other relevant planning variables. In 1990-91, the ADA conducted a similar study. These two studies provide most of the data used in this Chapter. While most of the data are available at these two dates (198687 and 1990-91), some other data were also available at 1992, and 1993. Whenever the date at which the data were collected is available it will be cited.
} 


\subsubsection{Household Income And Expenditures}

Although the city's economy is still dependent on government employment with about $80 \%$ of the citizens working in the public sector ${ }^{2}$, household income increased by $8.5 \%$ during $1986-91$. Such an increase is not significant and therefore is not expected to influence household locational decisions. Household expenditures have almost doubled during the same period. In 1986-87, Saudi household expenditures were 12 billion Saudi Riyals (SR3 = \$1), while in 1990-91, they were 21 billion riyals. The increase in expenditures may be explained by the population increase. As a result of the high natural growth rate many families must spend more to accommodate the newcomers. Another possible explanation is a change in spending behaviour. As families obtain their basic urban goods such as homes, cars, etc., households may be more inclined to spend more of their income on other amenities and non-basic goods.

\subsubsection{Vacant Lands \& Land Uses}

The second ADA survey has covered an area of 1782 square kilometers, an increase of $\mathbf{7 7 0}$ square kilometers from the first survey. Most of this increase was in developable vacant land in outer areas. Figure 6.1 shows the submunicipalities and Figure 6.2 shows the change in their vacant land areas during 1986-91; this change reflects the expansion of outer submunicipalities' boundaries during the second survey. The first ADA survey of 1986-87 had the same boundaries of the Urban Growth Limit (UGL) phase I. The second survey of 1990-91 had the same boundaries of the of the UGL phase II (throughout this thesis these surveys' boundaries should be interchangeable with the UGL boundaries). Vacant lands constitutes about $80 \%$ of the area

\footnotetext{
2 About $40 \%$ of the total labour force in Riyadh work in the public sector; $80 \%$ of this $40 \%$ are citizens (ADA, 1986: 82).
} 
covered by the second survey; the figure for $1986-87$ (the first survey) was around $51 \%$. The change in such percentages does not affect the relationship between vacant land and other urban elements (this relationship will be discussed in greater detail later). The second survey has shown that residential land uses increased by $14.5 \%$, commercial uses increased by $43.8 \%$, and service uses increased by $83.6 \%$. Although such percentile increases favour service and commercial use over residential use, residential uses have the largest share of such changes in terms of absolute values. 
Figure 6.1: The Submunicipalities

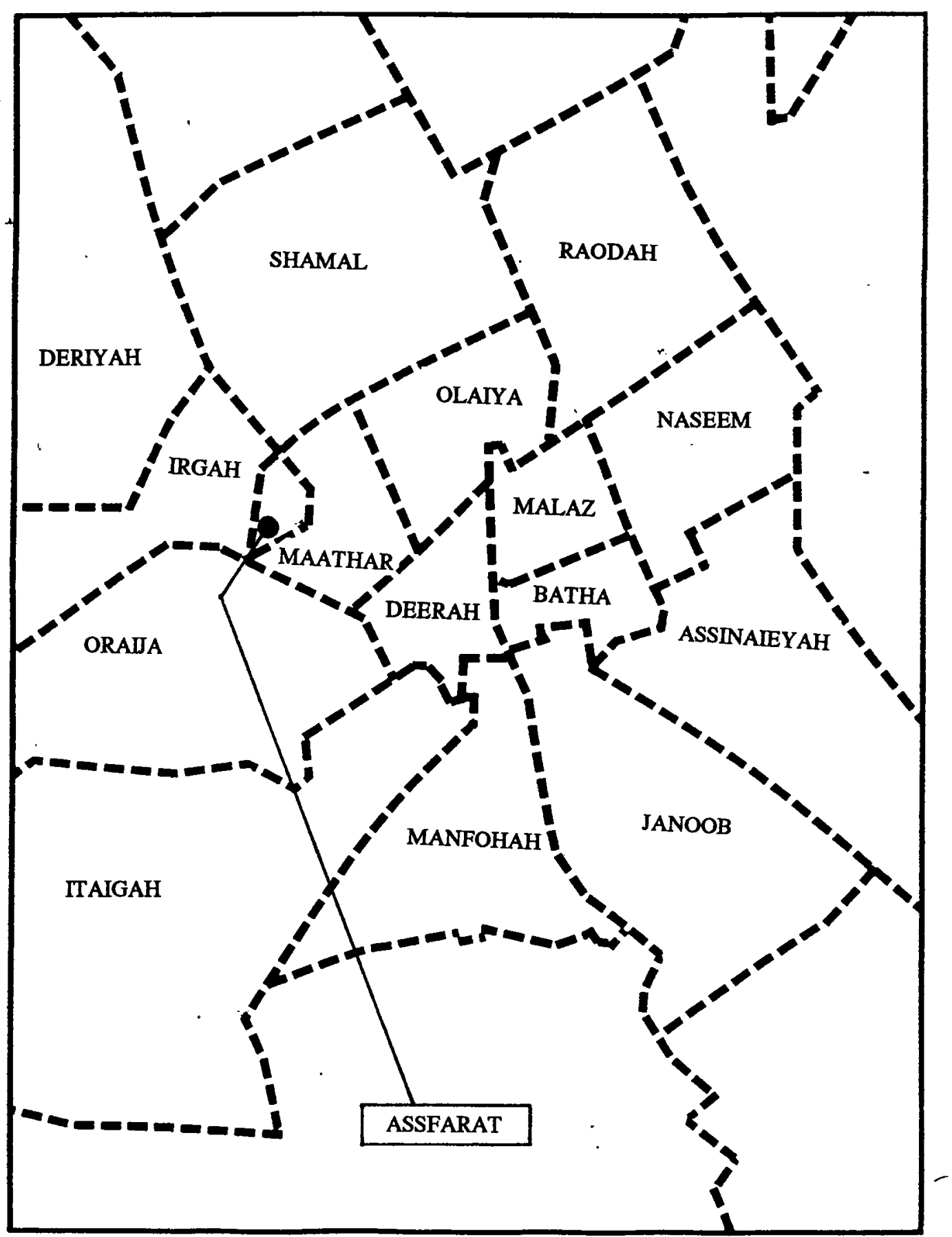

Source: ADA, 1986-87. 
Figure 6.2: The Changes In Vacant Lands (1986-87 And 1990-91)

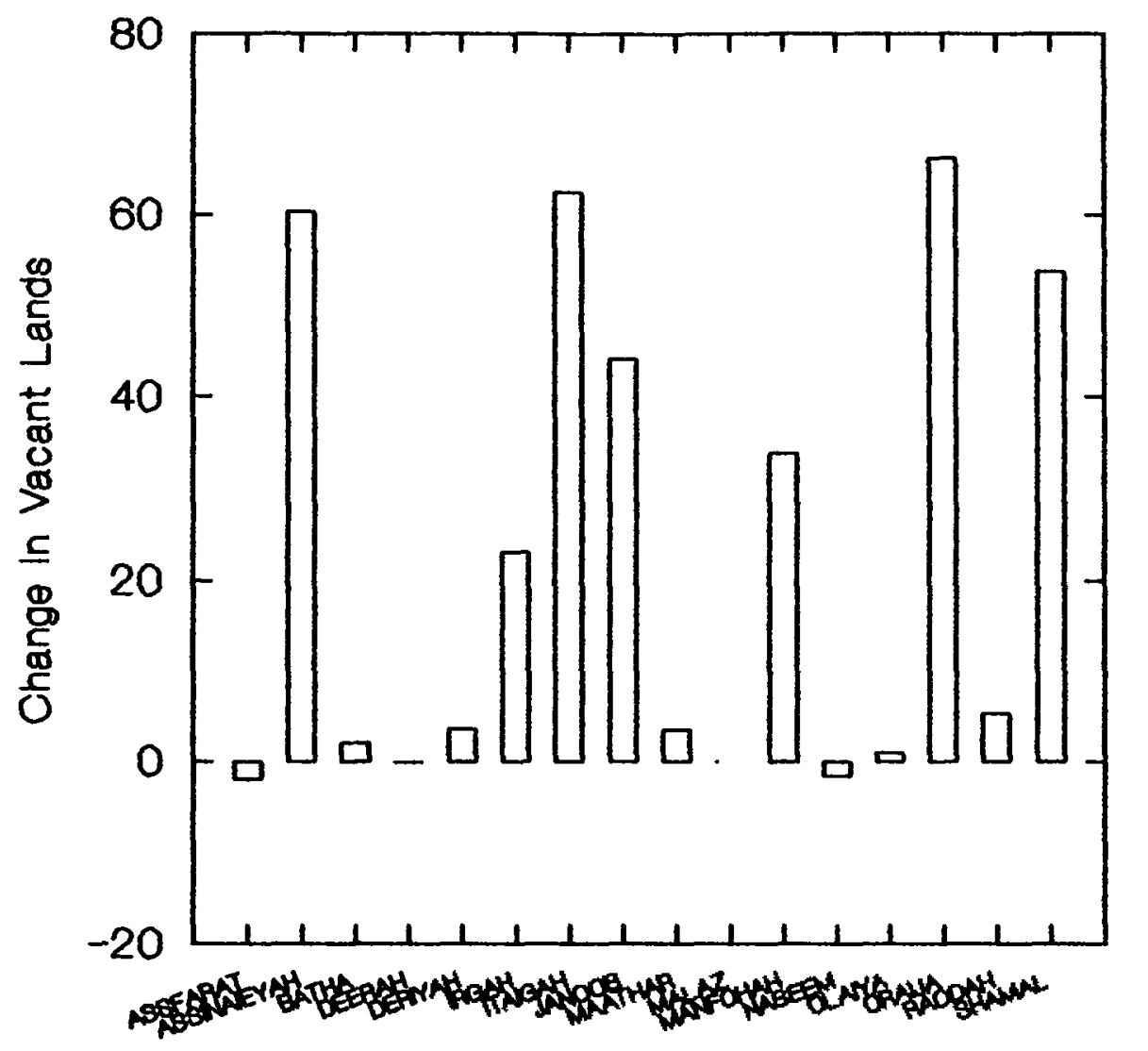

Submunicipalities

Residential use represents the largest increase in land uses in terms of absolute values. Most of residential land use growth is in the form of villas. In 1990-91, $72 \%$ of the buildings under construction were residential, the majority of which (99\%) were villas; on average, 10000 buildings were constructed annually (ADA, 1992: 22). Like residential uses, commercial uses grew to respond to population growth. The city of Riyadh houses around 41000 commercial establishments, 15600 of which were developed between the two survey periods (after the opening of major sections of the ring road). Naseem submunicipality, which is located outside the ring road, has the lion's share of this 15600 new establishments. As in other developed 
metropolitan areas, Riyadh witnessed its greatest percentile increase in the service sectors. This increase is natural in all cities which have passed the infrastructural development process. Industrial uses also witnessed growth but were limited to two municipalities. Batha submunicipality and Sinaieya are the areas which have major areas reserved for industrial uses. The major industries in these areas are furniture manufacturing, precast concrete, grain mills, building materials and commercial presses. Recreational and cultural uses are the lowest activities in the city with only 900 such uses identified.

To summarize, over a five year period Saudi population increased by $57 \%$ (city population increased by $50 \%$ ), the vacancy rate decreased by 19 percentage points, Saudi household spending increased by $75 \%$ (expatriates spending increased by $7 \%$ ), and commercial establishments grew by $43 \%$.

\subsection{Urban Variables}

The data collected at the sub-municipal level include several variables (some of which were available at both points in time 1986-87 and 1990-91). The variables include:
RESDTL:
land area of residential uses.
MANUFCT:
land area of manufacturing uses.
TRNSTUT:
land area of transportation and utilities uses.
TRADE:
land area of trade uses.
SERVICES: $\quad$ land area of service uses.
CULT\&ENT: land area of cultural and recreational facilities 
. GVTEFAC:

- RESOURCE:

- VCDVLPE:

- VCUNDVL:

- DISRPRE:

. P/HECTAR:

- DWLGUNTS:

- OCCUNTS:

. VACRTE:

- DWLG/HA:

. DWLN/HA:

. POP: land area of government and other public uses.

land area of resource production and extraction activities.

land area of vacant land that is developable. ${ }^{3}$

land area of vacant land that is not developable.

number of residential buildings in disrepair.

number of people for each hectare.

total number of dwelling units.

number of occupied units.

vacancy rate (number of unoccupied

units / total number of dwelling

units).

gross residential density (dwelling/ha).

net residential density (dwelling/ha).

All land areas of the above variables are in square meters. Other important variables such as LENGTH (the length of free way in each submunicipality), DIST (distant from the city center), APPLOANS (the number of approved personal construction loans provided by the Real Estate

\footnotetext{
3 Some of the non-developable vacant lands (VCUNDVL) in 1986-87 were reclassified as developable vacant lands in 1990-91. However, tables 6.1 and 6.2 will show the values of vacant developable lands as obtained from ADA's surveys. Therefore, the values of the VCDVLPE for 1986-87 may be less than what actually they were. Subsequent analyses will take this point into account whenever 1986-87 values of VCDVLPE are used, although most of the coming analyses will be based on 1990-91 data.

4 The value of the variable POP is calculated for both $1986-87$ \& 1990-91. The average number of people in each unit type (i.e., villa, apartment, etc) is used to calculate the population in each submunicipality. The data of both 1986-87 and 1990-91 provide the number of units of each type in each submunicipality along with the average occupants; this provided the basis for calculating POP.
} 
Development Fund REDF), and INCOME are developed by the author. LENGTH, the variable corresponding to freeway segment length in each submunicipality, is calculated from a recent map of Riyadh. Segments that penetrate submunicipalities are multiplied by 2 , while segments that are adjacent to submunicipalities are recorded as measured. When a freeway segment penetrates a submunicipality, it is assumed that its impact will be twice as much as that of a segment that is only adjacent to such a submunicipality. DIST is calculated by measuring the distance between the center of each submunicipality and the city center, using the Riyadh map.

APPLOANS is calculated using the total number of loans issued between 1986-87 and 1990-91 by the REDF. Over 20000 loans were approved; the difficult task was to distribute these loans to the submunicipalities. The REDF provided the researcher with the names of the neighbourhoods in which these loans are to be used. Since each submunicipality contains tens of such neighbourhoods, locating the loans so that they match the submunicipal level was very difficult. A data base program was used to facilitate the task. First the program grouped all loans by neighbourhood, then the researcher manually redistributed these neighbourhoods' loans to each submunicipality, and finally the outcome (APPLOANS) was calculated. Software packages such as LOTUS (a spread sheet software package) and SYSTAT (a statistical package) are the major programs used to analyze the data.

INCOME for 1986-87 is attained based on a secondary source; 5 the figure then recalculated for

\footnotetext{
5 Since the ADA socioeconomic data was at the aggregate level, income by submunicipality was not available in ADA's reports. The researcher extracted income by submunicipality based on data found in the work of Telmesani in his dissertation Exploration into Urban Structure and the Impact of Housing Construction Subsidies on Residential Location: The Case of Arriyadh, Saudi Arabia ( a Ph.d thesis, University of California at Berkeley, 1989).
} 
1990-91 based on the ADA estimated growth of income between 1986-87 and 1990-91. Finally, all subsequent analysis (tables, graphs, etc.) will be based on the 1990-91 data unless otherwise specified. However, 1986-87 data will be utilized in assessing changes in relationships among relevant variables. The next pages present tables 6.1 and 6.2 which list the numerical values of all introduced variables. Table 6.1 shows the data for $1986-87$, while table 6.2 shows the data for 1990-91. Both tables show these variables for each submunicipality. 
Table 6.1: The 1986-87 Variables*

\begin{tabular}{|c|c|c|c|c|c|c|c|c|}
\hline FREQUENCY & POP & LCOME & DWLGUNTS & occunts & VACRTE & VCDVLPE & VCUNDVL & DISRPRE \\
\hline DEERAH & 221631 & 73000 & 59011 & 38491 & 0.35 & 5461300 & 236100 & 5352 \\
\hline OLATYA & 115714 & 181000 & 26643 & 19237 & 0.28 & 11488400 & 548700 & 136 \\
\hline MALAZ & 102113 & 135000 & 21755 & 16145 & 0.26 & 10463400 & 923900 & 260 \\
\hline BATHA & 102919 & 65000 & 28943 & 18072 & 0.38 & 14531500 & 900 & 2655 \\
\hline MAATHAR & 43507 & 181000 & 10429 & 7371 & 0.29 & 13612600 & 5032700 & 79 \\
\hline ASSFARAT & 1251 & 181000 & 288 & 200 & 0.31 & 5538900 & 200000 & 0 \\
\hline ORAUA & 114655 & 65000 & 18717 & 14300 & 0.24 & 30968800 & 11216000 & 34 \\
\hline SHAMAL & 61558 & 100000 & 12208 & 8982 & 0.26 & 68185200 & 19772200 & 329 \\
\hline RAODAH & 82070 & 98000 & 14921 & 11222 & 0.25 & 80889300 & 5122100 & 79 \\
\hline NASEEM & 122333 & 80000 & 23243 & 16912 & 0.27 & 29976100 & 875000 & 284 \\
\hline ASSINAIEYA & 22059 & 72000 & 7536 & 3876 & 0.49 & 36380100 & 4949100 & 3 \\
\hline JANOOB & 51728 & 90000 & 13949 & 8264 & 0.41 & 49562700 & 8860200 & 158 \\
\hline MANFOHAH & 146813 & 77000 & 35816 & 23896 & 0.33 & 17043000 & 3671000 & 1446 \\
\hline ITAIGAH & 83860 & 84000 & 17202 & 12339 & 0.28 & 17548200 & 3957800 & 302 \\
\hline IRGAH & 1795 & 65000 & 574 & 444 & 0.23 & 6655500 & 4411500 & $n 2$ \\
\hline DERIYAH & 10038 & 65000 & 2076 & 1360 & 0.34 & 5025700 & 20000 & 134 \\
\hline FREQUENCY & GVTEFAC & CULT\&EN & RESDTL & MANUFCT & TRNS\&UT & TRADE & SERVICES & \\
\hline DEERAH & 3700000 & 450000 & 7950000 & 20000 & 390000 & 310000 & 1120000 & \\
\hline OLAYYA & 22190000 & 270000 & 2040000 & 40000 & 230000 & 220000 & 440000 & \\
\hline MALAZ & 1950000 & 860000 & 6890000 & 20000 & 330000 & 300000 & 840000 & \\
\hline BATHA & 560000 & 460000 & 1820000 & 510000 & 2000000 & 280000 & 4770000 & \\
\hline MAATHAR & 2300000 & 350000 & 6470000 & $\mathbf{0}$ & 120000 & 40000 & 1490000 & \\
\hline ASSFARAT & 300000 & 480000 & 80000 & o & 60000 & 0 & 0 & \\
\hline ORAIIA & 380000 & 200000 & 6320000 & 10000 & 680000 & 240000 & 330000 & \\
\hline SHAMAL & 6600000 & 880000 & 8100000 & 380000 & 900000 & 220000 & 5670000 & \\
\hline RAODAH & 480000 & 50000 & 5000000 & 70000 & 640000 & 150000 & 4750000 & \\
\hline NASEEM & 1290000 & 120000 & 16040000 & 210000 & 170000 & 920000 & 1740000 & \\
\hline ASSINAIEYA & 2050000 & 10000 & $\$ 220000$ & 3030000 & 5610000 & 340000 & 3830000 & \\
\hline JANOOB & 890000 & 50000 & 3770000 & 13700000 & 610000 & 420000 & 1070000 & \\
\hline
\end{tabular}

* Some of the variables of this table should be interpreted with care when compared with 1990-91 data. This is the case because in 1990-91 some of the criteria based on which the 1986-87 data were collected have changed. For example, some vacant lands were classified as non-developable in 1986-87 but in 1990-91 these lands were reclassified as developable and simultaneously many of the submunicipalities have witnessed expansions in their boundaries in 1990-91. This, for instant, might explain why some submunicipalities have more non-developable vacant lands in 1990-91 than they did in 1986-87. 


\begin{tabular}{|c|c|c|c|c|c|c|c|}
\hline MANFOHAH & 850000 & 40000 & 5090000 & 50000 & 690000 & 970000 & 840000 \\
\hline TTAIGAH & 400000 & 120000 & 7360000 & 10000 & 40000 & 150000 & 630000 \\
\hline IRGAH & 10000 & 0 & 170000 & 0 & 10000 & 0 & 10000 \\
\hline DERTYAH & 300000 & 220000 & 590000 & 0 & 20000 & 0 & 170000 \\
\hline FREQUENCY & VILLA & APARTME & DIST & LENGTH & & & \\
\hline DEERAH & 5503 & 30747 & 1 & 10.5 & & & \\
\hline OLATYA & 10145 & 16143 & 11.7 & 23.75 & & & \\
\hline MALAZ & 11235 & 9907 & 9 & 10.75 & & & \\
\hline ВАTHА & 985 & 14817 & 7.7 & 8.5 & & & \\
\hline MAATHAR & 2884 & 4409 & 8.9 & 15 & & & \\
\hline ASSFARAT & 141 & 153 & 11.4 & 7.5 & & & \\
\hline ORAUA & 18159 & 1084 & 14.8 & 20 & & & \\
\hline SHAMAL & 7027 & 4490 & 16.8 & 82 & & & \\
\hline RAODAH & 11294 & 4489 & 22.3 & 37.6 & & & \\
\hline NASEEM & 18049 & 4113 & 18 & 18.8 & & & \\
\hline ASSINAIEYA & 2580 & 4086 & 18.8 & 52 & & & \\
\hline JANOOB & 5236 & 6410 & 15.7 & 19.25 & & & \\
\hline MANFOHAH & 6809 & 15098 & 9 & 15.75 & & & \\
\hline TTAIGAH & 9800 & 4976 & 17 & 22.75 & & & \\
\hline IRGAH & 152 & 19 & 15.7 & 5 & & & \\
\hline DERTYAH & 1414 & 34 & 22.8 & 0.25 & & & \\
\hline
\end{tabular}

Source: ADA, 1986-87. 
Table 6.2: The 1990-91 Variables

\begin{tabular}{|c|c|c|c|c|c|c|c|c|}
\hline FREQUENCY & POP & INCOME & DWLGUNTS & OCCUNTS & VACRTE & DWLGHA & DWLNHA & DISRPRE \\
\hline DEERAH & 287577 & 79205 & 59064 & 49842 & 0.16 & 18 & 68 & 11028 \\
\hline OLAIYA & 161502 & 196385 & 29761 & 27753 & 0.07 & 5 & 31 & 85 \\
\hline MALAZ & 134332 & 146475 & 28330 & 24378 & 0.14 & 7 & 35 & 230 \\
\hline BATHA & 133568 & 20525 & 28535 & 24131 & 0.15 & 10 & 111 & 7835 \\
\hline MAATHAR & 80707 & 196385 & 13704 & 13181 & 0.04 & 3 & 15 & 371 \\
\hline ASSFARAT & 3297 & 196385 & 591 & 575 & 0.03 & 1 & 12 & 1 \\
\hline ORAIA & 215606 & 20525 & 28599 & 26792 & 0.06 & 2 & 34 & 229 \\
\hline SHAMAL & 95420 & 108500 & 16977 & 16069 & 0.05 & 1 & 21 & 194 \\
\hline RAODAH & 113903 & 106330 & 23104 & 20488 & 0.11 & 1 & 22 & 95 \\
\hline NASEEM & 216070 & 86800 & 32072 & 29688 & 0.07 & 4 & 56 & 130 \\
\hline ASSINAIEYA & 30946 & 78120 & 4349 & 3692 & 0.15 & 1 & 6 & -367 \\
\hline JANOOB & 94046 & 97650 & 17590 & 15952 & 0.09 & 1 & 24 & 814 \\
\hline MANFOHAH & 213234 & 83545 & 40136 & 34927 & 0.13 & 4 & 55 & 5594 \\
\hline ITAIGAH & 137635 & 91140 & 21536 & 19883 & 0.08 & 1 & 32 & 646 \\
\hline IRGAH & 6932 & 70525 & 922 & 897 & 0.03 & 1 & 10 & 120 \\
\hline DERIYAH & 20121 & 70525 & 3044 & 2923 & 0.04 & 1 & 29 & 301 \\
\hline FREQUENCY & TRNSUT & TRADE & SERVICES & CULTENT & GVTEFAC & VILLA & APARTMEN & DIST \\
\hline DEERAH & 946900 & 431930 & 887600 & 1155100 & 4566900 & 5795 & 36747 & 1 \\
\hline OLATYA & 876400 & 532000 & 500700 & 727300 & 19170100 & 11681 & 17443 & 12 \\
\hline MALAZ & 727700 & 438200 & 919100 & 1017700 & 1867100 & 11264 & 13357 & 9 \\
\hline BATHA & 2287500 & 335900 & 2693200 & 61300 & 1323900 & 1114 & 15519 & 8 \\
\hline MAATHAR & 765300 & 146200 & 293000 & 429100 & 1071100 & 4488 & 7118 & 9 \\
\hline ASSFARAT & 245700 & 12800 & 55100 & 1789600 & 367100 & 145 & 292 & 11 \\
\hline ORAIAA & 1060600 & 279100 & 588200 & 484900 & 648000 & 27733 & 2032 & 15 \\
\hline SHAMAL & 3000600 & 355600 & 3343000 & 2780600 & 3614300 & 8010 & 5696 & 17 \\
\hline RAODAH & 672500 & 367000 & 2413800 & 334000 & 525500 & 13532 & 4571 & 22 \\
\hline NASEEM & 992100 & 1053000 & 2702100 & 572500 & 2618400 & 24139 & 9387 & 18 \\
\hline ASSINAIEYA & 2267100 & 115600 & 5848400 & 1161600 & 305000 & 3035 & 1800 & 19 \\
\hline JANOOB & 630900 & 248100 & 1778000 & 166500 & 666600 & 6141 & 7995 & 16 \\
\hline MANFOHAH & 1210100 & 463700 & 1328700 & 112000 & 938300 & 9300 & 22633 & 9 \\
\hline ITAIGAH & 205100 & 279700 & 149000 & 137300 & 5494100 & 13704 & 6058 & 17 \\
\hline IRGAH & 145900 & 8300 & 108100 & 6900 & 126000 & 525 & 280 & 16 \\
\hline DERIYAH & 118900 & 19100 & 71700 & 285000 & 897100 & 1868 & 533 & 23 \\
\hline
\end{tabular}




\begin{tabular}{|c|c|c|c|c|c|c|c|c|}
\hline FREQUENCY & VCDVLPE & VCUNDVL & RESDTL & MANUFCT & LENGTH & APPLOANS & URBAN & PHECTAR \\
\hline DEERAH & 5292600 & 0 & 8981000 & 25100 & 11 & 49 & 2.61 & 83 \\
\hline OLAIYA & 12363400 & 0 & 9802900 & 7000 & 24 & 191 & 0.49 & 32 \\
\hline MALAZ & 10469000 & 0 & 7403400 & 60500 & II & 317 & 0.48 & 43 \\
\hline ВАTHA & 12353800 & 0 & 2303300 & 439500 & 9 & \$1 & 1.08 & $\$ 4$ \\
\hline MAATHAR & 17014100 & 180000 & 9228900 & 1200 & 15 & 163 & 0.41 & 20 \\
\hline ASSFARAT & 3552100 & 200000 & 481500 & 10800 & 8 & 0 & -1.18 & 1 \\
\hline ORAUAA & 97189500 & 26653500 & 8874500 & 816500 & 20 & 3282 & 0.08 & 12 \\
\hline SHAMAL & $1.22 e+08$ & 0 & 8082200 & 754500 & 82 & 2773 & -0.46 & 8 \\
\hline RAODAH & 86181800 & $\mathbf{0}$ & 9435600 & 29000 & 38 & 2879 & -0.25 & 18 \\
\hline NASEEM & 28403700 & 3696400 & 17126300 & 96900 & 19 & 1504 & 0.54 & 25 \\
\hline ASSINAIEYA & 96744300 & $\mathbf{0}$ & 0925500 & 6420400 & 52 & 225 & -1.05 & 3 \\
\hline JANOOB & 93616600 & 0 & 4404300 & 3316600 & 19 & 583 & -0.42 & 7 \\
\hline MANFOHAH & 50884500 & 428700 & 7293700 & 627200 & 16 & 1251 & 0.87 & -20 \\
\hline ITAIGAH & 79961800 & 2046300 & 7037200 & 118900 & 23 & 1380 & -0.23 & 9 \\
\hline IRGAH & 29793000 & 23712800 & 560400 & 1065300 & 5 & 242 & -1.18 & 1 \\
\hline DERIYAH & 8562500 & 7362900 & 1046000 & 73600 & 6 & 32 & -0.97 & 7 \\
\hline
\end{tabular}

Source: ADA, 1991-92 (Obtained from ADA planners during the author visits to the ADA Headquarter in Riyadh).

Note: LENGTH, DIST, APPLOANS, INCOME and URBAN of both tables $(6.1 \& 6.2)$ are developed by the author based on sources used in this thesis. 


\subsection{Urban Data Analysis}

The urban theories and models, which were discussed in Chapter II, are generally inapplicable to the urban dynamics of the city of Riyadh not only because of the limitations of these models but also because of the cultural differences between Riyadh and the Western cities where these models were developed. For example, Alonso's model might not be appropriate to explain the urban form of Riyadh not only because of its unrealistic assumptions (i.e the urban area is featureless and traversable in all directions with only one employment center (Ayeni, 1979:27)) but also because the factors which affect residential decisions in Riyadh are quite different. One factor is the fact lands in Riyadh could be obtained free from the government through the Land Granting System (LGS). Residents who developed these lands did not do so to balance the relationship between housing consumption and distance from the CBD, as suggested by Alonso's model. The reason for the development of these lands, in addition to the highly-developed road network, is that they were obtained at no cost and at the same their construction can be financed by the Real Estate Development Fund's interest-free housing loans. A second factor that affects residential location in Riyadh is the strong social ties among the citizens of the city. The analysis of the questionnaires' responses (discussed in the previous chapter) shows that residential location of relatives and friends are very important in Riyadh's residents housing decisions, a factor which is not relevant to the developers of the above models. Similar arguments can also be directed at Wingo's work, which is more restrictive and more unrealistic than that of Alonso. Therefore, these models will not be used in the following analyses to predict or explain the urban form of Riyadh. However, and as introduced earlier, certain components of some of the urban theories and models (e.g., the fully motorized city of Thomson) may contribute to better the understanding 
of the urban structure of Riyadh.

The following sections analyze the urban data at the submunicipal level. The purpose of this analysis is to examine which variables best explain the leapfrogging phenomenon and consequently the distribution of vacant urban lands. The following discussion compares vacant lands status between 1986-87 and 1990-91; then it analyzes the relationships between vacant urban lands and the most relevant urban variables. Variables which did not show clear relationships with vacant lands will not be highlighted in the following discussion.

\subsubsection{Vacant Lands Of 1986-87 \& 1990-91: A Comparative Analysis ${ }^{6}$}

In 1986-87, the ADA conducted its first survey covering all inner submunicipalities (i.e. Deerah, Oliaya, Malaz, Batha, and Maathar) and portions of outer submunicipalities (e.g. Shamal, Oraija ... etc.). In 1990-91, the ADA conducted its second survey covering most outer submunicipalities, and their boundaries were increased to accommodate all adjacent areas covered by this survey. In essence the 1986-87 and 1990-91 surveys played a major role in defining the boundaries of the submunicipalities. ${ }^{7}$ For example, Shamal (North) submunicipality area in 1986-87 is considered the area that was covered by the 1986-87 survey; in 1990-91 the area of the same

\section{!}

\footnotetext{
6 Unless otherwise specified, the term "vacant lands" shall always mean "developable vacant lands."

7 It is not suggested here that the surveys per se changed the boundaries. These boundaries were, in general, in place since the first survey of 1986-87. However, only geographical areas which were covered by such a survey constituted the data base for 1986-87, and therefore these areas represented the submunicipal boundaries of 1986-87. In 1990-91, areas which were not covered by the 1986-87 survey, were covered and consequently incorporated in the 1990-91 submunicipal boundaries.
} 
submunicipality is defined as the area which was covered by the $1990-91$ survey. $^{8}$

Most of the outer submunicipalities' had an increase in vacant land area between 1986-87 and 1990-91, while most inner submunicipalities did not. Increases in the areas of vacant lands in outer submunicipalities was primarily a result of the expansion of boundaries. In the case of inner submunicipalities the increases were not always real. In 1986-87, considerable amounts of vacant land was classified as non-developable, but in 1990-91 many of these lands were reclassified as developable. For example, in Malaz about 0.9 square kilometers of vacant lands were classified as non-developable, while in 1990-91 Malaz contained zero square kilometers of nondevelopable vacant lands (the most logical explanation is that this 0.9 square kilometers were reclassified as developable). In addition, there were vacant lands which were not included in the 1986-87 survey for a variety of reasons (e.g a fenced vacant land in 1990-91 may have not been considered vacant in $1986-87$ ). This may explain why some of the inner submunicipalities recorded increases in developable vacant lands area between 1986-87 and 1990-91 (table 6.1 \& 6.2). However, some of these increases in vacant lands were real primarily due the demolition of older buildings.

Comparing the percentages of vacant lands in outer and inner submunicipalities between the two surveys (1986-87 \& 1990-91) is not an accurate measure of leapfrogging because of the compounding effect of the expansions in the boundaries and the reclassification of many non-

\footnotetext{
8 In 1991 the ADA used different zonal system to conduct its survey. However, for the purpose of this thesis, the relevant ADA planners converted all the land use data in these areas to match the submunicipal boundaries and they consider this conversion accurate. The author acknowledges their kind assistance.
} 
developable vacant lands as developable. For example, Shamal submunicipality, between 1986-87 and 1990-91, changed its boundaries and at the same time reduced its non-developable lands from 19 square kilometers to zero (ADA, 1986-87 \& 1990-91). Therefore, the comparison of vacant developable land areas (VCDVLPE) of 1986-87 \& 1990-91 in all submunicipalities, as recorded in tables 6.1 and 6.2, will not provide accurate estimates of the change in vacant lands, but could give a good indication of how much change occurred. In addition, comparing the population growth (or the population densities) in the inner submunicipalities between 1986-87 and 1990-91 is not a good measure of leapfrogging. Leapfrogging can only be measured by the physical urban growth in outer areas at the expense of inner areas. Even if population increases in certain areas, it will not necessarily mean that such areas are witnessing physical growth. For example, assume a city has only two areas (i.e zones): $\mathrm{X}$ and $\mathrm{Y}$. If the population of area $\mathrm{X}$ increased by $200 \%$ while the population of area $\mathrm{Y}$ increased only by $25 \%$, then this change in population could mean that area $\mathrm{Y}$ witnessed physical growth while area $\mathrm{X}$ did not simply because the vacancy rate (number of unoccupied units/number of total units) in area $\mathrm{X}$ was very high while it was zero in area Y. This example is relevant to Riyadh, because the dwelling units' vacancy rate in 198687 was high, amounting to $31.2 \%$ (ADA, 1986-87: 61). Therefore, population growth in different submunicipalities may not be synonymous with physical growth, and therefore may not affect the development of developable vacant lands. Rather, population growth may reduce the vacancy rate and not affect leapfrogging.

The most appropriate method to compare the change in area of developable vacant lands during the $1986-87 \& 1990-91$ period is to compare the actual change in developable vacant land area 
during that period for the inner submunicipalities only. ${ }^{9}$ This comparison can be improved when treating the non-developable vacant lands of the 1986-87 survey as developable and subtract from them the area of non-developable lands in 1990-91 for each submunicipality. This method assures that if all non-developable vacant lands recorded in 1986-87 were reclassified as developable, the analysis will still be valid. In this case developable vacant lands in 1986-87 will be:

Developable Vacant Lands In 1986-87 = Developable Vacant Lands In 1986-87

+ Non-Developable Vacant Lands In 1986-87 - Non-developable Vacant Lands in 1990-91.

The next step is to compare the calculated amount of developable vacant lands of 1986-87 (the outcome of the above equation which equals column (c) in the following table) with developable vacant lands of 1990-91. Using the above definition (for the purpose of comparison) of vacant developable lands, the following table compares the change in such lands between 1986-87 and 1990-91. All land areas in the following table are vacant land areas.

\footnotetext{
9 Since many vacant lands were reclassified as developable in 1991 (with no accurate data on how many of them were reclassified), and since most outer submunicipalities observed changes in their boundaries, the inclusion of these submunicipalities in the comparison will not be considered.
} 
Table 6.3: Change In Vacant Land Areas (In Square Meters) In Inner submunicipalities (1986-87 \& 1990-91)

\begin{tabular}{|c|c|c|c|c|c|c|}
\hline $\mathrm{Sm}$ & $\begin{array}{l}\text { VCDUND } \\
1986-87 \\
\text { (a) }\end{array}$ & $\begin{array}{l}\text { VCUNDVL } \\
1990-91 \\
\text { (b) }\end{array}$ & $\begin{array}{l}\text { VCDVLPE } \\
1986-87 \\
\text { (c) }=(a)-(b)\end{array}$ & $\begin{array}{l}\text { VCDVLPE } \\
1990-91 \\
\text { (d) }\end{array}$ & $\begin{array}{l}\text { CHDV } \\
1990-91 \text { \& } \\
1986-87 \\
(e)=(d)-(c)\end{array}$ & $\begin{array}{l}\text { \% CHDV } \\
1990-91 \text { \& } \\
1986-87 \\
(f)=(e) /(a)\end{array}$ \\
\hline DEERAH & 5697400 & 0 & 5697400 & 5292600 & -404800 & $-8 \%$ \\
\hline OLATYA & 12037100 & 0 & 12037100 & 12363400 & $326300^{10}$ & $3 \%$ \\
\hline MALAZ & 11387300 & 0 & 11387300 & 10469000 & -918300 & $-9 \%$ \\
\hline BATHA & 14532400 & 0 & 14532400 & 12353800 & -2178600 & $-18 \%$ \\
\hline MAATHAR & 18645300 & 180000 & 18465300 & 17014100 & -1451200 & $-9 \%$ \\
\hline TOTAL & 62299500 & 180000 & 62119500 & 57492900 & -4626600 & $-8 \%^{1}$ \\
\hline
\end{tabular}

Sm: Submunicipality

VCDUND 1986-87: Developable and Non developable vacant land areas in 1986-87

VCUNDVL 1990-91: Non-Developable vacant land areas in 1990-91

VCDVLPE 1986-87: Developable Vacant Land areas In 1986-87

VCDVLPE 1990-91: Developable vacant lands areas in 1990-91

CHDV 1990-91 \& 1986-87: Change in developable vacant land areas

\% CHDV 1990-91 \& 1986-87: Percentage change in vacant land areas (1990-91 \& 1986-87)

Source: Author based on ADA data of 1986-87 \& 1990-91.

The table compares the change in vacant land areas between 1986-87 and 1990-91 for inner submunicipalities which kept same boundaries between these dates. Although the submunicipalities observed a reduction in developable vacant lands, such a reduction was very marginal amounting only to $8 \%$. When it is seen in light of the large number of housing units which were developed at the time (44625 new units were developed in the same period, a majority of which were single family units), this rate of $-8 \%$ is very low. It confirms that

10 The increase in vacant lands in Oliaya might not be real. As discussed earlier, in 1986 some lands were not included or classified as vacant, but in 1991 many of these lands were considered vacant.

11 The value in this cell is an average value. 
leapfrogging has occurred resulting from the fact that the majority of the new development (e.g. $75 \%$ of the 44625 new housing units) went to outer submunicipalities rather than inner submunicipalities. In order to assess this leapfrogging phenomenon in light of the land use data, one should consider the distribution of the new housing development with relation to the potential carrying capacity of inner submunicipalities.

The distribution of the new housing units in light of the potential carrying capacity of inner submunicipalities may provide a valid way of measuring leapfrogging. A potential carrying capacity of a submunicipality is the maximum number of dwelling units it can house. Since $70 \%$ of the vacant lands are zoned residential, ${ }^{12}$ one can assume that the potential residential carrying capacity of these submunicipalities equals $70 \%$ of the land area of their vacant lands. About 55\% of the dwelling units developed in Riyadh between 1986-87 and 1990-91 were villas (ADA, 1991: 8-9, Issue 5). Therefore, villa development will be used as proxy in the potential carrying capacity analysis. It is important to note that using the villa (instead of the apartment) may lead to conservative analysis because the land area consumed by an average Riyadh villa can house as much as four apartments. This means that any tract of vacant developable land which can house $x$ number of villas can also house $4 x$ number of apartments. However, a safe analysis and therefore conclusions can be attained when a conservative parameter (such as the villa) is used.

Using 500 square meters as the land area of a new villa, it is possible to estimate the maximum

12 In general terms, the residential zoning in Riyadh is exclusive to single family unit (villa, a two unit surrounded by a solid fence) town houses, and Arab houses. Apartment buildings are developed along arterials that are at least $\mathbf{3 0}$ meters wide. Apartment buildings might not be allowed in residentially zoned area except in certain parts of the city (e.g., in areas where most of the streets are less than 30 meters wide). 
number of villas which can be developed in the remaining vacant developable lands in each inner submunicipality. ${ }^{13}$ The following table shows the potential number of new villas which can be accommodated in the existing developable vacant urban lands, the existing number of villas, and the used capacity for each inner submunicipality in 1990-91.

\section{Table 6.4: Potential \& Used Capacity Of Inner Submunicipalities In 1990-91}

\begin{tabular}{|c|c|c|c|}
\hline Submunicipality & $\begin{array}{l}\text { Potential New } \\
\text { Villas }^{14} \\
\text { (a) }\end{array}$ & $\begin{array}{l}\text { Existing } \\
\text { Villas } \\
\text { (b) }\end{array}$ & $\begin{array}{l}\text { Used } \\
\text { Capacity } \\
(c)=(b) /((b+a)\end{array}$ \\
\hline DEERAH & 5557 & 5795 & $51 \%$ \\
\hline OLAIYA & 12982 & 11681 & $47 \%$ \\
\hline MALAZ & 10992 & 11264 & $51 \%$ \\
\hline BATHA & 12971 & 1114 & $8 \%$ \\
\hline MAATHAR & 17865 & 4488 & $20 \%$ \\
\hline TOTAL & 60368 & 34342 & $36 \%$ \\
\hline
\end{tabular}

Source: Author, Based on different sources used in this thesis.

13 The land area of a villa in Riyadh ranges from 400 square meters to over 1000 square meters. The land area of a lot distributed through the Land Granting System (LGS) is around 400 square meters. For example, the mayoralty of Riyadh distributed lots of dimensions $20 \mathrm{~m}$ x 20m in Oraija (Al-Mogren, 1993:277). In Malaz the typical villa size is 625 square meters (Ibid: 252). Since no other figures for the remaining submunicipalities were available for this research, 500 square meters will be used as an average land area for a villa. This figure is common in Riyadh, and the average of the previously introduced figures $((400+625) / 2=512.5)$ is very similar to it.

14 The potential carrying capacity of a submunicipality is computed by determining the amount of residential lands (70\% of vacant developable lands in 1990-91) less the land area of the road network (assumed to be 25\%) divided by the average unit land area ( 500 square meters is the average in this case). For example, the potential carry capacity for DEERAH is:

$$
\text { DEERAH }=(5292600 * 0.7 *(1-0.25)) / 500=5557 \text { villas }
$$

15 The value in this cell is an average value. 
The table clearly shows that the inner submunicipalities have only utilized about $36 \%$ of their 1990-91 total capacity in terms of accommodating new villas. In other words, these submunicipalities can still accommodate 26026 (60368-34342) new villas. Between 1986-87 and 1990-91, 44265 new housing units were developed in Riyadh; 55\% of these units were villas, therefore 23903 villas were developed. Less than $25 \%$ of the new housing units which were developed in that period located in the inner submunicipalities (ADA, 1992:9, issue 5). Indeed only 3590 villas were developed in these submunicipalities. ${ }^{16}$ This figure amounts only to $6 \%$ (5975/60368) of the remaining potential carrying capacity of these submunicipalities.

In 1986-87, the inner submunicipalities were the only ones in the city which have almost all services (water, electricity, sewage, telephone, roads... etc.), but by $1990-91$ and as introduced earlier, less than $25 \%$ of the new housing development went to these submunicipalities while more than $75 \%$ went to outer submunicipalities, e.g. Oraija, Shamal, Raodah, and Naseem (Ibid: 9). This indicates a clear leapfrogging behaviour on the part of the new housing development. This leapfrogging might have not happened at the rate it did if auto accessibility were not so high in the city. The ring road and its radial provided the medium (a necessary but not sufficient cause) that made this accessibility higher than ever witnessed in the past. This may also help to explain, besides other factors, why $70 \%$ of REDF loans, during the same period, went to lots located in the outer submunicipalities.

\footnotetext{
16 The 3590 figure is the difference between the number of villas in 1990-91 and 1986-87 for the five inner submunicipalities.
} 


\subsubsection{Vacant Lands \& Freeway Segment Length}

The correlation matrix (Appendix D) shows that the length of a freeway and the amount of vacant land in the same submunicipality are highly correlated. The correlation coefficient between vacant land and freeway length is about 0.75 for both 1986-87 and 1990-91. Table 6.5 shows the values of the variable LENGTH for each submunicipality.

Table 6.5: The LENGTH Variable

\begin{tabular}{|l|r|}
\hline FREQUENCY & \multicolumn{2}{|l|}{ LENGTH } \\
& $(\mathrm{Km})$ \\
\hline DEERAH & 10.5 \\
\hline OLAIYA & 23.75 \\
\hline MALAZ & 10.75 \\
\hline BATHA & 8.5 \\
\hline MAATHAR & 15 \\
\hline ASSFARAT & 7.5 \\
\hline ORAIJA & 20 \\
\hline SHAMAL & 82 \\
\hline RAODAH & 37.6 \\
\hline NASEEM & 18.8 \\
\hline ASSINAIEYAH & 52 \\
\hline JANOOB & 19.25 \\
\hline MANFOHAH & 15.75 \\
\hline ITAIGAH & 22.75 \\
\hline IRGAH & 5 \\
\hline DERIYAH & 6.25 \\
\hline
\end{tabular}


A regression model was performed to test the relationship. Taking vacant land as the dependent variable and length as the independent variable, the equation has the form:

$$
\begin{array}{ll}
\text { VCDVLPE }=12,370,500+1,565,316(\text { LENGTH }) & \mathrm{R} 2=0.57 \\
\text { VCDVLPE }=0.758(\text { LENGTH }) & \mathrm{R} 2=0.57
\end{array}
$$

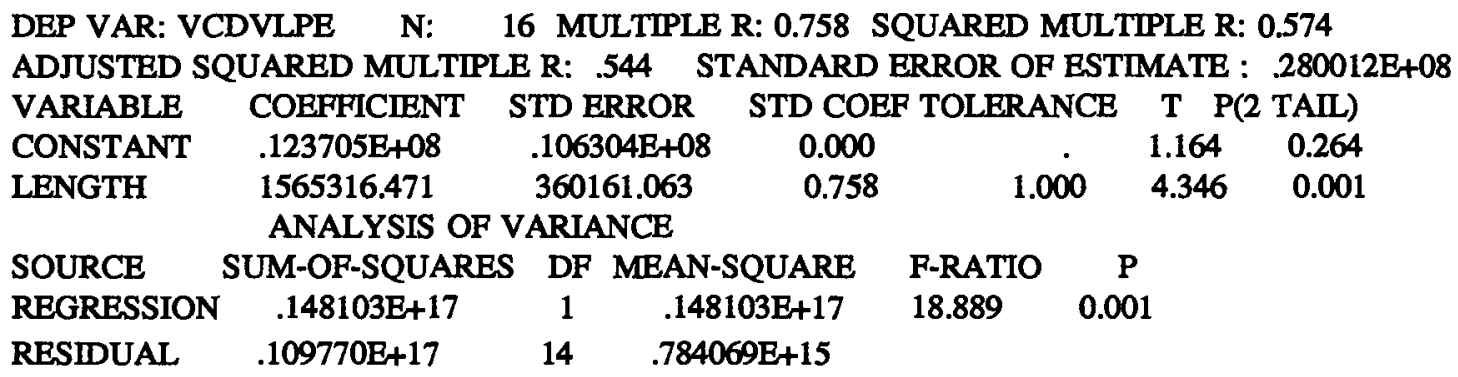

Equation (6.1) is the normal regression equation while equation (6.2) represents the standardized regression equation. The t-test for the constant of equation (6.1) is not significant from zero and therefore this constant is better ignored. The overall regression equation is acceptable with only a probability of 1 in 1000 that it is not significant. With an $R^{2}$ of about 0.60 , it is possible to say that about $60 \%$ of the changes in vacant land may be explained by the length of freeways in the 16 submunicipalities. Figure 6.3 shows a fitted regression line relating vacant urban lands with freeway length (in kilometers) in each submunicipalities. 
Figure 6.3: Vacant Urban Lands As A Function Of The LENGTH Variable

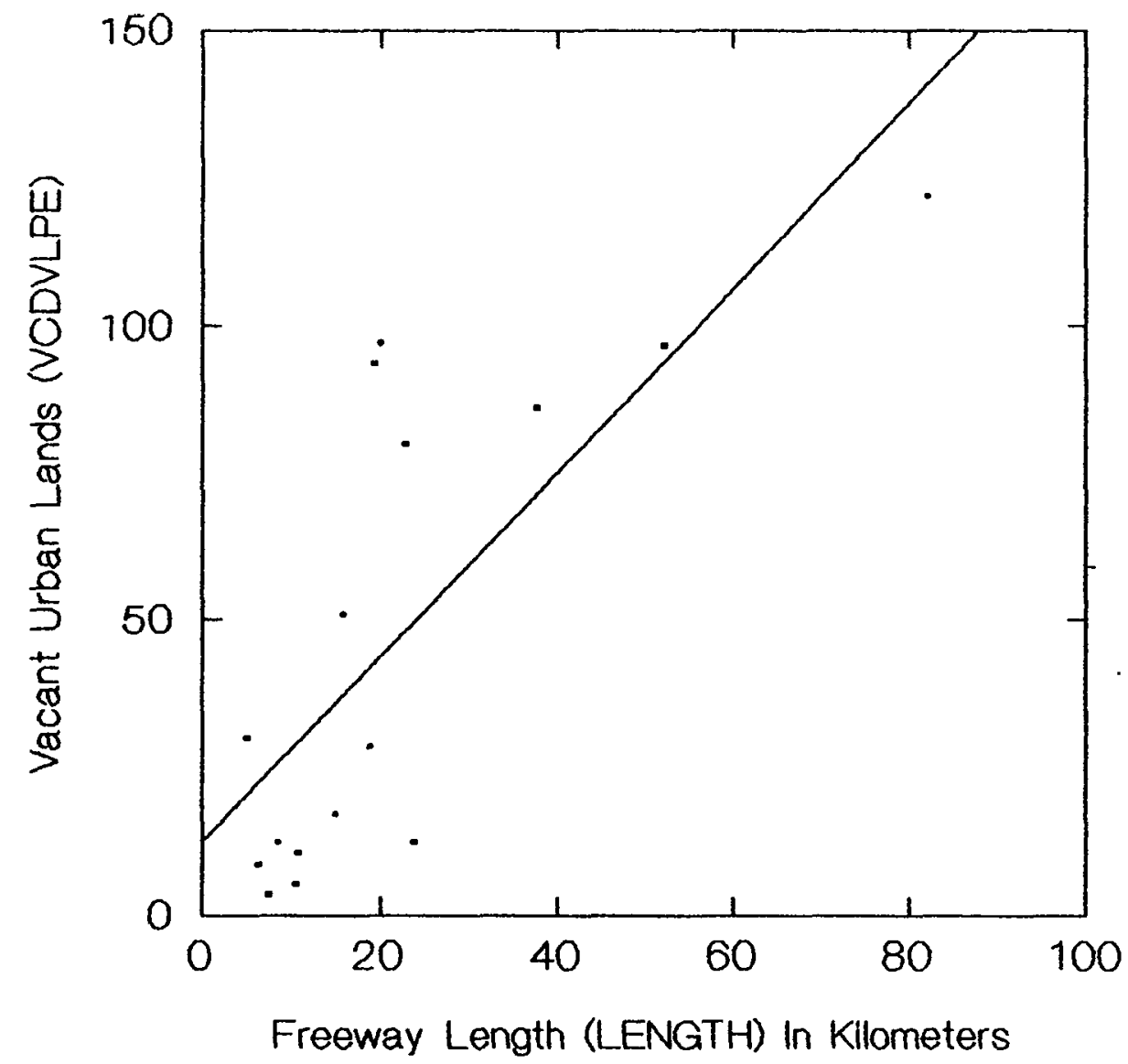

The logic behind the above relationship is unique to Riyadh. When there are more freeway kilometres in an area, such an area becomes more accessible, and thereby more susceptible for the speculative land development process (please see Chapter $V$, footnote \#10 for more discussions on such a process). This process, in which lands are held for sale at a later date, is one of the factors which causes scattered development (Archer, 1972). 
Figure 6.4: Freeway Impact On Urban Development

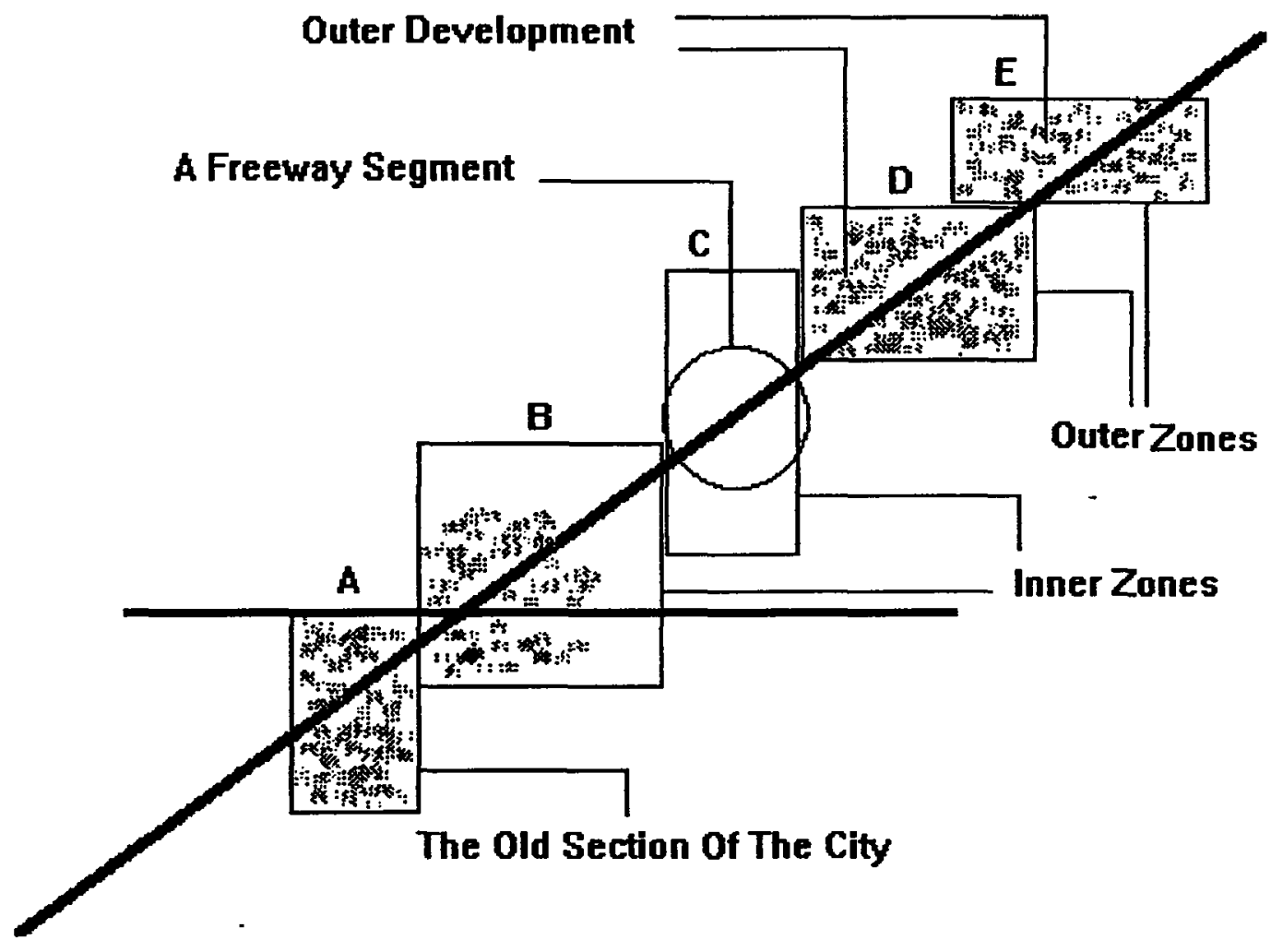

Zonal Boundaries

The above schematic diagram (Figure 6.4) shows how a freeway impacts urban development in outer areas and thereby influences the distribution and amounts of vacant lands in inner areas. For example, when a freeway is developed, it provides accessibility to areas located further out (zones D and E). When these areas start developing, the areas located between the old city and the new development (zones B \& C) become inner areas. The vacant lands in these areas (in addition to other city's vacant lands, prior to the freeway development) constitute the new total 
of vacant lands. As the diagram reveals, outer development is dependent on a freeway which passes through inner areas. Without the circled freeway segment (in zone C), for instant, outer development (in zone D and E) would have not occurred, simply because there will be no access to them. This case is true in auto dependent cities. The fact that development occurred at an outer area means it could have occurred at an inner area. Because the aforementioned segment of the freeway made development possible at an outer area, it contributed to the non-development of an inner area (i.e zone C) and therefore to the emergence of new vacant lands. Thus, holding every thing constant, the increase in this segment's length results in an increase in the amount of vacant lands.

When improvements in transport and other communication networks increase, the rate of suburbanization is expected to increase too ( e.g., the U.S. (Chinitz, 1991: 953)); the same improvements might be seen as a motivator for the phenomenon of leapfrogging in Riyadh. The fact that the correlation between vacant land and the number of units did not significantly change between 1986-87 $(r=-0.15)$ and 1990-91 $(r=-0.25)$ suggests that leapfrogging continues along with the noticeable improvements in transport and other communications networks (e.g., completion of most parts of the ring road and radial roads in that period). It is logical to assume that these correlations should change as over 44625 new dwelling units entered the market, but the proliferation of vacant lands seems to have kept pace with such changes. 


\subsubsection{Vacant Lands \& Distance From City Center And Approved Loans}

Distance from city center (DIST) and the number of approved personal construction loans (APPLOANS) come second to LENGTH (freeway length in kilometres) in terms of logical and statistical explanation of the distribution of VCDVLPE (developable vacant urban lands). It is logical to see the amount of urban voids increasing as distance from city center increases. Based on a regression model, about $25 \%$ of the change in vacant lands can be explained by their distance (DIST) from the city center (please see Appendix E). However, the low value of the figure (25\%) suggests that the distribution of vacant lands is not that logical in the city from a DIST vantage point. When approved loans (APPLOANS) is regressed against vacant lands the outcome is statistically significant. About $50 \%$ of the change in vacant land distribution can be explained by the number of approved loans (please see Appendix E). It is understandable to see people select areas where land supply is abundant to apply for home construction loans. Another dimension of the relationship between vacant lands and approved loans is market oriented. As more people apply for loans in a undeveloped area, a signal is sent to land owners and speculators. ${ }^{17}$ The signal is that the area is developing and demand will support higher land prices. For some land owners, the best way to get the most from their lands is to keep them vacant for a later date, until the whole area develops, then sell them.

\footnotetext{
17 Undeveloped areas are located in outer submunicipalities; these areas are large in size and it takes a substantial number of people to develop them. If these areas could accommodate $\mathbf{X}$ number of dwelling units and $10 \%$ of this $\mathrm{X}$ are put for development (i.e via housing loans), then the areas at which the development occur will need services. This will increase the land value of the undeveloped portions and thus could keep some lands vacant for a longer period as an investment strategy on the part of some land owners. However, it is relevant to note that the aforementioned figure of $0.10 \mathrm{X}$ might constitute a large share of the new developments at the city level. Therefore, it is possible that when more people apply for loans in undeveloped areas, new vacant lands emerge in these areas adding to the total vacant serviceable lands in the city.
} 
Table 6.6: Distance From City Center \& Approved Loans

\begin{tabular}{||l|r|r||}
\hline FREQUENCY & DIST & APPLOANS \\
\hline DEERAH & 1 & 49 \\
\hline OLAIYA & 11.7 & 191 \\
\hline MALAZ & 9 & 317 \\
\hline BATHA & 7.7 & 51 \\
\hline MAATHAR & 8.9 & 163 \\
\hline ASSFARAT & 11.4 & NA \\
\hline ORAIJA & 14.8 & 3282 \\
\hline SHAMAL & 16.8 & 2773 \\
\hline RAODAH & 22.3 & 2879 \\
\hline NASEEM & 18 & 1504 \\
\hline ASSINAIEYAH & 18.8 & 225 \\
\hline JANOOB & 15.7 & 583 \\
\hline MANFOHAH & 9 & 1251 \\
\hline ITAIGAH & 17 & 1380 \\
\hline IRGAH & 15.7 & 242 \\
\hline DERIYAH & 22.8 & 32 \\
\hline
\end{tabular}

When the three variables LENGTH, APPLOANS, and DIST are used together as independent variables and VCDVLPE as the dependent variable, the regression equation becomes: 
VCDVLPE $=-2730239+973600$ LENGTH +1154794 DIST $^{18}+14165$

APPLOANS ; $\quad \mathrm{R}^{2}=0.722 ;$ and F-ratio $=9.511$

If DIST and APPLOANS are controlled, then the equation suggests that increasing LENGTH by one kilometers will result in an increase in vacant land by 973600 square meters or roughly one square kilometers. The purpose of performing this equation is just to show that LENGTH is a good explaining variable of the vacant land even when controlling for other variables. However, subsequent analyses will be based on equation (6.1).

\subsubsection{Vacant Lands \& Areas Reserved For Manufacturing And Service Uses}

There is relatively noticeable relationship between vacant lands and areas reserved for manufacturing use. In submunicipalities with high designated manufacturing land use such as Sinaieya and Janoob, vacant lands score high. Second only to Shamal and Oraija, those two municipalities have the highest share of vacant lands in the city. Manufacturing as a land use element associated with urban voids may lead to a simple conclusion. Because the city is still in the developing stages of manufacturing, most of its lands assigned for such use is vacant. In 1986-87, only about one-third of the above two municipalities was developed. The correlation coefficient between vacant land and areas reserved for manufacturing is 0.49 .

Another variable which has similar correlation with vacant land is the areas assigned for service uses. The relationship is probably a by-product of the correlation of manufacturing lands with

\footnotetext{
18 The coefficient of DIST is higher than the coefficients of the other two variables (LENGTH \& APPLOANS). However, DIST has the lowest $R^{2}$ when regressed alone against VCDVLPE, therefore, DIST is weakest of the above variables in terms of explaining the change in VCDVLPE. Appendix E shows the values of the $\mathrm{R}^{2}$ 's for both DIST and APPLOANS when they are regressed against VCDVLPE in a univariate form.
} 
vacant lands. Areas assigned for services were found in large amounts in submunicipalities with high manufacturing lands. Indeed, the highest figure for service land areas is in the submunicipality of Sinaieya, a submunicipality primarily zoned for industrial and manufacturing purposes. The reason why service lands are more related to the manufacturing lands could be related to items included under the definition of services. Items such as warehouses and auto repairs and parts use the largest portion assigned for service uses yet they are more on the side of manufacturing and industrial activities than in the service activities.

\subsubsection{Vacant Lands \& Dwelling Units And Population Variables}

When dwelling units are broken by type, different types correlate differently with vacant lands. For example, the number of villas (normally a villa is a two storey unit occupied by a nuclear family) is found to positively correlate with vacant lands $(r=+0.27)$. On the other hand, the number of apartments relate negatively with such voids $(r=-0.45)$. In addition to different market factors, there is a cultural explanation for the above phenomenon. Usually, villas are owner-occupied. Some of these owners strive to own other lands adjacent to their property so that they can hand them to their children when they become adults (Miller-Ibold, 1990-1: 13). The social ties in Arabia are strong enough to keep certain lands undeveloped until one of the children grows up to utilize it. Another cultural point is that some property owners prefer to keep lots next to them vacant to enjoy more of the surrounding fresh air and maintain family privacy as much as possible. In the case of apartments, most of the users are not owners, as apartment ownership is not yet a popular idea ${ }^{19}$. Therefore, apartment users have almost no

\footnotetext{
19 The idea of condominiums is not popular in Riyadh. It is rare to find some one who owns an apartment in a building.
} 
stake in the properties around them in the way villa owners do. An additional factor is that such apartments are primarily located in the older parts of the city, which contain less amounts of vacant lands. Submunicipalities of Deerah and Manfohah have the largest number of apartments, 36747 and 22633 respectively. These two submunicipalities are among the oldest in the city as they contain large numbers of units in disrepair. The number of units in disrepair (DISRPRE) represents a good indicator of the age of an area. Figure 6.5 shows the number of buildings in disrepair in each submunicipalities. Deerah has the largest numbers of units in disrepair. Batha comes second and Manfohah comes third. These submunicipalities represent the old section of the city. 
Figure 6.5: Number Of Buildings In Disrepair

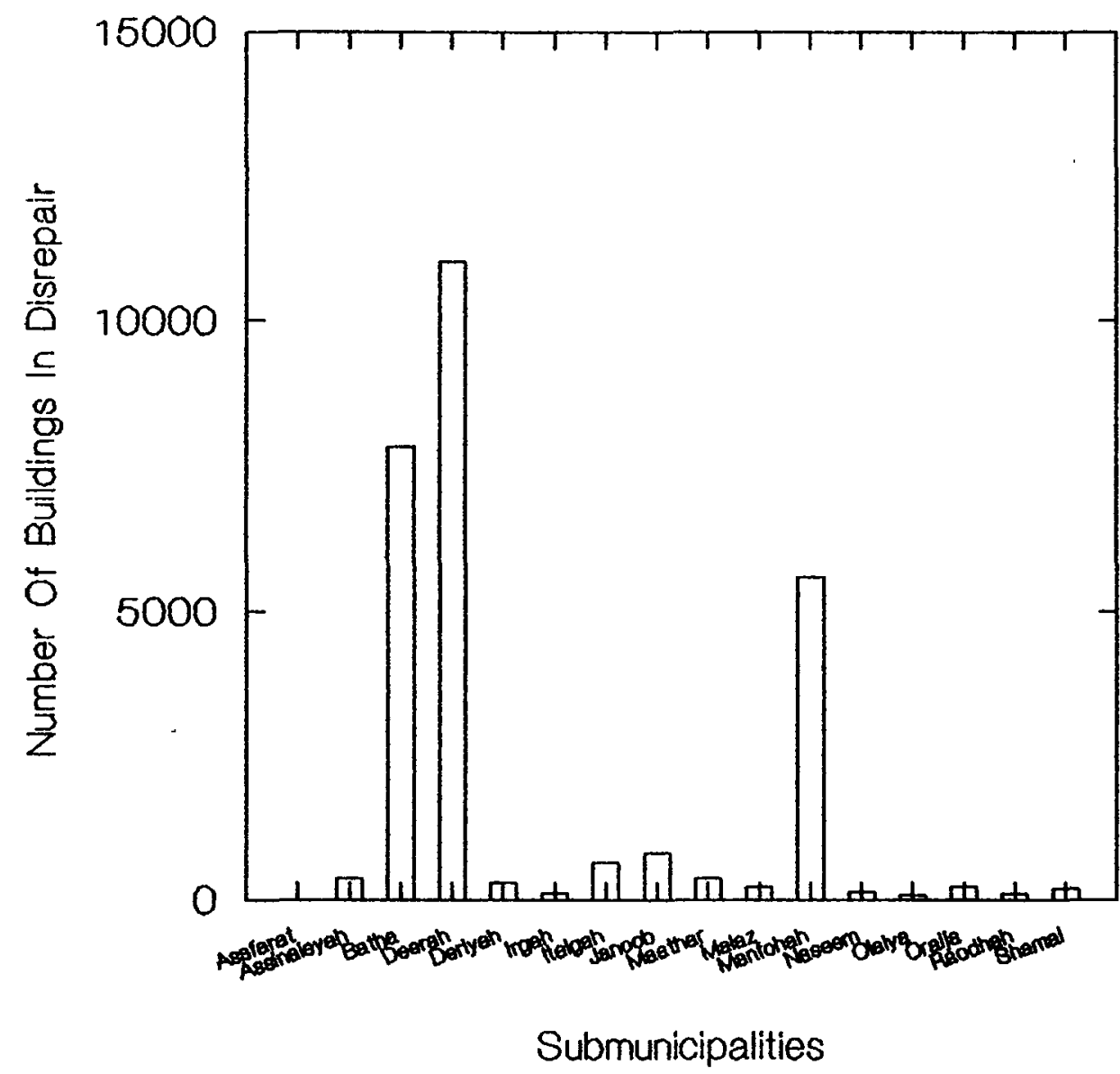

In addition to the number of apartments, there are other variables which are negatively related to vacant lands. The number of persons per hectare (PHECTAR) has an $r=-0.59$ which is logically understandable. This density per hectare suggests that highly urbanized areas have less urban voids than less urbanized areas. The absolute number of people (POP) is also negatively related to vacant lands. However, with an $r=-0.14$, the correlation is not as high as expected. 
Some submunicipalities are larger in areas containing a larger share of urban voids. At the same time they are inhabited by a larger number of people. For example, Oraija area has the second largest share of vacant lands and third largest share of population.

The total number of dwelling units (DWLGUNTS) and the number of occupied units (OCCUNTS) share similar negative relationships with urban voids, $r=-0.25$ and $r=-0.23$ respectively. These relationships have to be negative so the city can still operate as an urban area. Dwelling units gross and net densities (DWLGHA \& DWLNHA) show a higher negative relation with urban voids, $r=-0.59$ and $r=-0.43$ respectively.

\subsubsection{The Degree Of Urbanization In Each Submunicipality}

The above shows that dwelling units and population variables (DWLGUNTS, OCCUNTS, APARTMEN, PHECTAR, DWLGHA, POP, DWLNHA) share an underlying thread. When they are factored together to represent only one factor, such a factor becomes a good indicator of the degree of urbanization in a submunicipality. This factor will be called the urbanization variable (URBAN). ${ }^{20}$ A submunicipality with high score on urbanization suggests that it is highly developed and vice versa.

20 Factor analysis is used here to extract the common factor among logically and statistically related variables. It is a process of reduction, in which several variables (7 in this case) are reduced to one factor. SYSTAT is used here to extract the factor. The use of the computer program SYSTAT is limited to uncover the factor loadings on each variable and then provide the factor scores for each case (submunicipality). Almost identical scores can be obtained from the average value of the standardized variables for each case. For example, if we take these seven variables and standardize them, then average them, the outcomes will be very similar to those of the factor scores. The researcher also acknowledges that the correlation among the seven factored variables are relatively high. However, the logic that bonds these variables is strong enough to assure unbiased factoring. In addition, the use of factor analysis here is not directed for hypothesis testing, a situation which allows the use of the technique with less constraints. 
Figure 6.6: The Degree Of Urbanization

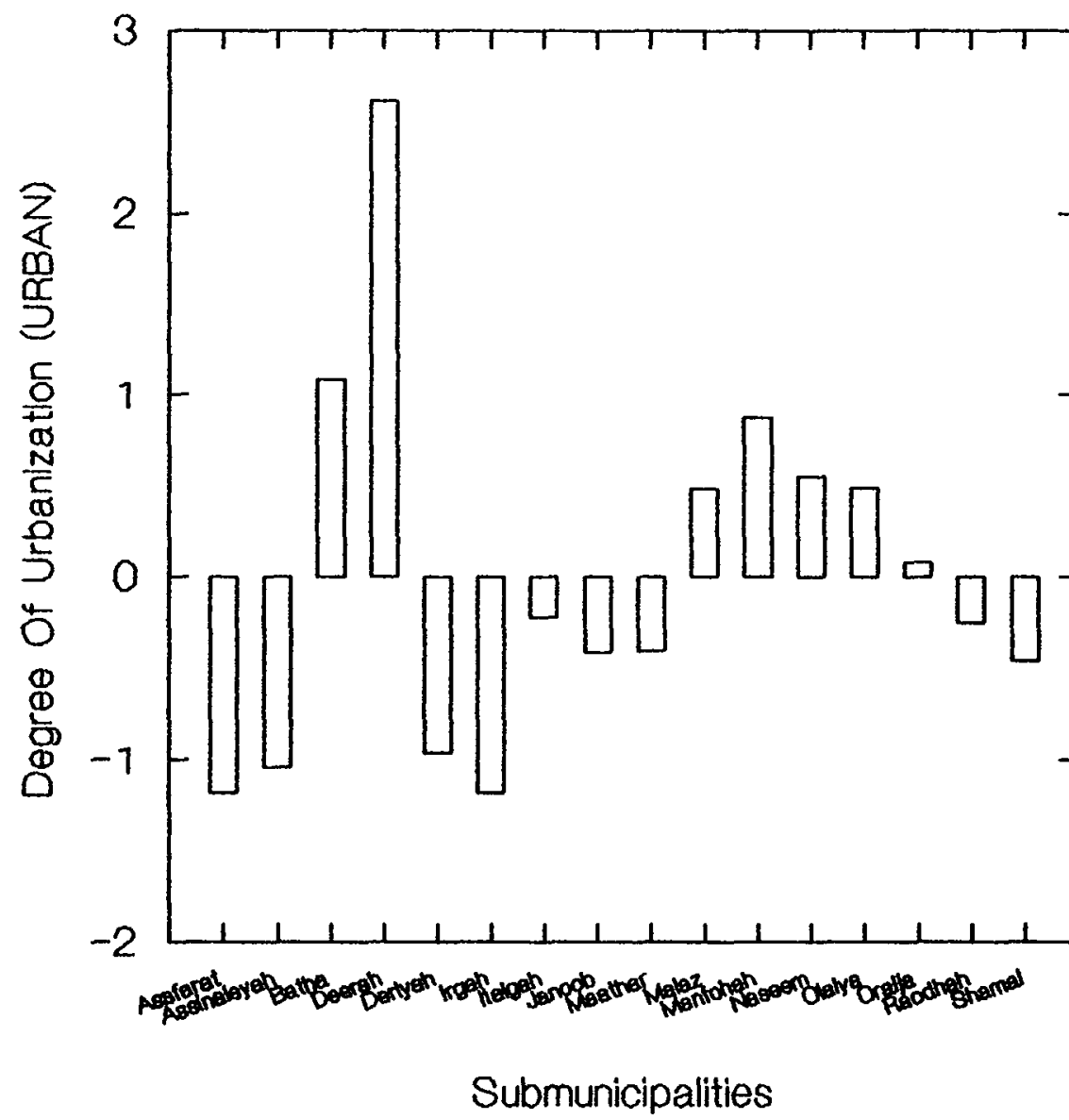

Figure 6.6 shows how submunicipalities score on the variable URBAN. Submunicipalities with higher values on URBAN represent older and more developed communities. URBAN is very representative of the existing conditions, in terms of urbanization, in contemporary Riyadh.

The variable URBAN displays a positive relationship with the vacancy rates (VACRTE) in the different submunicipalities, $r=+0.60$. This relationship suggests that vacant units are more available in more developed areas. There could be several interpretations for such a case. The 
vacancy rate among units in the form of apartments is higher than that in the form of villas (ADA, 1992: 29); and apartments are mainly located in the dense portions of the city. In addition, when an area gets developed and becomes dense, some families move toward semideveloped areas to enjoy more privacy and fresher air, leaving their previous units vacant until renters show up. ${ }^{21}$ Availability of more rental units in the more urbanized areas may also reflect on land prices in such areas. Indeed, the highest residential land prices in the city are not located in the most urbanized sections, where most vacant units exist. Communities which are located in or bordering the less developed Shamal submunicipality witness the highest land prices in the city. Land prices in many of these communities have increased five fold between 1987 and 1993 (Al Majallah, 1993: 58). For example, the Nakheel community land prices grew from SR200 (\$67) to SR1000 (\$333) between 1982-1993 (Figure 6.7 shows the location of the Nakheel community). ${ }^{22}$ Although, experiencing this increase in land prices (which suggests that the area is desired for residential purposes), Shamal submunicipality is primarily undeveloped with its URBAN variable having a value of -0.46 (the highest value for URBAN is in Deerah $(+2.61)$ and the lowest value is in both Irgah and Assafarat (-1.18)); table 6.5 shows the values of URBAN for each submunicipality.

\footnotetext{
21 In the past, the concept of the interior courtyard, a very distinct characteristic of the traditional ArabicIslamic city, provided private open space for the user. The disappearance of this concept in contemporary Arabic cities, like Riyadh, might have made the existence of vacant urban lands of some use to residents.
}

22 Land prices throughout this research is by SR (Saudi Riyal) per square meter. 
Table 6.7: The URBAN Variable

\begin{tabular}{||l|r|}
\hline FREQUENCY & URBAN \\
\hline DEERAH & 2.61 \\
\hline OLAIYA & 0.49 \\
\hline MALAZ & 0.48 \\
\hline BATHA & 1.08 \\
\hline MAATHAR & -0.41 \\
\hline ASSFARAT & -1.18 \\
\hline ORAIJA & 0.08 \\
\hline SHAMAL & -0.46 \\
\hline RAODAH & -0.25 \\
\hline NASEEM & 0.54 \\
\hline ASSINAIEYAH & -1.05 \\
\hline JANOOB & -0.42 \\
\hline MANFOHAH & 0.87 \\
\hline ITAIGAH & -0.23 \\
\hline IRGAH & -1.18 \\
\hline DERIYAH & -0.97 \\
\hline \hline
\end{tabular}

The variable URBAN which measures the intensity of urbanization is found to decrease as the distance from the city center (DIST) increase $(r=-0.79)$. This case is not unique for Riyadh, rather it is internationally observable. In most cities around the world the degree of urbanization increases toward the city center and decreases vice versa. 


\subsubsection{Vacant Lands \& Degree Of Urbanization}

A negative relationship was found between URBAN and the amount of vacant land in our 16 cases, although such a relationship was not very strong. For example, the correlation coefficient between URBAN and vacant lands is $r=-0.43$, a figure which mounts only to one half the correlation between URBAN and DIST $(r=-0.79)$. The fact that the degree of urbanization increases as vacant land areas decreases and the fact that it decreases as distant from the city center increases suggests that the city growth is still within the natural direction. However, the fact that the degree of urbanization and vacant land distribution are modestly related $(r=-0.43)$ may suggest some abnormality, especially for this type of relationship. The ideal relationship is that of " $\mathrm{r}=-1.0$ " which means fully developed areas have no vacant land and vice versa. Even when regression is run, the degree of urbanization of an area does not seem to provide any explanation of vacant land distribution. 


\section{Figure 6.7: The Location Of Nakheel Community}

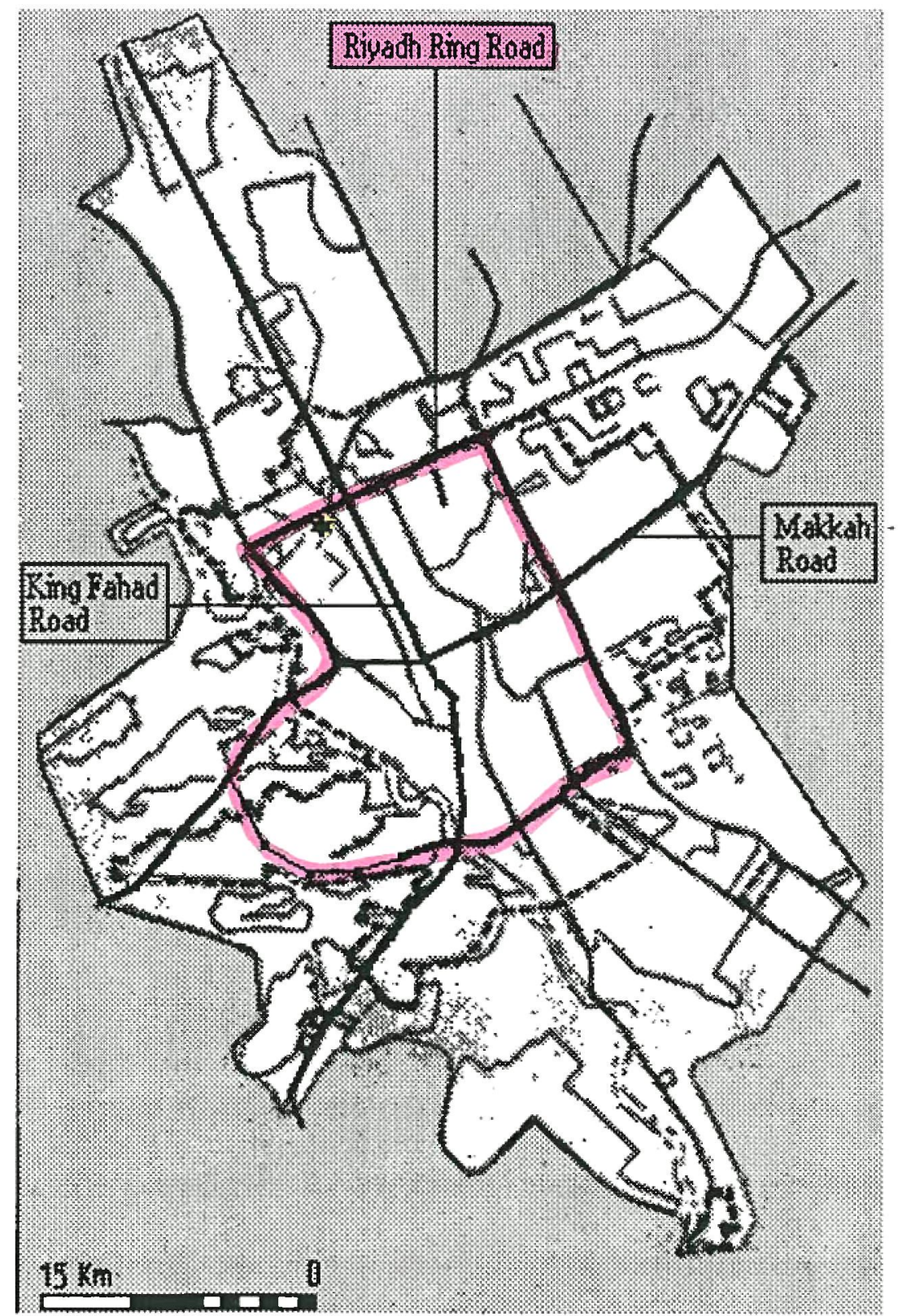

The star $\left(^{*}\right)$ in the map shows the location of the Nakheel community. The community is located in Shamal submunicipality which contains a good amount of urban voids. The URBAN value for Shamal has a minus sign, yet land prices in such an area is quite high. The Nakheel community enjoys a prime location which is highly accessible; such a location is served by both the Riyadh Ring Road and King Fahad Road. 


\subsection{Traffic Analysis}

Traffic data is obtained from the ADA which installed traffic counting devices (stations) at several parts of the city. Six of these stations are located on the ring road and the two radials (Makkah Road and King Fahad Road). As a result, traffic counts at sections of these freeways are recorded (please see Figure 6.8).

These traffic counts were recorded in November of 1990. In light of the two ADA surveys, such counts are within the time period of the second survey. Counts were recorded for a full week (Sunday to Sunday) for the 24-hour period. The choice for the location of such stations may reflect the increasing concerns of local planners over congested segments of the existing road network. The data shows King Fahad Road and Makkah Road to be the most congested. The former has its highest congested segments located south of Makkah Road. The volume capacity ratio $(\mathrm{V} / \mathrm{C})$ at certain hours of the day was high. For example, it was recorded that the lowest morning traffic volume on a working day (Saturday through Wednesday) was found to be 5663 vehicles (all traffic figures, i.e 5663, are per hour per three lanes) between 7:15 and 8:15 (North Bound). Using 2000 vehicle/hour as the maximum capacity of a freeway lane, the figures translate to a volume capacity ratio $(\mathrm{V} / \mathrm{C})$ of $0.94((5663 / 3) \div 2000))$. This $\mathrm{V} / \mathrm{C}$ figure suggests that the freeway operates at a level of service $D$ in that particular time (table 6.8). The least morning traffic figure on Makkah Road (East Bound) on a normal working day was found to be 5156 vehicles which leads to $\mathrm{V} / \mathrm{C}=0.85((5156 / 3) \div 2000))$, a figure which also belongs to the D level of service. 
Table 6.8: Level Of Service For Basic Freeway Sections

\begin{tabular}{|c|c|c|c|c|c|c|c|c|c|c|}
\hline \multirow[b]{2}{*}{ LOS } & \multirow[b]{2}{*}{$\begin{array}{c}\text { Density } \\
(\mathrm{pc} / \mathrm{mi} / \mathrm{ln})\end{array}$} & \multicolumn{3}{|c|}{$\begin{array}{c}70 \mathrm{mph} \\
\text { Design speed }\end{array}$} & \multicolumn{3}{|c|}{$\begin{array}{c}60 \mathrm{mph} \\
\text { Design speed }\end{array}$} & \multicolumn{3}{|c|}{$\begin{array}{c}50 \mathrm{mph} \\
\text { Design specel }\end{array}$} \\
\hline & & $\begin{array}{l}\text { Speed }^{A} \\
\text { (mph) }\end{array}$ & $V / c$ & $\begin{array}{c}\mathrm{MSF}^{\mathrm{h}} \\
(\mathrm{pc} / \mathrm{hr} / \mathrm{hn})\end{array}$ & $\begin{array}{l}\text { Speed" } \\
(\mathrm{mph})\end{array}$ & $V / c$ & $\begin{array}{c}\text { MSF' } \\
(p c / h r / / n)\end{array}$ & $\begin{array}{l}\text { Speced" } \\
\text { (mplli) }\end{array}$ & $1 \%$ & $\begin{array}{c}\text { MSI:" } \\
(p / h r / \mathrm{h})\end{array}$ \\
\hline A & $\leq 12$ & $\geq 60$ & 0.35 & 7001 & - & - & - & - & - & - \\
\hline B & $\leq 20$ & $\geq 57$ & 0.54 & 1100 & $\geq 50$ & 0.49 & 1000 & - & - & $\ldots$ \\
\hline C & $\leq 30$ & $\geq 54$ & 0.77 & 1550 & $\geq 47$ & 0.69 & 1400 & $\geq 43$ & 0.67 & 1300 \\
\hline D & $\leq 42$ & $\geq 46$ & 0.93 & 1850 & $\geq 42$ & 0.84 & 1700 & $\geq 40$ & 0.83 & 1600 \\
\hline $\mathrm{E}$ & $\leq 67$ & $\geq 30$ & 1.00 & 20000 & $\geq 30$ & 1.00 & 2000 & $\geq 28$ & 1.00 & 19001 \\
\hline $\mathrm{F}$ & $>67$ & $<30$ & . & 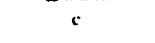 & $<30$ & . & & $<28$ & . & \\
\hline
\end{tabular}

"Average travel speed.

"Maximum service flow rate per lane under ideal conditions rounded to the nearest $50 \mathrm{pc} / \mathrm{hr}$.

'Highly variable, unstable.

Source: TRB, 1985 in Khisty, 1990: 214

It is understandable that segments of both radial roads have the highest share of congestion of the freeway network as both roads literally penetrate the city. However, the fact that these segments approached their capacity in low density and moderately populated areas raises some important points. Among the points of interest for the purpose of this research is the overproportional trips incurred by the trip makers. This type of trip is a result of the horizontally spread urban structure which contains many voids. This also results in an overly stretched peak hour time as the trip lengthens. A stretched peaking time, as Figure 6.9 shows, may be used as an indicator of the behavioral characteristics of the trip maker. Governmental agencies which employ $80 \%$ of Saudi's labour force open at 7:30 and close at 2:30. Private business and department stores, including small groceries and service shops (e.g., tailors) open roughly between 9 a.m. and 11 p.m., interrupted by prayer closing times and official business breaks (e.g., between 2-5 p.m.). Therefore, there is a natural tendency on the part of the residents to distribute their trips over the day since business are open most of the time. 
Figure 6.8 The Locations Of Traffic Counting Devices

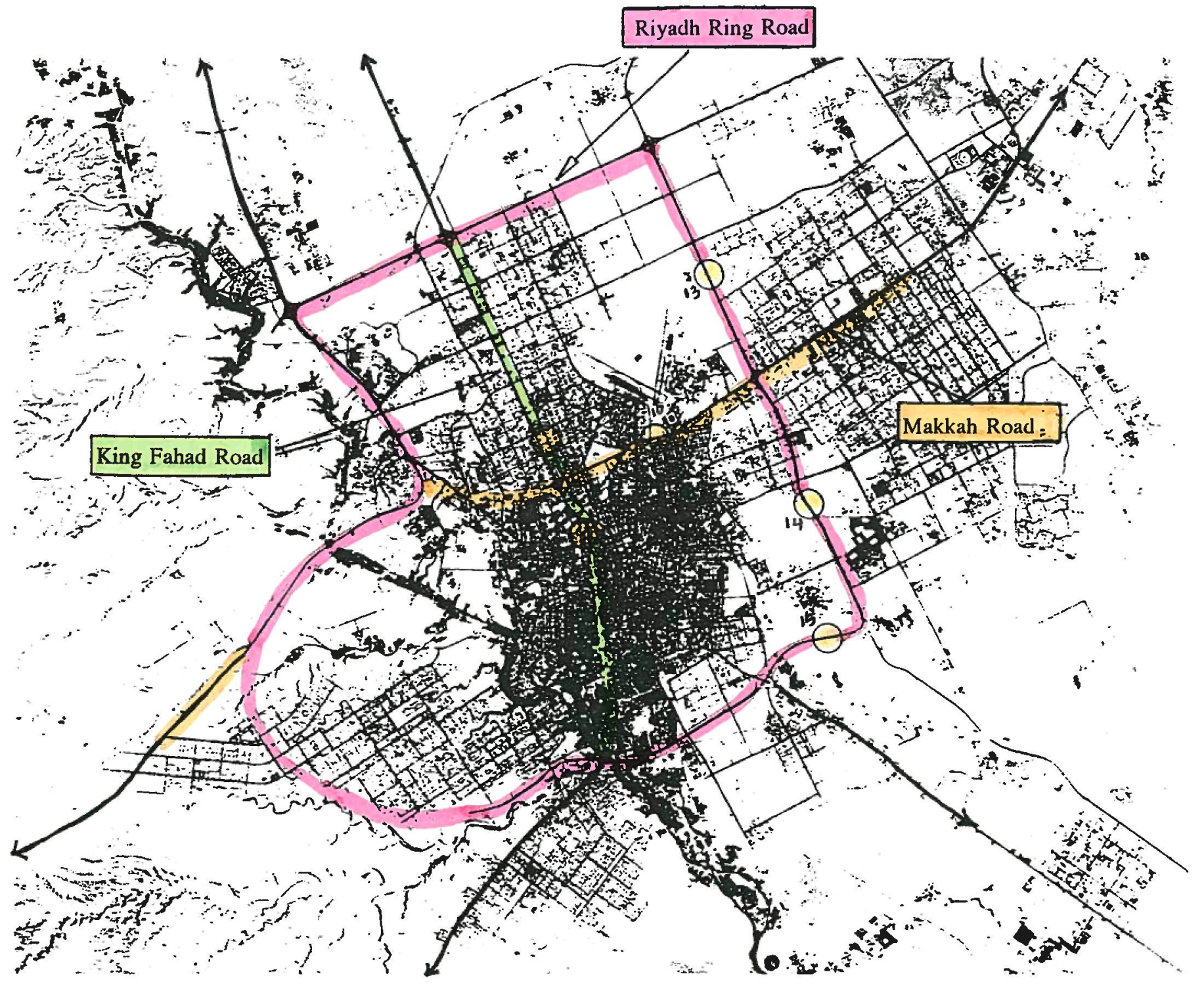

Locations Of The Traffic Counting Devices

Source: The Author, Using ADA Data (1992) 
With respect to the ring road, the highest recorded A.M. peak was found to be 4156 vehicles (North Bound) on the east leg of the road (segment 14) roughly at the middle distance between Makkah Road and the south leg of the road. The above figure gives a V/C of 0.69 which is located at the upper limit of the level of service C. While this figure is not that high, it deserves some attention. This segment of the road is flanked by large tracts of vacant lands with little urban development. Segments 15 and 13 of the road are also flanked by major urban voids. While these urban voids may cause major traffic problems should they get developed, keeping them vacant will lead to more leapfrogging which, in return, may result in a very stretched, difficult to manage city. What is relevant here is not so much the probable future traffic, rather it is the role that these urban voids play in stretching the city and the travel distances of its residents.

As freeway development increases accessibility to otherwise unaccessible areas, large tracts of lands increase in value. Many of these lands will be kept vacant until the right time comes for a sale. While the cumulative vacant lands impact on trip length may be difficult to extract, there is little doubt that they play a role in increasing trip length and eventually reducing the efficiency of the city as a whole. While it is difficult to measure accessibility efficiently (Al-Sahali, AbouElla, 1992:12), it is safe to say that the submunicipalities of Riyadh are highly accessible. All the sixteen submunicipalities covered by this research have access to the freeway network. Accessibility is also enhanced by both the availability of the car and its low operation cost, especially the low gasoline prices. ${ }^{23}$ per liter).

23 About $93 \%$ of Saudi households own cars. Gasoline costs in Riyadh is very low (11 to 12 Canadian cents 
Figure 6.9:

Traffic Distribution

During An Average Day

In Riyadh

The traffic on segments 10 ,

14 , and 24 is typical of most Riyadh arterials. Note that the traffic is stretched over a longer period of the day. The peaking is not as sharp as that of most Western cities.

Source: ADA, 1992.

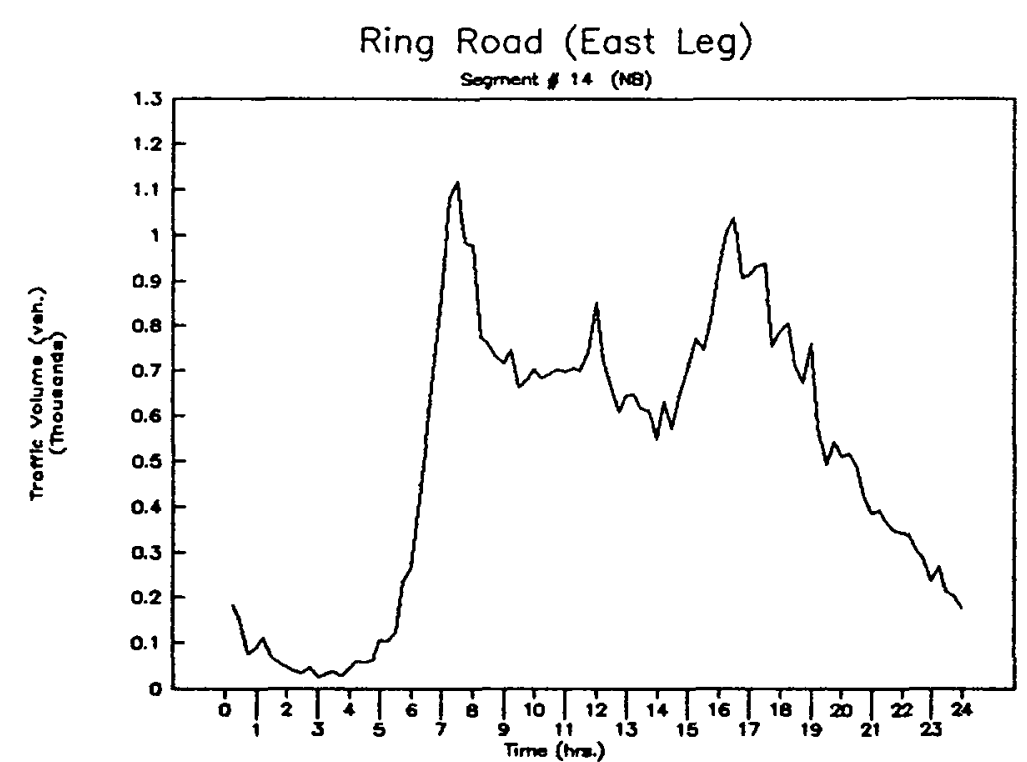

King Fahad Rd. South Makkah Rd.

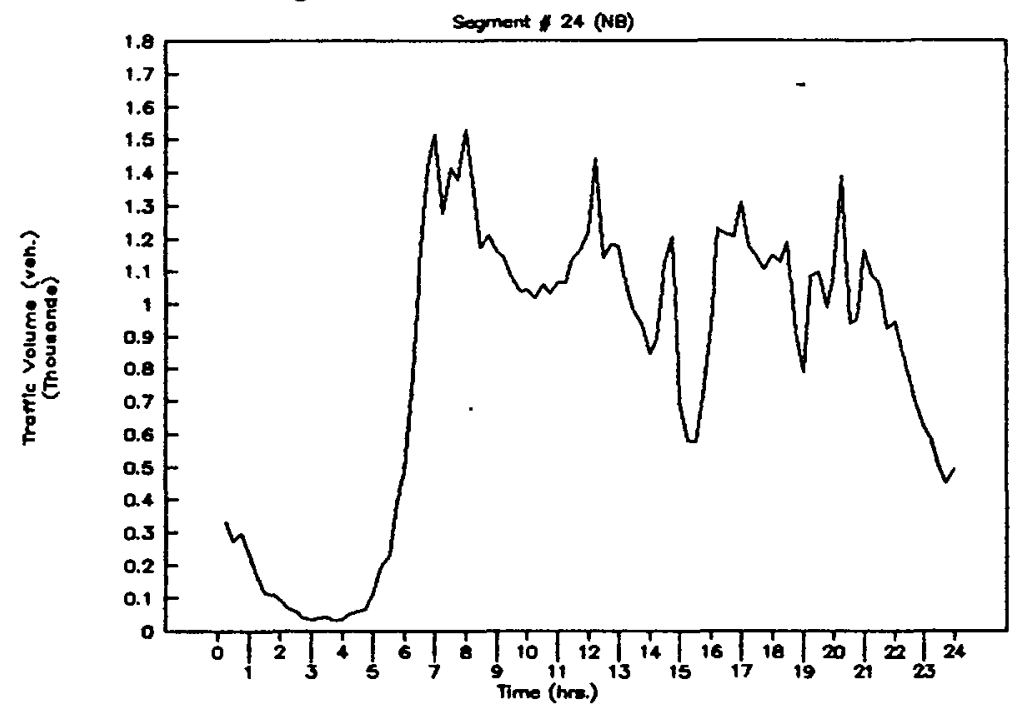

Makkah Road

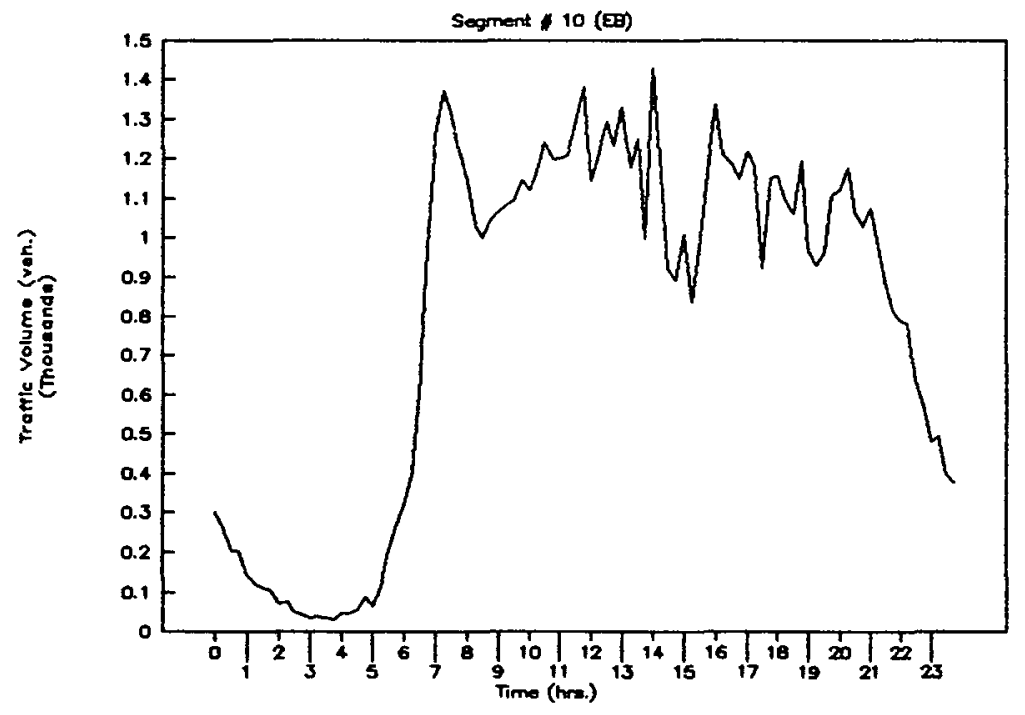

185 


\subsection{Aerial Images' Analysis}

Two unique images of the city of Riyadh (twenty years apart) were obtained. The first image was taken by Land Sat (US satellites) in 1973. At that particular year, Riyadh was just a small town with an area of less than 45 square kilometres and a population of about 600,000 (Daghistani, 1985: 78). At that year, the idea of improving the freeway network and in particular, the ring road became a reality. It was in 1973 that the agency of Municipalities tendered the design and the route of the Riyadh ring road.

Close inspection of the 1973 image (Figure 6.10) reveals several features of 1973 Riyadh. The airport is located at the northern part of the town with only few developments south of it. Virtually no development can be detected north, west or east of the airport. Most of the developments are located well south of the airport and north of the valley. The valley runs diagonally on a northwest-southeast axis. In addition to the airport runways and the valley, the Riyadh-Dammam Road can be seen just to the south of the airport heading northeast. Dammam is the major Saudi port on the Arabian Gulf, therefore its link to Riyadh, the capital, is vital. The airport runways, the valley, and the Riyadh-Dammam Road are the major elements that still exist in Riyadh today.

The topography of the Riyadh area, as the image shows, suggests that developments can extend in any direction except, probably, the areas south of the valley. Most of the areas that are located south of the valley are littered with smaller valleys, canyons, and hills--an environment not conducive to housing development. Ancient Arabians may have preferred level lands, so air and 
vision limitations can be kept to a minimum. Contemporary Arabians may still have the same preference modified by the economic factor. It is certainly easier to develop level land as opposed to a rolling land. As Riyadh developed, growth went towards the level lands of the east and north. The major developments which went south of the valley toward the western rolling terrain was the limited income housing subdivision project (the mayoralty supplied limited income people with thousands of plots to construct their own homes; as in other portions of the city, the Real Estate Development Fund was and still is the major financier).

The second image of Riyadh was taken in 1992 by LandSat (Figure 6.11). The image shows the tremendous change in the urban form of Riyadh. Keeping in mind the airport runways, the valley, and the route of Dammam Road, it is possible to make reasonable comparisons. As the second image shows, most of the growth is extended toward the east and the north. 
Figure 6.10: A Satellite Image Of Riyadh (1973)

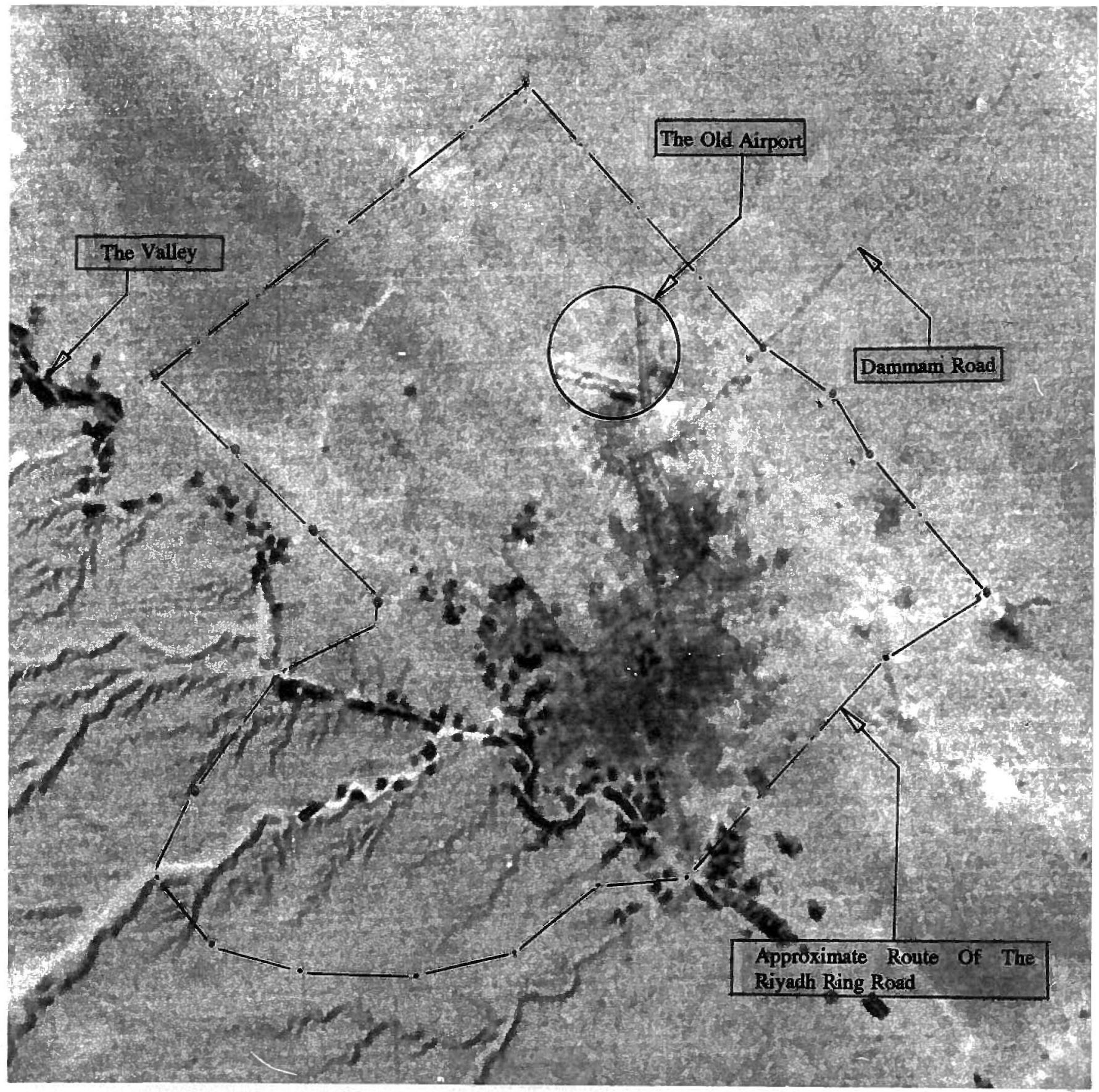

Source: LandSat, 1973. 
Figure 6.11: A Satellite Image Of Riyadh (1992)

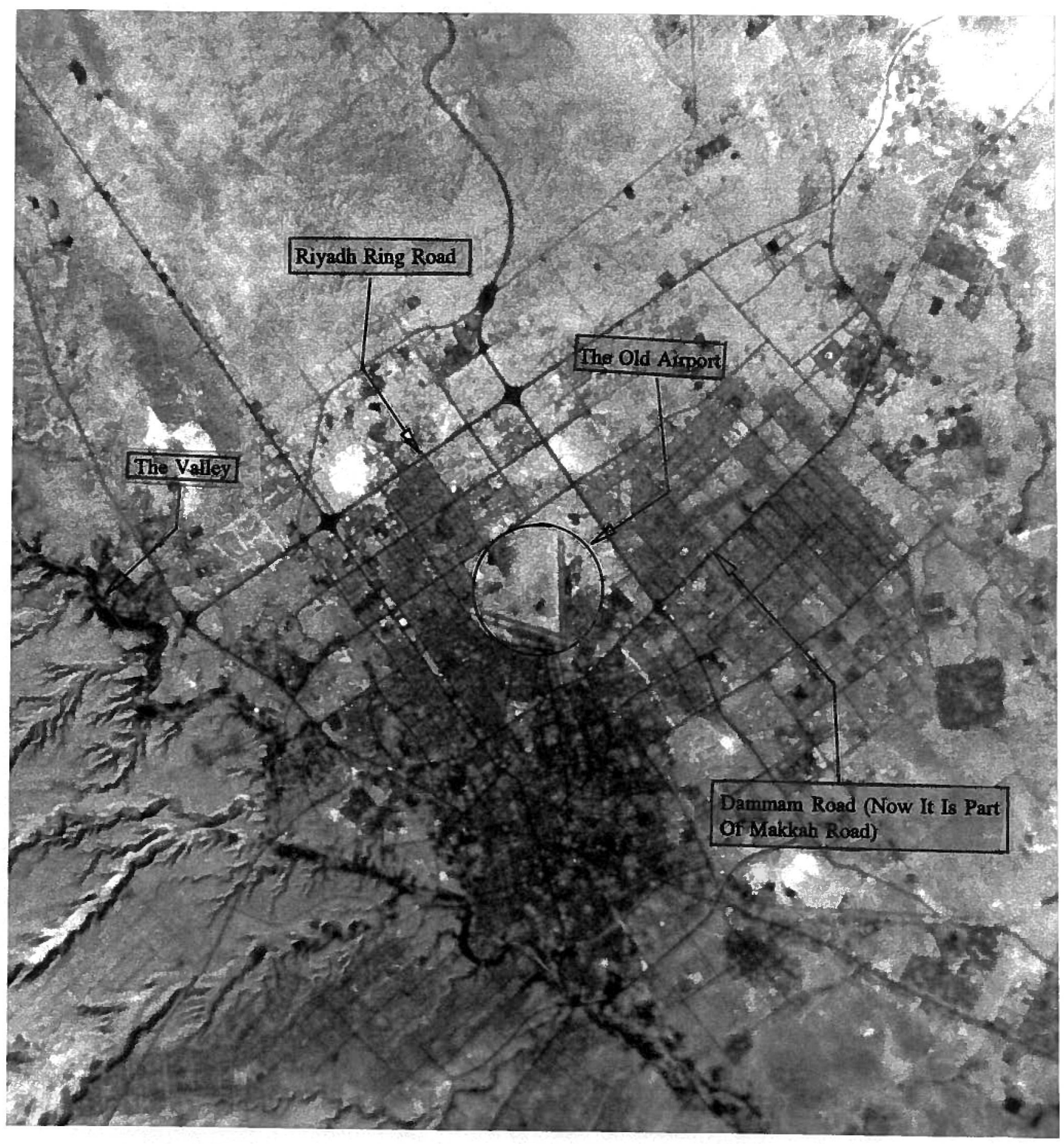

Source: LandSat, 1992 
The large chunk of urban development southwest of the valley (at the bottom of the picture) represents the limited income housing subdivision project. Most of the urban development induced by the market system chose the level lands of the east and north. Urban development to the east flanked Dammam Road (now known as Makkah Road). Almost all such development is within Raodah and Naseem submunicipalities. The gravity between Riyadh and Dammam along Makkah Road might also be a factor in the development of the east. The increased traffic between these two population centers required more services along Makkah Road; this process gradually encouraged development along the road especially at areas adjacent to the old city.

The level lands of the north also attracted development but at less intensity when compared to that of the east. Submunicipalities of Shamal and Olaiya represent the major chunk of the plain land of the north. As of today, the most expensive lands are within these two areas. Around 400 kilometers to the north of Riyadh lies another large urban center, Qassim. The gravity between Riyadh and Qassim has increased in intensity lately with the construction of Riyadh-Qassim freeway (when the freeway enters the city, it is called King Fahad Road).

\subsection{The Causal Model}

While establishing a total causal relationship ${ }^{24}$ between the ring road and its radials on one hand and urban voids on the other may not be easily attainable, it is possible to establish a causal

\footnotetext{
24 It is very difficult to establish a total causal relationship between any two variables in the urban planning field. A total causal relationship means that changes in variable $X$ is totally responsible for the changes in variable $Y$. Usually, it is possible to prove that changes in variable $X$ is partially responsible for the changes in variable $Y$. This is the case because a total cause is normally a combination of more than one variable. For example, a healthy growth of a tree can be function of several different variables (e.g. watering, soil condition, climate, fertilizing...). These variables together constitute a total cause, but none of them by itself could be described as a total cause.
} 
relationship between these freeways and the magnitude of urban voids. The development of such freeways causes the size of these voids to increase in the city. This is certainly different from saying that the ring road and its radials cause the existence of vacant lands. These lands may have existed any way with or without freeway development. However, their magnitude may not have reached the present size without the development of the freeway system.

Denoting the ring road and its radials as RR and size of urban voids as SV, a causal path can be established:

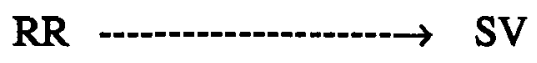

The model shows that the dominant causal path goes from RR to SV. Examining Asher and Jackson conditions for the existence of causal relationships, one observes the following:

. First, there is an association and concomitant variation between RR and SV. Equation (6.1) of the regression analysis supports such association. Increasing freeway length in a submunicipality by one kilometer results in an increase in the amount of vacant lands by 1.5 square kilometer (and when other variables are controlled (equation 3) the increase is 0.97 square kilometers). The point to stress here is that there is a concomitant variation whether using univariate or multiple 
regression (e.g equations 6.1 and 6.3 respectively).

- Second, there is a temporal, plausible consequence between RR and SV. The aerial images provide a valuable visual inspection of the relationship. In 1973 where there were no ring road, the city was compact with no noticeable urban voids. In 1992, after the completion of most of the parts of the freeway network, the image shows a city with a large concentration of urban voids. Again the intention here is not to say that the ring road and its radials caused the existence of these voids, rather they caused the increase in the size (total area) of such voids.

- Third, it is difficult to isolate the impacts of other exogenous variables to assure a perfect causal relationship between RR and SV:

...to demonstrate that the relationship [among any group of variables] is not spurious is always a challenge; one can never be fully complete (Jackson, 1988: 219).

This case is true not only in the above causal model, but also in all research which are not truly experimental. However, the discussed causal relationship can further be supported by the fact that the freeway system guided the direction of growth, thus determining the distribution of vacant lands. As in all studies informed by the before and after analysis, satisfying the external validity requirement is not perfectly attainable. However, as long as the researcher is aware of the common validity threats and the drawbacks of the approach, generalization can be improved. 


\subsection{Conclusion}

The discussion in this chapter has shown the tremendous urban changes experienced by the city during the five year period (1986-91). The population grew by about 700,000 . This growth reduced the vacancy rate in the city, but did not fill in the existing urban voids. The second ADA survey which covered all the area designated by UGL phase II (1995 to 2005), showed a large amount of vacant lands included under the expanded sub-municipal boundaries.

After rigorous analysis, only a few variables seem to explain the distribution and the amount of vacant lands. The most important variable was found to be LENGTH (the length of freeways in each submunicipality). About $60 \%$ of the change in vacant lands can be explained by LENGTH. The outcome is significant from zero with an f-ratio of 18.89 (for more information on the f-ratio, please see Chapter III section 3.5.2). This outcome is confirming of the main hypothesis which relates ring road development to vacant land. The existence of a freeway segment (either a ring road segment or any other freeway segment so long as it represents part of a freeway system that incorporates a ring road) is positively related to distribution and amounts of vacant land. In addition, DIST (distant from city center) and APPLOANS (approved personal construction loans by the REDF) represent the second set of variables in terms of explaining the urban void phenomenon.

Traffic analysis shows that the motorist's travel behaviour is stretched over the day time hours without a very clear peak as in most Western cities. Urban voids contributed to such a stretch by increasing travel distance, thus keeping cars on the freeway networks for longer time periods. 
The aerial images show a unique before and after portrait of the city confirming the role of roads in directing growth. Finally, the causal model suggests the existence of a causal relationship between the ring road and its radials on one hand and the size of urban voids, vacant urban lands, on the other. This finding is crucial to future ring road development. 
Chapter VII

\section{Planning Implications}




\subsection{Introduction}

The purpose of this chapter is to examine the planning implications of the analyses and conclusions discussed earlier. This examination is intended to facilitate the development of more effective and practical, future planning policies. Although a planning model will be presented (as a policy instrument) in this chapter, the discussion will be limited to the introduction of some suggestions which could offer valuable inputs for future policies.

The chapter starts by discussing planning implications on future ring road development. The discussion leads to the introduction of a planning model meant to assist policy makers in choosing the proper timing for ring road development. The model is called the Timing Model. It relates the overall land utilization pattern in a city with the establishment of a link between the timing of ring road development and the Actual Development Ratio, ADR (ADR = (Developed Land / Total land) $* 100$, expressed in \%)

The section to follow discusses planning implications on future planning philosophy in the city. It is then followed by a section which highlights the planning implications based on cultural considerations. The next topic discusses implications related to urban dynamics and urban growth of the city. It starts by drawing implications from the analyses of land use variables, extends to cover demographic implications, and concludes by highlighting growth management implications. In addition, the chapter examines ring road implications on central cities and the consequent redistribution of some commercial activities. 
The final section of this chapter introduces a ring road development process. This process consists of the following steps:

- Definition of the city boundaries;

. Determination of the Desired Development Ratio (DDR);

. Selection of the ring road route; and

- Implementation

This section concludes by highlighting the agencies which could be involved in the proposed process. It attempts to distribute decision making responsibilities among relevant agencies and provides guidelines for decision makers in assigning different responsibilities to different agencies. The intention is not to design an administrative structure for the city, a task beyond the scope of this thesis, but, rather, to provide alternative options to help decision makers and clarify which agency will assume what responsibilities. What matters here is the adoption of the process as proposed and not which agency does what task. However, if the proposed distribution of responsibilities is also adopted, then the chances of success will be greater. 


\subsection{Implications On Future Ring Road Development}

The impact of the Riyadh Ring Road development on the city as whole differs from that in Western cities in one major aspect. It has been associated with the appearance of large amounts of vacant lands, a phenomenon which has not been observed in other studies reviewed in this thesis. For example, The Capital Beltway Study (Connally, 1968) and The Land Use and Urban Development Impacts of Beltways' Study (Blaney-Dyett \& Payne-Maxie, 1980) did not record a large increase of vacant urban lands with the development of ring roads.

Future planning of ring roads should consider the causal relationships between Ring Roads and their Radials (RR) on one hand and the Size of Urban Voids (SV) on the other. The causal model introduced in Chapter VI shows that there exists a causal relationships between RR and SV. Ring road planning must take into account the temporal dimension of development. The temporal dimension can be considered by relating the timing of ring road development to the Actual Development Ratio (ADR). The following section introduces a proposed timing model, which draws from the causal model (discussed in chapter VI), and is designed to account for the importance of timing in ring road development.

\subsubsection{The Timing Model}

The analyses performed in Chapter VI can be used to extract a timing model with the aim of minimizing the spread of vacant urban lands when ring roads are developed. The model should facilitate choosing the proper time for ring road development. It treats timing as an essential element of the development policy to be pursued. The timing element relates ring road 
development to the amount of developed land in the city. ${ }^{1}$ In other words, the magnitude of vacant lands play an important part in formulating the model.

The general form of the model can be represented as follows:

Efficient Land Utilization = Function Of The Selection Of The Proper Timing Of Ring Road Development, assuming all other variables constant. What is meant by timing is the appropriate sequence of ring road development in relation to the sequence of urban growth and pattern. Premature development of a ring road may result in a dispersed pattern of growth that is difficult to control. The selection of good timing can result in maximising the efficiency of urban development and growth.

Timing must be related to the amount of vacant land in the city. The more vacant land, the better it is to wait and allow more time for building on vacant lands before developing a ring road. Determining the exact time for a ring road development is not easy. However, it is possible to estimate such a timing based on the thesis research analyses.

In 1970 , the entire city was well inside the path of the existing ring road (figure 7.1 ). In 1980 (figure 7.2), the only major development outside the existing path of the ring road was in the east along Makkah Road, and some other small isolated developments ${ }^{2}$. In 1990 (figure 7.3), when

To give an example, one may suggest that the ring road can only be developed when the ADR exceeds or equals a certain ratio.

2 Most of these developments are either older towns and villages or developments established for specific purposes (e.g. industrial, military, etc.). For example, there are some industrial developments along Alkharj road which branches from the south-east corner of the ring road and proceeds south. 
most sections of the ring road and its radials had been built, land development had scattered to surround all of the ring road.

The ring road has reoriented the direction of growth from a radial pattern to a circular one containing large amounts of vacant lands. Relatively speaking, the ring road and its radials made more areas accessible and did not help infill development. The important question becomes when is the proper time to allow a ring road to develop without resulting in massive dispersion and leapfrogging growth? 
Figure 7.1: Riyadh's Growth, 1970

(Before The Planning Of The Ring Road)

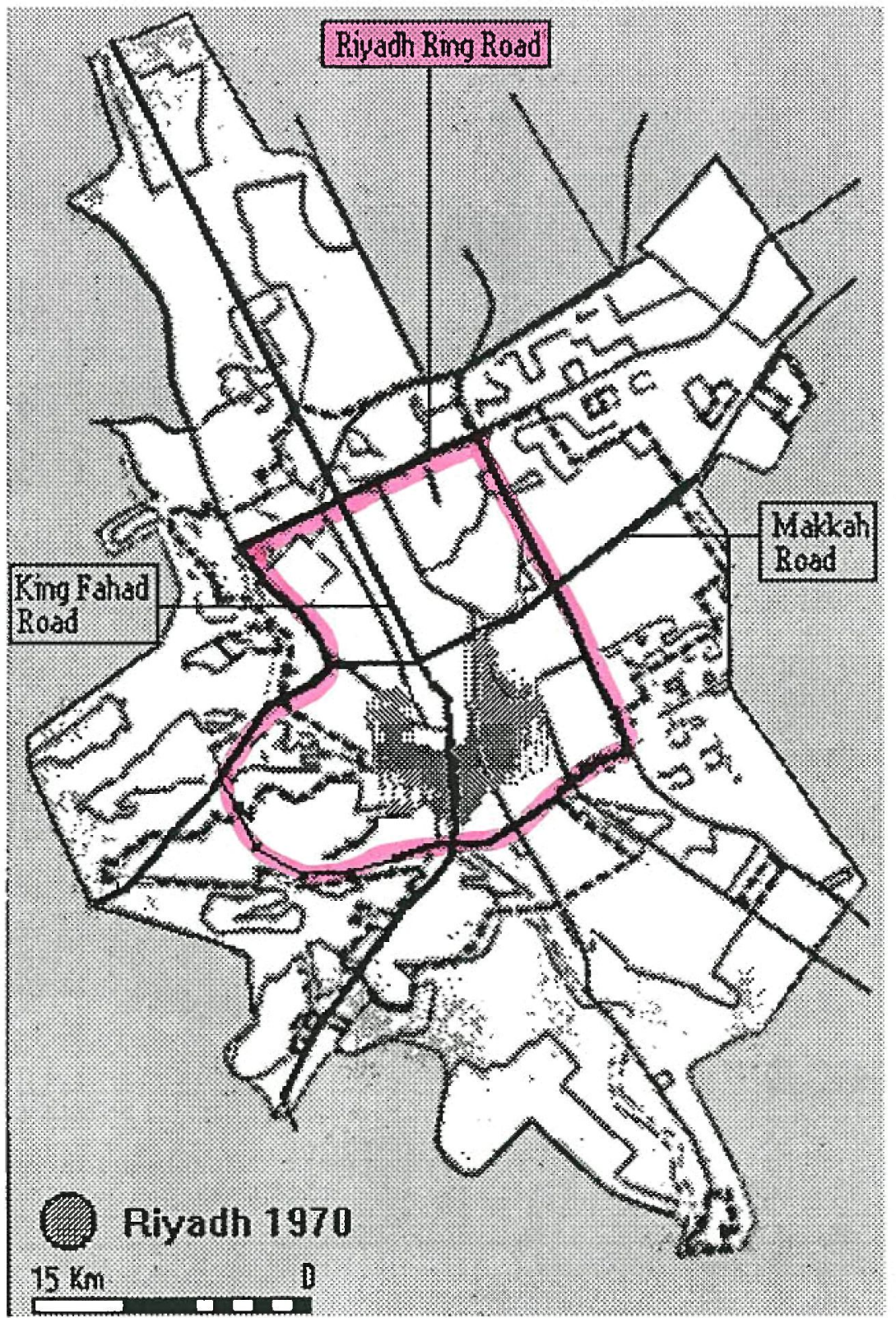

The above map shows the city of Riyadh with its present road network. The white section of the map represent the boundaries of the Urban Growth Limits (UGL) phase II. The darker irregular shape in the middle represents the approximate size of the city in 1970 . Note how small the size of the city is when seen in relation to the ring road.

Source: developed by the author based on different sources used in this dissertation. 
Figure 7.2: Riyadh's Growth, 1980

(At The Beginning Of The Construction Of The Ring Road)

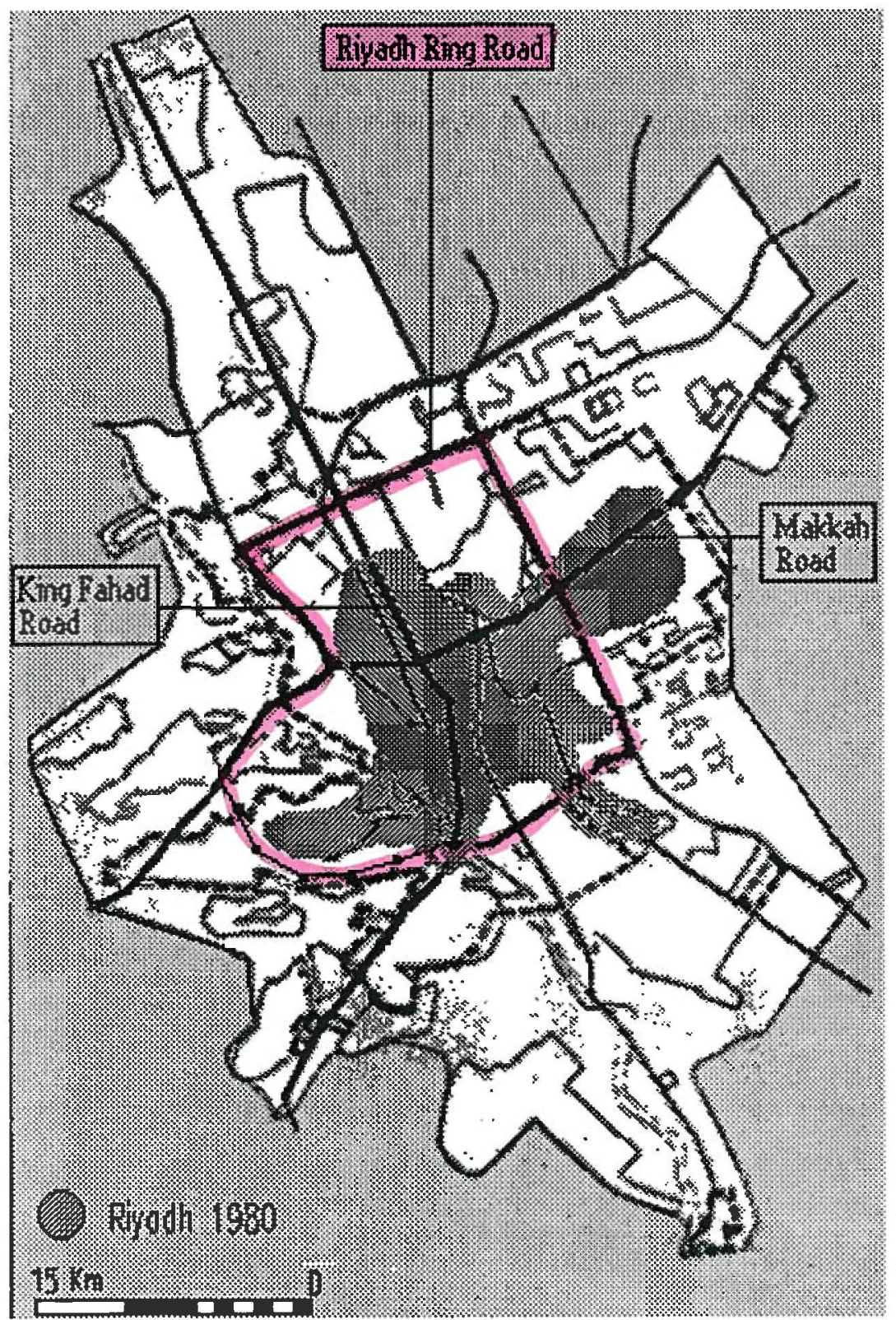

The above map shows the city of Riyadh with its present road network. The white section of the map represent the boundaries of the Urban Growth Limits (UGL) phase II. The darker irregular shape in the middle represents the approximate size of the city in 1980 . Note that growth was within the path of the ring road except for that of the eastern section along Makkah road and a small extension in the south-east portion of the city. Makkah road, previously called Dammam road, connects Riyadh, the capital, with the sea port of Dammam located off the Arabian Gulf. The south-east section of the city is a host to most industries, especially building materials industries. In 1980, the ring road was not developed and the city, as the map shows, was very limited in size.

Source: developed by the author based on different sources used in this dissertation. 
Figure 7.3: Riyadh's Growth, 1990

(After The Opening Of The Ring Road)

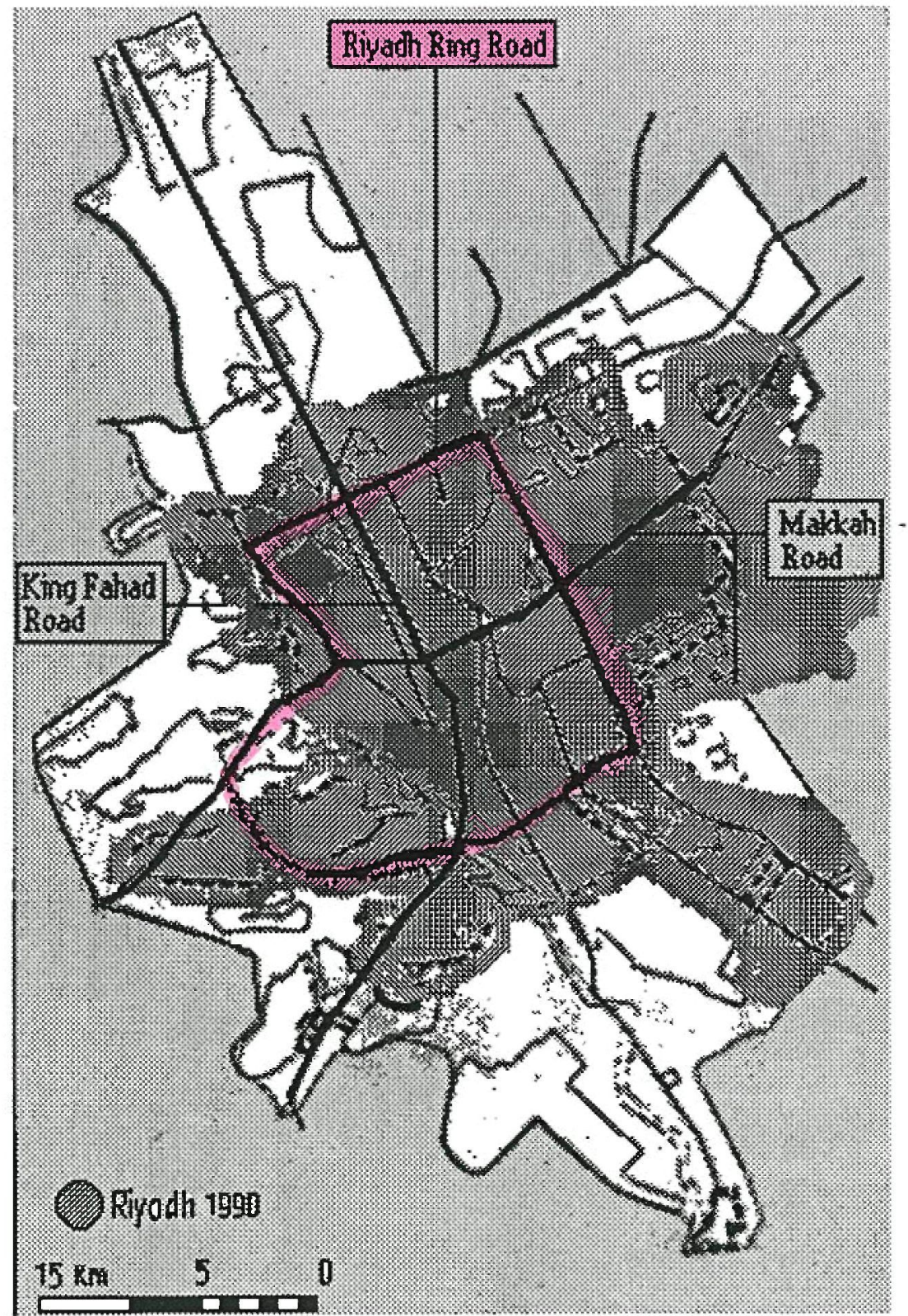

The above map shows the city of Riyadh as of 1990. The white section of the map represents the boundaries of the UGL phase II. The darker irregular shape in the middle represents the new size of the city. Roughly, if all developments (which existed as of 1990) are connected with a line then such a line will be the perimeter of the irregular shape. While this shape shows how growth extended almost in all directions, it does not show the agglomeration of urban voids. A noticeable size of urban voids is contained by such a shape (please refer to the urban voids map in Chapter IV). Note that growth has increased dramatically to transcend the ring road. Comparing this map with the previous map gives an idea of the changes in the city size after the development of the ring road.

Source: developed by the author based on different sources used in this dissertation. 
In 1986, when major portions of the road were opened, about $51 \%$ of the city (Urban Growth Limits (UGL), phase I) was in vacant lands. ${ }^{3}$ Five years later, in 1991, the boundaries of metropolitan Riyadh were redefined to encompass all potential growth up to the year 2005 (UGL phase II). The metropolitan area increased by 770 square kilometers to a total of 1782 square kilometers (1012 square kilometers in 1986-87). The percentage of vacant land increased to almost $80 \%$. Without the enormous accessibility the ring road and its radials provided, the expansion of the city boundaries would not have encompassed this 1782 square kilometers.

In other words, Urban Growth Limits (UGL) phase I defined the city boundaries covering an area of which $51 \%$ was vacant, while UGL phase II increased the urban boundaries to cover an area of which $80 \%$ was vacant. ${ }^{4}$ The development of the ring road, which preceded the development of the UGL program, may have influenced the size of the UGL, particulary phase II.

In order to devise the proper ring road development timing, the previous analysis is used. The following discussion introduces a method of selecting development timing by using equation

\footnotetext{
3 UGL phase I is the Urban Growth Limits as of 1986; it represents the city boundaries. UGL phase II represents the city boundaries between 1995 and 2005. UGL phase I and II are equivalent in areas to the areas covered by the two ADA surveys, which were discussed in the previous chapter. The land area of the first survey is equivalent to the land area of the UGL Phase I land area; similarly, the second survey land area is equivalent to that of the UGL Phase II

${ }^{4}$ By 1995 whoever develops in the area covered by the UGL boundaries phase II can ask for services. Although there is no guarantee that they will get such services up to the year 2005, the fact that people believe in service provision any time after 1995 encourage development in the second phase boundaries.
} 
(6.1). ${ }^{5}$ This method is meant to illustrate one way of timing selection and shall not be seen as the optimal way. Using 1986-87 data, equation (6.1) suggests that for every one kilometer in LENGTH, vacant lands increase by about 1.5 square kilometers Accordingly, the whole ring road may account for 118 square kilometers of vacant urban land (as of 1986-87 there were 517 square kilometers in vacant urban lands, equivalent to about $51 \%$ of the total area). This 118 square kilometers represents about $22 \%(118 / 517)$ of the total vacant lands. Therefore, $11 \%(22 \%$ of 51\%) of the vacant urban lands, within Urban Growth Limits (UGL) phase I, can be attributed to the ring road. ${ }^{6}$ Consequently, UGL phase I would have contained an area of which $40 \%(51 \%$ less $11 \%$ ) are vacant if the ring road were not developed. In other words, $40 \%$ of the lands would have been vacant if the ring road development did not occur.

Based on the above simple premise, one may recommend, for example, that a ring road should only be developed when not more than $40 \%$ of the city area is vacant. In other words, a ring road development at a time when $60 \%(100 \%$ less $40 \%)$ of the total city area is developed will have a minimum impact in terms of increasing the amount of vacant urban lands. The analysis suggested that $40 \%$ of Riyadh's total area would have been vacant without the ring road (as opposed to $51 \%$ with a ring road). Assuming this ratio (40\%) is natural (although not optimal), other Saudi cities contemplating ring road development should wait until at least $60 \%$ of their

\footnotetext{
5 Equation 6.1 is discussed in detail in Chapter VI. It has the following form: VCDVLPE $=12,370,500+$ 1,505,316 LENGTH; where VCDVLPE = Land Area Of Developable Vacant Urban Lands; LENGTH = The Length Of Freeway Kilometers By submunicipality;

Since the constant is not significant from zero, it will not be used in the calculation (please see Chapter VI for more details).

6 This estimate is very conservative as the combined impact of the ring road on other radials is not included.
} 
areas are developed. In this case, a ring road will not increase the area of vacant lands to more than $40 \%$ of these cities' total areas.

Assuming that this $40 \%$ is accepted as a maximum ratio that shall not be exceeded, then the remaining $60 \%$ can be called the Desired Development Ratio (DDR). If the DDR is $60 \%$ then a ring road may be developed. This means that $60 \%$ of the total area is developed or vacant land constitutes $40 \%$ of the total area. The route of the ring road must consider this $40 \%$. For example, this route may be located so that one half of this $40 \%$ (or $20 \%$ ) is located within it while the other one half (the other $20 \%$ ) is located outside it. Assuming that relevant decision makers choose to follow the above example in determining the ring road route, then this route must encircle an area of which $80 \%$ is developed. This $80 \%$ is another Desired Development Ratio (DDR). ${ }^{7}$

In any case estimating an exact ratio is not the goal of this thesis and it is beyond its scope; however, it constitutes a good topic for further research. Further research that is based on more than one city should be undertaken to develop an acceptable ratio. The major purpose of the above exercise is to establish the link that relates the Actual Development Ratio (ADR) to the proper timing of ring road development.

7 This DDR (80\%) differs from the other DDR (60\%) which was introduced earlier in the same paragraph in that the former (80\%) represents the ratio of developed land to the land encircled by the ring road, while the latter (60\%) represents the ratio of developed land to the total city area. The former (80\%) is apparently easy to work with when selecting ring roads routes, because all what it requires is that the ring road must entail an area of which $80 \%$, for example, is developed. 
There are several reasons not to take the above ratio $(80 \%)$ as final. First, urban variables hold probabilistic relationships and therefore deterministic outcomes are quite complex at best. In other words, it is only probable that adopting a certain ratio will result in reducing the amount of urban voids. Second, any similar ratio cannot be taken with full confidence unless proven true for other situations (e.g., cities). Although the first reason may be difficult to overcome, satisfying the requirements of the second reason should provide the basis of estimating an acceptable ratio. However, and more importantly, the fact that a figure exists will provide a valuable base from which planners can proceed.

The model is limited to Saudi cities contemplating ring road development. It cannot be generalized to all cities. In essence, it is a continuation of the research hypothesis intended to explain the phenomenon of urban voids in light of freeway (particulary ring road) development. The model should help understand and predict the dynamics of other Saudi cities. As figure 7.3 shows, the model suggests that the timing of ring road development is crucial for efficient urban development. The model assumes that the city has known boundaries. In addition, it assumes a societal environment which shares with Riyadh the four conditions introduced in chapter $1 \Pi{ }^{8}$

8 The conditions introduced in Chapter II are:

(a) the cities must be very similar in terms of their culture, value system, economic and political institution.

(b) the cities must possess a similar economic base.

(c) the cities must belong to a determined urban/transport structure; for example an urban structure based on the prototypes proposed by Thomson (1977) within certain time frames.

(d) the cities must have similar topographical/climatic settings.

Ring road development timing should be crucial for urban efficiency in cities which are similar to Riyadh in terms of the above four conditions. 
It suggests that developing a ring road at a time when large amounts of the area within such boundaries are not developed will be counter-productive to efficient land utilization and ultimately to urban efficiency. This timing model shows the critical role of timing in determining urban efficiency.

Figure 7.4: The Timing Model

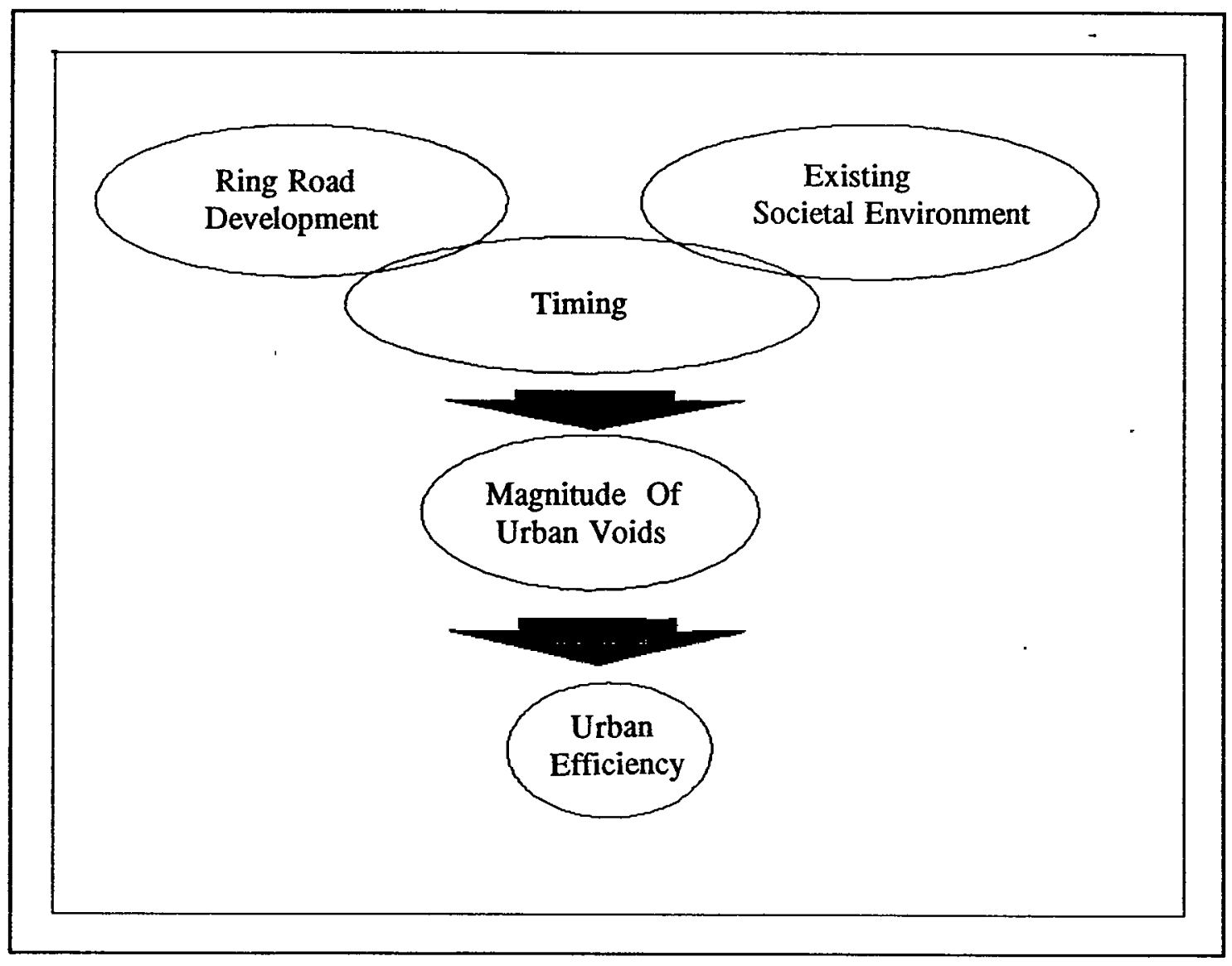




\subsection{Planning Philosophy Implications}

The planning approach in Riyadh is rational and is based on a centralized philosophy. Centralization may be useful at early stages of development (e.g. when cities are smaller in size), but as cities develop and grow in size centralization may not represent the best planning philosophy. Decentralization as a planning tool could prove helpful. ${ }^{9}$ Several authors such as Hart (1972), Rondinelli \& Cheema (1983), and Smith (1985), have investigated the concept of decentralization. Cheema \& Rondinelli define the concept as:

... transfer of planning, decision-making, or administrative authority from the central government to its field organizations, local governments, or nongovernmental organization ( Rondinelli \& Cheema, 1983: 18).

Transferring some powers from the mayoralty to the submunicipalities provide an avenue toward a decentralized planning approach, a paradigm that should be given a chance to prove its merits. The concept of the municipal council which was introduced by the municipal ordinance of 1977 can be integrated with submunicipal decentralization to give the latter more authority and status. For example, the members of the municipal council could be chosen (e.g, appointed or elected)so that they represent the submunicipalities.

The functions that should be delegated to submunicipalities can be sorted out by the municipal council. Although it is not the purpose of this thesis to devise a framework for functions' delegation, a minimum number of tasks should be transferred to local submunicipalities. These tasks may include, but are not exclusive to, permits issuing, land titles issuing, boundaries delineation, and any other function seen appropriate by the council.

\footnotetext{
For a detailed discussion on the arguments for decentralization please see Appendix G (The Concept Of Decentralization).
} 
However, there should always be a central agency to coordinate the actions and tasks of member submunicipalities. This agency should have the power to resolve differences among different local government planning units. The extent of such a power should be decided by relevant government institutions such as MOMRA in the case of Riyadh. An example of an agency which could best coordinate the activities of different submunicipal planning units in Riyadh is the ADA.

\subsection{Implications Of The Cultural Dimension}

The analyses and discussions introduced in this thesis suggest that the consideration of cultural dimensions (Islamic and arabic) is a necessary factor for achieving the ends of urban planning. Future planning policies should be interwoven with established Islamic principles and evolving cultural factors. ${ }^{10}$ Principles such as ownership rights, and the concept of Qadi (local judge) could further be developed to suit today's contemporary needs. For example, assigning a Qadi to each submunicipality would not only revive an established Islamic concept, but also would increase the power of submunicipalities and enhance the decentralization process. Granting land titles, resolving intra-submunicipal disputes, etc., would no longer be central functions, if submunicipalities have their own Qadis.

Cultural factors such as privacy should be taken into account. For example, privacy considerations may require the formulation of new policies that would make the existence of

10 Future planning policies which do not consider cultural dimensions such as ownership rights may fail to achieve the very ends they are formulated for. For example, any growth control measure will be difficult to enforce if it prohibits a person from building his own house (for sheltering purposes only) on his own land. 
urban voids of no benefit. The idea of the interior courtyard, instead of the existing requirement of setbacks, for instance, would provide each resident a small void to which he can orient his unit windows without worrying about violating others' privacy. In addition, it will make moving, on the part of the resident, to areas which are not fully developed (and thus contain vacant urban lands), not that rewarding--in terms of gaining more privacy. Since people's movement from fully developed areas to semi-developed or non-developed areas increases leapfrogging and perpetuates urban voids, policies which consider the concept of courtyard may prove useful.

Another factor which is increasingly becoming part of Riyadh culture is automobile dependency. This dependency is not helpful in reducing vacant urban lands, because it contributes to making residents less aware of the longer distances they travel. These distances are caused by the existence of these vacant urban lands.

Automobile dependency is one of the major characteristics of the urban life of Riyadh. The wealth from oil combined with other cultural factors (e.g, family privacy) increased this dependency. Reducing automobile dependency in Riyadh would probably be one of the most difficult tasks for local urban planners to face. The causes of automobile dependency, which were discussed in chapter IV, suggest that solving the problem would require more than simple, uncoordinated regulations. Future planning policies in this context must be comprehensive-dealing with transport, land use, and cultural issues concurrently. In Singapore, a policy to reduce automobile use and growth was successful because it was comprehensive; it restricted automobile ownership and use but simultaneously improved public transport (Pendakur, 1987). With the 
present level of automobile ownership and cost (only $7 \%$ of Saudi households in Riyadh do not own cars (ADA, 1988); and the cost of gasoline is 11 Canadian cents per liter), the physical layout, cultural factors, and the climatic conditions, the need for comprehensive policies cannot be underestimated.

There is a need for a comprehensive policy to deal with automobile dependency. This policy should help in making people more aware of the phenomenon of vacant urban lands. Because the auto is very inexpensive to operate and very handy to use, people are willing to drive longer distances while being unaware of the length of such distances caused by these urban voids. Because these vacant urban lands are privately owned, the chances that they will be converted into public open spaces are slim. One day these lands will be developed, and if development happens at a time when the city is so stretched (horizontally), moving in the city, and even living in it, could pose a serious challenge. A need for a comprehensive policy is required sooner rather than later. Devising such a policy is beyond the scope of this thesis, and it may require the input of several experts in the field. It is the author view that a list of suggestions such as the following will reduce automobile dependency which in turn should make the existence of these vacant urban lands an unpleasant phenomenon (because it stretches daily travelled distances): ${ }^{11}$

- Increase private transport cost.

- Improve public transport.

- Encourage pedestrianisation by improving the design specifications of sidewalks

11 These suggestions may be difficult to accept by most residents of the city. To some, these suggestions may be too idealistic and therefore should be dismissed. Nonetheless, they seem to provide the only hope of reducing auto-dependency. 
and plan new communities so that passways provide more shade for walkers. ${ }^{12}$

Increase environmental awareness.

The above list is by no means exhaustive; more analysis is needed to cover the whole aspect of the issue. A policy aimed at financing and encouraging research on automobile dependency would certainly contribute to the achievement of livable, healthy future cities.

\subsection{Urban Dynamics \& Growth Implications}

Planning implications which relate to urban dynamics and growth stem from several elements including land use variables, demographic characteristics, physical growth, and growth management measures. These are discussed below.

\subsubsection{Implications Of Land Use Variables}

One of the observations which can be derived from the urban data analysis is the fact that there exists a weak relationship between vacant lands on one hand and other variables (except for LENGTH, DIST, and APPLOANS) on the other. This suggests that changes in existing land uses-at the current time--may not result in changes in the size or distribution of vacant lands. For example, some people may claim that rezoning larger residential tracts of vacant lands into high density mixed uses would provide an incentive for owners to develop or put up for development

\footnotetext{
12 Sidewalks in Riyadh are not widely used by pedestrians; therefore, there is less public demand to improve them. Except for sidewalks constructed by public agencies such as the MOC, as part of road contracts, many of the city sidewalks--usually built by private developers--are not conducive for walking. There are many factors which could encourage residents to use sidewalks and abandon their automobiles, at least for short distances. One of these factors, is the provision of shaded sidewalks. The discussion in Chapter IV has shown that the modern Arabic city has failed to provide shaded sidewalks.
} 
their vacant lands. ${ }^{13}$ The analyses undertaken in this thesis produces no evidence to support such a claim for the time being. One way of combating the proliferation of vacant urban lands is imposing a certain financial cost on lands which are kept vacant for a determined number of years. Although imposing such a cost (e.g. in the form of taxes) may face some legal obstacles, which are beyond the scope of this analysis, it is nonetheless worth trying.

\subsubsection{Demographic Implications}

The data introduced in this thesis shows some distinct characteristics of the Riyadh population. The city has a population growth rate of $8.8 \%$ (4.7\% due to natural growth and $4.1 \%$ due to migration). The average family size is 6.8 persons in 1990-91, 6.34 in 1986-87, (ADA, 1992:30 \& 1986-87: 119). These figures, although high from Western standards, are typical of most Saudi cities. The growth of population resulted in the occupation of 107329 housing units during 198691; these units were either vacant, in the past, or were developed in that period. At the current rate, 20408 units are needed each year to satisfy the growing population, the market supplies about one half of this number. This suggests that shortly, there could be a housing shortage which normally results in increased housing costs to the residents. This situation will certainly increase the value of vacant urban lands as the demand for residential space increases. If land prices increase dramatically, then expropriating vacant lands for public uses will be very costly.

\footnotetext{
13 As explained earlier in the thesis, municipal regulations allow single family units development to occur anywhere in the city regardless of street width (except in industrially-zoned areas). Only lots which are located adjacent to streets that are 30 meters wide (or wider) can be developed for high density mix uses (namely commercial and residential). Since the majority of roads in the city are less than 30 meters, in width, most areas in the city have more residential uses than any other uses. Indeed, as of 1991 , about $80 \%$ of the uses in Riyadh are residential (ADA, 1992: 17).
} 
The considerable population growth did not substantially reduce the amounts of vacant urban lands, rather it stretched the city even further. Therefore, increasing the population, as some people may suggest, would not necessarily result in less urban voids, at least for the time being. What is more likely to happen is that the city will expand in all directions; and it will still contain vacant urban lands, which, when they are developed, will result in a large continuous city.

A policy that encourages the excess growth in population to settle in smaller towns and villages in the same area (e.g, Riyadh's area) should be examined. This policy should include elements which encourage developing towns and villages to absorb the expected growth of population. Shifting jobs, and establishing incentives to encourage more people to settle in nearer towns and villages could constitute instrumental parts of such a policy.

\subsubsection{Growth Management Implications}

The Urban Growth Limits (UGL) program of Riyadh was originally initiated to contain, control, and direct urban growth. It represents an avenue which can be used to delineate city boundaries, Riyadh utilized such an avenue. Cities which are surrounded by large amount of unused land (e.g. a large desert) may not find it necessary to delineate their boundaries, because there exist no nearby cities which may compete with them over such lands. However, today's urban planning requirements necessitate the need to demarcate boundaries, because it will be very difficult to develop future plans if there are no known boundaries. The timing model discussed earlier suggests that future ring road development can better be planned if a city has known boundaries. 
Developing boundaries, by employing a program such as the UGL or by using other means, should always come before developing ring roads. In the case of Riyadh, the ring road was developed first, then the UGL program was established. This may explain the huge area covered by the UGL program (Phase II). ${ }^{14}$ This program was extended to cover an area of 1782 square kilometers up to the year 2005, an increase of 770 square kilometers from that of 1995 . In other words, the city boundaries by the year 2005 will contain an area of 1782 square kilometers as opposed to 1012 square kilometers (from now until 1995). Containing vacant urban lands will be more difficult when city boundaries cover such a large area. Policies which encourage research tailored to develop optimal city boundaries should be prioritized.

The Land Granting System (LGS) and the Real Estate Development Fund (REDF) represent great potential to guide and manage growth in Riyadh and other Saudi cities. A policy which integrates these programs to control and direct growth could enhance the future livability of the concerned cities. For example, giving REDF loan priority to inner areas and limiting LGS lots to areas located within the city designated boundaries would not only encourage infill development but also it would curb leapfrogging. ${ }^{15}$ In addition, REDF loans may be used as a bargaining tool

14 Before the development of the ring road and its radials, accessibility was limited to areas close to the heart of the city. Therefore, extending the city's limits to outer areas was not contemplated because such areas were not accessible in the first place. After the development of the roads, accessibility has been greatly enhanced so that expanding the city to cover larger amount of land was seen acceptable by local planners who devised the UGL.

15 Some planners may suggest that the best solution for leapfrogging is abandoning the LGS completely. While this suggestion may be valid in theory, it is very difficult to observe it in practice. Land granting is an established tradition in Saudi Arabia and it can not be phased out overnight. Saudi citizens are very attached to land ownership. Every adult male citizen (around the marrying age) strives to own a piece of land to provide a secure and safe shelter (house) for his prospective family. In Saudi Arabia, owning a house, which requires owning a plot first, is one of the most important investment a man can do for his family. With the growing population, demand on the LGS is 
with vacant lands owners. For example, those who own inner vacant lots but want to use the loan to build their houses on lots located in outer areas may be required to use the loans for their inner lots.

\subsection{Central City \& Commercial Activities Implications}

The Riyadh Ring Road development did weaken the city center, similar to other cities in the West (Blaney-Dyett \& Payne-Maxie, 1980). Before the opening of major sections of the ring road, about $50 \%$ of the commercial establishments were located in the submunicipalities of Deerah and Batha which represent the central city area (ADA, 1986-87: 28). After the opening of several sections of the ring road, the above two submunicipalities accounted only for about $38 \%$ of the total number of commercial establishments (estimated from data in ADA, 1992: 23)). Submunicipality of Nassim, which is located outside the ring road, witnessed the highest increase in commercial establishments (Ibid: 23).

Since ring road impacts are distributional in nature, planners may not be able to prevent the very likely redistribution of some commercial activities. As discussed in chapter II, ring roads are more likely to redistribute commercial activities as opposed to creating new ones (Connally, 1968). Ring roads would certainly change the level of accessibility among different city zones. Commercial activities may follow by changing their locations to enhance their geographical accessibility. Planning policies tailored to alleviate possible adverse impacts should be developed well in advance of ring road development, but they should not be expected to keep city centers

expected to increase and it is very unlikely that this tradition (LGS) will be phased out in the near future. 
exactly the way they were before the occurrence of the development.

Another point which relates to minimizing the adverse affect of ring road development on central cities and simultaneously optimizing the transport network is the concept of reserving interchange areas, namely locations where the ring road intersects with the radials and other important thoroughfares, for high density, mixed use development including commercial development. ${ }^{16}$ If new mixed developments locate at ring road interchanges, city center would still be relatively accessible to them. People who live at such locations would still travel to the city center, which may help keep it alive even at a lower level of commercial interactions. In addition, concentrating

16 The type of development preferred to dominate areas adjacent to interchanges is probed by the questionnaire. The existing land use system allows any development (except industrial) to take place in these areas. The rule of thumb is that commercial development can take place along any road that is $\mathbf{3 0}$ meters or wider. Since all freeways are wider than $\mathbf{3 0}$ meters, commercial development is allowed along the freeways. According to the existing land use rules, residential development is not sensitive to road width. The majority of the respondents prefer to see commercial development at the ring road interchanges . Commercial developments have shown clear interest in beltways' location (DeBres, 1989).

The second residents' preference is institutional development. Industrial and residential development come third and fourth respectively. There may be several reasons why residential development came last in the preference list. Usually lots located along the freeway are eligible for commercial development and therefore will reward less financial return if they are used for mere residential purposes. In addition, households avoid areas adjacent to freeways because of pollution, especially noise pollution. One resident living close to the ring road said to the author that he is willing to pay $25 \%$ of the cost of his parcel to get rid of the traffic noise. He meant that had he known the extent of the noise problem he would have traded his parcel with any similar parcel in the same neighbourhood and offer $25 \%$ of the land value extra as an incentive.

According to an interviewed real estate agent, commercial lands along freeways in Riyadh are not more valued than those along major arterials. He suggested that the fact that all freeways are supplemented by service roads reduces the interaction between the through traffic and juxtaposition properties. For example, it is easier for a driver on a major arterial to spot a shopping outlet and stop to do business. This is not the case with freeways. Even if the outlet is spotted, the driver must go to the next exit and find his way to the service road before he gets to the outlet.

A visual inspection (by the author) of Riyadh suggests an unclear pattern of use in highly accessible points (freeway interchanges). The most likely explanation for such an observation is that most of these lands are owned privately by many different people and consequently developed independently. In other words, even if a commercial developer finds highly accessible vacant lands, he has to convince all different owners to sell, which is not always likely. This may raise the need for a policy dealing with land ownership in highly accessible areas. 
high density development at ring road interchanges would certainly offer a golden chance to enhance public transport use in Riyadh and other Saudi cities, which are very dependent on the automobile. A policy devised to encourage high density development at locations adjacent to ring road interchanges would contribute to the overall efficiency and liveability of our cities. Such locations may be designated for the development of secondary city centers. This may result in the establishment of a form of a multi-centered city that is manageable. In Riyadh, like other fully auto-oriented cities, several urban centers have emerged with improved accessibility. In other words, such centers will develop in any case. Therefore, it is vital to at least guide the locations of these centers so that, with the city center, they constitute hierarchy of centers which complement each other as opposed to compete with each other. The concept of city centers, or town centers, has proved promising in some cities. In Vancouver (Canada) a Town Center Policy (developed to provide alternative office locations, improve suburban services, improve public transport, and distribute costs and benefits equitably throughout the region) was considered moderately successful (Artibise, 1990).

A policy to develop the concept of multi-centered cities (in Riyadh and other Saudi cities) is needed to optimize the use of ring roads and their radials. This policy should take into account several considerations. First, it should be integrated with the LGS in terms of designating areas for public grants. For example, lots located in or around highly accessible areas may not be put out for public granting, rather they should be kept for future high density development. Second, the LGS and REDF should be used to encourage those who own lots in interchange areas to swap them for similar parcels, available in LGS city areas. For example, a person who owns a lot in 
a highly accessible area and intends to build it for single family housings purposes use may be offered a high priority loan (e.g instead of waiting for 5 or 6 years, he may get the loan in 1 or 2 years) if he swaps his parcel for another one available in the LGS areas. Some may suggest that the same outcome may be achieved simply by rezoning interchange areas into high density zones. Unfortunately, this will not suffice. The fact that numerous lots are owned by different people will still make unified, high density development difficult to achieve. A policy to achieve the concept of multi-centered city should bear in mind that high accessible areas (presumably to be designated as secondary centers) must be owned by one party or at least very few parties. Finally, more research and analyses should be undertaken to devise a multi-centered city policy that fits the Saudi environment.

\subsection{A Proposed Ring Road Development Process :}

This section introduces a process, in which a ring road planning process, suited to Saudi cities, is identified and explained. If adopted, the process would lead to a reasonable pattern of development which would not encourage large amounts of vacant lands to exist. The process includes four steps:

- Define the city's boundaries;

- Determine the Desired Development Ratio (DDR) and select the appropriate timing for ring road development;

- Choose the route of the ring road so that timing is satisfied; and

- Proceed into implementation.

The discussion examines each step and its relevance to the proposed process. The aim is to assure 
that such a process will discourage and prevent, in future ring road developments, the leapfrogging and urban dispersion. ${ }^{17}$

\subsubsection{Defining The City's Boundaries}

Defining clearly the city boundaries is a very important step without which the following steps would make only limited contributions. In Riyadh, the city boundaries were defined through the Urban Growth Limits (UGL) program; however, this definition came after the actual construction of the road began. Before the UGL program, Riyadh did not have clear boundaries. Simply put, the boundaries of the city were a reflection of the urban developments occurring around it. Services were expected to reach such developments upon their completion. With the advent of the UGL program, the situation changed. The city defined its boundaries; and only those developments occurring within such boundaries are considered within Riyadh and this consideration assures service provisions.

The demarcation of the boundaries of the city, under this process, should take place before the initial planning of the ring road. Route selection and construction of the ring road ought not to be undertaken until the boundaries are defined. Once the boundaries are defined, then services may only be provided to developments located within. In addition, the process requires

17 The process assumes the followings:

Ring roads are connected with radial roads or other highways.

Automobile ownership rates and auto-operation costs will not witness major changes in the future.

There will be no future drastic changes in both the current planning philosophy and the land use system.

All lands outside the urbanized area of the city are in public hands. 
consideration of the temporal dimension. That is, the boundaries are to represent the perimeter of the city and should be observed until the coming of a certain future year, for example, the year that comes ten year later. ${ }^{18}$ Determining the appropriate future year should be decided by the relevant planning agencies. However, a 10 year period seems suitable, because it coincides with the national census and it allows reasonable time to elapse. The national census provides valuable socioeconomic information for the planners assigned to prepare future plans. In addition, the 10 year period allows planners to observe major changes in the city's urban fabric, which represents important ingredients for future plans.

Defining the city boundaries should be based on several factors: existing conditions, available financial resources, and future forecasts. Existing conditions include population figures and other socioeconomic data, and the available vacant, publicly owned, developable lands. Population and socioeconomic data are essential for any type of planning, and planning the city boundaries is no exception. The available vacant lands shall represent the domain of the LGS (Land Granting System). That is, applicants of LGS may only be granted lots in these lands. However, if the number of eligible applicants exceeds the available lands, the boundaries of the city may be expanded, if feasible, to enclose more lands .

18 It is important to note that observing the proposed city boundaries does not mean preventing citizens from building their houses outside such boundaries. Rather this observation means that those who choose to reside outside the boundaries may not have the right to demand services. However, if the LGS and REDF programs are related to satisfy the proposed planning process, there should not be any developable private lands outside the proposed boundaries. For example, if the LGS restricts granting lands in areas outside the proposed boundaries and the REDF does not provide loans for developing such lands, then the chances that there will be development outside the boundaries would be very slim. 
The availability of financial resources should determine the boundaries from the service provisions' side. If the area to be covered by the designated boundaries cannot be served, within the selected time period, given the existing financial resources, then the boundaries should be redefined. Only areas which can be serviced should be included in the new city boundaries. In addition, the REDF (Real Estate Development Fund) loans priorities should be given to those lands contained by the defined boundaries.

Future forecasts for the city and its inhabitants represent the final stage in refining the proposed boundaries. Since a forecast represents an estimate (or a picture) of a future state--a city's future size, future needs...etc.--it should help planners match the proposed boundaries with such an estimate. Planners should use both data on the existing city's conditions and data on the available financial resources to articulate the most probable forecasts (e.g. demographic, housing, etc.). These forecasts may be refined if necessary. The process of refinement and feedback should continue until the three factors (existing conditions, available financial resources, and the forecasts) become complementary to each other and reach a state of balance. That is to occur when the picture drawn by the forecasts can logically be supported by the data on the existing conditions and can financially be furnished by the available resources. For example, if a forecast recommends certain city boundaries that include areas which can not be serviced, given the available resources, then the forecast should be rejected.

\subsubsection{Determining The Desired Development Ratio}

After delineating the city boundaries, the Actual Development Ratio (ADR) can be computed. 
Several methods can be used for such computation; however, a combination of ground surveying and aerial imaging should be adequate. Ground surveying will provide accurate information on different land uses including vacant lands and ultimately the total land area of the city. Aerial imaging will provide another means to check the data collected through ground surveying. The ADR equals the land area of developed areas divided by the total land area encompassed by the designated boundaries: $:^{19}$

(Developed Land / Total Land) $* 100=\mathrm{ADR} \%$

Once the ratio is determined, then it should be compared with the Desired Development Ratio (DDR). Attaining the DDR is more complicated and requires more than the simple division of two land areas as in the previous case. Two methods to attain the DDR are suggested here. The first method requires using various data analysis techniques such as those used in this dissertation, while the second depends on the selection of experts in the urban planning field to elicit their judgment.

Regression analysis was the primary analysis tool used in this dissertation. The analysis has shown that there exists a clear relationship between the length of freeway and the size and the distribution of vacant lands. In addition, the analysis shows that there exists a causal relationship between the ring road and its radials on one hand and the size of vacant lands on the other. The relationship suggests that the ring road and its radial cause changes in the size of vacant lands. In the previous timing model, the Desired Development Ratio (DDR) was calculated using

\footnotetext{
19 The ADR can also be obtained by subtracting from 1 the outcome of dividing vacant land areas by the total city area:

1 - (land areas of vacant lands / total city area)
} 
regression analysis. The advantage of this method is that it provides concrete figures based on land use data, which in return can be examined in different ways to assess the validity of the figures.

i

However, there are some drawbacks to this method. As in any technical exercise, the assumptions on which the analysis is based can play a considerable role in influencing the final outcome. These assumptions may reflect the values or judgment of the involved planners. Therefore, substantial efforts are needed to articulate suitable assumptions. In addition, most technical analyses do not account for intangible factors; e.g. cultural factors, due to the difficulty of quantifying these factors. Finally, technical analyses in the urban planning field cannot explain and account for all the changes in the phenomenon under study, because the relationships among urban variables are probabilistic in nature (vis-a-vis deterministic). For example, the regression model of equation (6.1) in chapter VI shows that about $40 \%$ of the changes in vacant lands' size is unaccounted for by the ring road and its radials, but this is acceptable because freeways and vacant lands' sizes (like other variables in uncontrolled environment) have probabilistic relationships which are not deterministic and perfect (e.g. $r=1$ ).

The other method which could be used to estimate the Desired Development Ratio (DDR) is the method of using expert judgments. The major theme of this method is contacting selected experts on the field to elicit their judgment. There are several ways of obtaining expert input. Experts can be invited to attend a special meeting and asked to have an open discussion on the issue. The figure on which the experts have consensus can, then, be used as the DDR. Another way of 
consulting experts may take the form of a Delphi approach to assure anonymity of the involved experts. Anonymity may become important should the route of the ring road generate opposition or support from interest groups or individuals. There are pros and cons associated with the use of this method. One of the advantages of this method is its convenience. Contacting a few experts would require less effort than conducting several analyses. In addition, consulting the experts would account for other intangible factors, usually difficult to quantify and therefore account for by technical analyses. The major drawback of the approach is the fact that experts are human and their judgments do not always escape their values.

Selecting the Desired Development Ratio (DDR) is a crucial step in the process. Therefore, it is very important that all concerned agencies and groups participate in selecting the method to be used. If feasible, a combination of the above two methods could prove useful. In this case, two DDR's will be developed, one is based on technical analyses and the other is based on the judgments of the experts. If these DDR's are far apart, a process of refinement may be employed until the two DDR's converge. Whatever method or combination of methods the concerned parties agree on should be the one used. Once the method is chosen, then the DDR can be developed. This Desired Development Ratio (DDR) is then compared with the Actual Development Ratio (ADR). If these two figures are very different, say the DDR equals $80 \%$ while the ADR 50\%, the process will stop at this stage as a ring road development would be inappropriate at this time. More analysis will be needed to estimate the convergence of the two 
ratios; possibly a few years later. ${ }^{20}$

\subsubsection{Route Selection}

Route selection is the third step in the process. It is important to note that this selection can not solely be based on the status of vacant urban lands. However, the size and distribution of vacant lands should be included as an important dimension, a criterion which is usually not considered in ring road route selection but which this research has shown important. Reserving the right-ofway when selecting the appropriate route should pose no difficulties, because the process assumes that all lands outside the urbanized area of the city are in public hands. The proposed process assumes that the public will only be granted lands (e.g. via the LGS) after the accomplishment of the four steps including route selection. However, if for any reason the selected route passes through private lands, then expropriation might be needed.

Route selection complements the previous step, computing the Desired Development Ratio (DDR). If a ring road has been accepted for development and the selected DDR is 70\%; for example, then the route of the road should be selected so that a certain percentage of vacant lands is enclosed by the road. In the analysis of the timing model, the estimated percentage of vacant lands (100\% less the DDR) was divided equally between the areas inside the road and the areas outside the road. If the same method is used, then the ring road--in this example--should contain $15 \%((1-0.70) / 2)$ vacant lands. Some may suggest that the encircling road should not contain

\footnotetext{
20 That is, the analysis may show that the ADR will equal the DDR after the passing of a certain number of years. If this is the case, then there is no need to increase accessibility (via the development of a ring road) to outer lands at the present time. On the other hand, if ADR and DDR are close (at the present time) or perceived by the policy makers to be close, then the process should proceed to the next step, route selection.
} 
any vacant lands, leaving all vacant lands (e.g. $30 \%$ in this example) outside, while others may suggest the opposite. While all options should be explored, locating the route of the road so that equal amounts of vacant lands lie inside and outside is preferable. If the road excludes all outer vacant lands and encircles only the developed area of the city, then it will provide little accessibility to outer areas. In addition, the road will soon be encircled by urban development. This will result in more congestion and pollution in the city area as through traffic from other towns bypasses the city. On the other hand if the road route is to encircle all lands within designated city boundaries so that the road and the city boundaries represent more or less the same perimeter, then the road may provide little service to city residents.

\subsubsection{Implementation}

Implementation is the final step in the proposed process. In this stage the relevant agencies publicize the plan of building the road so that all residents become aware of it. The announcement of the plan ought to give information on both the route of the road and the time frame of its construction. The local media, especially the daily newspaper, represent a suitable avenue of passing public information. Those who oppose the plan for any reason may channel their grievances through the Open Majlis, a tradition which allows any citizen to meet any official including the King to express their concerns.

\subsubsection{Responsibilities}

The proposed process can be performed by one or several agencies. Before proposing which agency performs what step, it is important to shed some light on the existing relationships 
between such agencies (MOMRA, MOC, ADA, and the Mayoralty along with its submunicipalities). The mayoralty of Riyadh has several submunicipalities which were initiated to relieve the center from the increasing work load. Deconcentration is the word which can be used to describe the form of decentralization that currently relates the mayoralty with its submunicipalities. Decentralization may take four forms: deconcentration, delegation to semiautonomous or parastatal agencies, devolution to local government, and transfer of functions from public to non-government institutions (Cheema \& Rondinelli, 1983: 18$){ }^{21}$ As discussed in chapter $\mathrm{V}$, the duties of the mayoralty and its submunicipalities are primarily in the domain of maintaining the city. The ADA, on the other hand, is involved more in planning as it is the agency responsible for formulating policies and strategies for city development. The mayoralty and its submunicipalities, and the ADA--on occasion--report to MOMRA. In addition, MOMRA has direct power over towns and cities which do not have mayoralties; it prepares plans for these cities and towns. The MOC is primarily an executive agency specializing in implementing transport projects, which are proposed by MOMRA's plans.

\subsubsection{The Mayoralty's Role}

Defining the city boundaries is the first step in the process. The mayoralty and its submunicipalities are the suitable agencies to undertake this task. Since the submunicipalities have no delegated powers, a form of decentralization other than that of deconcentration is needed to increase their involvement. Limited devolution seems the appropriate form. In limited devolution, submunicipalities would be given the power to undertake certain functions. The

\footnotetext{
${ }^{21}$ For a detailed discussion on the definitions of these forms of decentralization please see Appendix $G$ (The Concept Of Decentralization).
} 
inventory of functions to be transferred to the submunicipalities may include any function which can be satisfied by local expertise and resources. However, the proposed process would be facilitated if the power to delineate boundaries is delegated to submunicipalities. If the submunicipalities draw their boundaries, then these boundaries along with that of the mayoralty's would constitute the new city boundaries. Once these boundaries are drawn, the expertise of the ADA should be utilized to see if the proposed lines match the available resources and accommodate the probable future forecasts. Should disputes occur among different units in the process, then MOMRA should intervene and have the final say.

\subsubsection{The ADA's Role}

The ADA is the suitable agency to determine the Desired Development Ratio (DDR). The ADA has the expertise to perform this task with little difficulties. The ADA has been involved in several tasks in the city. They include developing the city central area, developing King Fahad Road, conducting two land use surveys, sampling city residents to collect socioeconomic data, elucidating urban problems (e.g. the increase of underground water levels in Riyadh), and providing expertise to other agencies.

The mayoralty and the submunicipalities should participate in selecting the methodology of attaining the DDR. The DDR may be refined continuously until consensus is achieved. If disputes occur, then the ADA should decide the DDR (the Open Majlis can always be used to channel grievances or concerns about any issue including the proposed figure). 


\subsubsection{The MOC's Role}

Choosing the route of road may best be performed by the MOC. The MOC has extensive experience in road design and construction throughout the Kingdom. The MOC has implemented 116000 Kilometres of roads of which 38000 are paved (MOC, The International Association on Roads Conferences, 1991:5). The MOC has used state of the art technologies to perform its responsibilities. It has employed several international consulting companies to assure the high standards of the road network in the Kingdom. The MOC has experience in the field of route selection. However, the route must satisfy the requirement of the Desired Development Ratio (DDR) performed by the ADA. For example, if the route encircles an area of which $50 \%$ are developed (Actual Development Ratio (ADR) equals 50\%), while the ADA suggested a DDR equalling $60 \%$, then the route must be redone.

The final step, the implementation process, consists of two parts. The first is publicizing the plan so ordinary citizens become aware of the potential development, and the second is putting the development out for tendering. Both parts could be performed by the MOC. 


\subsection{Conclusion}

The discussion in this chapter has shown that timing of ring road development is critical for efficient land utilization. The increase in vacant urban lands will be limited, when ring roads are developed, if timing is considered. In addition, the discussion has clarified the need for a more decentralized urban planning approach that allow the delegation of certain urban functions to smaller public units (e.g., the submunicipalities).

The need to satisfy certain cultural dimensions is also one of the conclusions of this chapter. Plans which satisfy cultural needs are more likely to succeed. The discussions of the current urban dynamics and growth elements has added that the majority of land use variables have little, if any, influence on the size and distribution of vacant urban lands. Therefore, land use changes alone will not resolve the problem of vacant urban lands. In addition, coordinating the uses of the LGS and REDF programs, so that they can be used as tools for guiding and controlling growth, has been seen very instrumental for non leapfrogging future growth.

The discussion has also shown that ring road development impacts on central cities and the distribution of economic activities in Riyadh is similar to what have been observed in western cities. The last section of this chapter introduces a proposed ring road development process. Its purpose is to assure that future ring road development in Saudi cities (and other similar cities) will not be accompanied by the spread of large amounts of vacant urban lands. Finally, the discussion has broadened to examine the roles of relevant public agencies in performing the components of such a process. 
Chapter VIII

Conclusions 


\subsection{Introduction}

This thesis is concerned with the city of Riyadh, the capital of the Kingdom of Saudi Arabia. Riyadh is a modern metropolis with a population of more than 2.3 million; it covers an area of 1650 square kilometers (Alsharq Alawsat, 1993). Most infrastructure is in place. Riyadh has a very efficient freeway network which was built at high international standards. This road network has provided a level of vehicular mobility which is not observed in many countries. It provides the average citizen with the freedom to locate almost anywhere in the city yet commute relatively easily to work. In order to assure the future efficiency of this network, and therefore the efficiency of the city as a whole, this thesis examined the impact of such a network, with particular reference to the ring road, on the pattern of urban development.

There is an important relationship between transport improvement and land development in urban planning. One aspect of this relationship is how transport improvements affect the form of urban growth. This thesis examines a specific example: the development of the Riyadh Ring Road and its impact on vacant urban lands. Both the amount and the distribution of vacant lands were examined in this thesis. The following examines the findings of this dissertation, planning implications, and the recommendation for future research.

\subsection{Findings}

This research has shown that there exists a clear relationship between ring road development, and the magnitude of vacant urban lands in the city. Leapfrogging and the amount of vacant urban land were found to be clearly associated with ring road development in Riyadh. The 
questionnaire's analysis, the urban data analysis, ${ }^{22}$ and the aerial images of 1973 and 1992 , which provide a unique "before and after" visual observation of the city, support this finding. It was found that many urban theories and models reflect the attributes and the value systems of the cities they were developed for, and therefore, they might not be applicable to cities that are culturally different. These models were not therefore used in the analysis of this thesis.

The analysis suggests that leapfrogging is related to the improvements in the freeway system, and in particular, the ring road. In addition to the existence of a very efficient freeway network, there are other factors which influence leapfrogging, including inexpensive lands in outer areas, high car ownership and low gasoline costs, and some cultural factors such as the privacy requirements. It confirms the main hypothesis which states that the development of ring roads at a time when a substantial amount of inner land is vacant encourages leapfrogging growth to occur and thus creates more vacant urban lands.

The analysis has also shown that the development of the ring road has contributed to the decentralization of urban activities, including residential and economic activities, leaving the city center with less economic advantages (the themes of sub-hypotheses A and B). About $75 \%$ of the new housing development which occurred after 1986, a time at which major sections of the

\footnotetext{
22 The analysis of urban variables shows that the dominant variable to influence vacant lands distribution is found to be LENGTH (the length of freeway kilometers in each submunicipality). None of the variables analyzed shows as good an explanation of the relationship as LENGTH. With the exception of DIST (distance from city center) and APPLOANS (number of approved construction loans in each submunicipality), none of the other variables shows any significant relationship with the distribution of vacant lands. The analysis confirms the role of the ring road in influencing the phenomenon of vacant urban lands.The analysis has also shown that a causal relationship exists between the ring road and its radial on one hand and the size as well as the distribution of vacant urban lands on the other. It confirms that the dominant causal path goes from the former to the latter.
} 
ring road were in operation, went to outer areas (ADA, 1992). In addition, Riyadh central district contained about $50 \%$ of the city's commercial establishments before the opening of these sections; this dropped to $38 \%$ after the opening of such freeway sections (Ibid). The analysis of the impacts of the ring road on the city center substantiates that ring roads have a general adverse impact on central cities, a finding observed in Western cities also (Blaney-Dyett \& Payne-Maxie, 1980).

In addition, the analysis shows that the contemporary socioeconomic conditions in the city promote "automobilization", the theme of the sub-hypothesis C. It was found that Riyadh is witnessing the growing phenomenon of auto dependency. The residents of the city are very dependent on the private automobile to the degree that about $97 \%$ of daily person-trips are auto based. Cultural, economic, and climatic factors work together to make the success of public transport (e.g making public transport modes used more than the private automobile) a very challenging task. Moreover, the analysis of this suggests that the proliferation of vacant urban lands and the accompanying dispersed layout of activities has resulted in an over-proportionate length of trips.

\subsection{Implications}

The research findings lead to several planning implications. They clarified the importance of the timing of ring road development. Proper timing could determine the amount of leapfrogging, and consequently the amount of vacant urban lands, in the city. It suggests that when a ring road is 
developed in a city similar to Riyadh in terms of the four given stipulations, ${ }^{23}$ then it is the timing of such development that will determine the size and distribution of vacant lands. If the development happens at a time, for instance, where the encircled area (by a ring road) is highly developed (i.e, when the ratio of the built up area to the total city area is high), then the potential of the creation of new vacant urban lands will be limited.

In order to make ring roads development compatible with the achievement of balanced urban growth and efficient land utilization patterns, the dissertation suggested a ring road development process. This process is designed to assure that ring road development will not be accompanied by unnecessary accumulation of large amounts of vacant urban land. This process consists of four steps:

. Definition of the city's boundaries;

- Determination of the Desired Development Ratio (DDR) and selection of the appropriate timing for ring road development;

. Choosing the route of the ring road so that timing is satisfied; and - Implementation.

It assumed that the adoption of this process will prevent future ring road development from inducing leapfrogging growth which in return would precipitate the spread of vacant urban lands.

23 The discussion of relevant urban theories and models led to the establishment of four stipulations necessary to make a model applicable to other cities. They relate to the cities in which the model is to be applied. First, the cities must be very similar in terms of their culture and their value systems as well as their economic and political institutions. Second, the cities must possess a similar economic base. Third, the cities must share certain basic characteristics in terms of their urban transport structure. For example, they must fall in the same category in Thomson's classifications of cities, and they should be at the same development stage (i.e., whether a city ADR is high or low). Fourth, the cities must have similar topographical/climatic settings. It is the view of the author that a model which successfully explains the urban structure of a city can generalize with higher chances of success to other cities which satisfy the same four stipulations. 
The discussion of the LGS and REDF programs has clarified that they can be used together as useful tools for managing and guiding urban growth. These two programs can be used as policy options aimed at reducing the spread of vacant urban lands. The LGS and REDF could be used to discourage development in outer areas. The city has experienced in the last few years alone (e.g., during 1986-91) a massive growth in population, but this growth did not result in infill development of the existing vacant urban lands.

If all the existing vacant lands were to be developed, assuming everything else remains constant, moving in the city might become a little more difficult. However, waiting for these lands to develop on their own, e.g. through dynamics of the market system, means that leapfrogging will continue and thereby more vacant urban lands will be created. This situation will lead to the formation of a very stretched city containing numerous voids. The inevitable development of these voids, because they are privately owned, will result in a large, continuous city in which travelling may become inefficient.

The analysis in this thesis has shown that there is need to interweave the Islamic and arabic cultural components with future urban plans. This will satisfy certain cultural needs such as privacy. One of the reasons that vacant urban lands are of use to some residents is that these lands satisfy some privacy requirements. For example, residents whose units are adjacent to vacant urban lands might enjoy more privacy as there will not be immediate neighbour(s) overlooking their houses. The traditional Islamic-Arabic City was characterized by containing housing units which have their own voids, the courtyard. To the contrary, our contemporary cities 
have adopted regulations (often from other cultures), such as setbacks, which have resulted in the disappearance of the courtyard. In the past, the courtyard has fully satisfied the privacy requirements as unit users could orient their unit openings to it without diminishing others' privacy. Therefore, there is a need to re-establish the concept of the courtyard in a way that satisfies our contemporary needs.

It is further recommended to designate areas around freeway (and other major roads) interchanges for intensified uses that reflect their maximum potential. These areas are highly accessible and therefore are recommended to be developed more intensively so that natural growth points in such areas flourish. This will help in the establishment of a more efficient public transport system which will, besides other services, link these areas with the city center and also with each other.

Finally, other measures to deal with the problem of vacant lands should be considered. Measures such as imposing certain financial costs on existing vacant lands and preventing commercial development in areas outside designated UGL boundaries may be of some value. Although there could be legal obstacles to the former, it does hold some promise. The latter, preventing commercial development in outer areas, present fewer legal problems (because it does not prevent a person from using his land for his own housing needs), but the effectiveness of such a measure may take a longer period of time to materialize. However, both measures, and indeed any other measure in this context, are but treatment measures. The theme of this thesis suggests a preventive measure (i.e., the proper timing of ring road development), a dimension which will prevent the problem from occurring in the first place. 


\subsection{Recommendations For Further Research}

One of the important issues this dissertation raises is the notion of efficiency of urban land utilization. It reflects the degree of utilization of infrastructural investments in urban areas. Urban areas with infrastructural lines in place, but containing large amount of vacant urban lands, are not efficiently utilizing their infrastructural investment. In this sense, a research topic which investigates land utilization efficiency taking into account the Islamic and arabic cultural imperatives (i.e. the need for privacy, the courtyard concept, and the attachment to the single family unit $)^{24}$ will be of significant contribution. The research should tackle relevant questions including: How can we maintain an efficient city development given these cultural imperatives and the contemporary needs of urban life? How can we improve road accessibility and maintain a compact Arabian city? The next two paragraphs elaborate on these two questions and the discussion to follow introduces recommended research topics.

Maintaining an efficient city development given the Islamic and arabic cultural imperatives and today urban life needs is a challenging research topic. Imperatives, such as privacy, the courtyard, and the attachment to the single family unit should be examined to determine how they interact with the contemporary urban life needs and consequently shape urban form. The research should

\footnotetext{
24 The attachment towards single family housing, in particular the villa, might provide some explanation for Riyadh horizontal growth instead of vertical growth in form of high rises. Between 1986-87 and 1990-91, 55\% of the dwelling units developed in Riyadh were villas, a two stories single family unit. Most of the Saudis prefer to live in single family unit. Even in the middle of this century, before the oil boom of the 1970's, people lived in Arab houses, one or two stories single family unit (some times extended families live in such a unit) and few chose apartment buildings. Today, as was the case in the past, apartment buildings are not the preferable type of housing in Riyadh. Privacy could be one of the reasons for such a preference for a family living in an apartment building will have to share many spaces (stairways, main entrance, etc...) with tens of other families living in the same buildings. This sharing reduce the amount of privacy for apartment users when compared with villa users who do not have to share any housing space with others.
} 
provide guidelines to develop an urban environment that caters to the cultural tenets and yet leads to an efficient city. In other words, how to assure that our new neighbourhoods will develop in such a way that satisfies privacy requirements, provide housing units that are not stacked over each other such as the case in high rise apartment buildings (which are not yet common in Riyadh but exist in many international cities), and utilize their infrastructure in an efficient manner?

Future research should also deal with future highway investment in a constructive way. Rather than classifying any future road development as unhealthy, it should find ways to make such a development--when needed--contributive to the achievement of efficient, sustainable, and compact cities. Since this dissertation has investigated how the ring road impacted urban growth in outer areas and thus the role such a road played in increasing the physical size of the city, future research should provide criteria to determine the appropriate geographical size of the our cities considering all relevant socioeconomic, cultural, climatic, and topographical factors. The efficiency of cities can not be divorced from their geographical location and size. The question to be raised here is what is the appropriate physical size of our cities (given their economic base, the cultural background of its residents, and the dominant desert climate) and how a ring road influences this size? How will such a size change if one these variables (e.g. climate) differs? If these questions are answered then we can use freeway development as a controlling factor influencing urban form. For example, we may develop a freeway in such a way that its urban impact will contribute to efficient development. One way of using freeway development as control variable is the timing of such a development. If a freeway takes the form of a ring road, then its development timing is a critical factor in shaping the ultimate urban pattern. This 
dissertation has uncovered the importance of such a timing, but it did not provide an accurate estimate for it. Estimating the proper timing of ring road development will be a very useful research topic.

In this dissertation, "timing"'s estimate was based on the ratio of the built up area of the city to the total city area. An accurate estimate of this ratio will represent an accurate estimate of "timing". In order to establish a reliable "timing", the proposed research should be based on several comparable cities of different sizes, but similar with respect to the four stipulations introduced in Chapter II. However, it will require more data, especially disaggregate data (e.g. data by Hara, a small community, as opposed to data by submunicipality ${ }^{25}$, than what have been used in this thesis. Specifically the following data will be required:

- Residential and commercial Land values (average and median by Hara).

- Travel demand patterns (e.g. origin/destination information).

- Auto ownership by both Hara and family size.

- The quality of road network (e.g. its ability to save traveller time and provide relatively equal auto accessibility to all city areas).

. Household income and per capita income.

- Population forecast by age group.

- Average male and female marriage age (to predict the formation of new households and thus the demand on urban land).

- Growth in employment by city zone.

25 Hara is a much smaller unit than a submunicipality. A submunicipality can easily accommodate more than 10 Haras. For example, Oliaya submunicipality contains 12 Haras and Shamal submunicipality contains 23 Haras. 
- Accurate data on all developable vacant lands which could be incorporated in a city within a certain period of time.

These data could be used in a model that is tailored to estimate the probable urban form at a selected future year if a ring road is to be developed. This model should be a planning model, that is it must not be totally dependent on quantitative analysis. It should clearly incorporate qualitative factors (e.g. cultural factors) and must consider the dominant value system in the concerned city. Upon its development, the model should be able to predict the ultimate urban pattern (e.g. the direction and intensity of urban growth, the amount of vacant lands, ... etc). It is necessary to update this model periodically as the cultural imperatives change.

The efficiency of the consequent urban form (following a ring road development) can be estimated by analyzing the percentages of vacant lands in each Hara and relating them to the potential investment in service provisions. In order to clarify such an analysis let us consider the following example. Assume that planners in a city are contemplating a ring road development and assume that this city is comprised of 6 rings and all within lands are developable. The first ring encircles the city center, the second ring encircles the first ring and so on. Assume also that each ring consists of one zone (just for the sake of simplicity) and that the city has defined its boundaries and included all the 6 rings within. If the city planners want to know the best estimate of the proper timing of the ring road development, then the model could be used. If the model predicts that at year " $\mathrm{t}$ " zone 6 (or ring 6) will highly develop (and therefore will require high investment in service provisions), zones 4 and 5 will slightly develop (and therefore will utilize little of the capacity of service lines which pass them going to zone 6), and the remaining zones 
$(1,2$, and 3) will stay the same (not affecting the investment in service provisions), then the city's planners should not recommend a ring road development at the present time. This is the case because restricting auto accessibility to zone 6 (by not developing a ring road) will force growth to take place in closer zones (i.e. 4 and 5). ${ }^{26}$ At this stage, planners should use the model to predict a future year " $t$ " at which zone 4 and 5, for instance, will highly develop. Using all relevant data such as those introduced earlier and controlling for road supply (e.g. restricting the building of ring roads, other radials, major arterials... etc.), the planners should be able to estimate the magnitude and direction of urban growth for a selected future year. At that year, the planners may recommend the development of a ring road. On the other hand, if the model predicts a normal pattern of growth (i.e. zones located closer to city center develop first), then the planners may recommend the ring road development.

Another topic of research, which relates to the above discussion is the study of how to create new efficiencies based upon improved road accessibility when a ring road is developed. This can be attained by encouraging higher-density mixed development projects in high auto-accessible areas (i.e. interchange areas). These developments projects should be required to accommodate all cultural requirements (i.e. Islamic $\&$ arabic). Freeway development is an urban investment which could be optimized with slight land use modifications. An interchange area exclusively zoned for mixed development (i.e. multifamily housing units as well as commercial and office spaces)

\footnotetext{
26 If the lands in zone 6 are not privately owned, then the chances of their development will be low. In addition, there will less demand on the granting of these lands because of their weak road accessibility. However, even if these lands are in private hands, their development will be slow because of their inadequate road accessibility. But if a freeway, a ring road in this case, improves accessibility to these lands, then the demand on their granting (if they are in public hands) or development (if they are in private hands) will be very high.
} 
would accommodate more people and dwelling units than if the same area were zoned for single family units (the current land use regulations in Riyadh do not restrict single family development from developing in interchange areas). The research should emphasize the need to make these development compatible with the dominant Islamic-Arabic culture. High density mixed development in this sense means low rise (few stories high) multifamily units which consist of at least 3 bedrooms and preferably 6 bedrooms. The relatively high number of bedrooms is necessary to accommodate the average Riyadh family size of 6.8 persons per household (ADA, 1992:30). These developments may include commercial and office space in the lower levels (e.g. ground levels). The research should provide suitable urban design criteria tailored to emphasize the human scale as opposed to serve the automobile. Criteria such as those limiting the width of the streets, elimination of the setbacks requirements, and reinstituting the courtyard concept. These criteria will result in communities which relate, architecturally, to the human scale. This will encourage walking which is a key ingredients in any successful public transportation program; walking will not be an inconvenient mode of travel for short trips if streets provide shaded passways. ${ }^{27}$ If these communities are achieved, then interchange areas might form nodal points. These points will constitute smaller sub-centers. It is better to direct all intense development to these nodal points (sub-centers), because in any auto dependent society subcenters will develop somewhere. If they develop in areas other than the highly accessible ones (by roads), then inefficient use of the road network occur. On the other hand, if these nodal points develop to be sub-centers and connect with the city center by a good quality public

27 Shaded passways can be attained most of the day-time by reducing the width of minor arterials, e.g. neighbourhood streets, and eliminating the front setbacks so that the housing structure can be adjacent to the property line. 
transport system (e.g., frequent bus services, air-conditioned busses, shaded bus stops, etc...), the residents and visitors of such sub-centers will realize that there are modes of travel other than the auto which can provide the same service. 


\section{Bibliography}




\section{Bibliography}

Abdulaal, W. "Implications of Subdivision Activity for the Urban Growth of Madinah." Urban Studies, Vol. 27, 1990, pp. 725-738.

Abrahamson, M. Urban Sociology, New Jersey: Prentice-Hall, Inc., 1980.

ADA, Demographic Transportation Land Use And Economic Studies For The City Of Arriyadh, (in Arabic), 1988.

Demographic Transportation Land Use And Economic Studies For The City Of Arriyadh, 1986-1987.

- The Report Of The Urban Growth Limits For The City Of Riyadh (in Arabic), Riyadh Mayoralty, 1988.

. Land Use Survey \& Population Study (in Arabic), 1992.

. Tadhweer (in Arabic), 1990-92.

. Tadhweer (in Arabic), issues 5-7, 1992-93.

Akbar, J. Crisis In The Built Environment: The Case Of The Muslim City, Singapore: Concept Media, 1988.

Almajallah (an Arabic magazine), "Saudi Real Estates." Almajallah, Issue 679 pp. 57-60, February 1993.

Al-Mogren, A. Bridging The Gap: Centralization Vs. Decentralization In The Saudi Municipal Planning System, And Its Impacts On The physical Environment, Unpublished Ph.D thesis: University of Pennsylvania, 1992.

Alsharq Alawsat (an Arabic newspaper), "Real Estate Prices Increase 20\% In September: Kuwaiti Investments and Early Marriage Activate Market." Alsharq Alawsat, Issue 5070 pp. 11, September 1992.

. "Riyadh...The Desert Oasis." Alsharq Alawsat, Issue 5426 pp.13, September 1993.

Alexander E. Approaches to Planning: Introducing Current Planning Theories, Concepts and Issues, New York: Gordon and Breach Publishers, 1986.

Alhammad, M. Growth Of Saudi Cities Between Theory And Practice. KSU: Arriyadh, 1987, pp. $31-61$. 
Alonso, W. Location and Land Use, Harvard University Press, Cambridge: 1964

Archer, R.W. "Land Speculation and Scattered Development: Failures in the Urban Fringes Land Market." Urban Research Unit Seminar Series, 1972.

Arnstein, Sherry, "A Ladder of Citizen Participation." Journal of the American Institute of Planners, July 1969, pp. 216-224.

Arrow, K. Social Choice and Individual Values, New York: John Wiley \& Sons, 1951.

Artibise, A. Town Centres and the Livable Region: A strategy for the 1990s, Burnaby, B.C.: Greater Vancouver Regional District, 1990.

AUDI, Riyadh The City Of The Future, Riyadh: King Saud University Press, 1986.

Ayeni, B. Concepts and Techniques in Urban Analysis, London: Croom Helm, 1979.

Babbie, E. The Practice of Social Research, Belmont: Wadsworth Publishing Company 1986 \& 1989.

Banfield, Edward, "Note on Conceptual Scheme." in Meyerson, Martin and Banfield, Edward, Politics, Planning and the Public Interest, pp. 303-329, New York:The Free Press, 1955.

Beckmann, Martin, "On the Distribution of Urban Rent and Residential Density." Journal of Economic Theory, 1, 1 (June, 1969): 60-67.

Berry \& Fieldman, Multiple Regression In Practice, Beverly Hills: Sage Publication, 1985.

Bibby \& Shepherd, Rates of Urbanization in England 1981-2001, London: HMSO, 1990.

Birch, B.J.L. "Toward a Stage Theory of Urban Growth." Journal of the American Institute of Planners, 37, pp. 78-87, 1971

Blumenfeld, H. The Modern Metropolis, Cambridge: The M.I.T Press, 1966.

Blunden \& Black, The Land use Transportation System, Sydney: Pergamon Press, 1984.

Blunden, W. The Land Use/Transport System, Oxford: Pergamon Press, 1971.

Bourne, L.S. Urban Systems, Oxford, Clarendon Press, 1975.

Brodsly, D. L.A. Freeways, Berkeley: University Of California Press, 1981.

Brown, A. "Evidence to the Expenditure Committee on Regional Development Incentives." 
London: House of Commons Paper \#5, 1973 (as discussed in Bruton pp. 31 and 49).

Brown, H.J., et. al. "Land Markets at the Urban Fringe." Journal of the American Planning Association, April, 1981.

Browning, C. "The Rise of the Beltways: A Powerful Force for Urban Change." FOCUS, 1990 pp. 18-22.

Brutzkus, Eliezer, "Centralized Versus Decentralized Patterns of Urbanization in Developing Countries: An Attempt to Elucidate a Guideline Principle." Economic Development and Cultural Change v:23, no:4, july 1975 , pp. 633-652.

Burchell and Sternlieb, (eds). Planning Theory in the 1980's (1979), pp. 209-211.

Burgess, E. "The Growth of the City." in Robert E. Park, et al (eds) The City, Chicago: University of Chicago Press, 1925.

Burrow, L. Growth Management Issues, Techniques, and Policy Implications, New Brunswick: The Center For Urban Policy Research, Rutgers University, 1978.

Carmines \& Zeller, Probability and Validity Assessment, Beverly Hills: Sage Publication, 1979.

Cervero, Robert, "Job-Housing Balancing \& Regional Mobility." Journal of the American Planning Association, Spring, 1989, 136-151.

Chaline \& Fares, The Contemporary Town Planning and Riyadh an Introduction to The Planning of Human Settlements in Arab and Western Countries, Riyadh, 1986.

Cheema,S.\& Rondinelli D. Decentralization and Development, Beverly Hills : Sage Publication 1983.

Chenery, H. Structural Change And Development Policy, Oxford: the International Bank, 1979.

Child, D. The Essentials Of Factor Analysis, London: Cassell Ed. Ltd.,1990.

Cole, S. Applied Transport Economies, London: Kogan Page Limited 1987.

Colenutt, R.J. "Building Models of Urban Growth and Spatial Structure." in Progress is Geography, 2 Arnold, London, pp. 109-152, 1970

Connally, J. with the Bureau of Population \& Economic Research, The Socio-Economic Impact Of The Capital Beltway On Northern Virginia, Charlottesville: University of Virginia, 1968.

Converse \& Presser, Survey Questions, Beverly Hills: Sage Publications, 1986. 
Conyers, D. "Decentralization and Development, vol. 14, no. 5, pp. 593-603 (1986)

Daghistani, A. Ar.Riyadh Urban Development and Planning, Riyadh: The Ministry of Information, 1985.

Dar Al-Handasa Consultants, Riyadh Ring Road: Reconnaissance and Engineering Report, Riyadh: 1983.

Dar Al-Handasa Consultants, Riyadh Ring Road: Preliminary Engineering, Riyadh: 1975.

Dare, C. Cedar Rapids I-380: Freeway Noise, Multiple Land Use And Aesthetics Study, Ames: Iowa State University, 1973.

Davidoff, P. \& Reiner, T.A. "A Choice Theory of Planning." Journal of the American Institute of Planners, 28 (2) (1962), pp. 103-115.

Davis, J. The Logic of Causal Order, Beverly Hills: Sage Publications 1985.

Davis, K. Land Use, New York: McGraw-Hill Book Company, 1976.

De Grove, J. Land Growth \& Politics, Washington: APA Planners Press, 1984.

Debres, K. "Jam Yesterday, Jam Today and certainly Jam Tomorrow: A personal View of the Costs, Benefits and Congestion of London's New Orbital Road." Focus, 1989 pp. 12-16.

De Tocqueville, A. Democracy In America, New York: Alfred A. Knof 1953.

Dickey, John W. et. al. Metropolitan Transportation Planning, 2nd ed.,McGraw-Hill: New York, 1978.

Dodge, W. "Discussion of the Interrelationship of the Changing Structure of American Transportation and Changes in Industrial Location." Land Economics, 1965, V. 41, pp. 180-182.

Dowall, D. The Suburban Squeeze, Berkeley: University of California Press, 1984.

Downs, A. "Regulatory Barriers To Affordable Housing." Journal of the American Planning Association, Autumn 1992, pp. 419-422.

Dror Y. Public Policy making Re-examined, Scarton: Chandler Publishing Company, 1968.

Dyett \& Payne-Maxie, The Land Use and Urban Development Impacts of Beltways, Berkeley: 1980. (Executive Summary) The Land Use and Urban Development Impacts of Beltways, Berkeley: 1980. (Final 
Report) Report)

. The Land Use and Urban Development Impacts of Beltways, Berkeley: 1980. (Technical The Land Use and Urban Development Impacts of Beltways, Berkeley: 1980. (Guide Book)

Faludi, Andreas, A Reader in Planning Theory, Oxford: Pergamon Press, 1973. Planning Theory, Oxford: Pergamon Press, 1973.

Farsi, Z. National Guide \& Atlas of the Kingdom of Saudi Arabia, Jeddah, 1989.

Fesler, James W. "Approaches To the Understanding of Decentralization." The Journal of Politics, v:27, no:1, Feb 1965, pp. 536-566.

Fesler, "Centralization and Decentralization." In International Encyclopedia of Social Science, v:2, ed David L. Sills, New York: MacMillan Company and the Free Press, 1968.

Firey, Walter, Land Use in Central Boston, Cambridge, Mass: Harvard University Press, 1947, pp. 48. Cited in Michael C. Romanos, Residential Spatial Structure, Lexington, Mass.: Lexington Books, 1976, pp. 47.

Friedmann, John, Planning in the Public Domain: From Knowledge to Action, Princeton: Princeton University Press, 1987.

Friedmann, John and Hudson, Barclay, "Knowledge and Action: A Guide to Planning Theory." Journal of the American Institute of Planning (January, 1974), pp. 2-16.

Gale, E. "Eight State-Sponsored Growth Management Programs: A Comparative Analysis." Journal of the American Planning Association, Autumn 1992.

Garrison \& Marts, Influence Of Highway Improvements On Urban Land: A Graphic Summary, Seattle: University of Washington, 1958.

Gay et al Social Research Methods, Boston: Allyn \& Bacon Inc., 1987.

Geiser, K. Urban Transportation Decision Making, Cambridge: MIT, 1970.

Godschalk, D. "In Defence Of Growth Management." Journal of the American Planning Association, 1992, pp. 422-424.

Graham, Bill, "Managing the Transportation System To Deal with Growth: San Diego's 
Experience." ITE Journal, August, 1989, 23-25.

Haig, R.M. Major Economic Factors in Metropolitan Growth and Arrangement, Regional Plan of New York and Its Environs, 1, New York: 1927

Haig, Robert, Regional Survey of New York and Its Environs, New York: New York City Plan Commission, 1927

Hajrah, H. Public Land Distribution in Saudi Arabia, London: Longman Group, 1982.

Hall, P. "Managing Growth In The World Cities." Berkeley Planning Journal, Vol. 6, 1992, pp. 19-35.

Harris C. \& Ullman E. "The Nature of Cities." The Annals of the American Academy of Political and Social Science, 242, November 1945, pp. 7-17.

Harrison, D. Simulating the Impact of Transportation Policies on Urban Land use Pattern, Cambridge: Harvard University.

Hart, David K. "Theories of Government Related to Decentralization and Citizen Participation, Public Administration Review, v:XXXII, Oct 19762, pp. 603-621.

Harvey, D.W. "Social Processes and Spatial Form: An Analysis of the Conceptual Problems of Urban Planning." Regional Science Association, 25, pp. 47-70: 1970

Hawley, Amos, Human Ecology: A Theory of Community Structure, New York: The Ronald Press Company, 1950

Hoover \& Giarratani, An Introduction to Regional Economics, N.Y: Alfred Knop Inc., 1984.

Hoyt, Homer, Structure and Growth of Residential Neighbourhoods in American Cities, Washington, D.C.: Federal Housing Administration, 1939

Hudson, Barclay, "Comparison of Current Planning Theories: Counterparts and Contradictions." Journal of the American Planning Association, V. 45:4, 1979, pp. 387-398.

Hughes, James and George Sternlieb, "The Suburban Growth Corridor." American Demographics: 35-37, April, 1986.

Humbach, J. "Existing-Use Zoning." Zoning News, Dec. 1992, pp. 1-2.

Hunter, H. "Transport in Soviet and Chinese Development." Economic Development and Cultural Change, 1965, V. 65, pp. 71-84. 
Hurd, R.H. Principles of City and Values, New York, The Record and Guide: 1903

Innes, J. "Group Process And The Social Construction Of Growth Management, Florida, Vermont, And New Jersey." Journal of the American Planning Association, Autumn 1992.

ITE, Transportation and Land Development, New Jersey: Prentice Hall, 1988.

Jackson, W. Research Methods, Scarborough: Prentice Hall Canada Inc., 1988.

Johnston, et al, "Growth Phasing and Resistance to Infill Development in Sacramento County, Journal of the American Planning Association, 434-446, Autumn, 1984.

Jones, et al, Understanding Travel Behaviour, Aldershot: GPL Ltd., 1983.

Kaufman, H. "Administrative Decentralization and Political Power." Public Administration Review, v:XXXIX, (Jan/Feb. 1969) pp. 3-16.

Khisty, C. Transportation Engineering : An Introduction, New Jersey: Prentice-Hall Inc., 1990.

Kim \& Mueller, Factor Analysis Statistical Methods And Practical Issues, Beverly Hills: Sage Publications, 1978.

Kim, T. Integrated Urban System Modelling: Theory and Application, Dordrecht: Kluwer Academic Publishers, 1989.

King, R.J. "Urban Housing Market Changes As Context For Transportation Change: Some Approaches To Analysis." Transport Review, Vol. 10, 1990, pp. 59-82.

Kirk, G. Urban Planning in a Capitalist Society, Croom Hill, London, 1980.

Klassen et al, Transportation and Reurbanization, Aldershot: Gower Publishing Company Ltd., 1981.

Kochen M. \& Deutsch K. Decentralization: Sketches Toward A Rational Theory, Cambridge: Oelgeschlager, Gunn \& Hain, Publishers, Inc.

Koushki, P. "The Effect Of Socio-Economic Development On Household Travel Behaviour In Saudi Arabia." Socio-Economic Planning Sciences, Vol. 22, No. 3, pp. 131-136, 1988.

Koushki, P. "Mobility Costs: Household Travel Expenditures in Riyadh, Saudi Arabia." Transportation Quarterly, Vol. 40, No.4, pp. 571-578, Oct 1986.

Krieger, M. Advice and Planning, Philadelphia: Temple University Press, 1981 
Krueckeberg \& Silvers, Urban Planning Analysis: Methods and Models, New York: J. Wiley \& Sons Inc., 1974.

Landis, J. "Do Growth Controls Work." Journal of the American Planning Association, 1992, Autumn.

Lee, D. How to Do a Transit Station Land Use Impact Study, Iowa City, University of Iowa.

Lehman, D. Market Research and Analysis, Homewood: Richard Irwin, Inc., 1985.

Leibbrand, K. Transportation and Town Planning, translated by N. Seymer, Cambridge: The M.I.T. Press, 1970.

Levinson \& Strate "Land Use and Energy Intensity." Transportation Research Record, 812 pp. 67-74, 1981.

Lewis-Beck, Applied Regression: An Introduction, Beverly Hills: Sage Pub. 1980.

Lindblom, C. "The Science of 'Muddling Through'." Public Administration Review (Spring 1959), pp. 79-88.

Marcuse, P. Professional Ethics and Beyond: Values in Planning, Journal of the American Institute of Planners, 42 (July) (1976), pp. 264-274.

Mather, A. Land use, London: Longman Group, 1986.

Mckinsey Inc. Mastering Urban Growth: A Blueprint For Management, A report prepared for the Ministry Of Municipal And Rural Affairs, New York, 1978.

Meyer Michael D. and Eric J. Miller, Urban transportation Planning: A Decision-Oriented approach, McGraw-Hill: New York, 1984.

Moore et al An Introduction to Urban Development Models and Guidelines for their Use in Urban Transportation Planning, US DOT, 1975.

Muth, Richard, Cities and Housing: The Spatial Pattern of Urban Residential Land Use, Chicago: University of Chicago Press, 1969.

Nelson, A. "Preserving Prime Farm Land In The Face Of Urbanization." Journal of the American Planning Association, Autumn 1992.

Newman \& Kenworthy, Cities And Automobile Dependence: An International Source Book, Aldershot: Gower Technical, 1989a \& 1991. 
Nowlan \& Stewart, "Downtown Population Growth and Commuting Trips Recent Experience In Toronto." Journal of the American Planning Association, Spring 1991, 165-182.

OECD, Cities and Transport, Paris: OECD, 1988.

Ogunjumo, A. "Inequality In Transport And Communication NetWork Development In Oyo State, Nigeria." Third World Planning Review, pp. 177-189.

Oppenheim, N. Applied Models in Urban and Regional Analysis, New Jersey: Prentice Hall, 1980.

Palumbo, George and Patricia Hutton, "On the Causality of Intraurban Location." Journal of Urban Economics: 22;1-13, 1987.

Patricios, N. International Handbook on Land Use Planning, New York: Greenwood Press, 1986.

Patton \& Sawiki, Basic Methods Of Policy Analysis \& Planning, New Jersey: Prentice Hall, 1986.

Pederson, G. Transportation in Cities, New York: Pergamon Press, 1980.

Pendakur, V. Setty, "Taming the Automobile: Lessons from Singapore." Plan Canada, 27:8, 208214.

Perloff, Harvey, "Education of City Planners: Past, Present and Future." Journal of the American Institute of Planners, pp. 186-217 (Fall, 1956).

Peterson, P. City Limits, Chicago: The University Of Chicago Press, 1981.

Pfaffenberger \& Patterson, Statistical Methods, Homewood: Richard Irwin, Inc., 1981.

Porter, D. \& Olson, E. "Some Critical Issues in Government Centralization and Decentralization." Public Administration Review, v:36 no. 1, Jan/Feb 1976, pp. 72-84.

Pusharev \& Zupan Public Transportation and Land Use Policy, Bloomington: Indiana University Press, 1977.

Putman, S. The Interrelationships of Transport Development and Land Development, Vol. 1. A report prepared for the U.S. Department of Transportation, 1971.

Real Estate Research Corporation, The Costs of Sprawl, Washington, 1974.

Rees \& Leigh, Models Of Cities And Regions, Chichester: J. Wiley \& Sons Ltd., 1977. 
Rich, D. "Population Potential, Potential Transportation Costs and Industrail Location." Area, V. 10, 1978 (as discussed in Bruton; pp. 31 and 49).

Richardo, D. On The Principals of Political Economy and Taxation, Washington, D.C.: J. Milligan, 1819.

Robert \& David, Urban Sociology, N. J.: Prentice Hall, Inc., 1978.

Robson, B.T. Urban Analysis, Cambridge University Press, Cambridge: 1969.

Rondinelli, D. "Government Decentralization in Comparative Perspective:Theory and Practice in Developing Countries." International Review of Administrative Sciences, no:2 1981, pp. 135-145.

Rondinelli, D. \& Cheema S. "Decentralization in Developing countries: A Review of Recent Experience." Word Bank, Washington, D.C., 1983.

Schmandt, H. "Municipal Decentralization: An Overview." Public Administration Review, v:32, Oct 1972, pp. 571-588.

Schroeder et al, Understanding Regression Analysis, Beverly Hills: Sage Publication 1986.

Sharpe, L. Decentralized Trends In Western Democracies, London: Sage Publication, 1979.

Siegel, J. Intrametropolitan Migration of White and Black Households, (Working Paper), Toronto, 1971.

Simon, H. Adminstrative Behaviour, New York: Free Press, 1976 (Original 1945).

Simon, H. et al Public Adminstration, New York: Alfred Knopf, 1950.

Singleton, R. Approaches to Social Research, New York: Oxford Univ. Press, 1988.

Smith, B. Decentralization: The Territorial Dimension of The State, London:

George Allen \& Unwin (Publishers) Ltd. 1985.

Smith, W. Future Highways And Urban Growth, New Haven, Connecticut. Under Commission From THE AUTOMOBILE MANUFACTURERS ASSOCIATION, 1961.

Sparks \& Montemayor, The Application Of Factor Analysis To Land Use Change In A Metropolitan Area, Austin: University of Texas, 1975.

Spector, P. Research Design, Beverly Hills: Sage Publications, 1981.

Spielberg, F. and S. Andrle, "The Implications of Demographic Changes on Transportation 
Policy." Journal of the American Planning Association, v. 48, Summer 1982, 301-308.

Susskind, Lawrence, "Citizen Participation and Consensus Building in Land Use Planning." in Judity I. de Neufville, The Land Use Policy Debate in the United States, pp. 184-204.

Taylor, M. Measuring the Effects of Transport Investment on the Land Use Activity System. The Martin Center, Cambridge, 1979.

Telmesani, A. Exploration into Urban Structure and the Impact of Housing Construction Subsidies on Residential Location: The Case of Arriyadh, Saudi Arabia, Ph.D. dissertation, University of California at Berkeley, 1989.

Thomson, J. Great Cities and Their Traffic, London: Victor Gollancz Ltd., 1977.

Thunen, V. Der Isolitierte Staat in Beziehung auf National o konomie und landwirtschaft, Stuttgart: Gustav Fischer, 1966 (Original, 1826).

Tinbergen, J. Central Planning, New Haven: Yale University Press, 1964.

Tomazinis, A. New Elements in the Urban Transportation Process, Philadelphia: Center for Urban Research Experiment, 1971.

True, J. Finding Out, Conducting and Evaluating Social Research, Belmon: Wadsworth Publishing Company, 1989.

Washington State Department of Highways, Social, Economic And Environmental Impact Of Highway Transportation Facilities On Urban Communities, Pullman: Washington State University, 1968.

Wilson et al The Impact Of Highway Investment On Development, Washington, D. C.: The Brooking Institution, 1966.

Wilson \& Schulz, Urban Sociology, New Jersey: Prentice Hall, 1978

Wingo, L., Jr. Transportation and Urban Land, Resources for the Future, Washington, D.C. 1961.

Winston and Clifford "Efficient Transportation Infrastructure Policy." Journal of Economic Perspective, V.5, No.1, Winter 1991, pp.113-127.

Yin, R. "Decentralization of Government Agencies: What Does It Accomplish" American Behavioral Scientist, v:22, no:5, May/June 1979, pp. 525-536. 


\section{APPENDICES}


Appendix: A

\section{The Questionnaire}




\section{The Questionnaire}

This questionnaire will be offered to planners (public actors), developers (private actors) who practice in the city of Riyadh, Saudi Arabia, and academicians.

To the respondent: please answer the following questions. You will find that most of which have five category close ended answers. In addition, two levels of answers are needed here: the first will be your personal answer while the second will be your thought of what you think the public or popular answer would be.

1. Which of the followings categories best describes the sector in which you work (please give some description of your title)?

. Public

. Private

. Academic (

2. There exists a relationship between the ring road and the phenomena of sporadic development (having urban voids in the middle while developments occur at the fringes)? Personal: Strongly Agree Agree No Opinion Disagree Strongly Disagree Public : Strongly Agree Agree No Opinion Disagree Strongly Disagree

3. The development at the fringes is possible even if there were no improvement of the free 
way system especially the ring road?

Personal: Strongly Agree Agree No Opinion Disagree Strongly Disagree Public : Strongly Agree Agree No Opinion Disagree Strongly Disagree

4. The ring road helped in increasing the rate of the growth at the fringes?

Personal: Strongly Agree Agree No Opinion Disagree Strongly Disagree

Public : Strongly Agree Agree No Opinion Disagree Strongly Disagree

5. The ring road causes the decentralization of urban activities?

Personal: Strongly Agree Agree No Opinion Disagree Strongly Disagree

Public : Strongly Agree Agree No Opinion Disagree Strongly Disagree

6. The ring road causes the decentralization of housing units?

Personal: Strongly Agree Agree No Opinion Disagree Strongly Disagree

Public : Strongly Agree Agree No Opinion Disagree Strongly Disagree

7. The ring road causes the decentralization of shopping centers?

Personal: Strongly Agree Agree No Opinion Disagree Strongly Disagree

Public : Strongly Agree Agree No Opinion Disagree Strongly Disagree

8. The ring road affected the decision of those who located in the fringes?

Personal: Strongly Agree Agree No Opinion Disagree Strongly Disagree 
Public : Strongly Agree Agree No Opinion Disagree Strongly Disagree

9. Cheaper land values are a major factor in household locations in the fringes?

Personal: Strongly Agree Agree No Opinion Disagree Strongly Disagree

Public : Strongly Agree Agree No Opinion Disagree Strongly Disagree

10. The efficiency of the transportation system is the major factor that determines locational decisions in the fringes?

Personal: Strongly Agree Agree No Opinion Disagree Strongly Disagree

Public : Strongly Agree Agree No Opinion Disagree Strongly Disagree

11. The ring road helped in decentralizing all economic activities (e.g. financial institutions, stores, shopping centers ... etc.)?

Personal: Strongly Agree Agree No Opinion Disagree Strongly Disagree Public : Strongly Agree Agree No Opinion Disagree Strongly Disagree

12. If the cost of using and operating the automobile (e.g. car prices and gas prices) is very high people would switch to other modes (bussing, cycling, or walking)?

Personal: Strongly Agree Agree No Opinion Disagree Strongly Disagree

Public : Strongly Agree Agree No Opinion Disagree Strongly Disagree

13. If weather is pleasant year around people will use modes other than their automobiles? 
Personal: Strongly Agree Agree No Opinion Disagree Strongly Disagree

Public : Strongly Agree Agree No Opinion Disagree Strongly Disagree

14. The existing urban physical layout of the city encourages the use of modes other than the private auto?

Personal: Strongly Agree Agree No Opinion Disagree Strongly Disagree

Public : Strongly Agree Agree No Opinion Disagree Strongly Disagree

15. The ring road helped in saving the overall travellers' time?

Personal: Strongly Agree Agree No Opinion Disagree Strongly Disagree

Public : Strongly Agree Agree No Opinion Disagree Strongly Disagree

16. The ring road helped in reducing the overall accident rate?

Personal: Strongly Agree Agree No Opinion Disagree Strongly Disagree

Public : Strongly Agree Agree No Opinion Disagree Strongly Disagree

17. The ring road helped in reducing the overall fuel consumption level?

Personal: Strongly Agree Agree No Opinion Disagree Strongly Disagree

Public : Strongly Agree Agree No Opinion Disagree Strongly Disagree

18. Rank the following (from 1 to 4 ) as the major advantages of the ring road?

. Promote economic growth 
. Make a variety of lands' prices accessible for a wider range of buyers

. Rerouting heavy transport

. Other (please specify):

19. What of the following do you think be the most preferred development at the ring road exchanges (rank from 1 to 5$)$ ?

. Commercial

. Industrial

. Institutional

. Residential

. Other (please specify):

20. Rank the following factors (from 1 to 4 ) in terms of explaining the automobile dependency of the citizens of Riyadh?

. Social (Norm \& Tradition)

. Economical

. Climatic

. Other (please specify):

21. Rank the following item (from 1 to 4 ) in terms of guiding households' locational decisions?

. Income 
. Accessibility

. Relatives \& friends

. Image (e.g. certain areas have more of a prestige image)

22. How do you see the freeway system in general and the ring road in particular in relation to the growth of the city of Riyadh?

23. How can Riyadh's advance experience in freeway planning, ring road in particular, can be used to help other urban centers in the kingdom and other similar countries?

24. Any other comments? 
Appendix: B

The Questionnaire's Frequencies: Normal Percentages 
The Questionnaire's Irequencies: Normal Percentages

\begin{tabular}{|c|c|c|c|c|c|}
\hline \multirow{6}{*}{$\begin{array}{r}\text { COUNT } \\
24 \\
5 \\
44 \\
3\end{array}$} & CUM & \multicolumn{3}{|c|}{ CUM } & \multirow{2}{*}{ (PERSONAL) } \\
\hline & COUNT & PCT & PCT & 02 & \\
\hline & 24 & 31.6 & 31.6 & \multicolumn{2}{|c|}{ AGREE } \\
\hline & 29 & 6.6 & 38.2 & \multicolumn{2}{|l|}{ DISAGREE } \\
\hline & 73 & 57.9 & 96.1 & \multirow{2}{*}{\multicolumn{2}{|c|}{$\begin{array}{l}\text { SAGREE } \\
\text { SDISAGREE }\end{array}$}} \\
\hline & 76 & 3.9 & 100.0 & & \\
\hline \multirow{7}{*}{$\begin{array}{r}\text { COUNT } \\
11 \\
26 \\
4 \\
10 \\
25\end{array}$} & \multicolumn{2}{|l|}{ CUM } & \multicolumn{2}{|l|}{ CUM } & \multirow[b]{2}{*}{ (PUBLIC) } \\
\hline & COUNT & $\mathrm{PCT}$ & PCT & Q2 ( & \\
\hline & 11 & 14.5 & 14.5 & \multicolumn{2}{|c|}{ (2) } \\
\hline & 37 & 34.2 & 48.7 & \multirow{2}{*}{\multicolumn{2}{|c|}{$\begin{array}{l}\text { AGREE } \\
\text { DISAGREE }\end{array}$}} \\
\hline & 41 & 5.3 & 53.9 & & \\
\hline & 51 & 13.2 & 67.1 & \multicolumn{2}{|l|}{$\begin{array}{l}\text { DISAGREE } \\
\text { NOPONION }\end{array}$} \\
\hline & 76 & 32.9 & 100.0 & \multicolumn{2}{|l|}{ SAGREE } \\
\hline \multirow{7}{*}{$\begin{array}{r}\text { COUNT } \\
27 \\
25 \\
5 \\
14 \\
5\end{array}$} & \multicolumn{2}{|l|}{ CUM } & CUM & \\
\hline & COUNT & PCT & PCT & \multicolumn{2}{|c|}{ Q3 (PERSONAL) } \\
\hline & 27 & 35.5 & 35.5 & AGREE & \\
\hline & 52 & 32.9 & 68.4 & DISAGREE & \\
\hline & 57 & 6.6 & 75.0 & NOPONION & \\
\hline & 71 & 18.4 & 93.4 & SAGREE & \\
\hline & 76 & 6.6 & 100.0 & SD ISAGREE & \\
\hline & CUM & & CUM & & \\
\hline COUNT & COUNT & PCT & PCT & Q3 1 & (PUBLIC) \\
\hline 13 & 13 & 17.1 & 17.1 & & \\
\hline 22 & 35 & 28.9 & 46.1 & AGREE & \\
\hline 15 & 50 & 19.7 & 65.8 & DISAGREE & \\
\hline 15 & 65 & 19.7 & 85.5 & NOPONION & \\
\hline 9 & 74 & 11.8 & 97.4 & SAGREE & \\
\hline 2 & 76 & 2.6 & 100.0 & SDISAGREE & \\
\hline & CUM & & CUM & & \\
\hline COUNT & COUNT & РCT & PCT & Q4 ( & (PERSONAL) \\
\hline & 2 & 2.6 & 2.6 & & \\
\hline 22 & 24 & 28.9 & 31.6 & AGREE & \\
\hline 3 & 27 & 3.9 & 35.5 & DISAGREE & \\
\hline 48 & 75 & 63.2 & 98.7 & SAGREE & \\
\hline 1 & 76 & 1.3 & 100.0 & SDISAGREE & \\
\hline & CUM & & CUM & & \\
\hline COUNT & COUNT & PCT & PCT & Q4 1 & (PUBLIC) \\
\hline 12 & 12 & 15.8 & 15.8 & & \\
\hline 27 & 39 & 35.5 & 51.3 & AGREE & \\
\hline 3 & 42 & 3.9 & 55.3 & DISAGREE & \\
\hline 3 & 45 & 3.9 & 59.2 & NOPONION & \\
\hline 31 & 76 & 40.8 & 100.0 & SAGREE & \\
\hline & CUM & & CUM & & \\
\hline COUNT & COUNT & PCT & PCT & Q5 1 & (PERSONAL) \\
\hline 2 & 2 & 2.6 & 2.6 & & \\
\hline 24 & 26 & 31.6 & 34.2 & AGREE & \\
\hline 13 & 39 & 17.1 & 51.3 & DISAGREE & \\
\hline 2 & 41 & 2.6 & 53.9 & NOPONION & \\
\hline $3 \overline{3}$ & 74 & 43.4 & 97.4 & SAGREE & \\
\hline 2 & 76 & 2.6 & 100.0 & SDISAGREE & \\
\hline & $\mathrm{CU}$ & & CUM & & \\
\hline
\end{tabular}




\begin{tabular}{|c|c|c|c|c|}
\hline $\begin{array}{r}\text { COUNT } \\
11 \\
28 \\
8 \\
9 \\
20\end{array}$ & $\begin{array}{r}\text { COUNT } \\
11 \\
39 \\
47 \\
56 \\
76\end{array}$ & $\begin{array}{l}\text { PCT } \\
14.5 \\
36.8 \\
10.5 \\
11.8 \\
26.3\end{array}$ & $\begin{array}{r}\text { PCT } \\
14.5 \\
51.3 \\
61.8 \\
73.7 \\
100.0\end{array}$ & $\begin{array}{l}\qquad \text { Q5 (PUBLIC) } \\
\text { AGREE } \\
\text { DISAGREE } \\
\text { NOPONION } \\
\text { SAGREE }\end{array}$ \\
\hline $\begin{array}{r}\text { COUNT } \\
26 \\
15 \\
1 \\
31 \\
3\end{array}$ & $\begin{array}{r}\text { CUM } \\
\text { COUNT } \\
26 \\
41 \\
42 \\
73 \\
76\end{array}$ & $\begin{array}{r}\text { PCT } \\
34.2 \\
19.7 \\
1.3 \\
40.8 \\
3.9\end{array}$ & $\begin{array}{r}\text { CUM } \\
\text { PCT } \\
34.2 \\
53.9 \\
55.3 \\
96.1 \\
100.0\end{array}$ & $\begin{array}{l}\text { Q6 (PERSONAL) } \\
\text { AGREE } \\
\text { DISAGREE } \\
\text { NOPONION } \\
\text { SAGREE } \\
\text { SDISAGREE }\end{array}$ \\
\hline $\begin{array}{r}\text { COUNT } \\
14 \\
29 \\
10 \\
6 \\
17\end{array}$ & $\begin{array}{r}\text { CUM } \\
\text { COUNT } \\
14 \\
43 \\
53 \\
59 \\
76\end{array}$ & $\begin{array}{r}\text { PCT } \\
18.4 \\
38.2 \\
13.2 \\
7.9 \\
22.4\end{array}$ & $\begin{array}{r}\text { CUM } \\
\text { PCT } \\
18.4 \\
56.6 \\
69.7 \\
77.6 \\
100.0\end{array}$ & $\begin{array}{l}\quad \text { Q6 (PUBLIC) } \\
\text { AGREE } \\
\text { DISAGREE } \\
\text { NOPONION } \\
\text { SAGREE }\end{array}$ \\
\hline $\begin{array}{r}\text { COUNT } \\
27 \\
18 \\
3 \\
24 \\
4\end{array}$ & $\begin{array}{r}\text { CUM } \\
\text { COUNT } \\
27 \\
45 \\
48 \\
72 \\
76\end{array}$ & $\begin{array}{r}\text { PCT } \\
35.5 \\
23.7 \\
3.9 \\
31.6 \\
5.3\end{array}$ & $\begin{array}{r}\text { CUM } \\
\text { PCT } \\
35.5 \\
59.2 \\
63.2 \\
94.7 \\
100.0\end{array}$ & $\begin{array}{l}\text { Q7 (PERSONAL) } \\
\text { AGREE } \\
\text { DISAGREE } \\
\text { NOPONION } \\
\text { SAGREE } \\
\text { SDISAGREE }\end{array}$ \\
\hline $\begin{array}{r}\text { COUNT } \\
14 \\
22 \\
14 \\
10 \\
16\end{array}$ & $\begin{array}{r}\text { CUM } \\
\text { COUNT } \\
14 \\
36 \\
50 \\
60 \\
76\end{array}$ & $\begin{array}{r}\text { PCT } \\
18.4 \\
28.9 \\
18.4 \\
13.2 \\
21.1\end{array}$ & $\begin{array}{r}\text { CUM } \\
\text { PCT } \\
18.4 \\
47.4 \\
65.8 \\
78.9 \\
100.0\end{array}$ & $\begin{array}{l}\quad \text { Q7 (PUBLIC) } \\
\text { AGREE } \\
\text { DISAGREE } \\
\text { NOPONION } \\
\text { SAGREE }\end{array}$ \\
\hline $\begin{array}{r}\text { COUNT } \\
3 \\
33 \\
10 \\
7 \\
21 \\
2\end{array}$ & $\begin{array}{r}\text { CUM } \\
\text { COUNT } \\
3 \\
36 \\
46 \\
53 \\
74 \\
76\end{array}$ & $\begin{array}{r}\text { PCT } \\
3.9 \\
43.4 \\
13.2 \\
9.2 \\
27.6 \\
2.6\end{array}$ & $\begin{array}{r}\text { CUM } \\
\text { PCT } \\
3.9 \\
47.4 \\
60.5 \\
69.7 \\
97.4 \\
100.0\end{array}$ & $\begin{array}{l}\quad \text { Q8 (PERSONAL) } \\
\text { AGREE } \\
\text { DISAGREE } \\
\text { NOPONION } \\
\text { SAGREE } \\
\text { SDISAGREE }\end{array}$ \\
\hline $\begin{array}{r}\text { COUNT } \\
12 \\
32 \\
7 \\
13 \\
12\end{array}$ & $\begin{array}{r}\text { CUM } \\
\text { COUNT } \\
12 \\
44 \\
51 \\
64 \\
76\end{array}$ & $\begin{array}{r}\text { PCT } \\
15.8 \\
42.1 \\
9.2 \\
17.1 \\
15.8\end{array}$ & $\begin{array}{r}\text { CUM } \\
\text { PCT } \\
15.8 \\
57.9 \\
67.1 \\
84.2 \\
100.0\end{array}$ & $\begin{array}{l}\quad \text { Q8 (PUBLIC) } \\
\text { AGREE } \\
\text { DISAGREE } \\
\text { NOPONION } \\
\text { SAGREE }\end{array}$ \\
\hline $\begin{array}{r}\text { COUNT } \\
1 \\
27 \\
9 \\
3\end{array}$ & $\begin{array}{r}\text { CUM } \\
\text { COUNT } \\
1 \\
28 \\
37 \\
40\end{array}$ & $\begin{array}{r}\text { PCT } \\
1.3 \\
35.5 \\
11.8 \\
3.9\end{array}$ & $\begin{array}{l}\text { CUM } \\
\text { PCT } \\
1.3 \\
36.8 \\
48.7 \\
52.6\end{array}$ & $\begin{array}{l}\qquad 99 \text { (PERSONAL) } \\
\text { AGREE } \\
\text { DISAGREE } \\
\text { NOPONION }\end{array}$ \\
\hline
\end{tabular}




\begin{tabular}{|c|c|c|c|c|}
\hline $\begin{array}{r}34 \\
2\end{array}$ & $\begin{array}{l}74 \\
76\end{array}$ & $\begin{array}{r}44.7 \\
2.6\end{array}$ & $\begin{array}{r}97.4 \\
100.0\end{array}$ & $\begin{array}{l}\text { SAGREE } \\
\text { SDISAGREE }\end{array}$ \\
\hline $\begin{array}{r}\text { COUNT } \\
12 \\
20 \\
7 \\
4 \\
30 \\
3\end{array}$ & $\begin{array}{r}\text { CUM } \\
\text { COUNT } \\
12 \\
32 \\
39 \\
43 \\
73 \\
76\end{array}$ & $\begin{array}{r}\text { PCT } \\
15.8 \\
26.3 \\
9.2 \\
5.3 \\
39.5 \\
3.9\end{array}$ & $\begin{array}{r}\text { CUM } \\
\text { PCT } \\
15.8 \\
42.1 \\
51.3 \\
56.6 \\
96.1 \\
100.0\end{array}$ & $\begin{array}{l}\quad \text { Q9 (PUBLIC) } \\
\text { AGREE } \\
\text { DISAGREE } \\
\text { NOPONION } \\
\text { SAGREE } \\
\text { SDISAGREE }\end{array}$ \\
\hline $\begin{array}{r}\text { COUNT } \\
2 \\
25 \\
17 \\
1 \\
27 \\
4\end{array}$ & $\begin{array}{r}\text { CUM } \\
\text { COUNT } \\
2 \\
27 \\
44 \\
45 \\
72 \\
76\end{array}$ & $\begin{array}{r}\text { PCT } \\
2.6 \\
32.9 \\
22.4 \\
1.3 \\
35.5 \\
5.3\end{array}$ & $\begin{array}{r}\text { CUM } \\
\text { PCT } \\
2.6 \\
35.5 \\
57.9 \\
59.2 \\
94.7 \\
100.0\end{array}$ & $\begin{array}{l}\quad \text { Q10 (PERSONAL) } \\
\text { AGREE } \\
\text { DISAGREE } \\
\text { NOPONION } \\
\text { SAGREE } \\
\text { SDISAGREE }\end{array}$ \\
\hline $\begin{array}{r}\text { COUNT } \\
13 \\
28 \\
6 \\
9 \\
17 \\
3\end{array}$ & $\begin{array}{r}\text { CUM } \\
\text { COUNT } \\
13 \\
41 \\
47 \\
56 \\
73 \\
76\end{array}$ & $\begin{array}{r}\text { PCT } \\
17.1 \\
36.8 \\
7.9 \\
11.8 \\
22.4 \\
3.9\end{array}$ & $\begin{array}{r}\text { CUM } \\
\text { PCT } \\
17.1 \\
53.9 \\
61.8 \\
73.7 \\
96.1 \\
100.0\end{array}$ & $\begin{array}{l}\quad \text { Q10 (PUBLIC) } \\
\text { AGREE } \\
\text { DISAGREE } \\
\text { NOPONION } \\
\text { SAGREE } \\
\text { SDISAGREE }\end{array}$ \\
\hline $\begin{array}{r}\text { COUNT } \\
1 \\
27 \\
21 \\
5 \\
17 \\
5\end{array}$ & $\begin{array}{r}\text { CUM } \\
\text { COUNT } \\
1 \\
28 \\
49 \\
54 \\
71 \\
76\end{array}$ & $\begin{array}{r}\text { PCT } \\
1.3 \\
35.5 \\
27.6 \\
6.6 \\
22.4 \\
6.6\end{array}$ & $\begin{array}{r}\text { CUM } \\
\text { PCT } \\
1.3 \\
36.8 \\
64.5 \\
71.1 \\
93.4 \\
100.0\end{array}$ & $\begin{array}{l}\quad \text { Q11 (PERSONAI) } \\
\text { AGREE } \\
\text { DISAGREE } \\
\text { NOPONION } \\
\text { SAGREE } \\
\text { SDISAGREE }\end{array}$ \\
\hline $\begin{array}{r}\text { COUNT } \\
13 \\
24 \\
14 \\
15 \\
10\end{array}$ & $\begin{array}{r}\text { CUM } \\
\text { COUNT } \\
13 \\
37 \\
51 \\
66 \\
76\end{array}$ & $\begin{array}{l}\text { PCT } \\
17.1 \\
31.6 \\
18.4 \\
19.7 \\
13.2\end{array}$ & $\begin{array}{r}\text { CUM } \\
\text { PCT } \\
17.1 \\
48.7 \\
67.1 \\
86.8 \\
100.0\end{array}$ & $\begin{array}{l}\quad \text { Q11 (PUBLIC) } \\
\text { AGREE } \\
\text { DISAGREE } \\
\text { NOPONION } \\
\text { SAGREE }\end{array}$ \\
\hline $\begin{array}{r}\text { COUNT } \\
1 \\
27 \\
25 \\
5 \\
8 \\
10\end{array}$ & $\begin{array}{r}\text { CUM } \\
\text { COUNT } \\
1 \\
28 \\
53 \\
58 \\
66 \\
76\end{array}$ & $\begin{array}{r}\text { PCT } \\
1.3 \\
35.5 \\
32.9 \\
6.6 \\
10.5 \\
13.2\end{array}$ & $\begin{array}{r}\text { CUM } \\
\text { PCT } \\
1.3 \\
36.8 \\
69.7 \\
76.3 \\
86.8 \\
100.0\end{array}$ & $\begin{array}{l}\quad \text { Q12 (PERSONAL) } \\
\text { AGREE } \\
\text { DISAGREE } \\
\text { NOPONION } \\
\text { SAGREE } \\
\text { SDISAGREE }\end{array}$ \\
\hline $\begin{array}{r}\text { COUNT } \\
13 \\
26 \\
20 \\
8\end{array}$ & $\begin{array}{r}\text { CUM } \\
\text { COUNT } \\
13 \\
39 \\
59 \\
67\end{array}$ & $\begin{array}{r}\text { PCT } \\
17.1 \\
34.2 \\
26.3 \\
10.5\end{array}$ & $\begin{array}{r}\text { CUM } \\
\text { PCT } \\
17.1 \\
51.3 \\
77.6 \\
88.2\end{array}$ & $\begin{array}{l}\quad \text { Q12 (PUBLIC) } \\
\text { AGREE } \\
\text { DISAGREE } \\
\text { NOPONION }\end{array}$ \\
\hline
\end{tabular}




\begin{tabular}{|c|c|c|c|c|c|}
\hline $\begin{array}{l}2 \\
7\end{array}$ & $\begin{array}{l}69 \\
76\end{array}$ & $\begin{array}{l}2.6 \\
9.2\end{array}$ & $\begin{array}{r}90.8 \\
100.0\end{array}$ & $\begin{array}{l}\text { SAGREE } \\
\text { SDISAGREE }\end{array}$ & \\
\hline $\begin{array}{r}\text { COUNT } \\
1 \\
10 \\
41 \\
2 \\
3 \\
19\end{array}$ & $\begin{array}{r}\text { CUM } \\
\text { COUNT } \\
1 \\
11 \\
52 \\
54 \\
57 \\
76\end{array}$ & $\begin{array}{r}\text { PCT } \\
1.3 \\
13.2 \\
53.9 \\
2.6 \\
3.9 \\
25.0\end{array}$ & $\begin{array}{r}\text { CUM } \\
\text { PCT } \\
1.3 \\
14.5 \\
68.4 \\
71.1 \\
75.0 \\
100.0\end{array}$ & $\begin{array}{l}\quad \text { Q13 } \\
\text { AGREE } \\
\text { DISAGREE } \\
\text { NOPONION } \\
\text { SAGREE } \\
\text { SDISAGREE }\end{array}$ & (PERSONAL) \\
\hline $\begin{array}{r}\text { COUNT } \\
13 \\
7 \\
33 \\
9 \\
1 \\
13\end{array}$ & $\begin{array}{r}\text { CUM } \\
\text { COUNT } \\
13 \\
20 \\
53 \\
62 \\
63 \\
76\end{array}$ & $\begin{array}{r}\text { PCT } \\
17.1 \\
9.2 \\
43.4 \\
11.8 \\
1.3 \\
17.1\end{array}$ & $\begin{array}{r}\text { CUM } \\
\text { PCT } \\
17.1 \\
26.3 \\
69.7 \\
81.6 \\
82.9 \\
100.0\end{array}$ & $\begin{array}{l}\quad \text { Q13 } \\
\text { AGREE } \\
\text { DISAGREE } \\
\text { NOPONION } \\
\text { SAGREE } \\
\text { SDISAGREE }\end{array}$ & (PUBLIC) \\
\hline $\begin{array}{r}\text { COUNT } \\
1 \\
13 \\
27 \\
3 \\
11 \\
21\end{array}$ & $\begin{array}{r}\text { CUM } \\
\text { COUNT } \\
1 \\
14 \\
41 \\
44 \\
55 \\
76\end{array}$ & $\begin{array}{r}\text { PCT } \\
1.3 \\
17.1 \\
35.5 \\
3.9 \\
14.5 \\
27.6\end{array}$ & $\begin{array}{r}\text { CUM } \\
\text { PCT } \\
1.3 \\
18.4 \\
53.9 \\
57.9 \\
72.4 \\
100.0\end{array}$ & $\begin{array}{l}\quad \text { Q14 } \\
\text { AGREE } \\
\text { DISAGREE } \\
\text { NOPONION } \\
\text { SAGREE } \\
\text { SDISAGREE }\end{array}$ & (PERSONAL) \\
\hline $\begin{array}{r}\text { COUNT } \\
14 \\
13 \\
25 \\
7 \\
4 \\
13\end{array}$ & $\begin{array}{r}\text { CUM } \\
\text { COUNT } \\
14 \\
27 \\
52 \\
59 \\
63 \\
76\end{array}$ & $\begin{array}{r}\text { PCT } \\
18.4 \\
17.1 \\
32.9 \\
9.2 \\
5.3 \\
17.1\end{array}$ & $\begin{array}{r}\text { CUM } \\
\text { PCT } \\
18.4 \\
35.5 \\
68.4 \\
77.6 \\
82.9 \\
100.0\end{array}$ & $\begin{array}{l}\quad \text { Q14 } \\
\text { AGREE } \\
\text { DISAGREE } \\
\text { NOPONION } \\
\text { SAGREE } \\
\text { SDISAGREE }\end{array}$ & (PUBLIC) \\
\hline $\begin{array}{r}\text { COUNT } \\
1 \\
21 \\
3 \\
1 \\
50\end{array}$ & $\begin{array}{r}\text { CUM } \\
\text { COUNT } \\
1 \\
22 \\
25 \\
26 \\
76\end{array}$ & $\begin{array}{r}\text { PCT } \\
1.3 \\
27.6 \\
3.9 \\
1.3 \\
65.8\end{array}$ & $\begin{array}{r}\text { CUM } \\
\text { PCT } \\
1.3 \\
28.9 \\
32.9 \\
34.2 \\
100.0\end{array}$ & \begin{tabular}{l}
\multicolumn{1}{c}{ Q15 } \\
AGREE \\
DISAGREE \\
NOPONION \\
SAGREE
\end{tabular} & (PERSONAL) \\
\hline $\begin{array}{r}\text { COUNT } \\
15 \\
21 \\
2 \\
5 \\
33\end{array}$ & $\begin{array}{r}\text { CUM } \\
\text { COUNT } \\
15 \\
36 \\
38 \\
43 \\
76\end{array}$ & $\begin{array}{r}\text { PCT } \\
19.7 \\
27.6 \\
2.6 \\
6.6 \\
43.4\end{array}$ & $\begin{array}{r}\text { CUM } \\
\text { PCT } \\
19.7 \\
47.4 \\
50.0 \\
56.6 \\
100.0\end{array}$ & $\begin{array}{l}\quad \text { Q15 } \\
\text { AGREE } \\
\text { DISAGREE } \\
\text { NOPONION } \\
\text { SAGREE }\end{array}$ & (PUBLIC) \\
\hline $\begin{array}{r}\text { COUNT } \\
25 \\
22 \\
7 \\
18 \\
4\end{array}$ & $\begin{array}{r}\text { CUM } \\
\text { COUNT } \\
25 \\
47 \\
54 \\
72 \\
76\end{array}$ & $\begin{array}{r}\text { PCT } \\
32.9 \\
28.9 \\
9.2 \\
23.7 \\
5.3\end{array}$ & $\begin{array}{r}\text { CUM } \\
\text { PCT } \\
32.9 \\
61.8 \\
71.1 \\
94.7 \\
100.0\end{array}$ & $\begin{array}{l}\quad \text { Q16 } \\
\text { AGREE } \\
\text { DISAGREE } \\
\text { NOPONION } \\
\text { SAGREE } \\
\text { SDISAGREE }\end{array}$ & (PERSONAL) \\
\hline
\end{tabular}




\begin{tabular}{|c|c|c|c|c|}
\hline $\begin{array}{r}\text { COUNT } \\
15 \\
15 \\
20 \\
14 \\
10 \\
2\end{array}$ & $\begin{array}{r}\text { CUM } \\
\text { COUNT } \\
15 \\
30 \\
50 \\
64 \\
74 \\
76\end{array}$ & $\begin{array}{r}\text { PCT } \\
19.7 \\
19.7 \\
26.3 \\
18.4 \\
13.2 \\
2.6\end{array}$ & $\begin{array}{r}\text { CUM } \\
\text { PCT } \\
19.7 \\
39.5 \\
65.8 \\
84.2 \\
97.4 \\
100.0\end{array}$ & $\begin{array}{l}\quad \text { Q16 (PUBLIC) } \\
\text { AGREE } \\
\text { DISAGREE } \\
\text { NOPONION } \\
\text { SAGREE } \\
\text { SDISAGREE }\end{array}$ \\
\hline $\begin{array}{r}\text { COUNT } \\
1 \\
20 \\
26 \\
11 \\
10 \\
8\end{array}$ & $\begin{array}{r}\text { CUM } \\
\text { COUNT } \\
1 \\
21 \\
47 \\
58 \\
68 \\
76\end{array}$ & $\begin{array}{r}\text { PCT } \\
1.3 \\
26.3 \\
34.2 \\
14.5 \\
13.2 \\
10.5\end{array}$ & $\begin{array}{r}\text { CUM } \\
\text { PCT } \\
1.3 \\
27.6 \\
61.8 \\
76.3 \\
89.5 \\
100.0\end{array}$ & $\begin{array}{l}\quad \text { Q17 (PERSONAL) } \\
\text { AGREE } \\
\text { DISAGREE } \\
\text { NOPONION } \\
\text { SAGREE } \\
\text { SDISAGREE }\end{array}$ \\
\hline $\begin{array}{r}\text { COUNT } \\
14 \\
14 \\
24 \\
12 \\
6 \\
6\end{array}$ & $\begin{array}{r}\text { CUM } \\
\text { COUNT } \\
14 \\
28 \\
52 \\
64 \\
70 \\
76\end{array}$ & $\begin{array}{r}\text { PCT } \\
18.4 \\
18.4 \\
31.6 \\
15.8 \\
7.9 \\
7.9\end{array}$ & $\begin{array}{r}\text { CUM } \\
\text { PCT } \\
18.4 \\
36.8 \\
68.4 \\
84.2 \\
92.1 \\
100.0\end{array}$ & $\begin{array}{l}\quad \text { Q17 (PUBLIC) } \\
\text { AGREE } \\
\text { DISAGREE } \\
\text { NOPONION } \\
\text { SAGREE } \\
\text { SDISAGREE }\end{array}$ \\
\hline
\end{tabular}


Appendix: $\mathrm{C}$

The Questionnaire's Frequencies: Valid Percentages

4 
The Questionnaire's Frequencies: Valid Percentages

\begin{tabular}{|c|c|c|c|c|c|}
\hline \multirow{6}{*}{$\begin{array}{r}\text { COUNT } \\
24 \\
5 \\
44 \\
3\end{array}$} & CUM & & CUM & \multirow{2}{*}{\multicolumn{2}{|c|}{ Q2 (PERSONAL) }} \\
\hline & COUNT & PCT & PCT & & \\
\hline & 24 & 31.6 & 31.6 & AGREE & \\
\hline & 29 & 6.6 & 38.2 & DISAGREE & \\
\hline & 73 & 57.9 & 96.1 & SAGREE & \\
\hline & 76 & 3.9 & 100.0 & SDISAGREI & \\
\hline & CUM & & CUM & & \\
\hline COUNT & COUNT & PCT & PCT & $\mathrm{Q} 2$ & (PUBLIC) \\
\hline 26 & 26 & 40.0 & 40.0 & AGREE & \\
\hline 4 & 30 & 6.2 & 46.2 & DISAGREE & \\
\hline 10 & 40 & 15.4 & 61.5 & NOPONION & \\
\hline 25 & 65 & 38.5 & 100.0 & SAGREE & \\
\hline
\end{tabular}

\begin{tabular}{rrrrll}
\multicolumn{5}{c}{ CUM } & \multicolumn{1}{c}{ CUM } \\
COUNT & COUNT & PCT & PCT & Q3 & (PERSONAL) \\
27 & 27 & 35.5 & 35.5 & AGREE \\
25 & 52 & 32.9 & 68.4 & DISAGREE \\
5 & 57 & 6.6 & 75.0 & NOPONION \\
14 & 71 & 18.4 & 93.4 & SAGREE \\
5 & 76 & 6.6 & 100.0 & SDISAGREE
\end{tabular}

\begin{tabular}{|c|c|c|c|c|}
\hline & CUM & & CUM & \\
\hline COUNT & COUNT & $\mathrm{PCT}$ & PCT & Q3 (PUBLIC) \\
\hline 22 & 22 & 34.9 & 34.9 & AGREE \\
\hline 15 & 37 & 23.8 & 58.7 & DISAGREE \\
\hline 15 & 52 & 23.8 & 82.5 & NOPONION \\
\hline$a$ & 61 & 14.3 & 96.8 & SAGREE \\
\hline 2 & 63 & 3.2 & 100.0 & SDISAGREE \\
\hline
\end{tabular}

\begin{tabular}{|c|c|c|c|c|}
\hline & CUM & & CUM & \\
\hline COUNT & COUNT & PCT & PCT & Q4 (PERSONAL) \\
\hline 22 & 22 & 29.7 & 29.7 & AGREE \\
\hline 3 & 25 & 4.1 & 33.8 & DISAGREE \\
\hline 48 & 73 & 64.9 & 98.6 & SAGREE \\
\hline 1 & 74 & 1.4 & 100.0 & SDISAGREE \\
\hline
\end{tabular}

\begin{tabular}{rrrrll}
\multicolumn{5}{c}{ CUM } & \multicolumn{1}{c}{ CUM } \\
COUNT & COUNT & PCT & PCT & Q4 & (PUBLIC) \\
27 & 27 & 42.2 & 42.2 & AGREE & \\
3 & 30 & 4.7 & 46.9 & DISAGREE \\
3 & 33 & 4.7 & 51.6 & NOPONION \\
31 & 64 & 48.4 & 100.0 & SAGREE
\end{tabular}

\begin{tabular}{|c|c|c|c|c|}
\hline & CUM & & CUM & \\
\hline COUNT & COUNT & $\mathrm{PCI}$ & PCT & Q5 (PERSONAL) \\
\hline & 24 & 32.4 & 32.4 & AGREE \\
\hline 13 & 37 & 17.6 & 50.0 & DISAGREE \\
\hline & 39 & 2.7 & 52.7 & NOPONION \\
\hline 33 & 72 & 44.6 & 97.3 & SAGREE \\
\hline 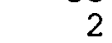 & 74 & 2.7 & 100.0 & SDISAGREE \\
\hline
\end{tabular}

\begin{tabular}{rrrrll}
\multicolumn{5}{c}{ CUM } & \multicolumn{1}{c}{ CUM } \\
COUNT & COUNT & PCT & PCT & Q5 & (PUBLIC) \\
28 & 28 & 43.1 & 43.1 & AGREE \\
8 & 36 & 12.3 & 55.4 & DISAGREE \\
9 & 45 & 13.8 & 69.2 & NOPONION \\
20 & 65 & 30.8 & 100.0 & SAGREE
\end{tabular}




\begin{tabular}{|c|c|c|c|c|}
\hline $\begin{array}{r}\text { COUNT } \\
26 \\
15 \\
1 \\
31 \\
3\end{array}$ & $\begin{array}{r}\text { CUM } \\
\text { COUNT } \\
26 \\
41 \\
42 \\
73 \\
76\end{array}$ & $\begin{array}{r}\text { PCT } \\
34.2 \\
19.7 \\
1.3 \\
40.8 \\
3.9\end{array}$ & $\begin{array}{r}\text { CUM } \\
\text { PCT } \\
34.2 \\
53.9 \\
55.3 \\
96.1 \\
100.0\end{array}$ & $\begin{array}{l}\text { Q6 (PERSONAL) } \\
\text { AGREE } \\
\text { DISAGREE } \\
\text { NOPONION } \\
\text { SAGREE } \\
\text { SDISAGREE }\end{array}$ \\
\hline $\begin{array}{r}\text { COUNT } \\
29 \\
10 \\
6 \\
17\end{array}$ & $\begin{array}{r}\text { CUM } \\
\text { COUNT } \\
29 \\
39 \\
45 \\
62\end{array}$ & $\begin{array}{r}\text { PCT } \\
46.8 \\
16.1 \\
9.7 \\
27.4\end{array}$ & $\begin{array}{r}\text { CUM } \\
\text { PCT } \\
46.8 \\
62.9 \\
72.6 \\
100.0\end{array}$ & $\begin{array}{l}\text { Q6 (PUBLIC) } \\
\text { AGREE } \\
\text { DISAGREE } \\
\text { NOPONION } \\
\text { SAGREE }\end{array}$ \\
\hline $\begin{array}{r}\text { COUNT } \\
27 \\
18 \\
3 \\
24 \\
4\end{array}$ & $\begin{array}{r}\text { CUM } \\
\text { COUNT } \\
27 \\
45 \\
48 \\
72 \\
76\end{array}$ & $\begin{array}{r}\text { PCT } \\
35.5 \\
23.7 \\
3.9 \\
31.6 \\
5.3\end{array}$ & $\begin{array}{r}\text { CUM } \\
\text { PCT } \\
35.5 \\
59.2 \\
63.2 \\
94.7 \\
100.0\end{array}$ & $\begin{array}{l}\text { Q7 (PERSONAL) } \\
\text { AGREE } \\
\text { DISAGREE } \\
\text { NOPONION } \\
\text { SAGREE } \\
\text { SDISAGREE }\end{array}$ \\
\hline $\begin{array}{r}\text { COUNT } \\
22 \\
14 \\
10 \\
16\end{array}$ & $\begin{array}{r}\text { CUM } \\
\text { COUNT } \\
22 \\
36 \\
46 \\
62\end{array}$ & $\begin{array}{r}\text { PCT } \\
35.5 \\
22.6 \\
16.1 \\
25.8\end{array}$ & $\begin{array}{r}\text { CUM } \\
\text { PCT } \\
35.5 \\
58.1 \\
74.2 \\
100.0\end{array}$ & $\begin{array}{l}\text { Q7 (PUBLIC) } \\
\text { AGREE } \\
\text { DISAGREE } \\
\text { NOPONION } \\
\text { SAGREE }\end{array}$ \\
\hline $\begin{array}{r}\text { COUNT } \\
33 \\
10 \\
7 \\
21 \\
2\end{array}$ & $\begin{array}{r}\text { CUM } \\
\text { COUNT } \\
33 \\
43 \\
50 \\
71 \\
73\end{array}$ & $\begin{array}{r}\text { PCT } \\
45.2 \\
13.7 \\
9.6 \\
28.8 \\
2.7\end{array}$ & $\begin{array}{r}\text { CUM } \\
\text { PCT } \\
45.2 \\
58.9 \\
68.5 \\
97.3 \\
100.0\end{array}$ & $\begin{array}{l}\quad \text { Q8 (PERSONAL) } \\
\text { AGREE } \\
\text { DISAGREE } \\
\text { NOPONION } \\
\text { SAGREE } \\
\text { SDISAGREE }\end{array}$ \\
\hline $\begin{array}{r}\text { COUNT } \\
32 \\
7 \\
13 \\
12\end{array}$ & $\begin{array}{r}\text { CUM } \\
\text { COUNT } \\
32 \\
39 \\
52 \\
64\end{array}$ & $\begin{array}{r}\text { PCT } \\
50.0 \\
10.9 \\
20.3 \\
18.8\end{array}$ & $\begin{array}{r}\text { CUM } \\
\text { PCT } \\
50.0 \\
60.9 \\
81.3 \\
100.0\end{array}$ & $\begin{array}{l}\text { Q8 (PUBLIC) } \\
\text { AGREE } \\
\text { DISAGREE } \\
\text { NOPONION } \\
\text { SAGREE }\end{array}$ \\
\hline $\begin{array}{r}\text { COUNT } \\
27 \\
9 \\
3 \\
34 \\
2\end{array}$ & $\begin{array}{r}\text { CUM } \\
\text { COUNT } \\
27 \\
36 \\
39 \\
73 \\
75\end{array}$ & $\begin{array}{r}\text { PCT } \\
36.0 \\
12.0 \\
4.0 \\
45.3 \\
2.7\end{array}$ & $\begin{array}{r}\text { CUM } \\
\text { PCT } \\
36.0 \\
48.0 \\
52.0 \\
97.3 \\
100.0\end{array}$ & $\begin{array}{l}\text { Q9 (PERSONAL) } \\
\text { AGREE } \\
\text { DISAGREE } \\
\text { NOPONION } \\
\text { SAGREE } \\
\text { SDISAGREE }\end{array}$ \\
\hline $\begin{array}{r}\text { COUNT } \\
20 \\
7 \\
4 \\
30 \\
3\end{array}$ & $\begin{array}{r}\text { CUM } \\
\text { COUNT } \\
20 \\
27 \\
31 \\
61 \\
64\end{array}$ & $\begin{array}{r}\text { PCT } \\
31.3 \\
10.9 \\
6.3 \\
46.9 \\
4.7\end{array}$ & $\begin{array}{r}\text { CUM } \\
\text { PCT } \\
31.3 \\
42.2 \\
48.4 \\
95.3 \\
100.0\end{array}$ & $\begin{array}{l}\text { Q9 (PUBLIC) } \\
\text { AGREE } \\
\text { DISAGREE } \\
\text { NOPONION } \\
\text { SAGREE } \\
\text { SDISAGREE }\end{array}$ \\
\hline & $\mathrm{Cu}$ & & $\mathrm{CUN}$ & \\
\hline
\end{tabular}




\begin{tabular}{|c|c|c|c|c|}
\hline $\begin{array}{r}\text { COUNT } \\
25 \\
17 \\
1 \\
27 \\
4\end{array}$ & $\begin{array}{r}\text { COUNT } \\
25 \\
42 \\
43 \\
70 \\
74\end{array}$ & $\begin{array}{r}\text { PCT } \\
33.8 \\
23.0 \\
1.4 \\
36.5 \\
5.4\end{array}$ & $\begin{array}{r}\text { PCT } \\
33.8 \\
56.8 \\
58.1 \\
94.6 \\
100.0\end{array}$ & $\begin{array}{l}\quad \text { Q10 (PERSONAL) } \\
\text { AGREE } \\
\text { DISAGREE } \\
\text { NOPONION } \\
\text { SAGREE } \\
\text { SDISAGREE }\end{array}$ \\
\hline $\begin{array}{r}\text { COUNT } \\
28 \\
6 \\
9 \\
17 \\
3\end{array}$ & $\begin{array}{r}\text { CUM } \\
\text { COUNT } \\
28 \\
34 \\
43 \\
60 \\
63\end{array}$ & $\begin{array}{r}\text { PCT } \\
44.4 \\
9.5 \\
14.3 \\
27.0 \\
4.8\end{array}$ & $\begin{array}{r}\text { CUM } \\
\text { PCT } \\
44.4 \\
54.0 \\
68.3 \\
95.2 \\
100.0\end{array}$ & $\begin{array}{l}\quad \text { Q10 (PUBLIC) } \\
\text { AGREE } \\
\text { DISAGREE } \\
\text { NOPONION } \\
\text { SAGREE } \\
\text { SDISAGREE }\end{array}$ \\
\hline $\begin{array}{r}\text { COUNT } \\
27 \\
21 \\
5 \\
17 \\
5\end{array}$ & $\begin{array}{r}\text { CUM } \\
\text { COUNT } \\
27 \\
48 \\
53 \\
70 \\
75\end{array}$ & $\begin{array}{r}\text { PCT } \\
36.0 \\
28.0 \\
6.7 \\
22.7 \\
6.7\end{array}$ & $\begin{array}{r}\text { CUM } \\
\text { PCT } \\
36.0 \\
64.0 \\
70.7 \\
93.3 \\
100.0\end{array}$ & $\begin{array}{l}\quad \text { Q11 (PERSONAL) } \\
\text { AGREE } \\
\text { DISAGREE } \\
\text { NOPONION } \\
\text { SAGREE } \\
\text { SDISAGREE }\end{array}$ \\
\hline $\begin{array}{r}\text { COUNT } \\
24 \\
14 \\
15 \\
10\end{array}$ & $\begin{array}{r}\text { CUM } \\
\text { COUNT } \\
24 \\
38 \\
53 \\
63\end{array}$ & $\begin{array}{r}\text { PCT } \\
38.1 \\
22.2 \\
23.8 \\
15.9\end{array}$ & $\begin{array}{r}\text { CUM } \\
\text { PCT } \\
38.1 \\
60.3 \\
84.1 \\
100.0\end{array}$ & $\begin{array}{l}\text { Q11 (PUBLIC) } \\
\text { AGREE } \\
\text { DISAGREE } \\
\text { NOPONION } \\
\text { SAGREE }\end{array}$ \\
\hline $\begin{array}{r}\text { COUNT } \\
27 \\
25 \\
5 \\
8 \\
10\end{array}$ & $\begin{array}{r}\text { CUM } \\
\text { COUNT } \\
27 \\
52 \\
57 \\
65 \\
75\end{array}$ & $\begin{array}{r}\text { PCT } \\
36.0 \\
33.3 \\
6.7 \\
10.7 \\
13.3\end{array}$ & $\begin{array}{r}\text { CUM } \\
\text { PCT } \\
36.0 \\
69.3 \\
76.0 \\
86.7 \\
100.0\end{array}$ & $\begin{array}{l}\quad \text { Q12 (PERSONAL) } \\
\text { AGREE } \\
\text { DISAGREE } \\
\text { NOPONION } \\
\text { SAGREE } \\
\text { SDISAGREE }\end{array}$ \\
\hline $\begin{array}{r}\text { COUNT } \\
26 \\
20 \\
8 \\
2 \\
7\end{array}$ & $\begin{array}{r}\text { CUM } \\
\text { COUNT } \\
26 \\
46 \\
54 \\
56 \\
63\end{array}$ & $\begin{array}{r}\text { PCT } \\
41.3 \\
31.7 \\
12.7 \\
3.2 \\
11.1\end{array}$ & $\begin{array}{r}\text { CUM } \\
\text { PCT } \\
41.3 \\
73.0 \\
85.7 \\
88.9 \\
100.0\end{array}$ & $\begin{array}{l}\quad \text { Q12 (PUBLIC) } \\
\text { AGREE } \\
\text { DISAGREE } \\
\text { NOPONION } \\
\text { SAGREE } \\
\text { SDISAGREE }\end{array}$ \\
\hline $\begin{array}{r}\text { COUNT } \\
10 \\
41 \\
2 \\
3 \\
19\end{array}$ & $\begin{array}{r}\text { CUM } \\
\text { COUNT } \\
10 \\
51 \\
53 \\
56 \\
75\end{array}$ & $\begin{array}{r}\text { PCT } \\
13.3 \\
54.7 \\
2.7 \\
4.0 \\
25.3\end{array}$ & $\begin{array}{r}\text { CUM } \\
\text { PCT } \\
13.3 \\
68.0 \\
70.7 \\
74.7 \\
100.0\end{array}$ & $\begin{array}{l}\quad \text { Q13 (PERSONAL) } \\
\text { AGREE } \\
\text { DISAGREE } \\
\text { NOPONION } \\
\text { SAGREE } \\
\text { SDISAGREE }\end{array}$ \\
\hline $\begin{array}{r}\text { COUNT } \\
7 \\
33 \\
9 \\
1 \\
13\end{array}$ & $\begin{array}{r}\text { CUM } \\
\text { COUNT } \\
7 \\
40 \\
49 \\
50 \\
63\end{array}$ & $\begin{array}{r}\text { PCT } \\
11.1 \\
52.4 \\
14.3 \\
1.6 \\
20.6\end{array}$ & $\begin{array}{r}\text { CUM } \\
\text { PCT } \\
11.1 \\
63.5 \\
77.8 \\
79.4 \\
100.0\end{array}$ & \begin{tabular}{l}
\multicolumn{1}{c}{ Q13 (PUBLIC) } \\
AGREE \\
DISAGREE \\
NOPONION \\
SAGREE \\
SDISAGREE
\end{tabular} \\
\hline
\end{tabular}




\begin{tabular}{|c|c|c|c|c|}
\hline $\begin{array}{r}\text { COUNT } \\
13 \\
27 \\
3 \\
11 \\
21\end{array}$ & $\begin{array}{r}\text { CUM } \\
\text { COUNT } \\
13 \\
40 \\
43 \\
54 \\
75\end{array}$ & $\begin{array}{r}\text { PCT } \\
17.3 \\
36.0 \\
4.0 \\
14.7 \\
28.0\end{array}$ & $\begin{array}{r}\text { CUM } \\
\text { PCT } \\
17.3 \\
53.3 \\
57.3 \\
72.0 \\
100.0\end{array}$ & $\begin{array}{l}\quad \text { Q14 (PERSONAL) } \\
\text { AGREE } \\
\text { DISAGREE } \\
\text { NOPONION } \\
\text { SAGREE } \\
\text { SDISAGREE }\end{array}$ \\
\hline $\begin{array}{r}\text { COUNT } \\
13 \\
25 \\
7 \\
4 \\
13\end{array}$ & $\begin{array}{r}\text { CUM } \\
\text { COUNT } \\
13 \\
38 \\
45 \\
49 \\
62\end{array}$ & $\begin{array}{r}\text { PCT } \\
21.0 \\
40.3 \\
11.3 \\
6.5 \\
21.0\end{array}$ & $\begin{array}{r}\text { CUM } \\
\text { PCT } \\
21.0 \\
61.3 \\
72.6 \\
79.0 \\
100.0\end{array}$ & $\begin{array}{l}\quad \text { Q14 (PUBLIC) } \\
\text { AGREE } \\
\text { DISAGREE } \\
\text { NOPONION } \\
\text { SAGREE } \\
\text { SDISAGREE }\end{array}$ \\
\hline $\begin{array}{r}\text { COUNT } \\
21 \\
3 \\
1 \\
50\end{array}$ & $\begin{array}{r}\text { CUM } \\
\text { COUNT } \\
21 \\
24 \\
25 \\
75\end{array}$ & $\begin{array}{r}\text { PCT } \\
28.0 \\
4.0 \\
1.3 \\
66.7\end{array}$ & $\begin{array}{r}\text { CUM } \\
\text { PCT } \\
28.0 \\
32.0 \\
33.3 \\
100.0\end{array}$ & $\begin{array}{l}\quad \text { Q15 (PERSONAL) } \\
\text { AGREE } \\
\text { DISAGREE } \\
\text { NOPONION } \\
\text { SAGREE }\end{array}$ \\
\hline $\begin{array}{r}\text { COUNT } \\
21 \\
2 \\
5 \\
33\end{array}$ & $\begin{array}{r}\text { CUM } \\
\text { COUNT } \\
21 \\
23 \\
28 \\
61\end{array}$ & $\begin{array}{r}\text { PCT } \\
34.4 \\
3.3 \\
8.2 \\
54.1\end{array}$ & $\begin{array}{r}\text { CUM } \\
\text { PCT } \\
34.4 \\
37.7 \\
45.9 \\
100.0\end{array}$ & $\begin{array}{l}\text { Q15 (PUBLIC) } \\
\text { AGREE } \\
\text { DISAGREE } \\
\text { NOPONION } \\
\text { SAGREE }\end{array}$ \\
\hline $\begin{array}{r}\text { COUNT } \\
25 \\
22 \\
7 \\
18 \\
4\end{array}$ & $\begin{array}{r}\text { CUM } \\
\text { COUNT } \\
25 \\
47 \\
54 \\
72 \\
76\end{array}$ & $\begin{array}{r}\text { PCT } \\
32.9 \\
28.9 \\
9.2 \\
23.7 \\
5.3\end{array}$ & $\begin{array}{r}\text { CUM } \\
\text { PCT } \\
32.9 \\
61.8 \\
71.1 \\
94.7 \\
100.0\end{array}$ & $\begin{array}{l}\quad \text { Q16 (PERSONAL) } \\
\text { AGREE } \\
\text { DISAGREE } \\
\text { NOPONION } \\
\text { SAGREE } \\
\text { SDISAGREE }\end{array}$ \\
\hline $\begin{array}{r}\text { COUNT } \\
15 \\
20 \\
14 \\
10 \\
2\end{array}$ & $\begin{array}{r}\text { CUM } \\
\text { COUNT } \\
15 \\
35 \\
49 \\
59 \\
61\end{array}$ & $\begin{array}{r}\text { PCT } \\
24.6 \\
32.8 \\
23.0 \\
16.4 \\
3.3\end{array}$ & $\begin{array}{r}\text { CUM } \\
\text { PCT } \\
24.6 \\
57.4 \\
80.3 \\
96.7 \\
100.0\end{array}$ & $\begin{array}{l}\text { Q16 (PUBLIC) } \\
\text { AGREE } \\
\text { DISAGREE } \\
\text { NOPONION } \\
\text { SAGREE } \\
\text { SDISAGREE }\end{array}$ \\
\hline $\begin{array}{r}\text { COUNT } \\
20 \\
26 \\
11 \\
10 \\
8\end{array}$ & $\begin{array}{r}\text { CUM } \\
\text { COUNT } \\
20 \\
46 \\
57 \\
67 \\
75\end{array}$ & $\begin{array}{r}\text { PCT } \\
26.7 \\
34.7 \\
14.7 \\
13.3 \\
10.7\end{array}$ & $\begin{array}{r}\text { CUM } \\
\text { PCT } \\
26.7 \\
61.3 \\
76.0 \\
89.3 \\
100.0\end{array}$ & $\begin{array}{l}\quad \text { Q17 (PERSONAL) } \\
\text { AGREE } \\
\text { DISAGREE } \\
\text { NOPONION } \\
\text { SAGREE } \\
\text { SDISAGREE }\end{array}$ \\
\hline $\begin{array}{r}\text { COUNT } \\
14 \\
24 \\
12 \\
6 \\
6\end{array}$ & $\begin{array}{r}\text { CUM } \\
\text { COUNT } \\
14 \\
38 \\
50 \\
56 \\
62\end{array}$ & $\begin{array}{r}\text { PCT } \\
22.6 \\
38.7 \\
19.4 \\
9.7 \\
9.7\end{array}$ & $\begin{array}{r}\text { CUM } \\
\text { PCT } \\
22.6 \\
61.3 \\
80.6 \\
90.3 \\
100.0\end{array}$ & \begin{tabular}{l}
\multicolumn{1}{c}{ Q17 (PUBLIC) } \\
AGREE \\
DISAGREE \\
NOPONION \\
SAGREE \\
SDISAGREE
\end{tabular} \\
\hline
\end{tabular}


Appendix: D

The Correlation Analysis Appendix 

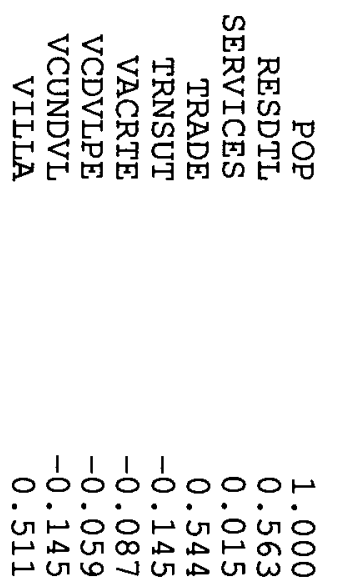

ชั

जU

0000! o0

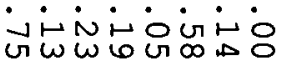

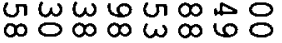

lo 0000 or is inंo

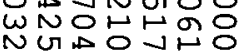

이이 is $\dot{0}$ in $\dot{0}$ -

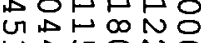

MUONO

dood irivio Oํㅠ용ㅇㅇ

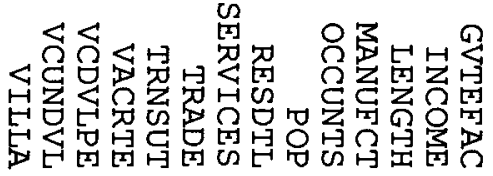

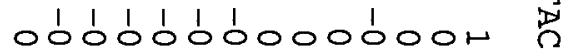
OO

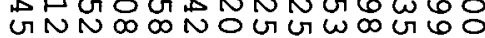

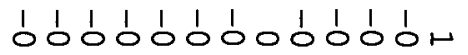

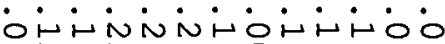

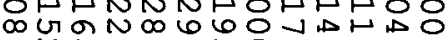

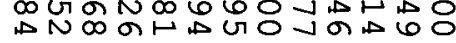

000000000인 i -10 in $\dot{0}$ i GMU

do 00000000

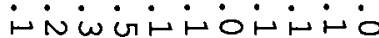
NANNADO

$\triangle \omega 0 \omega G \bowtie \pitchfork \infty \circ 0$

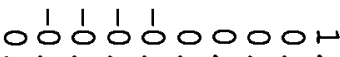

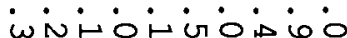

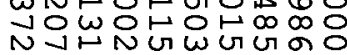

봃

旨

苞

号

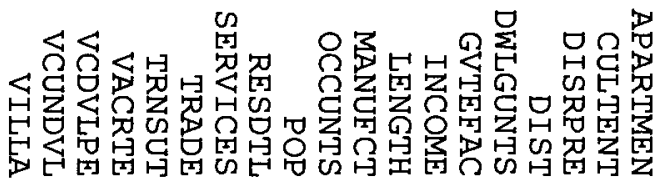

ól 00000000000000001 - iv í

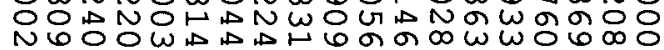

boĺl Oi ONंNinoinNini is

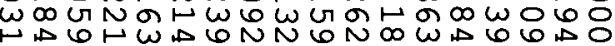

jól 00000000000001

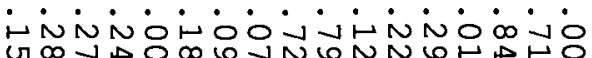
MOD正品

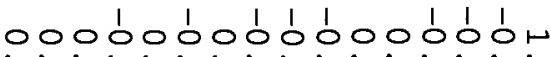

品

Niroinoininino

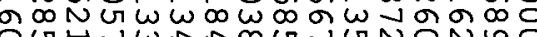

ólólo000000́00 Nivio is o inini

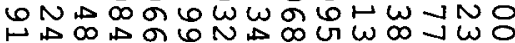

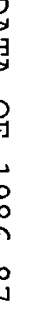


VACRTE VCDVLPE VCUNDVL VILLA

VACRTE

VCDVLPE

VCUNDVL

VILLA

1.000
-0.032
-0.159
-0.469

1.000

0.680

0.326

1.000

0.189

1.000 


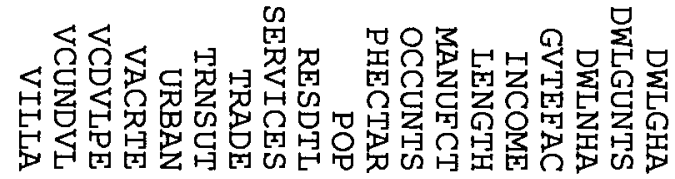

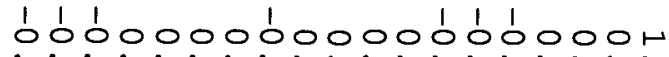

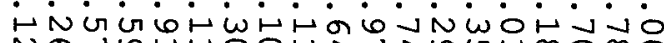

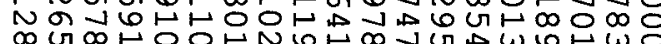

!용

蛋

0

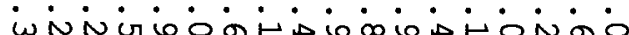
WNWGHAN

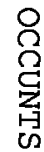

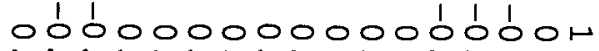
on in is oin $9 \omega \omega$ ino NFWNON

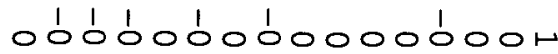
inNinownNiñNió

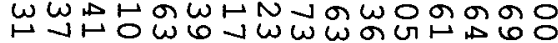

\%

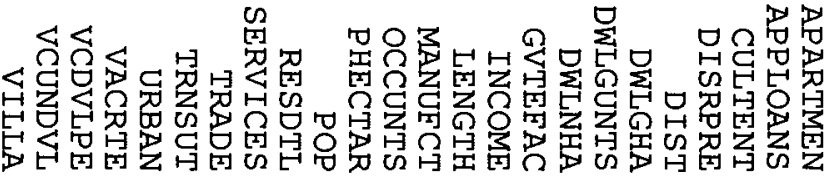

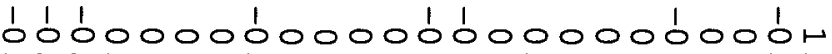

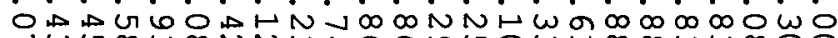
ЈW

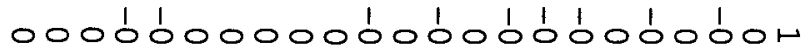
-

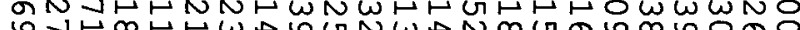

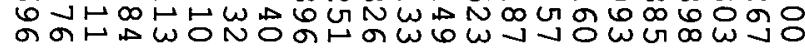

0100000000000000000001

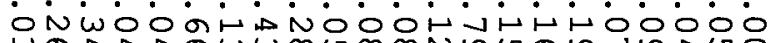

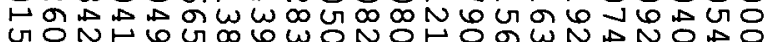

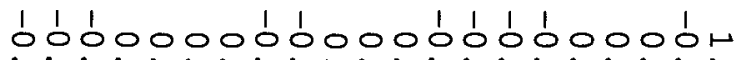
inivis

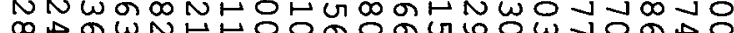

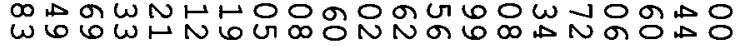

范

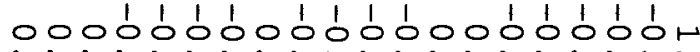

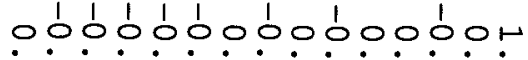
owñóinióó

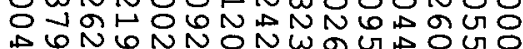

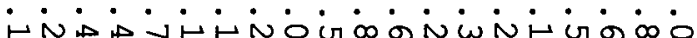

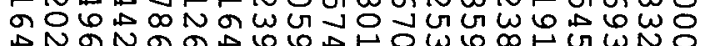




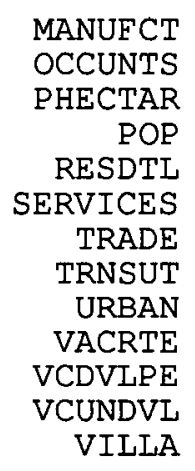

RESDTL SERVICES

TRADE

TRNSUT

URBAN

VACRTE

VCDVLPE

VCUNDVI

VILLA

VACRTE

VCDVLPE

VCUNDVI

VILLA

$\begin{array}{rr}0.364 & 1.000 \\ -0.176 & -0.424 \\ -0.339 & -0.387 \\ -0.168 & -0.398 \\ 0.252 & -0.180 \\ 0.661 & 0.698 \\ 0.031 & -0.322 \\ 0.700 & 0.355 \\ -0.292 & -0.404 \\ -0.015 & 0.282 \\ 0.747 & 0.493 \\ -0.266 & -0.050 \\ 0.069 & -0.260\end{array}$

RESDTI SERVICES

1.000

0.198

0.818

0.119

0.350

0.067

0.081

$-0.246$

0.723

1.000

0.154

0.763

$-0.121$

0.478

0.478

$-0.364$

$-0.080$

VACRTE

VCDVLPE

VCUNDVL

$$
1.000
$$

0.131

0.553

0.222

$-0.144$

$-0.297$

0.622

TRNSUT

1.000

0.659

0.193

$-0.107$

0.380

0.104

0.921

0.604

$-0.592$

$-0.347$

$-0.059$

1.000

0.611

$-0.143$

0.695

0.048

0.879

0.398

$-0.144$

$-0.107$

0.585

URBAN

$$
\begin{array}{r}
1.000 \\
0.112 \\
0.357 \\
0.384 \\
-0.299 \\
-0.101
\end{array}
$$

1. 000

0.592

$-0.425$

$-0.301$

0.176
1.000
-0.058
-0.498
-0.114
1.000

0.088

0.272
1.000

0.286
VILLA

1.000 
Appendix: E

The Regression Analysis Appendix 
The Regression Analysis Appendix

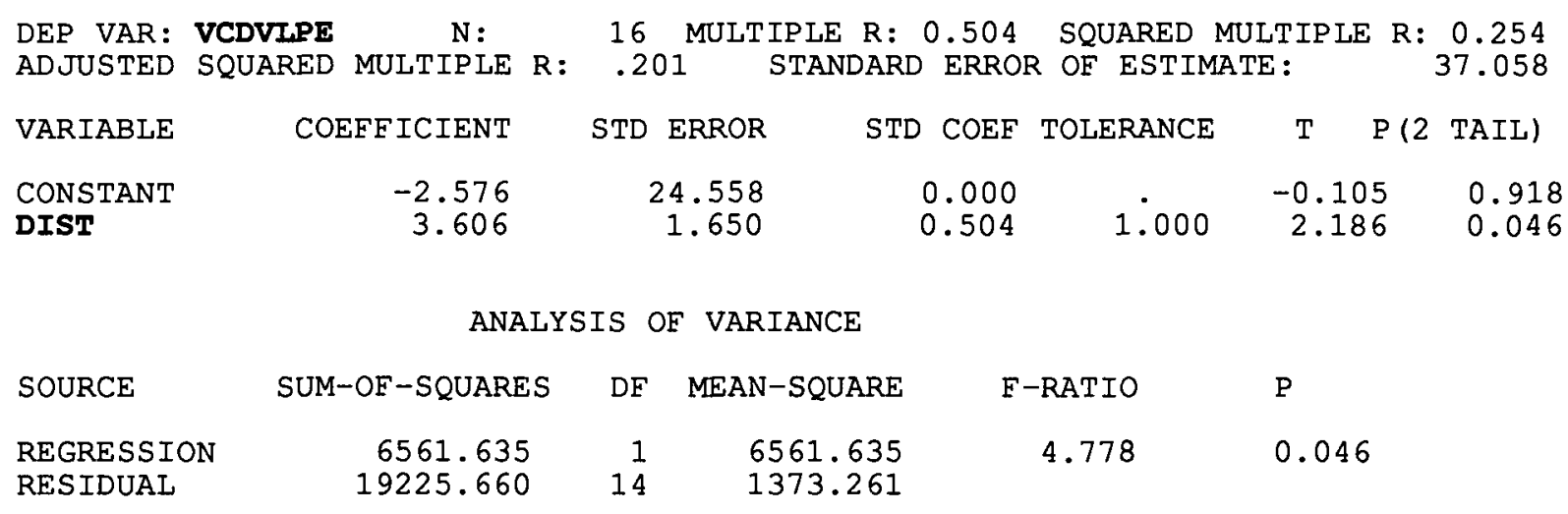

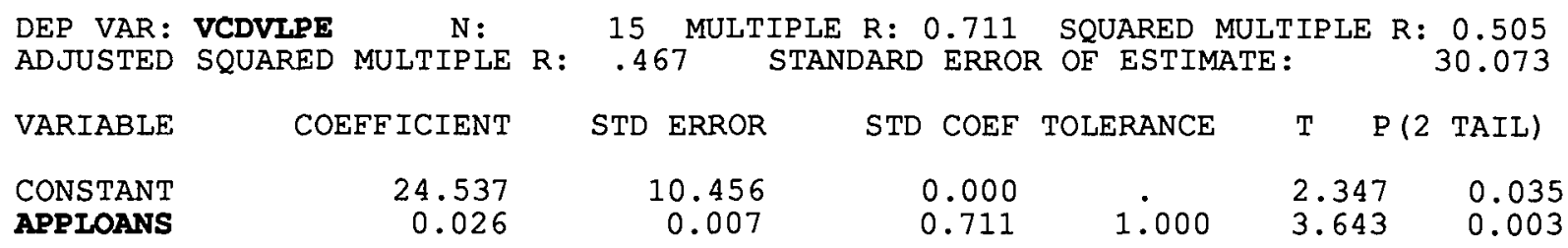

ANALYSIS OF VARIANCE

$\begin{array}{lcrrrr}\text { SOURCE } & \text { SUM-OF-SQUARES } & \text { DF } & \text { MEAN-SQUARE } & \text { F-RATIO } & \text { P } \\ \text { REGRESSION } & 12003.891 & 1 & 12003.891 & 13.273 & 0.003 \\ \text { RESIDUAL } & 11756.827 & 13 & 904.371 & & \end{array}$

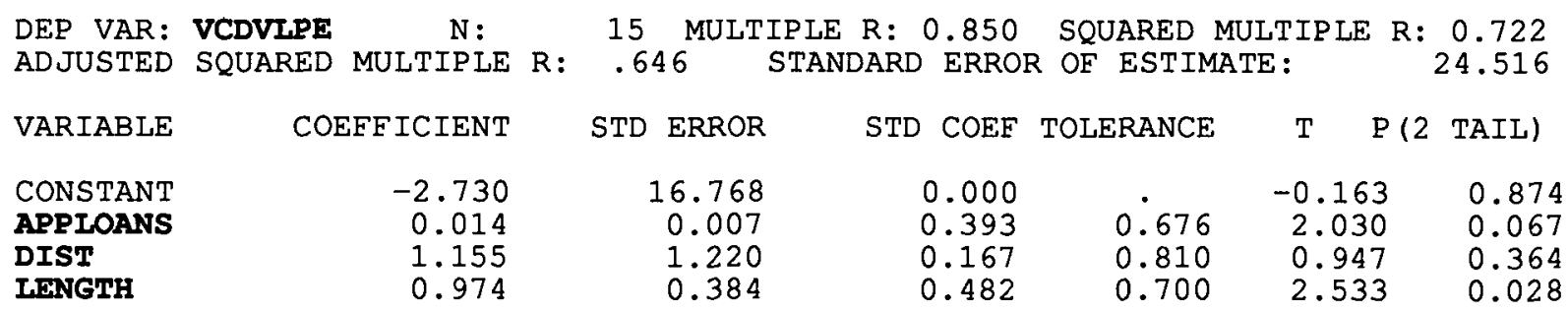

ANALYSIS OF VARIANCE

SOURCE SUM-OF-SQUARES DF MEAN-SQUARE F-RATIO P

$\begin{array}{lrrrrr}\text { REGRESSION } & 17149.322 & 3 & 5716.441 & 9.511 & 0.002 \\ \text { RESIDUAL } & 6611.396 & 11 & 601.036 & & \end{array}$


Appendix: F

\section{The Factor Analysis Appendix}


The Factor Analysis Appendix

LATENT ROOTS (EIGENVALUES)

$\begin{array}{lllll}1 & 2 & 3 & 4 & 5 \\ 5.782 & 0.671 & 0.406 & 0.109 & 0.027 \\ 6 & 7 & & & \\ 0.004 & 0.000 & & & \end{array}$

COMPONENT LOADINGS

$\begin{aligned} \text { POP } & 0.891 \\ \text { DWLGUNTS } & 0.965 \\ \text { OCCUNTS } & 0.952 \\ \text { DWLGHA } & 0.903 \\ \text { DWLNHA } & 0.779 \\ \text { APARTMEN } & 0.935 \\ \text { PHECTAR } & 0.924\end{aligned}$

VARIANCE EXPLAINED BY COMPONENTS

5.782

PERCENT OF TOTAL VARIANCE EXPLAINED

82.602

FACTOR SCORE COEFFICIENTS

$\begin{aligned} \text { POP } & 0.154 \\ \text { DWLGUNTS } & 0.167 \\ \text { OCCUNTS } & 0.165 \\ \text { DWLGHA } & 0.156 \\ \text { DWLNHA } & 0.135 \\ \text { APARTMEN } & 0.162 \\ \text { PHECTAR } & 0.160\end{aligned}$

FACTOR SCORES

FACTOR (URBAN)

$\begin{array}{lrr}\text { CASE } & 1 & 2.611 \\ \text { CASE } & 2 & 0.485 \\ \text { CASE } & 3 & 0.478 \\ \text { CASE } & 4 & 1.080 \\ \text { CASE } & 5 & -0.413 \\ \text { CASE } & 6 & -1.181 \\ \text { CASE } & 7 & 0.078 \\ \text { CASE } & 8 & -0.464 \\ \text { CASE } & 9 & -0.253 \\ \text { CASE } & 10 & 0.544 \\ \text { CASE } & 11 & -1.046 \\ \text { CASE } & 12 & -0.418 \\ \text { CASE } & 13 & 0.871 \\ \text { CASE } & 14 & -0.225 \\ \text { CASE } & 15 & -1.181 \\ \text { CASE } & 16 & -0.966\end{array}$




\section{Appendix: G \\ The Concept Of Decentralization}




\section{Arguments For Decentralization}

There are historical and intellectual reasons for decentralization. In the West, particularly in North America, the concept of decentralization has been very appealing due to a suspicious attitude towards a strong central government. This attitude is particulary strong in the United States :

The idea of decentralization in government has broad appeal in the United States. Partisans of the left and right of the political spectrum support decentralization. Americans have an enduring suspicion of strong, centralized government dating from before the American Revolution (Porter \& Olsen, 1976: 75).

In addition, centralization was associated with dissatisfaction on the part of the masses. In Medieval Europe, feudalism represented the extreme of centralization. Up to the middle of the twentieth century, colonized societies were operated and directed by distant colonizers and the colonized had no control over their resources. Therefore, based on historical events, the desires for decentralization by people in both the developed and developing world are not surprising.

Intellectually, decentralization has been associated with freedom and democracy. Though decentralization may not always lead to them, by and large it will provide for better and wider representation of the constituents. Town meetings and neighbourhood planning committees represent a forum in a decentralized planning process where residents participate in shaping their future community. De Toqueville showed great passion for decentralizing the planning process and described town meetings as a major prerequisite for a more liberal life. He stated:

... [t]own meetings are to liberty what primary schools are to science; they bring it within the people's reach, they teach men how to use and how to enjoy it. A 
nation may establish a free government, but without municipal institutions it cannot have the spirit of liberty (De Tocqueville, 1945: 61).

In addition to the notion of democracy or liberty suggested by De Tocqueville, there are other factors which may play a positive role in increasing the demand for decentralization. Among them are efficiency, effectiveness, flexibility and the limitations of the rational decision making approach . Decentralization has been perceived as an efficient technique to allocate resources. Because cities and states are more concerned about their resources than their central governments, it is assumed that they will use their resources more efficiently. For example, service delivery will be performed more efficiently by decentralized organizations than by large bureaucracies which, in any case, are exorbitant to maintain.

Effectiveness has always been linked to decentralization. Local citizens will be better served by local elected officials because the latter should have better knowledge of the formers' needs than officials of the state capital. Porter and Olsen believe that this argument is a strong one in favour of decentralization. They stated that political decentralization

...will increase the ability of elected state and city officials to deal with the needs of their constituents...there are stronger likelihood that state or local officials will be able to integrate and coordinate the resources coming to them from the federal government in such a way that they will meet the highest local priorities (Porter \& Olsen, 1976: 76).

In other words, decentralization is effective because it increases citizens' access to information, and participation. Indeed, some empirical studies support the above argument. Yin, in a study of the influence of decentralization on urban governments (considering 215 cases) showed that in over $60 \%$ of the cases, access to information had been increased and in about $70 \%$ of the 
cases, services had been improved and that is a good indicator of responsiveness.

Flexibility, as a positive associate of decentralization, refers to the notion that decentralization is a risk accommodative strategy. That is, when uncertainty toward goals or technologies exists, it is less risky to implement policies on a smaller decentralized scale. In centralized systems, the cost of implementing the wrong policy is often irretrievable due to the scale on which such policies are applied. Decentralized systems allow smaller units to implement policies under uncertain conditions with little chance of hurting the overall state structure. If such policies have negative consequences they will be limited to where they were implemented. Decentralization allows for innovation, because each of the decentralized units have greater discretion over local political, social, and economic life. In this context, two points are relevant to flexibility as a criterion for decentralization. First, the concept allows for adapting strategies to each particular context and preference. In other words, it does not lead to the notion that one way is the best for all environments. Second, the concept allows for diffusion of knowledge as each unit, (e.g. local community) learns to be responsible for its future wellbeing. With centralization, knowledge is centralized with few actors therefore diffusion of knowledge is denied.

A final argument for decentralization is the limitation of the rational decision making approach. Centralization could be justified if the concerned actors are perfectly informed and perfectly able to evaluate all possible options and all possible consequences for each option. Since such an argument is unrealistic in theory, let alone practice, this becomes a strong argument for decentralization. Indeed, there is no such actor as a rational centralist (e.g. to justify centralism) 
because the human mind is not perfect.

\section{Forms Of Decentralization}

According to Cheema and Rondinelli four forms of decentralization can be identified: deconcentration, delegation to semi-autonomous or parastatal agencies, devolution to local governments, and transfer of functions from public to non-government institutions (Cheema \& Rondinelli, 1983: 18). According to these authors, deconcentration pertains to redistribution of responsibility within the central government. In other words, deconcentration is shifting the workload from the central government offices to regional offices without giving the latter the authority to carry out exclusive decisions. Fesler has described deconcentration as not identical to decentralization :

...[d]ecentralization of the workload, however, is not identical with decentralization of administrative power.To move workload out of the capital may be efficient and convenient for the public and may even promote a feeling that government is close to people. But it may not involve any decentralization of power, that is, it may not provide the opportunity to exercise subnational local discretion in decision making (Fesler, 1968: 373).

The delegation to semi-autonomous agencies form of decentralization occurs when the central government delegates management and decision authority of certain functions to organizations which are not under the direct control of the central government. This form of decentralization allows the recipient organization, which is assumed to be technically and managerially capable, to articulate and implement decisions in certain areas without the direct supervision of higher units of government (Cheema \& Rondinelli, 1983: 21). Indeed, delegation to parastatal agencies represents a clear move toward true decentralization when compared to deconcentration. 
Devolution, as a form of decentralization, refers to the devolution of functions and authorities to different units or level of government (Ibid: 22). Cheema and Rondinelli did clarify devolution by characterizing it with five aspects. First, the local units of governments are autonomous with little or no control from the central government. Second, the local governments have identified boundaries within which they may exercise their power. Third, the local governments have the power (as in corporate status form) to secure resources and independently perform governmental functions. Fourth, local governments ought to be seen by local citizens as a means to satisfy their needs and should work on their citizens' behalf. Fifth, the relationship between local governments and the central government--under devolution--is reciprocal and mutually beneficial (Cheema \& Rondinelli, 1983: 22). Devolution represents a significant move towards complete decentralization.

Transfer of functions from public institutions to non-governmental agencies is the fourth category of decentralization suggested by Cheema and Rondinelli. This form of decentralization pertains to transferring functions or task management from the government to non-governmental (e.g. voluntary or private) agencies. This form of decentralization is sometimes associated with privatization as governments shift the responsibility of producing major goods and services from public organizations to private ones (Ibid: 24). 